\title{
ASSOCIAÇÃO ENTRE HANSENÍASE E INFECÇÃO PELO VIRUS DA HEPATITE B: ESTUDO DE CASO-CONTROLE
}

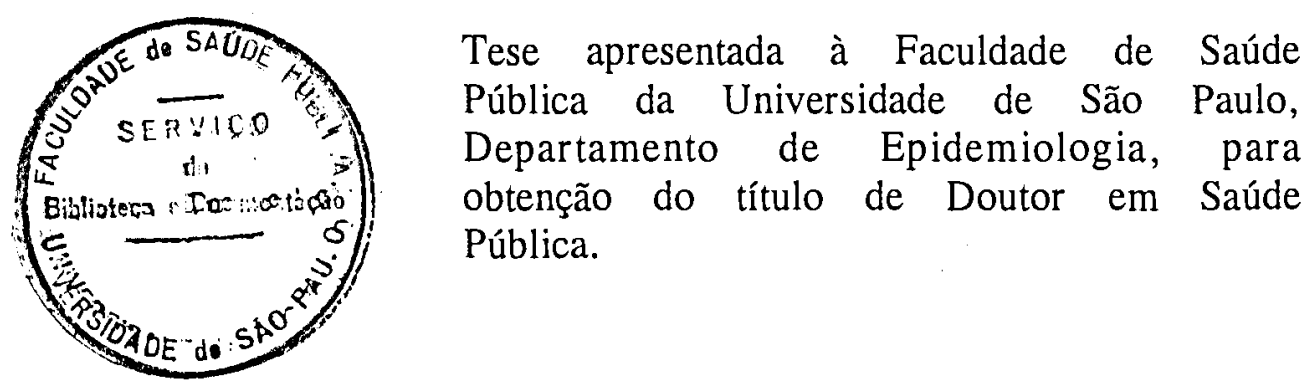

Orientador: Euclides Ayres de Castilho 


\author{
we
}

\title{
ASSOCIAÇÃO ENTRE HANSENÍASE E INFECÇÃO PELO VÍRUS DA HEPATITE B: ESTUDO DE CASO-CONTROLE
}

Tese apresentada à Faculdade de Saúde Pública da Universidade de São Paulo, Departamento de Epidemiologia, para obtenção do título de Doutor em Saúde Pública.

Orientador: Euclides Ayres de Castilho 
MARTELLI C.M.T. Associação entre hanseníase e infecção pelo vírus da hepatite B: Estudo de caso-controle. São Paulo, 1995. [Tese de Doutoramento Faculdade de Saúde Pública da USP].

\section{RESUMO}

Um estudo de caso-controle para investigar a associação entre a hanseníase e infecção pelo vírus da hepatite B (VHB) foi conduzido no período de $1992 / 93$, na cidade de Goiânia e municípios contíguos - Estado de Goiás. Avaliou-se, também, a distribuição espacial da hanseníase neste aglomerado urbano.

Inicialmente, os indivíduos com suspeita clínica de hanseníase foram submetidos a exames baciloscópicos e histopatológicos, independentemente da rotina do Programa de Controle de Hanseníase. Do total de 855 pacientes recémdiagnosticados de hanseníase, 600 eram residentes em área urbana, e foram categorizados em casos multibacilares $(31,3 \%)$, paucibacilares $(51,8 \%)$ e prováveis $(16,8 \%)$. Foi realizada análise descritiva desta casuística, havendo nítida predominância do sexo masculino na forma multibacilar de hanseníase. A distribuição espacial dos pacientes possibilitou, através da análise exploratória das taxas de detecção, discriminar estratos de risco intra-urbano.

Para o estudo de caso-controle, 552 pacientes de hanseníase de 10 a 70 anos foram incluídos. Os controles $(\mathrm{N}=552)$ foram selecionados de indivíduos com ausência de sinais e sintomas sugestivos de hanseníase oriundos da demanda espontânea de ambulatórios de 7 unidades de saúde, localizadas na região de procedência dos casos. Os participantes - casos e controles - foram entrevistados para avaliar fatores de risco para hanseníase e infecção pelo vírus da hepatite $B$. Foram coletadas amostras de sangue para detecção de marcadores ao vírus da hepatite B pela técnica de ELISA. 
Comparou-se a prevalência de marcadores de exposição (anti-HBc), de imunidade (anti-HBs) e de portador (AgHBs) entre casos e controles. Foram avaliados como potenciais fatores de confusão: sexo, idade, condições sócioeconômicas, estado nutricional, cicatriz vacinal de BCG e utilização dos serviços de saúde. Casos e controles foram similares quanto às características sócioeconômicas e nutricionais indicando que o princípio de selecionar controles da mesma base populacional que os casos parece ter sido adequado. Cicatriz vacinal de BCG esteve estatisticamente associada aos diferentes tipos de hanseníase. Houve maior proporção de indivíduos hospitalizados nos útimos 5 anos entre casos que em controles indicando que o emparelhamento por local de residência não eliminou completamente as diferenças entre os grupos em relação ao uso dos serviços de saúde.

Entre os participantes do estudo, $18,1 \%$ dos casos e $19,6 \%$ dos controles foram soropositivos ao anti-HBc. Em análise multivariada, utilizando-se o modelo de regressão logística politômica, a associação da hanseníase e anti-HBc entre casos e controles apresentou odds ratio de 0,9 (IC95\% 0,7-1,3) para a categoria de multibacilar; 1,0 (IC 95\% 0,7-1,3) para a de paucibacilar e 1,1 (IC95\% 0,8-1,5) para a de provável. Estes resultados mostraram que subgrupos de casos e os controles estiveram igualmente expostos ao vírus da hepatite B.

As proporções de indivíduos imunes foram semelhantes nos grupos de casos $(9,2 \%)$ e controles $(10,2 \%)$. Casos multibacilares responderam à exposição viral com formação de anticorpos protetores, qualitativa e quantitativamente de maneira semelhante aos pacientes paucibacilares e grupo controle. Os resultados dos índices de persistência de infecção (PPI) indicaram não haver diferença quanto ao clearance do antígeno viral nos subgrupos de casos e controles.

Os resultados obtidos nesta investigação mostraram nos subgrupos de casos e controles: (i) prevalências semelhantes dos marcadores de exposição, de imunidade e de estado de portador; (ii) capacidade similar para produção de 
anticorpos protetores, avaliada através dos percentuais do marcador anti-HBs e, quantitativamente, através do Índice de Elisa e (iii) baixa probabilidade de persistência da antigenemia mensurada pelo PPI. Em conclusão, não houve evidências epidemiológicas de uma associação entre hanseníase e infecção pelo vírus da hepatite B, avaliada através de estudo de caso-controle, conduzido em área de baixa endemicidade ao VHB e alta endemicidade de hanseníase. 
MARTELLI C.M.T. Association between, leprosy and hepatitis B virus infection: A case-control study. São Paulo, 1995. [Thesis - School of Public Health. University of S. Paulo].

\section{SUMMARY}

A case-control study was conducted in Goiânia, Central Brazil, a highly endemic area for leprosy and low endemic region for hepatitis B virus (HBV) infection. The purpose was to investigate the association between leprosy types and hepatitis $B$ infection. The spatial distribution of leprosy in urban area was assessed.

Between 1992 and 1993, newly detected leprosy cases $(\mathrm{N}=855)$ were investigated and 600 cases lived in the urban area. They were classified in multibacillary $(31.3 \%)$, paucibacillary $(51.8 \%)$ and probable cases $(16.8 \%)$ according to histopathological and baciloscopic exams, independently of the leprosy control routine. The majority of multibacillary cases was males. Detection rates of leprosy were calculated by mapping cases and several risk strata were identified by using exploratory data analysis. This methodology seems to be particularly useful for targeting control activities in urban areas.

Cases were 552 leprosy patients from the urban area and adjacent counties, between the ages of 10 and 70 years who self-referred or were referred to the main outpatient clinic for treatment in the region. 552 controls were selected from among self-referred outpatients from 7 health centers geographically located in areas where the cases came from. The main criteria for eligibility for control subjects was that they must not have any signs or symptoms indicative of leprosy.

Blood samples were collected for all participants to determine serological markers of $\mathrm{HBV}$ infection and tested by enzyme immunoabsorbent assay technique 
(ELISA). Cases and controls were interviewed in order to evaluate risk factors for leprosy and hepatitis B virus (HBV) infection.

Prevalence of HBV exposure (anti-HBc), immunity (anti-HBs) and carrier status (AgHBs) were compared among cases and controls. Cases and controls were also compared for age, sex, socio-economic conditions, nutritional status, BCG scars and previous hospitalization. The participants had similar socio-economic pattern and also nutrition status, suggesting that the source of control selection was adequate for controlling for the most common confounding variables. BCG vaccine appeared to provide protection against multibacillary and paucibacillary types of leprosy and percentage of hospitalization was higher among cases.

Prevalence of anti-HBc was similar among leprosy cases (18.1\%) compared to controls $(19.6 \%)$. An analysis of association between anti-HBc infection and leprosy types in terms of odds ratio, calculated by polytomous logistic regression, showed no positive association: multibacillary ( $\mathrm{OR}=0.9 \quad \mathrm{CI} 95 \%$ 0.7-1.3); paucibacillary $(\mathrm{OR}=1.0 \mathrm{CI} 95 \% 0.7-1.3)$ and probable $(\mathrm{OR}=1.1 \mathrm{CI} 95 \% 0.8-1.5)$.

The main findings of the case-control study were: (i) cases and controls had similar levels of viral exposure, immune and carrier status (ii) the persistence of antigen response (PPI) was low among cases and controls respectively; (iii) ELISA indices were similar among multibacillary, paucibacillary and control group indicating that all participants mount antibody response to viral infection. In conclusion, there was no association between multibacillary leprosy and HBV infection in this setting. 


\title{
ÍNDICE
}

\author{
Resumo \\ Summary \\ Índice \\ Lista de Tabelas \\ Lista de Mapas e Figuras \\ Agradecimentos
}

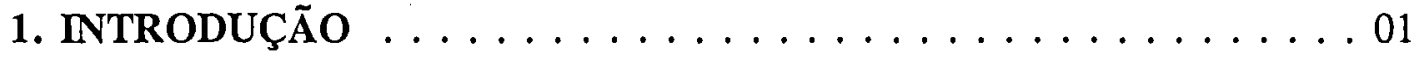

Estudos epidemiológicos de associação entre hanseníase e infecção pelo vírus da hepatite $B$

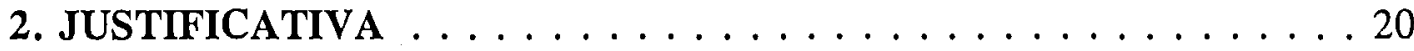

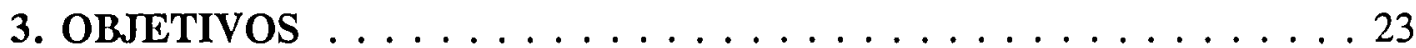

4. METODOLOGIA . . . . . . . . . . . . . . . . . 24

4.1 Área de Estudo . . . . . . . . . . . . . . . . . . . . . 24

4.2 Delineamento do estudo . . . . . . . . . . . . . . 25

4.3 Organização do trabalho de campo . . . . . . . . . . . 25

4.4 Definição de casos e controles . . . . . . . . . . . . . . 27

4.5 Tamanho da amostra .................... 28

4.6 Triagem clínica . . . . . . . . . . . . . . . . . . . 29

4.7 Exames complementares . . . . . . . . . . . . . . 29

4.8 Entrevista . . . . . . . . . . . . . . . 31

4.9 Medidas Antropométricas . . . . . . . . . . . . . . 32

4.10 Exames sorológicos para infecção pelo VHB . . . . . . . . . . . 32

4.11 Processamento e análise de dados . . . . . . . . . . . . . 34

a) Primeira Etapa - Análise Exploratória de Dados . . . . . 34

b) Segunda Etapa - Estudo de caso-controle . . . . . . . . . 36 
4.12 Estudo piloto . . . . . . . . . . . . . . . . . 37

4.13 Considerações éticas . . . . . . . . . . . . . . . . . 38

5. RESULTADOS E DISCUSSÃO . . . . . . . . . . . . . . . . 45

5.1 Caracterização da amostra de casos . . . . . . . . . . . . 45

5.2 Distribuição espacial e características migratórias dos casos . . . . 62

5.3 Caracterização de casos e controles . . . . . . . . . . . . 77

5.4 Associação da infecção pelo vírus da hepatite $B$ entre casos e controles . . . . . . . . . . . . . . . . . . . . 95

5.5 Considerações metodológicas $\ldots \ldots \ldots \ldots . \ldots \ldots$

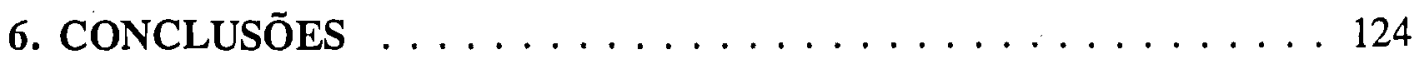

7. REFERÊNCIAS BIBLIOGRÁFICAS . . . . . . . . . . 125

ANEXO 1. Sumário das publicações sobre

associação entre hanseniase e infecção

pelo vírus da hepatite $\mathrm{B} \ldots \ldots \ldots \ldots$. . . . . 1

ANEXO 2. Questionário (Primeira parte) ........... A5

ANEXO 3. Questionário (Segunda parte) ............... 11

ANEXO 4. Roteiro para preenchimento e

codificação do questionário . . . . . . . . . . . A20 


\section{LISTA DE TABELAS}

Tabela 5.1-1

Distribuição dos 600 casos de hanseníase por idade, sexo, exame baciloscópico, contactantes domiciliares e duração dos sintomas . 53

Tabela 5.1-2

Distribuição dos 600 casos de hanseníase segundo idade e tipo de contactantes . . . . . . . . . . . . . . . . . 54

Tabela 5.1-3

Distribuição dos 600 casos de hanseníase segundo tipo, sexo, idade, contactantes domiciliares e duração dos sintomas . . . . . . . . . 56

Tabela 5.2-1

Distribuição dos fluxos de migração intra-urbana dos casos de hanseníase em áreas administrativas do município de Goiânia e municípios do aglomerado, nos últimos 10 anos $\ldots \ldots \ldots \ldots$

Tabela 5.3-1

Distribuição dos casos e controles segundo área de abrangência da unidade de saúde e local de residência $\ldots \ldots \ldots$. . . . . . . 86

Tabela 5.3-2

Características de casos e controles em relação à idade, sexo, cicatriz vacinal de BCG e índice de massa corporal . . . . . . . . . .87

Tabela 5.3-3

Odds ratio (OR) e intervalo de $95 \%$ de confiança (IC 95\%) para formas multibacilares, paucibacilares e casos prováveis de hanseníase por faixa etária $\ldots \ldots \ldots 88$ 
Tabela 5.3-4

Odds ratio (OR) e intervalo de $95 \%$ de confiança (IC 95\%)

para formas multibacilares, paucibacilares e casos prováveis

de hanseníase por sexo. . . . . . . . . . . . . . . . . . 89

Tabela 5.3-5

Odds ratio (OR) e intervalo de $95 \%$ de confiança (IC 95\%)

para formas multibacilares, paucibacilares e casos prováveis

de hanseníase em relação à presença de cicatriz vacinal de $\mathrm{BCG}$. . . . . . 90

Tabela 5.3-6

Características sócio-econômicas dos casos e controles . . . . . . . . . . 91

Tabela 5.3-7

Distribuição de casos e controles segundo características sócio-econômicas . . . . . . . . . . . . . . . . . 92

Tabela 5.3-8

Indicadores de mobilidade espacial dos casos e controles $\ldots \ldots . \ldots 93$

Tabela 5.3-9

Indicadores de utilização dos serviços de saúde, uso de injeção, drogas e prática sexual dos casos e controles . . . . . . . . . . . . . 94

Tabela 5.4-1

Distribuição de marcadores sorológicos para a infecção

pelo vírus da hepatite B entre casos e controles . . . . . . . . . . . . . 104

Tabela 5.4-2

Odds ratio (OR) e intervalo de $95 \%$ de confiança (IC 95\%)

para formas multibacilares, paucibacilares e casos prováveis

de hanseníase em relação ao marcador anti- $\mathrm{HBc}$ do vírus da hepatite B 105 
Tabela 5.4-3

Número de casos multibacilares associados ao marcador anti-HBc estratificados por idade, sexo, hospitalização e cicatriz de BCG, com os respectivos odds ratio (OR) e intervalo de $95 \%$ de confiança $($ IC $95 \%) \ldots \ldots \ldots \ldots 6 \ldots \ldots \ldots \ldots$

Tabela 5.4-4

Número de casos paucibacilares associados ao marcador anti-HBc estratificados por idade, sexo, hospitalização e cicatriz de BCG, com os respectivos odds ratio (OR) e intervalo de $95 \%$ de confiança $($ IC $95 \%) \ldots \ldots \ldots 7 \ldots \ldots \ldots$

Tabela 5.4-5

Número de casos prováveis associados ao marcador anti-HBc estratificados por idade, sexo, hospitalização e cicatriz de BCG, com os respectivos odds ratio (OR) e intervalo de $95 \%$ de confiança (IC 95\%) . . . . . . . . . . . . . . . 108

Tabela 5.4-6

Coeficiente de regressão e odds ratio resultante de modelo de regressão logística com variável de resposta politômica . . . . . . . . . . . . 109

Tabela 5.4-7

Coeficiente de regressão e odds ratio resultante de modelo de regressão logística para casos multibacilares, paucibacilares e prováveis . . . . 110

Tabela 5.4-8

Odds ratio (OR) e intervalo de $95 \%$ de confiança (IC 95\%) para formas multibacilares, paucibacilares e casos prováveis de hanseníase em relação ao marcador anti-HBs do vírus da hepatite B . 111 


\section{LISTA DE MAPAS E FIGURAS}

Figura 4.3

Fluxograma do trabalho de campo . . . . . . . . . . . . . . . 39

Figura 4.4

Fluxograma de definição de caso $\ldots \ldots \ldots$. . . . . . . . . . 40

Figura 4.5

Fluxograma da seleção de casos e controles . . . . . . . . . . . . . 44

Figura 4.10

Fluxograma da triagem sorológica para infecção pelo VHB . . . . . . . . . 42

Mapa 4.1

Localização dos distritos urbanos de Goiânia e municípios do aglomerado . . . . . . . . . . . . . . . . . . . . 43

\section{Mapa 4.3}

Distribuição espacial das unidades de saúde: local de captação de casos e controles . . . . . . . . . . . . . . . . . . 444

Figura 5.1-1

Percentual de casos de hanseníase de acordo com grau de parentesco do contactante para distintos grupos de idade . . . . . . . 55

Figura 5.1-2

Pirâmide populacional dos casos de hanseníase por sexo, faixa etária e categorias de definição de casos . . . . . . . . . . 5 57

\section{Figura 5.1-3}

Percentagem de casos de hanseníase e respectivos

limites de $95 \%$ de confiança com baciloscopia positiva

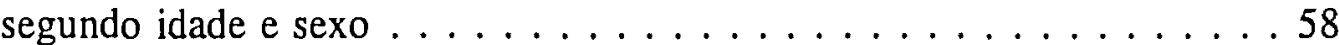


Figura 5.1-4

Percentuais de Índices Baciloscópicos e pontos de corte para definição de caso multibacilar (MB) . . . . . . . . . . . . . . . . 59

Figura 5.1-5

Distribuição de Ramos e Folhas e Gráficos de caixas para

a variável meses de duração dos sintomas . . . . . . . . . . . . . . 60

Figura 5.1-5 (Continuação)

Distribuição de Ramos e Folhas e Gráficos de caixas para

a variável meses de duração dos sintomas . . . . . . . . . . . . . 66

Figura 5.2-1

Distribuição da população de Goiânia por regiões e casos de hanseníase . 69

Figura 5.2-2

Distribuição de Ramos e Folhas e Gráficos de caixas para taxas

de hanseníase por 100000 habitantes em Distritos urbanos de Goiânia . . 70

Figura 5.2-2 (Continuação)

Distribuição de Ramos e Folhas e Gráficos de caixas para

taxas de hanseníase por 100000 habitantes em Distritos

urbanos de Goiânia . . . . . . . . . . . . . . . . . 71

Mapa 5.2-1

Casos de Hanseníase pelos distritos urbanos de Goiânia e

municípios do aglomerado . . . . . . . . . . . . . . . . 73

\section{Mapa 5.2-2}

Taxas de Hanseníase por 100000 hab, pelos distritos urbanos

de Goiânia e municípios do aglomerado . . . . . . . . . . . . . . . 74

\section{Mapa 5.2-3}

Casos de Hanseníase em menores de 15 anos pelos distritos urbanos de Goiânia e entorno da capital . . . . . . . . . . . . . . .75 
Mapa 5.2-4

Taxas de Hanseníase em menores de 15 anos por 100000 hab.

pelos distritos urbanos de Goiânia e municípios do aglomerado . . . . . 76

\section{Figura 5.4-1}

Índice de Elisa para o marcador sorológico anti-HBs de acordo com as formas clínicas de hanseníase . . . . . . . . . . . . 112 


\section{AGRADECIMENTOS}

Ao Dr. Euclides Ayres de Castilho, agradeço a sua competente e segura orientação. Foi verdadeiro privilégio contar com guia tão brilhante que, mesmo a distância, fez sentir constantemente sua presença. Desejo também registrar aqui a minha "incurável inveja" dos que podem usufruir, no dia-a-dia, de sua experiência científica e sabedoria de vida .

Agradeço à Dra . Ana Lúcia Sampaio Sgambatti de Andrade, titular de Epidemiologia do Departamento de Saúde Coletiva/ IPTSP - UFG, que foi cúmplice e parceira neste projeto desde a concepção. Agradeço ainda a ajuda nas estratégias de análise de dados e nas infindáveis discussões metodológicas. Sua incansável capacidade de trabalho, criatividade e entusiasmo constituiram fonte de permanente estímulo durante esta caminhada.

Ao Dr. Fábio Zicker, titular de Epidemiologia do Departamento de Saúde Coletiva/ IPTSP - UFG e Assessor para Doenças Transmissíveis da Organização Panamericana de Saúde/OMS, o meu reconhecimento pelas valiosas sugestões metodológicas e pelo incentivo científico durante minha trajetória acadêmica.

Esta investigação não poderia ter sido conduzida e completada sem a participação, encorajamento e valiosas sugestões dos meus colegas e amigos da Universidade Federal de Goiás e da Secretaria de Saúde e Meio Ambiente (SESMAGo). É com prazer que nomeio os componentes da equipe diretamente envolvida no projeto:

- Dr. Otaliba Libâneo Moraes Neto, professor do Departamento de Saúde Coletiva/ IPTSP -UFG, coordenador do trabalho de campo, profissional competente, sereno e firme nas atividades desenvolvidas junto aos serviços de saúde; 
- Dra . Simonne Almeida e Silva, professora do Departamento de Saúde Coletiva/ IPTSP -UFG, verdadeiro talento em encontrar soluções criativas para as questões de processamento eletrônico;

- Dra . Ilma Mondanez Silva, dermatologista da SESMA, responsável pela triagem clínica dos pacientes, cuja dedicação a este projeto e especialmente à causa da eliminação da hanseníase ultrapassam os limites do dever e da competência;

- Prof ${ }^{a}$. Lilian Souza, docente e pesquisadora do Departamento de Microbiologia/ IPTSP - UFG, responsável pela leitura de baciloscopia, tarefa à qual dedicou tanto entusiasmo e determinação;

- Dr. Maurício Barcelos Costa, Professor do Departamento de Patologia/ IPTSP UFG, responsável pelos resultados histopatológicos, com o qual compartilhamos as angústias técnicas e operacionais na realização desta investigação;

- Dr. Marcos Antônio Cabral, médico sanitarista, cuja participação na organização e condução do trabalho de campo foi de grande valia;

- Prof ${ }^{a}$. Divina das Dores de Paula Cardoso, Departamento de Microbiologia/ IPTSP - UFG, pela sua participação na parte referente aos exames sorológicos;

- Prof ${ }^{\mathrm{a}}$. Stelamaris Tronco Monego, Faculdade de Enfermagem e Nutrição- UFG, pelo treinamento e acompanhamento da equipe de campo nas medidas antropométricas;

- Dra ${ }^{a}$. Mírian Lane Rodrigues, pela sua participação na revisão dos diagnósticos clínicos de hanseníase;

- Gildete Ferre de Fonseca e Durcilene Jerônimo de Oliveira Silva, auxiliares de enfermagem da Fundação Nacional de Saúde pelo apoio ao trabalho de campo;

- Andrea Linhares Lacerda e Sirlene de Almeida e Silva, especialistas em computação, pela determinação em desvendar os labirintos dos programas de geo-referenciamentos, possibilitando iniciar a construção de mapas digitais vinculados a bancos de dados, em nossa unidade;

- João Borges Peres Jr, de quem registramos o profissionalismo e entusiasmo pelo trabalho de digitação dos dados e parte da editoração da tese; 
- À bolsista de aperfeiçoamento do CNPq $\mathrm{Dr}^{\mathrm{a}}$. Valéria Valdez Gomes e aos bolsistas de Iniciação Científica - do CNPq Débora Batista Ferreira, e Pierpaolo Martelli do PIBIC/PRPPG/UFG -, pela participação no trabalho de campo.

Agradecemos à $\mathrm{Dr}^{\mathrm{a}}$. Ana Maria $\mathrm{C}$ Gaspar e à $\mathrm{Dr}^{\mathrm{a}}$. Clara $\mathrm{T}$ Yoshida, pesquisadoras do Centro de Referência para Hepatites Virais da Fundação Oswaldo Cruz do Rio de Janeiro, a responsabilidade e presteza na realização dos testes sorológicos, bem como o incentivo.

Ao Dr. Diltor V. A. Opromolla, Diretor da Divisão de Pesquisa e Ensino do Instituto Lauro de Souza Lima/Bauru, pesquisador emérito e dedicado a causa da eliminação da hanseníase, pela oportunidade de treinamento de vários elementos da nossa equipe, bem como pelas valiosas sugestões. Ao Dr. Raul Negrão, a boa vontade e eficiência na leitura das lâminas de biópsia, realizadas durante o estudo piloto, para avaliar o grau de concordância dos exames histopatológicos.

Ao Dr. Clóvis Lombardi, Assessor Regional de Hanseníase da Organização Panamericana de Saúde, o meu agradecimento sincero pelo incentivo científico e pelas reflexões sobre as perspectivas de eliminação da hanseníase na América Latina que muito influenciaram esta apresentação.

Ao Dr. Gerson Oliveira Penna e ao Dr Gerson Fernando Mendes Pereira ambos do Ministério da Saúde, agradeço a oportunidade de participar das reuniões de controle da hanseníase no âmbito nacional. Convém ressaltar que o profissionalismo e a dedicação que imprimiram nas atividades do Programa de Dermatologia Sanitária/MS; tornam a meta de eliminação da hanseníase no Brasil um projeto institucional viável.

Não poderíamos deixar de lembrar aqui, Deolinda de Santana, responsável pelo Programa de Controle de Hanseníase/ SESMA-Go, no período de realização do projeto, por ter facilitado a condução do estudo nos serviços de saúde. 
O Dr. José Carlos Seraphin, Professor Titular do Departamento de Estatística/UFG e o Dr. Jorge de Souza, Professor Visitante da mesma unidade, pelas valiosas sugestões no uso de aplicativos estatísticos. Suas indicações possibilitaram valiosa economia de tempo.

À Diretora do Instituto de Patologia Tropical e Saúde Pública, $\mathrm{Dr}^{\mathrm{a}}$. Dulcinéa Maria Barbosa Campos, incentivadora deste projeto, e exemplo de seriedade e competência profissional, gostaria de registrar meus agradecimentos especiais.

À Dra Mariane Martins de Araújo Stefani, Professora do Departmento de Imunologia e Patologia Tropical do IPTSP/UFG pelas leitura crítica dos aspectos referentes à imunologia da hanseníase.

Aos professores do meu Departamento, em especial ao Dr. Renato Maurício de Oliveira e ao Dr. Paulo Roberto Macedo Olinto, na chefia da unidade neste período, o meu melhor reconhecimento.

Um agradecimento, todo particular à $\mathrm{Dr}^{\mathrm{a}}$. Marília Dalva Turchi, pela sua capacidade crítica, pela paciência fraterna em escutar, não só as apresentações técnicas, como também as dúvidas e angústias, pelas inúmeras sugestões na redação da tese, e apoio constante, em todas as fases deste projeto.

Aos meus familiares, Professora Celenita Amaral Turchi e Professora Maria Zaira Turchi, pelo apoio emocional, pela colocação e retirada das vírgulas, discussão de normas gramaticais e ortográficas, sem as tornar responsáveis pela versão final. A Piero, meu companheiro de caminhada, meus filhos Pierpaolo e Letícia, agradeço e prometo recolher todos os livros e artigos espalhados pela casa nos últimos anos, ... até a próxima empreitada.

Finalmente, este projeto contou com o apoio financeiro da Organização Panamericana de Saúde, CNPq e FUNAPE/UFG e bolsa de doutorado da CAPES. 


\section{INTRODUÇÃO}

Estudos epidemiológicos de associação entre hanseníase e infecção pelo vírus da hepatite B

As evidências sobre uma possível associação entre a infecção pelo vírus da hepatite B (VHB) e a hanseníase aparecem na literatura científica no final da década de 60 , quando a primeira geração de testes laboratoriais para detecção de marcadores sorológicos da hepatite B tornaram-se disponíveis. A observação de altas prevalências do antígeno de superfície viral em pacientes da forma "lepromatosa" da hanseníase decorre de estudos sistemáticos para identificar proteínas polimórficas no sangue em populações de diferentes partes do mundo, em politransfundidos e em várias patologias (Blumberg et al., 1967; London \& Blumberg, 1985). Historicamente, essa hipótese de associação está temporalmente vinculada à própria descrição do vírus da hepatite $\mathrm{B}$ na década de 60 .

Nas duas décadas seguintes, há inúmeros estudos sobre a associação entre a hanseníase e a infecção pelo vírus da hepatite $\mathrm{B}$, sem resultados conclusivos, ao contrário, apresentam, muitas vezes, resultados opostos. Com a descoberta de outros marcadores sorológicos da infecção para o VHB (AgHBs - antígeno de superfície do vírus da hepatite $\mathrm{B}$; anti-HBs - anticorpo para AgHBs; anti-HBc anticorpo para o antígeno do "core"; AgHBe - antígeno $e$; anti-HBe - anticorpo para $e$; sub-tipos do AgHBs e DNA polimerase) e a disponibilidade de técnicas laboratoriais mais sensíveis e de fácil execução, os estudos soroepidemiológicos tornam-se freqüentes no grupo de pacientes hansenianos. Os estudos realizados na Índia são particularmente numerosos (Blumberg \& Melartin, 1970; Kulkarni et al.,

O termo "lepromatoso" do inglês "lepromatous" foi empregado para os artigos de língua inglesa, embora o termo virchowiano seja recomendado pela classificação adotada oficialmente pelo Programa de Controle de Hanseníase do Brasil. 
1972; Ananthakrishnan et al., 1972; Kelkar et al., 1973; Saha \& Dutta, 1977; Vaishnavi et al., 1989), tornando-se possível identificar resultados divergentes sobre esta associação em todos os continentes.

Ao rever a literatura sobre a associação entre hanseníase e infecção pelo vírus da hepatite $\mathrm{B}$, optou-se por descrever os resultados de acordo com os diferentes delineamentos dos estudos: rastreamento sorológico da infecção entre pacientes hansenianos, inquéritos de prevalência, estudos de caso-controle e de coorte. Esta classificação permite analisar as limitações metodológicas inerentes a cada delineamento, condição essencial na interpretação das evidências neste tipo de associação.

Vale ressaltar que somente estudos com tamanho de amostra superior a 40 foram incluídos no quadro sumário no Anexo 1 e os estudos de casos não são apresentados. Neste anexo os estudos foram categorizados por tipo de delineamento, em ordem decrescente do tamanho amostral, sem considerar as formas iniciais da doença. Tendo-se em vista as diferenças de técnicas laboratoriais utilizadas para detecção de anticorpos e a relativa escassez de dados sobre a classificação dos tipos de hanseníase na maioria dos estudos, há limitações metodológicas para realizar uma meta-análise das publicações. Assim, procurou-se, através da análise qualitativa da metodologia, estabelecer os principais pontos comuns, as consistências e as limitações referentes à validade interna e externa de cada investigação epidemiológica. Nos estudos para os quais havia informações sobre marcadores de exposição viral (anti-HBs, anti-HBc e outros), além da detecção do antígeno AgHBs, foi calculada a Probabilidade de Persistência da Infecção Viral (PPI), isto é, o índice de clearance antigênico (Serjeantson \& Woodfield, 1978).

\section{Rastreamento sorológico para infecção pelo VHB em pacientes hansenianos}

O primeiro rastreamento para AgHBs em pacientes hansenianos foi conduzido em Cebu, nas Filipinas, por Blumberg et al. (1967), detectando-se alta 
prevalência do antígeno em pacientes "lepromatosos", quando comparados com um grupo de pacientes tuberculóides e um de controles. As prevalências encontradas foram de 9,9\% entre 803 pacientes "lepromatosos", 4,3\% entre 605 pacientes tuberculóides e 5,0\% entre controles sem doença manifesta. $O$ padrão epidemiológico foi que pacientes "lepromatosos" e limítrofe - "borderline" - em grupos etários mais jovens e homens apresentavam mais altas prevalências de antígeno de superfície do que o grupo de comparação.

A hipótese levantada para explicar a variação entre a forma polar "lepromatosa" versus a forma tuberculóide, nesta interessante primeira investigação, foi a postulação da diferença genética. Convém lembrar que, neste período, a natureza do AgHBs - "antígeno Austrália" - era desconhecida. Pacientes de forma "lepromatosa" e pacientes com leucemia eram considerados geneticamente mais suscetíveis à infecção crônica pelo VHB (Blumberg et al., 1967; Shwe \& Zuckerman, 1972). Os autores também questionam se os resultados obtidos foram decorrentes de viés de seleção da população de estudo ou mesmo de variáveis de confusão não avaliadas. Pacientes "lepromatosos" foram selecionados entre internos de colônias para tratamento de hanseníase, e esta condição poderia favorecer a transmissão viral, enquanto pacientes tuberculóides eram na maioria das vezes tratados ambulatorialmente. O grupo de comparação foi composto por estudantes de medicina, enfermeiras, doadores de sangue, os quais diferiam em muitos aspectos dos pacientes hansenianos, particularmente em relação aos aspectos sócioeconômicos e, conseqüentemente, de exposição ao vírus da hepatite B.

A postulação da teoria de deficiência imunológica na hanseníase do tipo "lepromatosa", como uma possível justificativa da associação entre a hanseníase e a infecção pelo VHB, surge imediamente após a constatação científica de que o antígeno de superfície faz parte integrante do vírus da hepatite B. De acordo com esta hipótese, o aumento observado na freqüência do AgHBs é principalmente decorrente da depressão de imunidade celular em pacientes "lepromatosos", que os torna mais suscetiveis à infecção viral e também interfere em sua eliminação. 
Outras alternativas aventadas, porém com menor ênfase, foram a possibilidade de transmissão iatrogênica e as baixas condições de higiene decorrentes da reclusão dos pacientes "lepromatosos" (Shwe \& Zuckerman, 1972; Papaevangelou et al., 1972).

Depois do estudo pioneiro das Filipinas (Blumberg et al., 1967), diversos estudos de associação foram conduzidos em diferentes áreas do mundo: Sul da Índia, Japão, Cingapura, Hong Kong, Austrália e Brasil.

O estudo do Sul da Índia (Blumberg \& Melartin, 1970) apresentou o maior tamanho da amostra com 556 pacientes da forma "lepromatosa", 385 tuberculóides e 253 controles, e confirmou os resultados do estudo inicial de Blumberg et al. (1967). Um aumento de quase 5 vezes de prevalência antigênica foi encontrado em pacientes "lepromatosos" (6,3\%) comparados aos tuberculóides $(1,3 \%)$ e ao grupo controle de não pacientes $(2,8 \%)$. O mesmo tipo de explicação foi utilizado neste estudo, mesmo porque Blumberg é o autor principal de ambas as investigações. $\mathrm{O}$ grupo de comparação apresenta as mesmas possibilidades de vieses não analisadas, e a institucionalização poderia estar associada tanto com a hanseníase quanto com a infecção pelo VHB. Estudos conduzidos em outras regiões tinham menor tamanho da amostra e não evidenciaram maior freqüência de portadores ao VHB em área de baixa endemicidade de infecção, como na região Sul do Brasil (Salzano \& Blumberg, 1970).

Somente para 6 estudos, classificados como rastreamento sorológico, o PPI pôde ser calculado. O estudo de Saha \& Dutta (1977), na Índia, mostrou pequena detecção de anticorpos em pacientes "lepromatosos" e também no grupo de controle composto de "soldados saudáveis", conseqüentemente, fornecendo altos índices de infecção persistente (PPI=0,93 e 0,95 ) para ambos os grupos. Foi utilizado na detecção de anticorpos anti-HBs a eletroimunodifusão, considerada uma técnica de baixa sensibilidade quando comparada à técnica de ensaio imunoenzimático (ELISA) e radioimunoensaio (RIA) (Hoofnagle, 1981; Edwards, 1988) o que poderia explicar os resultados encontrados. 
Os estudos da África do Sul (Sher et al., 1977) e Senegal (Chiron et al., 1978a; Chiron et al. 1978b) não mostraram diferenças significantes na resposta de anticorpos entre pacientes "lepromatosos" e grupo controle, com variação do PPI de 0,18 a 0,36 . A partir destes resultados os autores concluiram que pacientes com hanseníase, expostos ao VHB, independente do tipo de hanseníase, desenvolvem resposta imune adequada com formação de anticorpos protetores. No entanto, os pacientes estudados na Somália por Nuti et al. (1979) apresentaram diferenças entre o nível de resposta humoral calculado para os pacientes "lepromatosos" (PPI $=0,34)$ quando comparados aos do tipo tuberculóide (PPI $=0,16)$, apesar da obtenção de resultado intermediário para o grupo controle (PPI=0,29). Ao contrário, em Papua, Nova Guiné, a resposta imune à infecção ao VHB entre os dois grupos foi similar, o que levou os autores a concluir que o defeito imunológico dos pacientes "lepromatosos" não se estende ao VHB (Ree \& Talonu, 1981).

Fakunle \& Whittle (1981) registraram maiores taxas de marcadores virais em formas "lepromatosas" que em formas tuberculóides. Os autores sugerem que há maior risco de exposição em pacientes "lepromatosos" comparados aos tuberculóides, considerando-se que os primeiros foram submetidos a repetidas e prolongadas admissões hospitalares. Neste estudo, o índice de resposta humoral foi 4 vezes maior do que entre o grupo controle, sugerindo uma resposta imune inadequada na forma "lepromatosa" da doença.

No Brasil, a associação entre hanseníase e VHB tem sido pouco estudada. $\mathrm{Na}$ pesquisa bibliográfica de publicações indexadas e teses, apenas 6 estudos foram conduzidos no Brasil, 5 dos quais em áreas de baixa e intermediária endemicidade para a infecção pelo VHB. Apenas um estudo foi realizado na região Norte do país, considerada de alta endemicidade para ambas as doenças/infecções. O primeiro estudo de Salzano \& Blumberg (1970) não revelou nenhuma associação através do rastreamento sorológico entre 200 pacientes e 275 "controles sadios", no Rio Grande do Sul. Zyngier et al. (1979) publicaram prevalências de $15,5 \%$ e 9,1\% para AgHBs entre 90 pacientes "lepromatosos" e 11 pacientes tuberculóides, 
respectivamente em leprosário do Rio de Janeiro. Ottati \& Candeias (1979) descreveram sorotipos de AgHBs em pacientes "lepromatosos" em São Paulo, sem grupo de comparação. Sarno et al. (1980) rastrearam 129 pacientes "lepromatosos" e 24 tuberculóides com uma prevalência geral de 1,3\%, comparada a 2,0\% para o grupo controle, composto de 300 indivíduos. Os outros dois estudos são do tipo caso-controle e são descritos no item apropriado.

No Anexo 1 encontram-se listados os principais estudos de associação. A detecção dos marcadores sorológicos da hepatite B variou desde as técnicas iniciais de imunodifusão, imunoeletroforese, contra-imunoeletroforese, hemaglutinação passiva reversa, ensaio imunoenzimático, de acordo com a técnica disponível à época de realização das investigações, com sensibilidade e especificidade diferentes, limitando a comparabilidade dos resultados sorológicos.

\section{Estudo de prevalência}

Apenas um estudo de prevalência foi conduzido em uma comunidade da Nova Guiné, para avaliar simultaneamente a prevalência de hanseníase e do VHB (Patterson et al., 1988). Neste inquérito populacional em área de alta endemicidade para ambas as doenças, 84 casos clínicos de hanseníase e uma soroprevalência global de $60 \%$ para o VHB foi detectada entre 960 indivíduos examinados. Dentre as 151 famílias analisadas, para 61 não havia nem casos de hanseníase, nem de indivíduos AgHBs positivos. Em 29 residências, havia indivíduos AgHBs positivos sem pacientes de hanseníase, e em 35 foram detectados casos de hanseníase, mas sem portadores do VHB.

Ainda em relação ao estudo de Patterson et al. (1988), o pico de prevalência da hanseníase e da infecção pelo VHB ocorreram em diferentes grupos etários, sugerindo "um processo diferencial de transmissão da hepatite B e $M$. leprae não havendo dependência entre o aparecimento da infecção pelo vírus da hepatite $\mathrm{B}$ e a suscetibilidade individual a hanseníase". Vale a pena ressaltar que a residência 
foi a unidade de análise ao invés de indivíduos, a questão do aglomerado familiar foi levada em consideração, mas as diferenças nas condições sócio-econômicas poderiam ainda ser consideradas um fator de confusão para a associação.

\section{Estudos de caso-controle}

Dois estudos foram delineados para investigar a associação entre hanseníase e infecção pelo VHB. Apesar de ambos terem sido conduzidos em áreas de alta endemicidade para VHB e hanseníase, os resultados são conflitantes.

O primeiro estudo foi conduzido em Papua Nova Guiné (Serjeantson \& Woodfield, 1978), numa região onde a soroprevalência de marcadores de infecção viral excede $50 \%$ em muitas localidades. Neste estudo, avaliou-se a resposta imunehumoral de pacientes com hanseníase e seus controles. Os controles foram emparelhados por sexo, idade e local de residência aos casos e os marcadores AgHBs e anti-HBs foram detectados por hemaglutinação passiva. Os resultados mostraram que a idade foi o fator de risco isolado mais importante para se identificar o estado de portador viral. No entanto, pacientes da forma "lepromatosa" estiveram positivamente associados ao marcador antigênico mesmo quando a idade foi controlada na análise multivariada. $\mathrm{O}$ índice de resposta à exposição viral (PPI) entre os "lepromatosos" foi de 0,42 comparado com 0,25 entre os tuberculóides, sugerindo deficiência de resposta imune-humoral no primeiro grupo. Em contraposição, pacientes tuberculóides tiveram semelhante resposta imune-humoral ao grupo de controles saudáveis. A prevalência do marcador de exposição anti- $\mathrm{HBc}$ não foi avaliado por esse estudo, e aproximadamente de $3 \%$ a $5 \%$ dos pacientes expostos ao vírus podem não ter sido detectados (Hoofnagle, 1981, Edwards, 1988).

Quase uma década após, o estudo conduzido na Grécia por Papaioannou et al. (1986) investiga sorologicamente 217 pacientes hansenianos (135 LL, 82 TT/BT) e 382 controles hospitalares. Dois grupos de pacientes "lepromatosos" foram 
definidos: (i) aqueles com "infecção ativa" - indivíduos positivos ao AgHBs e (ii) "indivíduos expostos" - aqueles com um ou mais marcadores sorológicos positivos, mas sem antígeno detectável. O estudo concluiu que a prevalência de "infecção ativa" (AgHBs) não diferiu estatisticamente entre tuberculóides e controles ou entre "lepromatosos" e controles. Entretanto, a prevalência de exposição ao VHB foi de aproximadamente $86 \%, 87 \%$ e $59 \%$ para o grupo casos "lepromatosos", tuberculóides e controles hospitalares, respectivamente. Assim, o aumento da prevalência de exposição não parece ser decorrente de fatores biológicos, mas da maior oportunidade de infecção, com os fatores ambientais sendo considerados o determinante crítico para a antigenemia entre os grupos estudados. Neste estudo, em oposição ao estudo de Searjentson \& Woodfield (1978), os pacientes do tipo "lepromatoso" foram eficientes para desenvolver resposta imune com níveis de anticorpos protetores (PPI $=0,007$ "lepromatosos" e 0,009 para tuberculóides e controles).

Rosa et al. (1992) publicaram um estudo de rastreamento sorológico com análise tipo caso-controle, para avaliar os marcadores sorológicos do VHB e o papel da institucionalização como fator de risco para aquisição da infecção na região Centro-Oeste do Brasil. Dois grupos de pacientes "lepromatosos" foram avaliados: 83 pacientes ambulatoriais e 171 institucionalizados na Colônia Santa Marta em Goiânia. A prevalência de AgHBs no grupo de pacientes institucionalizados foi de $8,8 \%$ versus $4,8 \%$ no grupo de ambulatório, diferença não estatisticamente significante. Houve, no entanto, maior prevalência de marcadores de infecção ao VHB em pacientes institucionalizados da forma "lepromatosa" (50,3\%), quando comparados com pacientes ambulatoriais da mesma forma clínica (16,9\%), independentemente de idade e sexo, diferença estatísticamente significante. As maiores taxas de soropositividade, considerando-se qualquer marcador pela técnica de radioimunoensaio (RIA), foram detectadas em pacientes com mais de 20 anos de hospitalização. Os autores levantam duas hipóteses para explicar os resultados encontrados: (i) os pacientes admitidos na colônia poderiam representar uma amostra diferente dos demais. Nestas circunstâncias haveria um viés de seleção de 
amostra e as baixas condições sócio-econômicas poderiam determinar o nível de exposição viral; (ii) a própria institucionalização seria um fator de risco à infecção viral. Os autores sugerem que o local de estudo, a cidade de Goiânia, com altas taxas de detecção de casos de hanseníase e baixa endemicidade para a infecção pelo vírus $B$, pode ser considerado um cenário privilegiado para a condução de estudos de caso-controle. Os principais óbices do estudo referem-se ao grupo controle de ambulatório e também à comparação com dados de doadores de sangue, cujas questões metodológicas na utilização de rastreamento sorológico de doadores de sangue como fonte de dados de morbidade populacional são exploradas por outros autores (Martelli et al., 1991).

Em tese intitulada - Hanseniase no Estado do Amazonas - Estudo das características epidemiológicas da hanseníase no munícípio de Lábrea - formula-se uma interessante hipótese: "A ampla e precoce disseminação da infecção pelo vírus da hepatite $B$ na população em estudo atua como fator de indução do adoecimento por hanseníase nos indivíduos infectados pelo $M$. leprae". Nessa investigação, pacientes "lepromatosos" estiveram positivamente associados ao AgHBs, quando comparados com os tuberculóides e o grupo de não-caso, concluindo-se que o estado de portador viral é fator de risco para a hanseníase clínica (Braga, 1993). Convém ressaltar que se trata de um estudo de prevalência em comunidade de alta endemicidade para o VHB e análise tipo caso-controle.

Uma outra questão, abordada também por um estudo de caso-controle, refere-se à variação na excreção de antígeno (AgHBs) em diferentes secreções entre pacientes hansenianos e não hansenianos (Sherif et al., 1988). Foram avaliados o suor, a saliva, o fluido seminal e conjuntival, verificando-se que pacientes hansenianos tiveram uma mais alta "incidência" de AgHBs que o grupo de comparação. Considerando-se que o antígeno foi o único marcador investigado, não há como separar as etapas de exposição e imunidade entre os grupos. O estudo não especifica se há casos agudos de hepatite $\mathrm{B}$ entre os indivíduos antigenicamente positivos. Apesar dos autores apresentarem os resultados como sendo positivamente 
maior para AgHBs em todas as secreções, somente para a saliva há uma diferença significativa entre os dois grupos. Vale a pena mencionar que o tamanho da amostra é pequeno (8 pacientes "lepromatosos", 8 pacientes tuberculóides e 30 controles).

\section{Estudo de coorte}

Um estudo de seguimento para detectar soroconversão de pacientes foi realizado em um leprosário da África do Sul por Sher et al. (1977). Entre os objetivos do estudo, encontra-se o papel da hospitalização como fator de risco para infecção pelo vírus da hepatite $B$. Os pacientes foram investigados na admissão e em vários intervalos de tempo, para medidas de incidência de soroconversão. $O$ grupo de comparação consistiu de pacientes tuberculóides do mesmo hospital. Do total de 88 casos estudados, 51 eram soronegativos à admissão, e 5 pacientes "lepromatosos" adquiriram a infecção enquanto hospitalizados. Os autores sugerem que pacientes "lepromatosos" são mais suscetíveis a infecção viral no contexto de institucionalização do que o grupo tuberculóide. No entanto, o grupo tuberculóide apresentava tempo inferior de hospitalização e, portanto, de acompanhamento, não sendo este aspecto considerado na análise de dados. Uma leitura crítica fica prejudicada, uma vez que a metodologia do estudo é descrita de forma suscinta e o artigo não apresentou resultados conclusivos.

Pacientes hansenianos vacinados contra a hepatite B (Engerix-B - Smith Kline Biologicals, Belgium, $20 \mu \mathrm{g}$, IM, esquema padrão) apresentaram após 12 meses de seguimento, baixa taxa de soroconversão. Sugerem os autores que o grupo de pacientes "lepromatosos" deveria ser considerado uma população candidata para se testarem as vacinas de maior poder imunogênico, uma vez que, no estudo anterior, a produção da resposta imune ao vírus natural parece ser adequada (Rosa et al., 1992; Rosa et al., 1994). 
Recentemente, Banerjee et al. (1994) estudaram 41 pacientes das diferentes formas de hanseníase, utilizando-se análise do DNA do VHB e AgHBs (ELISAAbbot $^{R}$ ), porém sem informação sobre os outros marcadores de infecção viral. Como resultado, quase $50 \%$ dos pacientes classificados clínica e histologicamente como na categoria "lepromatosos" (forma LL da classificação de Ridley \& Jopling, 1962) eram sorologicamente positivos ao DNA do VHB ou AgHBs. Segundo os autores, "fica evidente que há maior incidência da infecção pelo VHB em pacientes da forma LL, sugerindo uma correlação entre infecção viral e resposta imunecelular contra Mycobacterium leprae". No entanto, deixam claro que houve pequena concordância entre os marcadores estudados, AgHBs pela técnica de ELISA e DNA do VHB pela técnica de dot-plot, explicável, talvez, pela maior sensibilidade do teste de DNA. Reconheceram ainda que a amostra estudada é pequena e insuficiente para se obterem resultados conclusivos.

Em resumo, apesar de existirem inúmeras investigaçōes de campo sobre a associação entre hanseníase e hepatite $\mathrm{B}$, a maioria dos estudos são rastreamentos sorológicos entre pacientes. As perguntas se a infecção pelo VHB constitui-se um fator de risco para hanseníase ou, vice-versa, se diferentes formas de hanseníase diferem quanto a resposta imune, com persistência do antígeno para o grupo "lepromatoso", dificilmente são formuladas pelos autores e não podem ser distinguidas através de estudos descritivos.

Uma análise detalhada destas publicações deixa antever algumas dificuldades na interpretação destes resultados e na comparabilidade entre os diferentes estudos. Algumas considerações precisam ser feitas como: (i) tipo de estudo, estando a maioria na categoria de triagem sorológica; (ii) tamanho da amostra com pequeno poder estatístico para detectar pequenas diferenças de proporção de marcadores entre os grupos de hanseníase; (iii) diversas técnicas laboratoriais utilizadas na detecção dos marcadores sorológicos para o VHB e, conseqüentemente, diferentes sensibilidades e especificidades dos testes, dificultando a comparação dos resultados; (iiii) falta de uma definição clara das formas de hanseníase. 
Não fica claro se a divergência entre os estudos conduzidos em diferentes regiōes é só devida a problemas metodológicos, ou se há diferenças na suscetibilidade e/ou resposta ao VHB, de acordo com a endemicidade da hanseníase e infecção pelo VHB em diferentes regiōes geográficas. Partindo-se do pressuposto de que existe uma associação entre hanseníase e VHB, pelo menos duas alternativas podem ser levantadas:

1) A associação deve-se a fatores ambientais. Muitas doenças tropicais são distribuídas desigualmente e seria esperado que, em certas circunstâncias, o mesmo indivíduo estaria exposto a um risco maior de adquirir ambas as infecções, viral e pelo $M$. leprae, vindo a desenvolver hanseníase clinicamente detectável. Nestas circunstâncias, a concomitância de fatores de risco entre ambas as infecções, ao invés de uma verdadeira associação biológica, indica que os indivíduos estão expostos independemente ao risco de adquirir uma e outra infecção, porém sem alteração do seu curso natural. Por exemplo, a condição sócio-econômica parece ser simultaneamente fator de risco para a hanseníase e para a infecção pelo VHB. Contrários a esta hipótese estão os achados de alguns estudos de variação de prevalência entre formas clínicas de hanseníase, bem como a diferença na resposta imunológica ao VHB da forma "lepromatosa" em relação ao estado de portador viral.

2) Esta associação apresentaria uma plausibilidade biológica com mecanismos possíveis de serem explicados através dos conhecimentos no campo da biologia e, nesta situação, algumas hipóteses podem ser levantadas: (i) a infecção prévia pelo VHB poderia facilitar a aquisição da infecção pelo $M$. leprae ou poderia exacerbar uma infecção latente ou influir na história natural da hanseníase, causando alteração no espectro de formas clínicas, na gravidade das manifestações clínicas, na resposta ao tratamento ou na infectividade; (ii) a infecção prévia pelo $M$. leprae poderia modificar a suscetibilidade à infecção ao VHB e/ou aumentar a persistência do estado de portador viral.

$O$ perfil imunológico nas diferentes formas de hanseníase e a interação biológica entre o hospedeiro e o vírus da Hepatite B surge como eixo central desta 
avaliação. A importância da resposta imune-celular na hanseníase pode ser aquilatada na sua própria definição e classificação. Definida como doença infecciosa espectral causada pelo Mycobacterium leprae, é caracterizada em formas clínicas que estabelecem pólos tuberculóides e "lepromatosos" distintos, considerando-se a resistência do hospedeiro à infecção. As diferenças nas manifestações clínicas dos tipos polares são tão pronunciadas que sugerem duas doenças distintas (Scollard, 1993). As formas polares de hanseníase têm-se prestado como rico modelo para entendimento das respostas imunes, tanto sistêmicas quanto locais, pela supressão ou pela exacerbação da resposta imune-celular.

\section{Classificações das formas de hanseníase}

As características clínicas da hanseníase são atribuídas à proliferação bacteriana, a resposta imune do hospedeiro à infecção, e danos neurais causados pelos dois processos. As variadas manifestações clínicas da hanseníase podem ser classificadas em pelo menos 3 sistemas diferentes:

i) o sistema mais simplificado baseia-se na contagem bacilar, índice baciloscópico, possibilitando distinguir os pacientes negativos (Paucibacilares) dos positivos (Multibacilares), classificação utilizada com finalidade de tratamento (WHO, 1988); ii) a classificação de Madrid (Congresso Internacional de Leprologia, 1953) separa as formas tuberculóide, virchowiana, dimorfa e indeterminada e tem sido adotada pelo sistema de vigilância brasileiro para notificação e acompanhamento dos pacientes (Ministério da Saúde, 1994a);

iii) a classificação de Ridley \& Jopling (1966) baseia-se na biópsia e no quadro clínico e propõe um gradiente com cinco grupos variando do pólo relativamente resistente TT "tuberculoid" ao pólo mais suscetível LL "lepromatous" com o espectro intermediário designado BB "borderline leprosy", BT "borderline tuberculoid" e BL "borderline lepromatous". Esta classificação parece ser a mais utilizada pela literatura, e é nesta forma esquemática que o espectro da hanseníase é melhor entendido (Scollard, 1993). O índice baciloscópico, o número de lesões dos pacientes, os níveis de anticorpos são maiores em direção ao pólo 
"lepromatoso" do espectro, porém, a resposta mediada por célula aumenta em direção ao pólo tuberculóide (Modlin \& Rea, 1987).

O Guia de Controle da Hanseníase (Ministério da Saúde, 1994a) apresenta, em capítulo isolado, os aspectos imunológicos, especificando as etapas da resposta imune-celular, antecedendo o capítulo sobre diagnóstico e classificação da doença. Isto sinaliza a importância da compreensão dos mecanismos de regulação imunecelular na patogênese da hanseníase e para a classificação das formas clínicas. As palavras chaves na definição/classificação da hanseníase para a pesquisa de campo e controle são a avaliação clínica, exames bacterioscópicos e histopatológicos, bem como o teste de Mitsuda, este último avaliando a resposta imune-celular in vivo. Ensaios de linfoproliferação, detecção de $M$. leprae por técnica de Polymerase Chain Reaction (PCR), dosagem de citocinas estão ainda restritas a investigação científica e a aplicação em menor escala.

\section{Reposta imune-celular na hanseniase}

Em relação à hanseníase, foram publicados mais artigos sobre imunologia que a respeito de questões clínico-epidemiológicas na última década (Kronvall, 1981; Fine, 1981; Sehgal et al., 1989; Fine, 1989; Yamamura et al., 1991; Vries, 1991; Kaufmann et al., 1992; Britton, 1993). Esta avaliação visa a possibilitar "um olhar epidemiológico" sobre as evidências existentes da associação entre a hanseníase e o vírus da hepatite $B$, e não pretende fazer uma revisão das pesquisas imunológicas que englobaria determinar entre outros aspectos: (i) o repertório antigênico do $M$. leprae nas respostas mediadas por células com seus 15-16 antígenos protéicos já estabelecidos; (ii) as diferenças no reconhecimento do antígeno - papel da molécula HLA e o mapeamento de epítopos reconhecidos por células $\mathrm{T}$; (iii) os fatores genéticos na hanseniase, incluindo-se a suscetibilidade do hospedeiro e fatores relacionados à virulência bacteriana; (iiii) as subpopulações de células $\mathrm{T}$ e citocinas envolvidas na produção da resposta imune e suas implicações 
nả proteção/patologia da hanseníase. Esta citação pode deixar antever os complexos fenômenos imunológicos na hanseníase (Ottenhoff, 1994).

O $M$. leprae é capaz de sobreviver e se replicar em muitas células do hospedeiro, notadamente em macrófagos, entretanto, seu cultivo in vitro ainda não foi realizado com sucesso, embora tenha sido o primeiro agente etiológico imputado a uma doença infecciosa (Britton, 1993; Colston, 1993). As infecções bacterianas intra-celulares, de forma geral, caracterizam-se pela dependência de células $\mathrm{T} e$ independência da produção de anticorpos, baixa toxicidade, curso crônico das infecções, reação granulomatosa tecidual e reação do tipo retardada (Kaufmann, 1993).

Os mecanismos imunológicos que controlam a maior resistência ou suscetibilidade à infecção pelo $M$. leprae são ainda pouco conhecidos, mas envolvem citocinas que regulam a ativação e a desativação de macrófagos. $O$ complexo sistema de citocinas representa a chave para determinar o efeito final da resposta imune aos agentes infecciosos pois além das funções específicas das citocinas, estas proteínas também regulam outras subpopulações celulares e a produção de outras citocinas. Pouco se conhece ainda acerca da biologia da infecção intra-celular e dos mecanismos de escape que estes parasitas adotam para sobreviver, ou, ainda pior, para explorar a resposta imune em sua vantagem, conforme citação de Ottenhoff (1994). Modelos simplificados para explicar o papel da ativação preferencial de resposta humoral ou celular foram substituídos por conceitos de interdependência e regulação no estímulo/produção de citocinas. Um arsenal de símbolos e letras são utilizados para explicar os mecanismos de regulação, exigindo dos não imunológos uma nova alfabetização.

A ativação da resposta imune-celular ou humoral depende da indução preferencial de linfócitos $\mathrm{T} \mathrm{CD}^{+}$tipo $\mathrm{T}_{\mathrm{H}} 1$ e $\mathrm{T}_{\mathrm{H}} 2$, respectivamente, que diferem no perfil de citocinas após estimulação. Os linfócitos $\mathrm{T} \mathrm{CD}^{+}$do tipo $\mathrm{T}_{\mathrm{H}} 1$ produzem IL-2 (Interleucina) e INF- $\gamma$ (Interferon gama) entre outras citocinas, sendo o 
INF- $\gamma$ crucial para a ativacão dos macrófagos, levando-os a um estado microbicida. Os linfócitos $\mathrm{T} \mathrm{CD}^{+}$tipo $\mathrm{T}_{\mathrm{H}} 2$ produzem IL-4, IL-5 e IL-10 e auxiliam na produção de anticorpos pelos linfócitos $B$. Além disto, as células $\mathrm{T}_{\mathrm{H}} 2$ através da IL-4 e IL-10 interferem na produção das citocinas pelas células $T_{\mathbf{H}} 1$, notadamente o IFN- $\gamma$, impedindo a estimulação e destruição das células-alvo, que são os macrófagos infectados (Kaufmann, 1993). Patógenos de origem bacteriana geralmente induzem uma predominante ativação de celula $T\left(T_{H} 1\right)$ que pode levar a ativação do tipo $\mathrm{T}_{\mathrm{H}} 2$, dependendo do tempo e agravamento da infecção (Janeway \& Travers, 1994).

Há evidências em estudos experimentais e em populações humanas, que a genética do hospedeiro influencia o tipo de hanseníase que se desenvolve pósinfecção conforme revisão de Bloom et al. (1992). Mais detalhadamente, reconhecese o papel de moléculas HLA-DQ controlando a supressão de resposta imunecelular ao M. leprae, porém estes dados não são conclusivos (Fine et al, 1979).

Simplificadamente, pacientes tuberculóides mostram marcada resposta imune mediada por células T, também encontrada em contactantes saudáveis. Este tipo de resposta é responsável pela destruição do agente infeccioso com persistência de poucos ou nenhum bacilo nas lesões. Células $\mathrm{T} \mathrm{CD}^{+}$do tipo $\mathrm{T}_{\mathrm{H}} 1$ e as citocinas IL-2 e INF- $\gamma$ são predominantemente encontradas nas lesões deste grupo de pacientes (Yamamura et al., 1991). Enquanto a imunidade mediada por células limita a multiplicação e disseminação dos bacilos na hanseníase tuberculóide, não é raro encontrar-se a estimulação da resposta imune-celular associada a dano tecidual severo, como observado em pacientes tuberculóides.

Em contraste, a ativação da resposta imune-celular com linfócitos T CD4 ${ }^{+}$ do tipo $\mathrm{T}_{\mathrm{H}} 2$ em pacientes de forma "lepromatosa". é responsável pelos altos índices bacilares e lesões disseminadas com ausência de imunidade específica mediada por células. Pacientes do pólo virchowiano não produzem ou produzem baixas taxas de IL-2 e INF- $\gamma$. Estudos do perfil de citocinas em lesões de pacientes do pólo 
virchowiano indicam predominar IL-4, IL-5 e IL-10 (Yamamura et al., 1991). Entre os pólos tuberculóides e "lepromatosos" estão os casos limítrofes "borderline", descritos no sistema de classificação de Ridley \& Jopling (1966) ou os dimorfos (Congresso Internacional de Leprologia, 1953). Estes, mesmo quando não tratados, tendem a gravitar entre um dos pólos, isto é, são imunológica e clinicamente instáveis (Scollard, 1993).

A importância deste tipo de revisão consiste em compreender a dificuldade de estabelecer grupos homogêneos em hanseníase com finalidade de comparação, utilizando-se as classificações e instrumental imunológico existentes. Em instigante artigo, Scollard (1993) discute o uso da classificação de Ridley \& Jopling (1966), concebida como um espectro contínuo, para distinguir subgrupos de pacientes. Assim, a simples menção desta classificação pelos estudos parece não garantir homogeneidade, nem uma classificação definitiva dos pacientes. O autor sugere a incorporação da idade de aquisição da infecção e duração da doença/infecção com o objetivo de tornar os grupos de pacientes mais homogêneos. Pontua, ainda, a necessidade de desenvolver novos métodos que possibilitem o acompanhamento do status imunológico dos pacientes para sua classificação.

O defeito na resposta da célula $\mathrm{T}$ na infecção pelo $M$. leprae, em relação a ativação de macrófagos, tem sido avaliado como extremamente específico. Citase, como exemplo, que em pacientes hansenianos a resposta a uma bactéria altamente semelhante - $M$. tuberculosis - está preservada, apesar de ambas compartilharem várias estruturas antigênicas comuns. Esta especificidade da imunodeficiência da hanseníase tem sido descrita por diferentes autores (Reitan, 1986; Britton, 1993; Ottenhoff, 1994).

Apenas uma publicação intitulada "Linfocitotoxinas na hanseníase e no portator assintomático do vírus da hepatite B", Serjeantson \& Dry (1980), procura estabelecer qual o mecanismo imune envolvido na associação entre hanseníase do tipo "lepromatosa" e infecção pelo vírus da hepatite B. Infelizmente, os dados 
apresentados não podem ser interpretados à luz dos avanços imunológicos recentes. Vale ressaltar que se trata da mesma autora de um dos estudos epidemiológicos de associação anteriormente citado (Serjeantson \& Woodfield, 1978).

Embora os avanços recentes da imunologia sejam fascinantes do ponto de vista do conhecimento científico e mesmo do potencial de aplicabilidade para diagnóstico, prognóstico e terapêutica da hanseníase (Kaplan, 1991; Damasco et al. 1992; Pimentel et al., 1993), estes instrumentos não oferecem ainda opções práticas claras para uso em pesquisa epidemiológica de maior escala ou mesmo para o programa de controle, conforme enfatizado por Fine (1989). Os testes sorológicos para diagnosticar o estado de infecção, fase pré-clínica e lesões precoces não apresentaram ainda sensibilidade e especificidade adequadas para uma doença de baixa freqüência na população como a hanseníase (Fine, 1989; Smith, 1992b). Em síntese, o desenvolvimento recente da imunologia e genética na hanseníase ainda não se reverteu em aplicações práticas para os estudos epidemiológicos. Assim, as investigações epidemiológicas majoritariamente utilizam, para estabelecer grupos com certa homogeneidade, os clássicos métodos diagnósticos, baseados na clínica e na confirmação laboratorial pela baciloscopia e histopatologia.

\section{Considerações sobre a transmissão do vírus da hepatite $B$}

Diferentemente da hanseníase, a sorologia na hepatite B tem-se constituído em um dos principais e mais usados estratégias para avaliar a infecção, a imunidade e o estado de portador. Entre os modelos de transmissão do vírus da hepatite $B$ incluem-se: a exposição a produtos sanguíneos e hemoderivados, a via de transmissão sexual e a transmissão vertical mãe-filho. Em áreas de alta endemicidade há predominância da transmissão vertical, enquanto a transmissão sexual é predominante em áreas de baixa e média endemicidade, indicando aquisição da infecção mais tardia. Em relação ao estado de portador do vírus B (AgHBs), a idade de aquisição da infecção tem sido considerada o principal determinante da 
freqüência de portadores em nível de população (Beasley, 1988; Edmunds et al., 1993).

Os mecanismos imunológicos que determinam a infecção crônica ao VHB não foram totalmente especificados, mas é caracterizada pela específica falha da célula $T$ para reconhecer o envelope polipeptídico viral, etapa crítica para aquisição de imunidade protetora (Almarri \& Batchelor, 1994). A incidência de infecção crônica após à exposição ao VHB é maior naqueles em que se tem uma relativa deficiência da função de células $\mathrm{T}$ - recém-nascidos, idosos, portadores de síndrome de Down, com tumores malignos, recebendo imunoterapia e em indivíduos HIV sintomáticos. A presença de células citotóxicas dirigidas especificamente ao AgHBs em portadores assintomáticos tem sido demonstrado in vivo e in vitro (London \& Blumberg, 1985; Alexander, 1990; Thomas, 1990).

A interação das doenças infecciosas vem sendo discutida com mais detalhes, particularmente após o surgimento da infecção HIV e as suas conseqüências no recrudescimento de doenças como a tuberculose entre outras, no contexto dos países desenvolvidos e em desenvolvimento (Blaser \& Cohn, 1986; Smith et al., 1988; Ponnighaus et al., 1991). As exposições a agentes infecciosos de forma simultânea e o potencial de interações biológicas nos diferentes grupos populacionais de suscetíveis, infectados, imunes, com imunidade parcial e/ou imunidade temporária abrem um amplo leque de possibilidades na condução de estudos epidemiológicos em doenças infecciosas, deixando antever, no entanto, a complexidade das relacões biológicas e ambientais a serem enfrentadas na condução dos estudos de associação. 


\section{JUSTIFICATIVA}

Houve considerável progresso das atividades desenvolvidas pelos programas de controle de hanseníase, em nível mundial, desde a formulação da meta de eliminação, enquanto problema de saúde pública (Noorden, 1994; Noorden, 1995). Entretanto, a taxa global de prevalência das Américas estimada em 4,6 por 10000 habitantes em 1994 precisará de ser reduzida quase 5 vezes para se atingir esta meta operacional de prevalência de 1 por 10000 habitantes. O Brasil congrega $79 \%$ dos casos na América Latina, sendo que, no ano de 1993, cerca de 200000 doentes de hanseníase encontravam-se em registro ativo, com taxa de prevalência de 13,0 por 10000 habitantes, considerada alta pelos critérios da Organização Mundial de Saúde. A região Centro-Oeste apresenta a segunda maior taxa de prevalência do território nacional (Penna, 1994).

Constituem desafios identificáveis à eliminação da hanseníase, a urbanização da população, os movimentos migratórios rural-urbano, a complexidade das estruturas do sistema de saúde instalado e a persistência de núcleos de atendimento especializados nos grandes centros urbanos (Andrade, 1993; Martelli et al., 1995a).

A Hepatite B é um processo infeccioso, com transmissão predominantemente parenteral ou através do contato direto com sangue/ secreções, que pode evoluir de forma assintomática ou cursar com quadros agudos/crônicos de gravidade variável (Shapiro \& Margolis, 1990). Estima-se que existam 170 milhões de portadores do vírus da Hepatite $\mathrm{B}(\mathrm{VHB})$ em todo o mundo, havendo uma estreita correlação entre a incidência de carcinoma hepatocelular e a prevalência do estado de portador (Beasley, 1988). Estudo recente, realizado no nosso meio, encontrou prevalências de $1,9 \%$ e $11,0 \%$ respectivamente para AgHBs e para Anti-HBs, permitindo classificar a cidade de Goiânia como área de intermediária endemicidade para o vírus da Hepatite B (VHB) (Martelli et al.,1990). A prevalência desta infecção varia 
amplamente entre diferentes regiōes geográficas. Desta forma a prevenção da transmissão do VHB, através da vacinação, passa a ser um problema de saúde pública mundial.

A associação entre a forma multibacilar de hanseníase e estado de portador do vírus da hepatite $\mathrm{B}$ tem sido estudada para diferentes regiões do mundo, apresentando, no entanto, resultados controversos, que geram mais dúvidas que respostas. No capítulo sobre hepatite $B$, no tópico referente a persistência viral do clássico compêndio de infectologia (Robinson, 1990), os pacientes "lepromatosos" são considerados de maior risco para o estado de portador viral.

O delineamento tipo caso-controle surge como a primeira opção para avaliar a interação de doenças infecciosas (Smith et al., 1988). Este tipo de estudo, inicialmente concebido para doenças crônicas, teve sua aplicação expandida para o estudo da etiologia e fatores de risco em doenças infecciosas e afecções congênitas (Selby, 1994; Andrade et al., 1994). No entanto, a falta de um marcador de infecção em hanseníase surge como complicador para estes estudos analíticos, impossibitando discriminar os subgrupos de suscetíveis, infectados e doentes dentro de uma mesma população. Paradoxalmente, a característica de longo período de incubação aproxima a hanseníase aos modelos de estudo caso-controle para doença crônica não transmissível. Outro complicador é a transposição da teoria de dependência dos eventos das doenças infecciosas, que vincula o surgimento de casos novos a casos antigos, isto é, a incidência está na dependência da prevalência da doença (Halloran \& Struchiner, 1991; Giesecke, 1994).

O conhecimento da dinâmica de transmissão das infecções é imprescindível para testar a hipótese de associação entre hanseníase e vírus da hepatite $B$. Epidemiologicamente, a aquisição da infecção ao vírus da hepatite B (VHB) nos primeiros anos de vida constitui o fator determinante para persistência da antigenemia viral - estado de portador (Beasley, 1988; Edmunds et al., 1993). Esta característica dificulta a investigação desta associação em regiões de alta 
endemicidade ao VHB, uma vez que a idade de aquisição da infecção deve ser entendida como variável de interação, e não uma variável de confusão que possa ser ajustada através da análise estratificada e multivariada.

Desta forma, Goiânia preenche os requisitos necessários para condução desta investigação por ser uma região de alta endemicidade para hanseníase, com proporção de casos multibacilares superior a $30 \%$ de todos os casos novos (Ministério da Saúde, 1994b) e de baixa/intermediária endemicidade para infecção pelo VHB (Martelli et al., 1990). A localização dos serviços de saúde, facilitando a etapa de seleção/captação de casos e controles, merece ser citada entre as vantagens adicionais de condução do estudo nesta região. Este é o primeiro estudo de caso-controle conduzido dentro deste contexto epidemiológico.

Dentro da perspectiva de redução da prevalência da hanseníase, a adoção de critérios rigorosos é de fundamental importância para a definição de casos, não só com finalidade de pesquisa, mas também para o Programa de Controle da Hanseníase (Feenstra, 1994; Pannikar, 1992; Scollard, 1993; Lombardi et al., 1994). O delineamento proposto possibilita, através de criteriosa definição de caso de hanseníase e representatividade da amostra, estudar as características regionais da hanseníase e a distribuição espacial dos casos na delimitação de áreas críticas intra-urbanas.

Considerando o benefício potencial da utilização da vacina contra o vírus da hepatite B em pacientes hansenianos, a resposta à associação entre hanseníase e estado de portador viral poderia ser relevante do ponto de vista científico e de saúde pública. 


\section{OBJETIVOS}

\subsection{Objetivo principal}

Investigar a associação entre hanseníase e estado de portador do vírus da hepatite $B$, através de estudo de caso-controle.

\subsection{Objetivos secundários}

Avaliar características sócio-econômicas e migratórias como fatores de rịsco da hanseníase.

Apresentar a distribuição espacial da hanseníase no aglomerado urbano de Goiânia, Estado de Goiás. 


\section{METODOLOGIA}

\section{1 Área de Estudo}

A pesquisa foi realizada na cidade de Goiânia, capital do Estado de Goiás. A área de estudo incluiu 4 municípios contíguos, que fazem parte do Aglomerado Urbano de Goiânia (AGLUG): Município de Goiânia, Aparecida de Goiânia, Senador Canedo e Trindade.

A população total da área de estudo é de aproximadamente 1200000 habitantes (hab.) com uma concentração de 920000 hab. na cidade de Goiânia, e menos de $1 \%$ da população residente em área rural (FIBGE, 1991). Na última década houve uma tendência irreversível de criação de uma aglomeração contínua destes municípios por efeito da polarização da capital. Um crescente contingente de pessoas utiliza os municípios do entorno de Goiânia apenas como opção de moradia, sendo a capital o pólo de absorção de mão de obra (IPLAN, 1992a; IPLAN, 1992b). Os distritos urbanos da cidade de Goiânia e os municípios vizinhos estão apresentados no Mapa 4.1.

A área de estudo faz parte da Macrorregião Centro-Oeste do Programa de Controle da Hanseníase da Divisão Nacional de Dermatologia Sanitária do Ministério da Saúde (PCL/DNDS/Ministério da Saúde), considerada área de prioridade 1 (um) para controle da doença no Brasil (Ministério da Saúde, 1989). De acordo com a classificação de endemicidade da OMS, esta Macrorregião é considerada de alta endemicidade para hanseníase, com prevalência de 29,4/10000 hab. e de detecção de 64,4 por 100000 hab. (Ministério da Saúde, 1994a). Nas duas últimas décadas estima-se um aumento de aproximadamente $8 \%$ nas taxas anuais de deteç̧ão da doença nesta região (Motta \& Zuniga, 1990).

Em relação à infecção pelo vírus da hepatite $\mathrm{B}$ (VHB), a área de estudo é considerada de baixa/intermediária endemicidade, com prevalência de 
aproximadamente $2 \%$ e, $11 \%$ para AgHBs e anti-HBs pela técnica de ELISA, respectivamente, conforme avaliação recente realizada em 1033 primodoadores de sangue (Martelli et al., 1990). A vacinação contra hepatite B não faz parte da rotina de imunização da rede pública e nenhuma campanha de vacinação em massa foi conduzida nesta região.

\subsection{Delineamento do estudo}

A pesquisa foi planejada como um estudo de caso-controle para investigacão da associação entre hanseníase e infecção pelo vírus da hepatite $B$, incluindo um componente de estudo dos casos e da distribuição espacial dos pacientes residentes na área urbana.

Para o estudo caso-controle foi realizado o emparelhamento dos controles por região de residência dos casos.

\subsection{Organização do trabalho de campo}

a) Fonte de recrutamento dos casos - O local de recrutamento dos casos foi o Centro de Saúde Juarez Barbosa (CSJB), unidade de saúde da rede estadual, que concentra quase $80 \%$ dos casos de hanseníase da cidade de Goiânia e municípios vizinhos (Martelli et al., 1995a). O CSJB dispõe de um setor especializado, para atendimento de dermatologia sanitária, com três ambulatórios funcionando em período integral. Todos os indivíduos com quadro clínico sugestivo de hanseníase, no período de outubro de 1992 a outubro de 1993, foram encaminhados para o dermatologista responsável pelos exames neuro-dermatológicos deste projeto, para confirmação clínica, preenchimento da ficha clínica padronizada (Anexo 2), para realização de biópsia de pele e lâmina para baciloscopia, quando apropriado.

b) Local de realização dos exames laboratoriais: (i) $\mathrm{O}$ conjunto de lâminas de baciloscopia e as biópsia, com o mesmo código das fichas individuais foram 
encaminhadas diariamente ao Laboratório de Micobactérias do Departamento de Microbiologia do Instituto de Patologia Tropical e Saúde Pública (IPTSP) da Universidade Federal de Goiás (UFG) e Laboratório de Patologia da Faculdade de Medicina da UFG, para processamento e leituras, independentemente da rotina dos serviços de saúde; (ii) as amostras sorológicas eram transportadas diariamente para o Laboratório 'de Virologia do IPTSP/UFG para centrifugação, separação e armazenamento em soroteca a $-20^{\circ} \mathrm{C}$. Os testes foram realizados durante o mês de julho de 1994, no Laboratório de Hepatites Virais da Fundação Oswaldo Cruz (FIOCRUZ) do Ministério da Saúde, no Rio de Janeiro.

c) Fonte de recrutamento dos controles - Após o término da seleção de casos, iniciou-se o recrutamento dos controles em dezembro 1993. Optou-se por selecionar controles não concorrentes no tempo com os casos, por constituir-se em uma estratégia de campo mais viável do ponto de vista operacional e financeira. A seleção de controles foi realizada em 7 unidades de saúde da rede pública:

Centro de Saúde Juarez Barbosa (CSJB)

Centro de Assistência Integral à Saúde (CAIS) Jardim Novo Mundo, Centro de Assistência Integral à Saúde (CAIS) Jardim Novo Horizonte, Centro Integrado de Assistência Médico Sanitária (CIAMS) Urias Magalhães, Centro de Atenção Integral à Saúde (CAIS) Dergo, Centro Integrado de Assistência Médico Sanitária (CIAMS) Pedro Ludovico, Centro de Atenção Integral à Saúde (CAIS) Cândido de Moraes

A escolha destas unidades deveu-se à localização espacial dos casos na área de abrangência destas unidades e ao atendimento de clientela ambulatorial procedente das diversas regiões da município de Goiânia e dos municípios do aglomerado (Mapa 4.3). Controles foram selecionados da demanda espontânea, de acordo com as características de funcionamento de cada unidade, dos seguintes ambulatórios: pediatria, ginecologia e obstetrícia, clínica médica, "carteira de saúde" e atendimento de urgência. O tempo médio para recrutamento de controles em cada unidade variou de uma a seis semanas, dependendo da demanda dos ambulatórios, com conclusão desta etapa de investigação em março de 1994. 
A seleção de casos e controles foi realizada pela mesma equipe de campo, sob a supervisão da investigadora principal. O fluxograma do trabalho de campo encontra-se esquematizado na Figura 4.3.

O processamento e a análise de dados foram realizados no Departamento de Saúde Coletiva do IPTSP/UFG, sede da coordenação do projeto.

\subsection{Definição de casos e controles}

Foram considerados casos todos os pacientes recém-diagnosticados de hanseníase, isto é, virgens de tratamento específico, de 10 a 70 anos, residentes no município de Goiânia e municípios do entorno. O critério de seleção de caso levou em consideração a triagem clínica e os resultados de exames complementares exames histopatológico e baciloscópico.

Para efeito de definição de caso de hanseníase e análise de dados, estabeleceu-se um gradiente de certeza do diagnóstico, para todos os pacientes recém-detectados de hanseníase, utilizando-se os seguintes critérios:

a) "Caso multibacilar" (MB) - triagem clínica indicativa ou sugestiva de hanseníase e resultado da baciloscopia positivo (qualquer positividade) ou com laudo histopatológico de forma multibacilar;

b) "Caso paucibacilar" (PB) - triagem clínica indicativa ou sugestiva de hanseníase e resultado da baciloscopia negativo, porém com laudo histopatológico de forma paucibacilar;

c) "Caso provável" (PR) - triagem clínica indicativa ou sugestiva de hanseníase, porém com resultado baciloscópico negativo e exame histopatológico não conclusivo/inespecífico.

No intuito de verificar possíveis inconsistências entre triagem clínica e exames complementares, a ficha clínica e os exames baciloscópicos e histopatológicos foram revistos por um dermatologista, independente do investigador 
principal, para determinação dos critérios de multibacilar (MB), paucibacilar (PB) e provável (PR) para assegurar a qualidade da informação.

O critério de seleção de controles foi a ausência de lesões de pele suspeita de hanseníase em pacientes ambulatoriais das unidades de saúde correspondentes à localização de moradia do caso. Os procedimentos de exame clínico obedeceram à mesma padronização da triagem clínica dos casos (Figura 4.4).

\subsection{Tamanho da amostra}

O tamanho da amostra foi estabelecido levando-se em conta a ocorrência de portador do vírus da hepatite $\mathrm{B}$ entre controles de $4 \%$. Desta forma, assumindo 1 controle por caso, foi calculado que 600 casos e 600 controles seriam suficientes para detectar odds ratio maiores ou iguais a 2, com um erro Tipo II de $20 \%$ (80\% de poder estatístico) e erro Tipo I de 5\% (Schlesselman, 1982).

Foram triados seqüencialmente, através de exame clínico, 855 indivíduos da demanda espontânea do ambulatório de dermatologia sanitária do CSJB, no período de aproximadamente 13 meses (outubro 1992 a outubro 1993). Destes, 624 casos eram residentes no município de Goiânia e aglomerado urbano. Foram excluídos 24 indivíduos com diagnóstico histopatológico sugestivo de outras patologias: esclerodermia (8), eczemátide/eczema (3), granuloma anular (2), elastose solar (1); paniculite esosinofílica (1), eritema multiforme (1), eritema pigmentar fixo (1), esporotricose (1) e seis casos (6) com exame baciloscópico negativo e histopatológico inespecífico avaliados clinicamente como diagnóstico pouco provável de hanseníase.

Assim, 600 pacientes foram considerados como casos em potencial e estudados quanto às características biológicas e de distribuição/mobilidade espacial. 
Excluiram-se 36 por não serem elegíveis para participar do estudo de casocontrole devido à idade inferior a 10 anos ou superior a 70. Para 12 casos não foi possível selecionar um controle da mesma abrangência da unidade de saúde. Desta. forma, o tamanho final do estudo de caso-controle foi de 552 casos e 552 controles (1:1), emparelhados por local de residência. Nenhum caso e aproximadamente $1 \%$ dos controles se recusou a participar do estudo. O fluxograma de seleção de casos e controles encontra-se especificado na Figura 4.5.

\subsection{Triagem clínica}

A primeira etapa para a seleção dos casos consistiu na triagem clínica de todos os indivíduos oriundos da demanda espontânea do ambulatório de dermatologia, durante o período de estudo. Através de exame dermato-neurológico procedeu-se a inspeção de todo o corpo para identificação de lesões cutâneas, pesquisa de sensibilidade em áreas suspeitas, palpação de nervos periféricos e avaliação de função motora.

O exame clínico foi realizado por dermatologistas treinados, com experiência prévia em hanseníase, alocados ao projeto, independente do serviço de rotina. Para todos os casos em potencial foi preenchida uma ficha clínica padronizada e, aqueles que apresentavam suspeita clínica de hanseníase foram encaminhados para exames complementares (exame baciloscópico e histopatológico).

\subsection{Exames complementares}

Exame baciloscópico - Após a triagem clínica, foram realizadas as coletas de esfregaço de pele para exame baciloscópico, em dois conjuntos de lâminas. A primeira lâmina foi colhida, corada e lida como parte da rotina do Programa de Controle de Hanseníase em nível local e utilizada como lâmina guia para alocação dos pacientes nos esquemas de tratamento. Outras duas lâminas, contendo 3 círculos 
previamente delimitados em cada uma, foram coletadas especificamente para esta investigação. Priorizou-se a coleta de material dos seguintes locais: lesões ativas, lóbulos auriculares direito e esquerdo (LOD, LOE) e região de cotovelo. Para as lesões de pele classificadas como tubérculos ou nódulos, a coleta foi realizada de material da zona central, e, nas outras lesões (maculares, em placas ou infiltrativas), a coleta de material foi feita na borda externa. A coloração foi realizada pela técnica de Ziehl-Neelsen, de acordo com as normas do Ministério da Saúde (1989). Os resultados foram catalogados de acordo com o sítio da lesão, utilizando-se a escala logarítmica de Ridley, citada por Talhari \& Neves (1989). A leitura foi realizada por um único observador, especialista em microbiologia e com treinamento prévio no Centro de Referência Nacional - Instituto Lauro de Sousa Lima- Bauru/São Paulo.

Exame histopatológico - Biópsias de pele foram realizados para todos os pacientes baciloscopicamente negativos e, em aproximadamente $20 \%$, para os positivos. A coleta foi realizada através de "punch" de $4 / 5 \mathrm{~mm}$, por dermatologista, após a avaliação clínica. As leituras dos exames histopatológicos foram realizadas por um único patologista do Departamento de Patologia da UFG. O patologista desconhecia a avaliação clínica e o resultado da baciloscopia (exame às cegas). Os resultados foram reportados considerando-se o critério de classificação de Ridley \& Jopling (1966) e Ridley \& Jopling (1962), em formas: indeterminada (I); tuberculóide (TT); limítrofe (borderline) tuberculóide (BT); limítrofe (borderline) central (BB); limítrofe (borderline) "lepromatoso" (BL) e "lepromatoso" (LL). Colorações de Hematoxilina-Eosina (H\&E) e Fite-Faraco foram utilizadas para pesquisa de bacilos álcool ácido resistentes. A pesquisa de bacilos nas biópsias de pele foram realizadas em múltiplos cortes, usando-se à semelhança dos exames baciloscópicos, a escala logarítmica. 


\subsection{Entrevista}

Após a triagem clínica, todos os casos em potencial e controles foram entrevistados por auxiliares de pesquisa. Os entrevistadores desconheciam a hipótese de estudo, no intuito de minimizar possíveis tendenciosidades na coleta de informações. Os Anexos 3 e 4 referem-se, respectivamente ao questionário e ao código para preenchimento.

Através de entrevista foram coletados, para os casos e controles, os seguintes dados sobre:

- Características demográficas - Sexo, idade, estado civil, endereço de residência e de trabalho.

- Condições sócio-econômicas - Anos de escolaridade, posição na família, profissão, tipo de trabalho atual, rendimento individual e familiar, número de familiares com salário, proprietário de residência, número de cômodos, moradores por moradia e número de habitantes por casa. A classificação do tipo de ocupação obedeceu ao Manual de Orientação de Especificações Técnicas (Ministério do Trabalho, 1993).

- Características de mobilidade espacial intra-urbana - Anos de moradia na área de estudo (AGLUG), número de mudanças, migração pendular, isto é, - deslocamento inter-municipal por motivo de trabalho. A história de mudanças de residência permitiu a construção de matriz de fluxo migratório, tomando-se como origem o local de residência há 10 anos atrás, e de destino a residência atual.

- Características de utilização dos serviços de saúde - Tipo da demanda, número de consultas nos últimos seis meses, hospitalização nos últimos 5 anos.

- Principais fatores de risco para exposição ao VHB - Freqüência do uso de medicação injetável, uso de droga recreativa e prática sexual. 


\subsection{Medidas antropométricas}

Peso, medido com precisão de 100 gr em balança eletrônica, e altura em centímetros. O Índice de Massa Corporal (IMC) ou Índice de Quetelet, foi calculado para os indivíduos adultos (casos e controles) e categorizado de acordo com Shetty et al. (1994) como sendo igual ao peso $(\mathrm{kg}) / \mathrm{altura}^{2}(\mathrm{~m})$.

Normal $\geq 18,5$;

Desnutrição:

Grau I = 17,0-18,5;

Grau II = 16,0-16,9;

Grau III $<16,0$.

\subsection{Exames sorológicos para infecção pelo VHB}

No momento da entrevista, foram coletados $10 \mathrm{ml}$ de sangue por via venocubital, com utilização de sistema "vacutainer" de coleta, para detecção de marcadores de infecção do vírus da hepatite B (anti-HBc total, anti-HBs, AgHBs). A técnica utilizada foi o ensaio imunoenzimático (ELISA) (Voller et al.,1978; Yoshida et al., 1984). Os procedimentos de coleta, armazenamento e transporte seguiram as normas padronizadas pelo Centro de Referência para Hepatites Virais da /Fiocruz do Ministério da Saúde.

Em uma primeira etapa, as amostras referentes aos casos e controles foram testadas para detecção do marcador anti-HBc (total), uma vez que este é considerado o melhor marcador sorológico para triagem (Hoofnagle, 1981; Edwards, 1988). As amostras soropositivas foram retestadas em uma segunda etapa para os marcadores AgHBs e anti-HBs:

i) AgHBs é o marcador de infecção aguda identificado no soro 30-60 dias após a exposição ao VHB, e persiste em portadores até por 20 anos;

ii) anti-HBs é considerado marcador de imunidade ao VHB, resultante de infecção ativa desde que vacinação contra o vírus $B$ não faça parte do esquema de vacinação 
de massa em nosso meio. Para a exclusão dos indivíduos com infecção aguda, as amostras positivas ao AgHBs foram testadas para o anti-HBc (IgM). Foram utilizados reagentes biológicos do Centro Nacional de Referência para Hepatites Virais (CNRHV), da FIOCRUZ. Os testes sorológicos foram realizados com o mesmo lote de reagentes, por uma só equipe de laboratório. A validade dos reagentes para os testes de ELISA com vistas ao diagnóstico de hepatite B é avaliada periodicamente pelo CNRHV, através da aplicação de amostras de cada lote produzido a um painel constituído de amplo espectro de soros. Exige-se que a sensibilidade e especificidade dos reagentes tenham um limite de aceitabilidade mínimo igual a 90\%, para controle de qualidade (Schatzmayr, 1989).

As amostras foram consideradas positivas quando a densidade ótica obtida na leitura por espectofotômetro em microplacas com filtro de comprimento de onda de $450 \mathrm{~nm}$ era maior que o valor do ponto de corte o qual é estabelecido como sendo igual à média das leituras dos controles negativos multiplicado por 2,1 (Voller et al., 1978; Fields \& Maynard , 1985).

As amostras com resultados limítrofes ao anti-HBc (total) foram retestadas e consideradas positivas na persistência deste resultado, para assegurar que todas as amostras potencialmente positivas ao anti-HBc fossem testadas para os demais marcadores de infecção pelo vírus da hepatite B. As amostras limítrofes, com relação aos demais marcadores sorológicos, também foram retestadas e na persistência de resultados limítrofes, foram consideradas como negativas.

De acordo com os marcadores sorológicos testados, foram identificadas as seguintes categorias de exposições ao VHB (Hoofnagle, 1981; Edwards, 1988):

i) "estado de portador do VHB" - AgHBs positivo e anti-HBc (IgM) negativo;

ii) "imunes" - Anti-HBs positivo e anti-HBc total positivo;

iii) "infecção prévia ao VHB" ou "expostos ao VHB": positividade a qualquer marcador (HBsAg, anti-HBs, ou anti-HBc total).

A figura 4.10, em anexo, apresenta o fluxograma da triagem sorológica. 


\subsection{Processamento e Análise de Dados}

As fichas clínicas e as dos resultados dos exames sorológicos, bacteriológicos e histopatológicos foram padronizadas e pré-codificadas, visando processamento eletrônico. Os dados foram inicialmente armazenados em programa gerenciador de banco de dados, FoxPro, com a utilização simultânea de programa de computador feito especificamente para avaliar a consistência dos dados. Os aplicativos SPSS/PC (SPSS/PC,1990), EGRET - Epidemiological Graphics, Estimation and Testing Package" (SERC, 1991) e Statistical Analysis System (SAS, 1985) foram utilizados no processamento e análise dos dados.

Os mapas de distribuição dos municípios e distritos urbanos foram obtidos do Instituto de Planejamento Urbano (IPLAN), digitalizados e analisados no Departamento de Saúde Coletiva, utilizando-se os sistemas dbMapa ${ }^{\circledR}$ e MaxiCAD ${ }^{\circledR}$ em mesa digitalizadora Sumagrid IV.

$\mathrm{Na}$ estratégia de análise de dados construiu-se dois bancos de dados: i) banco de dados 1 , contendo os dados referentes a todos os pacientes com hanseníase da área de estudo $(\mathrm{N}=600)$ para o detalhamento dos casos em potencial e estudo da distribuição espacial e do fluxo de migração intra-urbana; ii) banco de dados 2 , com os dados dos casos $(\mathrm{N}=552)$ e controles $(\mathrm{N}=552)$. Este último banco de dados foi utilizado para o estudo de caso-controle na avaliação dos fatores de risco e associação do vírus da hepatite B entre casos e controles.

\section{a) Primeira etapa - Banco de dados 1}

Além do uso de estatísticas descritivas clássicas, tais como, medidas de tendência central, de dispersão, e distribuição percentual das variáveis, optou-se, inicialmente, pela aplicação da técnica de Análise Exploratória de Dados (Tukey, 1977). Esta técnica consiste em explorar a distribuição das taxas de detecção de casos ("outliers" - valores discrepantes versus "inliers" - valores concordantes) relativas às diversas variáveis consideradas potenciais descritores. A mediana e os 
quartis foram as estatísticas adotadas nesta fase inicial de análise, uma vez que são estatísticas menos afetadas por valores extremos (Tukey, 1977).

Foram analisados:

i) as características de detecção precoce de casos, através da variável "duração dos sintomas", pela mediana e o intervalo inter-quartílico;

ii) o perfil de distribuição da hanseníase por distritos urbanos para pesquisar os possíveis descritores das taxas de deteç̧ão de casos. Foram calculadas as taxas brutas de detecção de casos e taxas de detecção para casos por faixa etária pelos distritos urbanos. Foram identificadas as suas características de ordem e construídos diagramas de ramos e folhas e gráficos - caixas para os potenciais descritores.

Apenas as variáveis do exame clínico e exames laboratoriais consideradas relevantes para identificar precocidade do diagnóstico e para a definição de caso foram avaliadas. A história de contactante intra e extra-domicilar, e gradiente de certeza diagnóstico foi avaliada, considerando-se a importância no mecanismo de transmissão.

Para a análise dos fluxos de migração urbana utilizaram-se as áreas de I a VIII localizadas do centro para periferia pelo setor de planejamento municipal (IPLAN, 1992a). A área VIII foi considerada atípica, pois inclui os três municípios do entorno da capital. Estabeleceu-se um período fixo de 10 anos para construção da matriz de mobilidade intra-urbana. O Índice de Mobilidade (IM) foi calculado como o percentual de indivíduos que se deslocaram nos últimos 10 anos. O Saldo Migratório para as regiões do entorno foi estabelecido pela diferença entre o número total de migrantes recebidos e os que abandonaram a área pela totalidade da população (Renner \& Patarra,1980). 
b) Segunda Etapa - Estudo de caso-controle

Casos e controles foram comparados em relação às principais características biológicas, sócio-econômicas, de mobilidade espacial e de utilização dos serviços de saúde.

Testes de hipótese, usando as estatísticas " $t$ " de Student e análise de variância, foram feitos para avaliar as diferenças entre duas ou mais médias, respectivamente. Foram aplicadas as estatísticas - teste de qui-quadrado e quiquadrado para tendência linear, para avaliar as magnitudes das diferenças observadas nas distribuições de freqüências. Quando uma estatística era utilizada em múltiplas comparações referentes a uma mesma hipótese, utilizou-se a correção de Bonferroni. Portanto, o nível de significância de cada teste individualmente, para as características demográficas, sócio-econômicas, de mobilidade espacial e de utilização de serviços de saúde (20 variáveis), foi de $\alpha=0,0025(0,05 / 20)$. Para todos os demais testes o nível de significância adotado foi $\alpha=0,05$.

Análise univariada - Foi realizada, mantendo-se o emparelhamento por área geográfica dos 552 casos e 552 controles, quanto às características demográficas, sócio-econômicas, de mobilidade espacial, de utilização dos serviços de saúde e de potenciais fatores de risco para exposição ao VHB.

Os casos foram analisados em três categorias: multibacilares (MB), paucibacilares (PB) e prováveis (PR). Assim, $\mathrm{MB}, \mathrm{PB}$ e $\mathrm{PR}$ foram considerados como variáveis de efeito para o cálculo das estimativas de risco (odds ratio ou razão de odds - OR) e respectivos intervalos de $95 \%$ de confiança (IC 95\%). O procedimento de Mantel-Haenszel (1959) foi utilizado para cálculo de odds ratio entre duas variáveis estratificado por variáveis de confusão, após o teste de heterogeneidade, teste de Woolf, entre os estratos (Breslow \& Day, 1980).

$O$ índice de resposta humoral ao vírus da hepatite $B$, nos diferentes tipos de hanseníase, foi calculado conforme a fórmula de Probabilidade de Persistência de 
Infecção pelo vírus da hepatite-PPI (Serjeatson \& Woodfield, 1978). A interpretação deste índice é que, quanto mais baixo o PPI, melhor a resposta imune, uma vez que implica resposta ao VHB com formação de anticorpos, indicando clearance do antígeno. Calculou-se o Índice de ELISA para o marcador anti-HBs como a razão entre a densidade ótica (DO) de cada amostra sorológica e a média dos controles negativos da respectiva placa, para permitir a comparação semi-quantitativa entre as amostras (Couroucé, 1990).

Análise multivariada - foi utilizada a técnica de regressão logística para avaliar associação de variáveis, segundo casos e controles. Utilizaram-se, também, nesta etapa, as categorias de casos $\mathrm{MB}, \mathrm{PB}$ e PR como variáveis de efeito.

Foram calculadas estimativas de riscos relativos ajustadas (Razão de OddsOR) para casos em relação a controles, levando-se em consideração as principais variáveis de confusão entre as quais idade, sexo, hospitalização no últimos 5 anos, cicatriz vacinal de BCG e variáveis sócio-econômicas com respectivos intervalos de 95\% de confiança (IC 95\%) e testes de hipótese com nível de significância de $5 \%$. Optou-se pela análise de regressão com variável de resposta politômica - polytomous logistic regression (Hosmer \& Lemeshow, 1989) e análise de regressão logística não condicional utilizando-se os aplicativos estatísticos SAS (1985) e SERC (1991) respectivamente.

\subsection{Estudo piloto}

O estudo principal foi precedido por um estudo piloto, para testar a estratégia operacional, os questionários de avaliação dos fatores de risco e a qualidade dos exames laboratoriais. Lâminas de biópsias de 50 indivíduos com suspeita clínica de hanseníase foram enviadas ao Instituto Lauro de Sousa Lima/ Bauru/ São Paulo, para uma segunda leitura, a fim de verificar a concordância entre os resultados. A leitura independente destas lâminas de biópsia por dois 
histopatologistas apresentou índice kappa maiores do que $75 \%$ sendo, portanto, considerados como níveis de concordância satisfatórios (Fleiss, 1981).

\subsection{Considerações éticas}

Este protocolo foi apreciado pela Divisão de Dermatologia Sanitária do SUSGoiás e considerado relevante do ponto de vista de saúde pública.

Todos os participantes, casos de hanseníase e grupo-controle, foram informados dos objetivos da pesquisa e foi dado consentimento informado individual para entrevista e exames laboratoriais.

As informações obtidas foram mantidas em sigilo e somente os responsáveis pelo projeto tiveram acesso ao cadastro nominal dos pacientes e aos resultados de exames laboratoriais. Os resultados sorológicos foram entregues nas unidades de saúde de captação dos casos e controles, ou através de carta-convite para comparecimento a uma consulta agendada. Uma assistente social permaneceu na unidade de saúde para orientar os participantes do estudo com relação à interpretação dos exames laboratoriais. Todos os indivíduos AgHBs positivos foram encaminhados ao ambulatório de referência para hepatites virais do Hospital das Clínicas /UFG, para investigação clínica.

Os resultados de exames complementares (exames histopatológicos e baciloscópicos) de todos os casos foram fornecidos à unidade de saúde de procedência dos casos. No entanto, a alocação dos pacientes hansenianos foi procedido conforme a rotina do programa de controle do ambulatório de dermatologia.

O projeto foi submetido e aprovado pelo Conselho Regional de Medicina do Estado de Goiás, sob o ponto de vista ético. 
Figura 4.3

Fluxograma do trabalho de campo
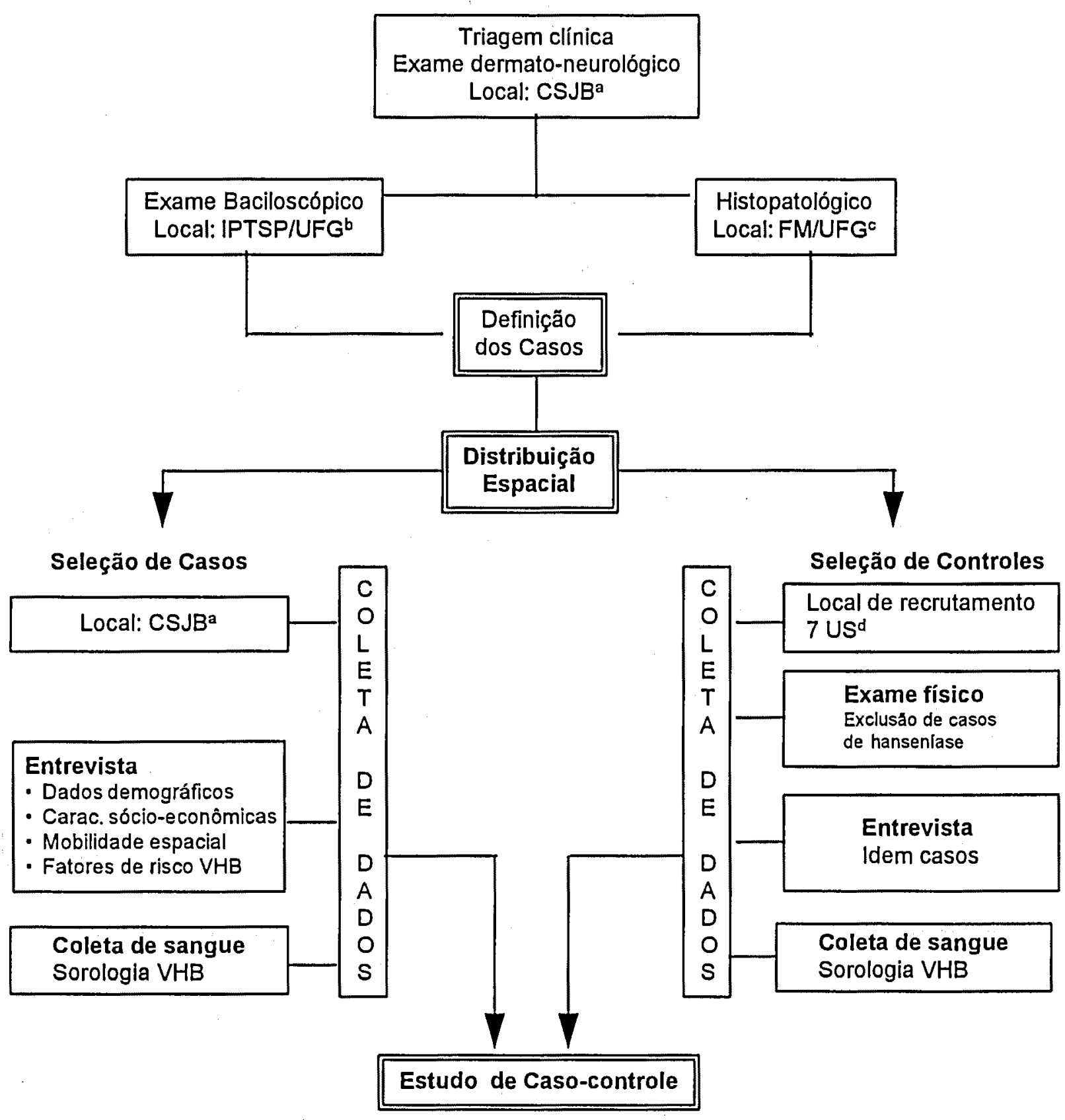

- Centro de Saúde Juarez Barbosa

- Depto. de Microblologia do Instituto de Patologia Tropical e Saúde Pública da Universidade Federal de Golás

- Depto. de Patologia da Faculdade de Medicina da Unlversidade Federal de Golás

- Unidades de Saủde: Centro de Saúde Juarez Barbosa, Cais Jardim Novo Mundo, Cais Novo Horizonte, Cais Urias Magalhåes,

Cais do Dergo, Cais Cândida de Moraes, CIAMS Pedro Ludovico. 
Figura 4.4

Fluxograma de definição de caso

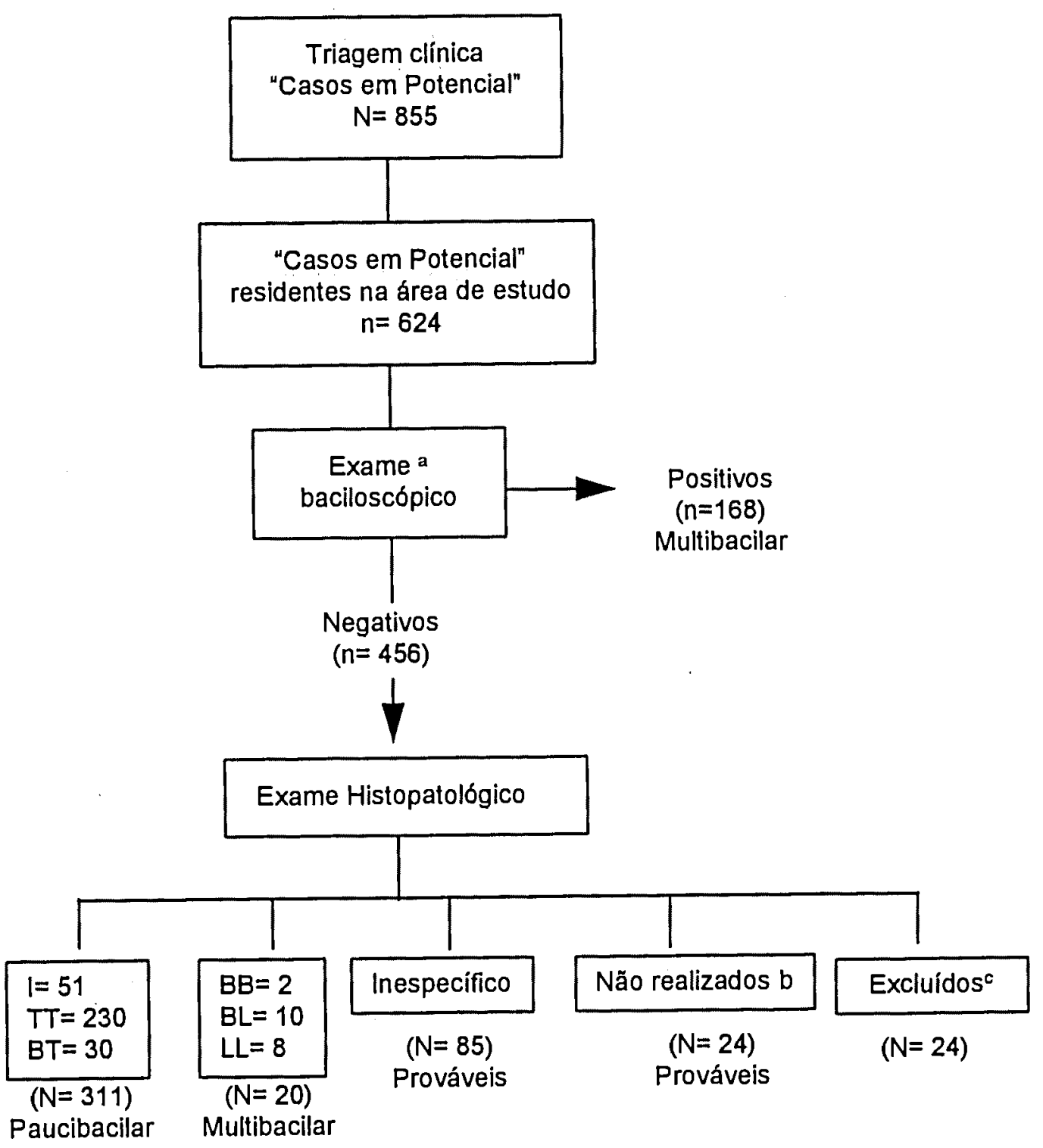

a 2 exames baciloscópicos não realizados

b 16 exames histopatológicos não realizados considerados casos pela triagem clínica

c diagnóstico histopatológico compatível com outra doença

I Indeterminada

BB Limitrofe central

TT Tuberculóide

BL Limítrofe lepromatosa

BT Limítrofe tuberculóide

LL Lepromatosa 
Figura 4.5

Fluxograma da seleção de casos e controles

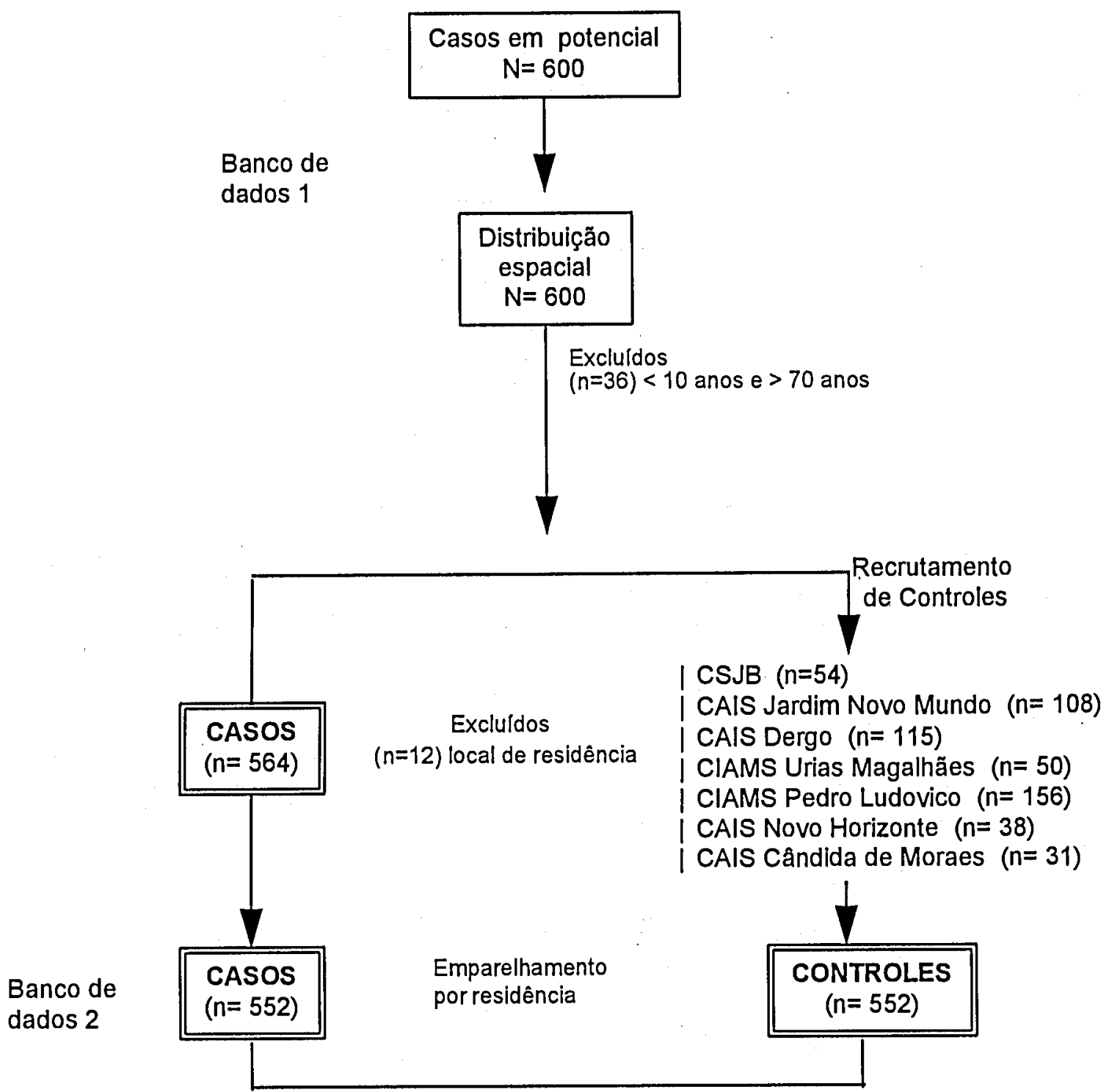

Estudo de caso-controle 
Figura 4.10

Fluxograma da triagem sorológica para infeção pelo VHB

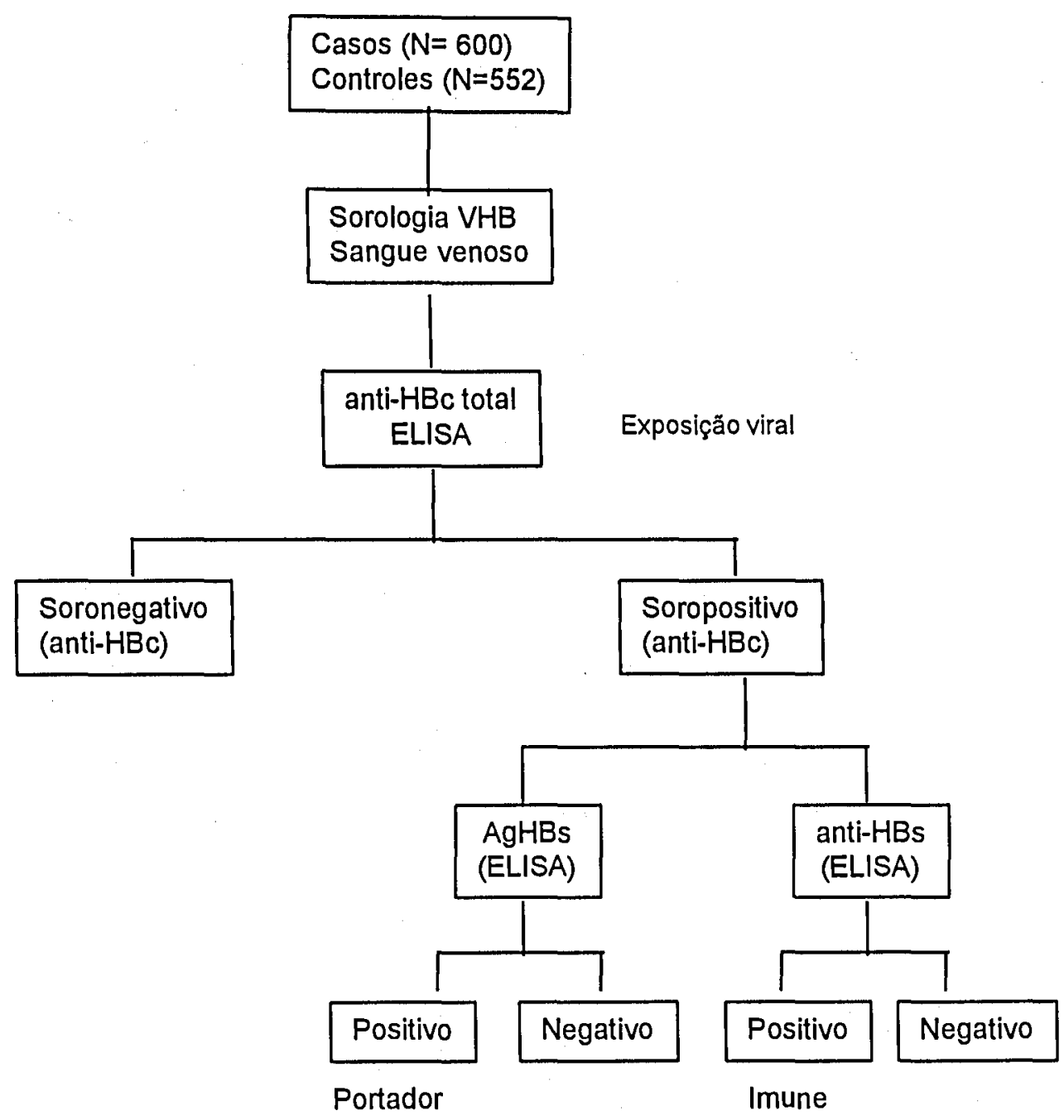


Mapa 4.1

Localjzacão dos djstrjtos urbanos de Gojânja e munjelpjos do aglomerado

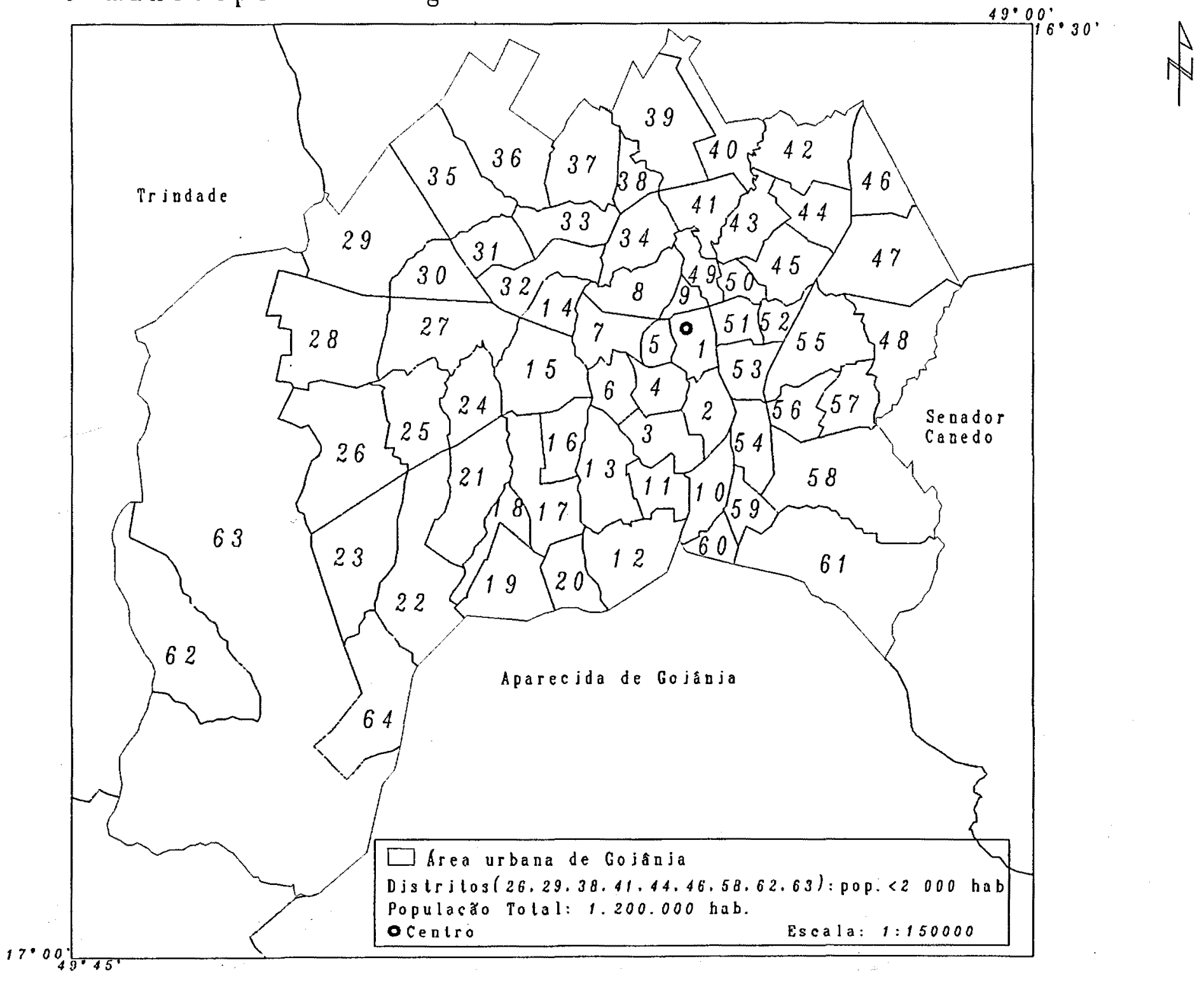




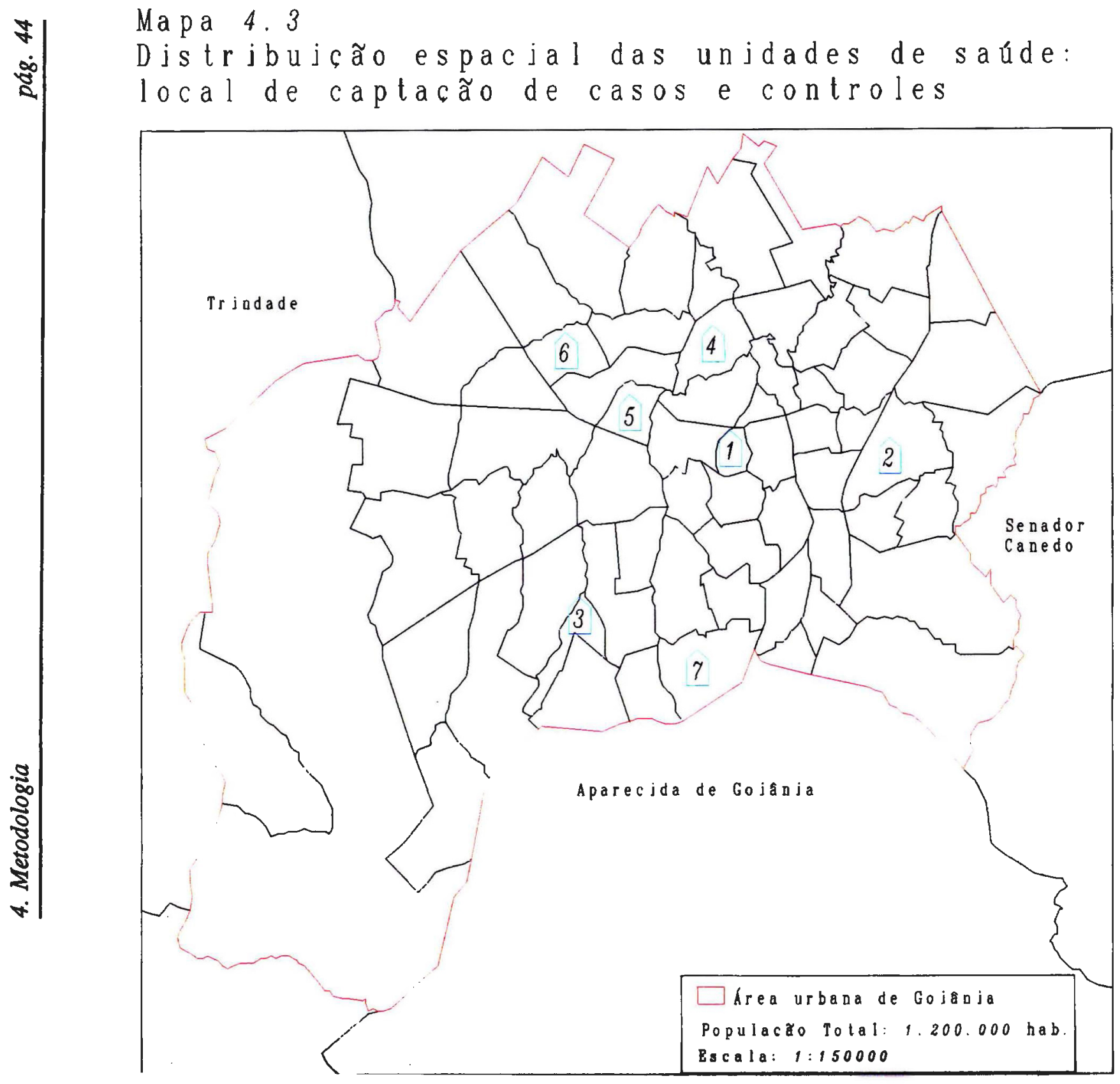

\begin{tabular}{llc|}
\hline Uajdades de Sade & Controles \\
1 CS Juarez Barbosa & 54 \\
2 CAIS Jardim Novo Mudo & 108 \\
3 CIAMS Novo Horjzonte & 38 \\
4 CIAMS Urias Magalhăes & 50 \\
5 CAlS Dergo & 115 \\
6 CAIS Candido de Moraes & 39 \\
7 CJAMS Pedro Ludovico & 156
\end{tabular}




\section{RESULTADOS E DISCUSSÃO}

\subsection{Caracterização da amostra de casos}

A amostra foi constituída de 600 casos recém-diagnosticados de hanseníase, triados seqüencialmente da demanda espontânea do ambulatório de dermatologia sanitária do CSJB, no período de 13 meses, residentes no município de Goiânia e área de conurbação. O estudo descritivo desta série de casos possibilita discutir os critérios de definição de caso em hanseníase com a finalidade de caracterizar o grupo selecionado para o estudo de caso-controle dentro do contexto do sistema de vigilância de hanseníase. No entanto, não foi possível estabelecer os índices endêmicos regionalmente. Isto porque, pelas características de cronicidade da hanseníase seriam necessárias grandes séries temporais na avaliação de sua tendência secular, como as publicadas de forma continuada pelo sistema oficial de informação do Programa de Controle e analisadas por diversos autores para algumas regiões do Brasil (Gontijo Junior \& Furtado, 1988; Lombardi, 1989; Cestari et al., 1989; Lombardi, 1993).

A Tabela 5.1-1 apresenta a distribuição dos casos recém-diagnosticados de hanseníase, de acordo com características demográficas, proporção de exames baciloscópicos positivos, antecedentes de contactantes intra ou extradomiciliares e duração dos sintomas. Aproximadamente $10 \%$ dos casos recém-diagnosticados de hanseníase apresentavam idade inferior a 15 anos. $O$ achado de hanseníase clínica, baciloscópica e/ou histopatologicamente confirmada em população menor de 15 anos indica um padrão de distribuição etária típica de áreas de alta endemicidade. Estes resultados são próximos aos percentuais de casos novos registrados pelas estatísticas oficiais do Programa de Controle de Hanseníase de 9\% (244/2697) e 11\% (3125/29169) para o Estado de Goiás e para o Brasil, respectivamente (Ministério da Saúde, 1994c). 
O aumento da idade de aparecimento da hanseníase e a conseqüente redução da incidência dos casos infantis têm-se constituído o padrão epidemiológico de declínio na maioria dos países endêmicos, o que pode ser interpretado como redução. do risco de adoecer na comunidade. De fato, a média de idade para manifestação clínica da doença parece estar mais associada ao decréscimo da endemicidade do que a predominância do tipo de hanseníase ou da razão de sexos. Esta parece ser também a lógica da avaliação da tendência secular aplicável às doenças infecciosas com longo e variável período de incubação como a tuberculose (Irgens, 1981; Fine, 1982; Irgens \& Skjaeven, 1985; Sehgal \& Srivastava, 1987; Sehgal \& Sehgal, 1988; Zárate, 1992; Lombardi, 1993, Ulrich et al., 1993). Ponnighaus et al. (1994a) sumarizam os estudos de padrão de distribuição da hanseníase por faixa etária, concluindo que a incidência por idade varia em diferentes populacões. Argumentam, ainda, que a dificuldade de interpretação advém do longo e variável período de incubação da hanseníase, dentro da seqüência da exposição ao agente infeccioso ocasionando a infecção, ao aparecimento de sintomas até o diagnóstico da doença.

Os resultados da baciloscopia foram negativos em $68,7 \%$ dos indivíduos triados clinicamente. Este padrão de casos paucibacilares é compatível com altas endemicidades (Irgens \& Skjaeven, 1985; Fine, 1992a). Há uma certa dificuldade em se comparar esses resultados com as estatísticas oficiais, uma vez que o sistema de informação oficial registra os casos novos agrupados por formas clínicas de acordo com a classificação de Madrid, e não pela baciloscopia. Recentemente, em análise da série temporal de dois períodos pré e pós-introdução da poliquimioterapia (PQT) no Brasil, detectou-se um crescimento rápido nas taxas de detecção de formas $\mathrm{MB}$, não condizente com as características de alta endemicidade de nosso meio, nem com as características de cronicidade da hanseníase. Esta alteração do tipo de hanseníase em larga escala foi interpretada como sendo um artefato decorrente da implantacão universal da PQT, ao invés de uma mudança real no perfil epidemiológico do país, refletindo possivelmente um comportamento conservador na adoção de um esquema terapêutico de maior duração (Martelli et 
al., 1994; Martelli et al., 1995b). Esta tendência de alteração da classificação do tipo de hanseníase tem sido observado também em outros países endêmicos (Cartel et al., 1992; Pattyn, 1994).

Referiram antecedentes de contactante(s) domiciliar(es) ou extradomiciliar(es) $31,6 \%$ dos casos (Tabela 5.1-1). A estratificação dos casos em duas faixas etárias ( $<15$ anos $\mathrm{e} \geq 15$ anos) evidenciou que 0 diagnóstico em idade precoce está associado à maior freqüência de contactantes $(61,0 \%)$, quando comparado aos diagnósticos em adultos (28,3\%), diferença estatisticamente significante $\left(x^{2}=26,3 p<0,001\right)$ (Tabela 5.1-2). A história de contactante foi principalmente entre indivíduos compartilhando a mesma moradia (contactantes intradomicilares) sendo o número de contactantes domiciliares maior para os pacientes em idades menores de 15 anos. Em relação ao grau de parentesco, 53,6\% dos pacientes menores de 15 anos tiveram identificados mãe ou pai como contactante. Também para os pacientes adultos, quase $70 \%$ dos contactantes eram pais ou irmão, seguido por filho $(11,6 \%)$ e conjuge $(9,9 \%)$ (Tabela 5.1-2 e Figura 5.1-1). Contactantes intrafamiliares são um grupo reconhecidamente de alto risco para aquisição da infecção pelo $M$. leprae, e conseqüente manifestação clínica da doença. Entretanto, apenas uma minoria dos casos "incidentes" pode ser identificada como oriunda de contato intrafamiliar (Fine, 1982).

Casos "incidentes" de hanseníase entre membros de uma mesma família são por vezes considerados como casos secundários (Rao et al., 1969; Fine, 1982; George et al., 1990). Em tais circunstâncias há considerável introdução de ruído, do inglês noise, pelas fontes de infecção fora do domicílio, e pelo potencial de infecção na comunidade. Entre os fatores comuns dentro da moradia, a genética e a dieta, e não necessariamente a transmissão da infecção, devem ser levadas em consideração. Mesmo assumindo que a hanseníase se manifesta após um longo período de incubação, o padrão de múltiplos pacientes por família parece refletir a exposição à doença fora da família (Fine, 1982). Em qualquer das circunstâncias as bases para se interpretar a história familiar e os aglomerados familiares de casos 
são complexos, e, ademais, o presente estudo não foi delineado para estudar agregados familiares, impossibilitando a separação de caso índice do caso secundário.

Durante o período de investigação, para os 600 casos estudados, em 20 domicílios, moravam múltiplos casos. Assim, identificaram-se 3 irmãos em 1 moradia e 2 casos novos em 19 moradias, totalizando 41 pacientes, tendo o intervalo entre as datas do diagnóstico variado de dias a 8 meses em cerca de metade dos múltiplos casos detectados na mesma residência. Obviamente, os casos diagnosticados a pequenos intervalos de tempo dentro de uma mesma família não representam os casos secundários e seus respectivos casos índices, considerando-se o longo período de latência do Mycobacterium leprae.

Procuraram os serviços de saúde no primeiro ano de aparecimento dos sintomas $70,4 \%$ dos casos, com mediana de 12 meses e amplitude de variação de 0 a 420 meses (Tabela 5.1-1). É interessante observar que os valores de mediana do início dos sintomas, da ordem de 10 meses, foram reportados para uma série histórica do Nordeste do país (Albuquerque et al., 1989) e também para os Estados Unidos da América (Mastro et al., 1992), indicando que esta aparente demora do diagnóstico faz parte do aparecimento insidioso da doença, e não apenas a dificuldade de acesso aos serviços de saúde.

O grau de incapacidade foi também avaliado durante a triagem clínica como medida indireta da precocidade do diagnóstico, e 427 dos 600 casos recémdiagnosticados foram classificados como não apresentando nenhum grau de incapacidade (Grau 0), enquanto para 22,9\% (134/600) e 6,6\% (39/600) foram atribuídos Grau 1 e Grau 2, respectivamente. É esperado que os percentuais de incapacidade se reduzam à medida que os casos sejam diagnosticados mais precocemente, uma vez que a instalação das deformidades é lenta. (Noordeen \& Bravo, 1986; Trindade \& Nemes, 1992). Em interessante estudo populacional na República do Malaui, o índice de incapacidade caiu de $20 \%$ para $10 \%$, quando a 
investigação foi realizada na demada espontânea ou em inquérito populacional (Ponnighaus et al., 1990).

A distribuição dos casos de hanseníase, de acordo com a definição de formas multibacilares (MB), paucibacilares (PB) e prováveis (PR) está apresentada na Tabela 5.1-3. A média de idade é superior a 30 anos nos três subgrupos estudados, não havendo diferença estatísticamente significante intra e intergrupos $\left(\mathrm{F}_{(2,597)}=1,9\right.$ $\mathrm{p}>0,05)$. Considerando-se as formas $\mathrm{PB}$ e $\mathrm{MB}$, a proporção de indivíduos com baciloscopia negativa no grupo de menores de 15 anos foi de $82 \%$ (41/50), enquanto nos maiores de 15 anos correspondeu a 60\% (270/449) da casuística. Indivíduos do sexo masculino constituíram $73,9 \%$ dos $\mathrm{MB}$, enquanto entre $\mathrm{PB}$ a proporção foi de $35,7 \%\left(x^{2}=68,4 p<0,001\right)$. Casos PR apresentaram menor diferença percentual de distribuição entre os sexos, sexo masculino $(47,5 \%)$ e sexo feminino $(52,5 \%)$. A Figura 5.1-2 apresenta a pirâmide dos casos de hanseníase por sexo e idade, evidenciando a maior proporção de indivíduos do sexo masculino entre os MB. A distribuição percentual dos casos com baciloscopia positiva segundo idade e sexo, com os respectivos limites de $95 \%$ de confiança, estão apresentados na Figura 5.1-3. Indivíduos do sexo masculino apresentaram maior proporção de exames baciloscópicos positivos nas faixas etárias de 30-39 e 40-49 anos, diferença estatisticamente significante (Figura 5.1-3). Houve, portanto, uma nítida predominância de formas multibacilares (MB) entre os pacientes do sexo masculino.

A predominância do sexo masculino entre formas multibacilares de hanseníase é consistente com os dados da literatura (Rao, et al., 1969; Fine, 1982; Ulrich et al., 1993; Lombardi, 1993). Se a diferença observada na "incidência" e forma clínica entre sexo reflete diferenças na exposição, na suscetibilidade, na gravidade da doença não parece bem determinado. Diferenciais entre sexo na prevalência de infecção na população e na morbi-mortalidade são fenômenos encontrados com freqüência na epidemiologia de outras doenças infecciosas (Andrade et al., 1992; Barreto \& Andrade, 1994). Tem sido sugerido que a relativa proteção para as formas clínicas mais graves (multibacilares) entre indivíduos do 
sexo feminino, após a puberdade, pode ser explicada pelo aumento de estrógenos e outros níveis de hormônios, uma vez que esta diferença de proporção de formas clínicas não é observada em crianças (Ulrich et al., 1993).

Embora aspectos referentes à definição dos casos, para estudos de casocontrole, sejam discutidos no item 5.5, vale ressaltar, aqui, que a definição de casos, no presente estudo, utilizando-se do exame complementar para conferir maior especificidade aos casos $\mathrm{MB}$ e $\mathrm{PB}$, possibilitou estabelecer, de forma clara, a associação de formas clínicas e a variável sexo. Homens apresentaram estimativas de risco 5,1 vezes maior (IC $95 \% 3,4-7,8$ ) de terem baciloscopia positiva. Ao contrário, para as formas prováveis, aproximadamente metade dos indivíduos foram do sexo feminino, indicando proporções semelhantes entre sexo em oposição às formas PB e MB (Tabela 5.1-3). Em nosso meio, estudos descritivos com dados de registro, ou descrição de casuística, apresentam razão de 1:1 para o sexo masculino e feminino, porém, sem levar em consideração as formas clínicas (Albuquerque et al., 1989; Quaresma et al., 1989; Cestari et al., 1989; Andrade, 1990). Análise global de casos de registro por formas clínicas e por sexo pode mascarar a associação levando-se a conclusão geral de riscos semelhantes de adoecimento e evolução da hanseníase.

A Figura 5.1-4 indica que aproximadamente $75 \%$ das formas multibacilares (MB) apresentam índice baciloscópico maior que 2,0. Dezenove casos seriam excluídos se o ponto de corte escolhido para definição de casos MB fosse o índice baciloscópico maior que 1,0.

Chama a atenção que $43,6 \%$ dos casos prováveis tenham apresentado contactantes domiciliares, enquanto para os casos confirmados MB e PB essa proporção não ultrapassa $30 \%$ do total. Desta forma, a diferença de proporção de contactantes entre casos PB e PR, é estatísticamente significante $\left(x^{2}=6,3 p<0,01\right)$, bem como entre MB e PR $\left(x^{2}=6,8 p<0,01\right)$ sugerindo valorização de história de 
antecedentes de contato prévio com pacientes de hanseníase no diagnóstico de um caso novo.

A duração dos sintomas em meses apresenta uma mediana de 12 meses para todos os indivíduos, com amplitude da variação entre 0 a 420 meses. A amplitude inter-quartílica, quartil-3 (Q3) menos quartil-1 (Q1), é de 20 meses para as formas $\mathrm{MB}$ e $\mathrm{PB}$, e, 30 meses para as $\mathrm{PR}$, indicando que $50 \%$ desta distribuição encontram-se dentro dos valores acima mencionados. A análise exploratória desta variável está apresentada na Figura 5.1-5. Os valores extremos das observações estão representados acima da cerca interna superior do gráfico-caixa. Uma analogia entre a distribuição empírica resultante da duração dos sintomas e a distribuição normal possibilita interpretar os valores extremos como taxas de difícil ocorrência por localizarem-se em zonas de rejeição ou de baixa probabilidade. Para as categorias de hanseníase $\mathrm{MB}, \mathrm{PB}$ e PR o índice de assimetria é superior a zero, respectivamente com valores de 3,9; 3,8 e 3,5, indicando que a distribuição dos dados é positivamente desviada e que o pressuposto de normalidade não é aplicável. A medida de achatamento ou curtose, que leva em conta o tamanho da amostra, denota que o desvio é importante, devendo ser corrigido através de transformações matemáticas para utilização dos dados $(\mathrm{MB}=19,4 ; \mathrm{PB}=21,7$ e $\mathrm{PR}=15,0)$.

Metodologicamente, os casos recém-diagnosticados estudados apresentam como limitante serem constituídos por subgrupo populacional oriundo da demanda espontânea de ambulatório (Henneckens \& Buring, 1987). No entanto, em hanseníase, a utilização dos serviços de saúde para captação dos casos é justificável, e talvez a única alternativa, devido à relativa baixa freqüência desta doença na comunidade, o que inviabiliza a seleção de casos através de triagem populacional, pelo grande tamanho de amostra que seria necessário para este tipo de estudo. Em contrapartida, a condução do estudo em áreas urbanas apresenta como vantagem o maior acesso da população aos serviços de saúde, possibilitando um menor intervalo de tempo entre o aparecimento dos sintomas, procura dos serviços de saúde, suspeição e caracterização do caso de hanseníase. A distribuição espacial dos casos 
e as características de utilização do serviços de saúde estão descritas nos itens $\mathbf{5 . 2}$ e 5.3 . 
Tabela 5.1-1

Distribuição dos 600 casos de hanseníase por idade, sexo, exame baciloscópico, contactantes domiciliares e duração dos sintomas.

\section{Casos de Hanseníase}

Característica № \%

Faixa Etária

$<15$ anos

$59 \quad 9,8$

$\geq 15$ anos

54190,2

Sexo

Feminino

30250,3

Masculino

$298 \quad 49,7$

Exame Baciloscópico

Positivo

$188 \quad 31,3$

Negativo

41268,7

Contactantes Intra/extra Domiciliares ${ }^{\mathbf{a}}$

Não

$410 \quad 68,4$

Sim

18931,6

Duração dos Sintomas ${ }^{\mathrm{b}}$ (anos)

$\leq 1$

$2-3$

$\geq 4$

41470,4

$\begin{array}{ll}96 & 16,3\end{array}$

$78 \quad 13,3$

mediana - meses

12

amplitude de variação

$0-420$

a 1 caso sem informação

b 12 casos sem informação. 
Tabela 5.1-2

Distribuição dos 600 casos de hanseníase segundo idade e tipo de contactantes.

\begin{tabular}{|c|c|c|c|c|}
\hline \multirow{3}{*}{ Característica } & \multicolumn{4}{|c|}{ Idade (anos) } \\
\hline & \multicolumn{2}{|c|}{$<15$} & \multicolumn{2}{|c|}{$\geq 15$} \\
\hline & № & $\%$ & & $\%$ \\
\hline \multicolumn{5}{|l|}{ Contactante $^{\mathrm{a}}$} \\
\hline Sim & 36 & 61,0 & 153 & 28,3 \\
\hline \multirow[t]{2}{*}{ Não } & 23 & 39,0 & 387 & 71,5 \\
\hline & \multicolumn{4}{|c|}{$x^{2}=26,3 \quad p<0,001$} \\
\hline \multicolumn{5}{|c|}{ Número de Contactantes Domiciliares } \\
\hline 0 & 26 & 44,1 & 397 & 73,4 \\
\hline 1 & 28 & 47,5 & 121 & 22,4 \\
\hline \multirow[t]{2}{*}{$\geq 2$} & 5 & 8,5 & 23 & 4,3 \\
\hline & \multicolumn{2}{|c|}{$x^{2}=19,7$} & $p<0,001$ & $g l(l)$ \\
\hline \multicolumn{5}{|l|}{ Tipo de Contactante ${ }^{b}$} \\
\hline \multicolumn{5}{|l|}{ Único } \\
\hline Mãe ou Pai & 15 & 53,6 & 39 & 32,2 \\
\hline Irmão & 3 & 10,7 & 42 & 34,7 \\
\hline Avó/Tio/Primo & 10 & 35,7 & 11 & 9,1 \\
\hline Filho & - & - & 14 & 11,6 \\
\hline Cônjuge & - & - & 12 & 9,9 \\
\hline Não parente & - & - & 3 & 2,5 \\
\hline \multicolumn{5}{|l|}{ Múltiplo } \\
\hline Pais/Irmãos & 2 & 40,0 & 11 & 47,8 \\
\hline Avós/Tios/Sobrinhos & 3 & 60,0 & 3 & 13,0 \\
\hline Cônjuge/Filho & - & - & 7 & 30,4 \\
\hline Pai/Filho & - & - & 1 & 4,3 \\
\hline Não parente & - & - & 1 & 4,3 \\
\hline
\end{tabular}

a 1 registro sem informação

b 3 casos menores de 15 anos e 9 casos maiores de 15 anos referem contato extradomiciliar 


\section{Figura 5.1-1}

Percentual de casos de hanseníase de acordo com o grau de parentesco do contactante para distintos grupos de idade.

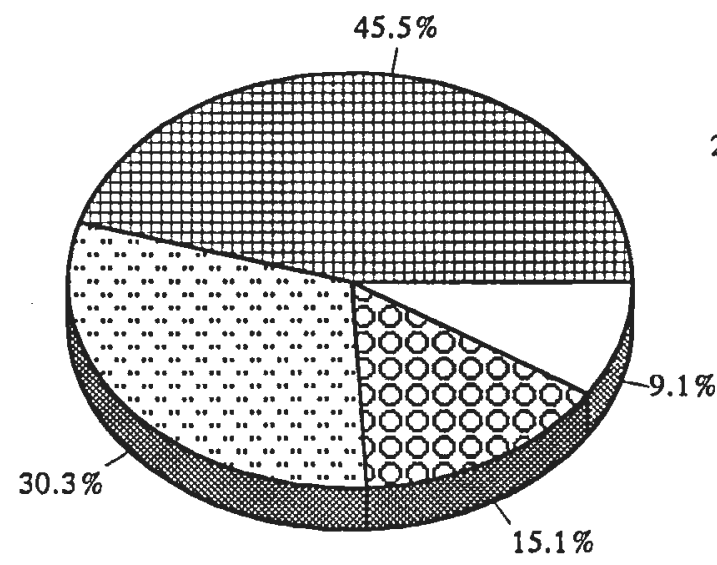

$<15$ anos

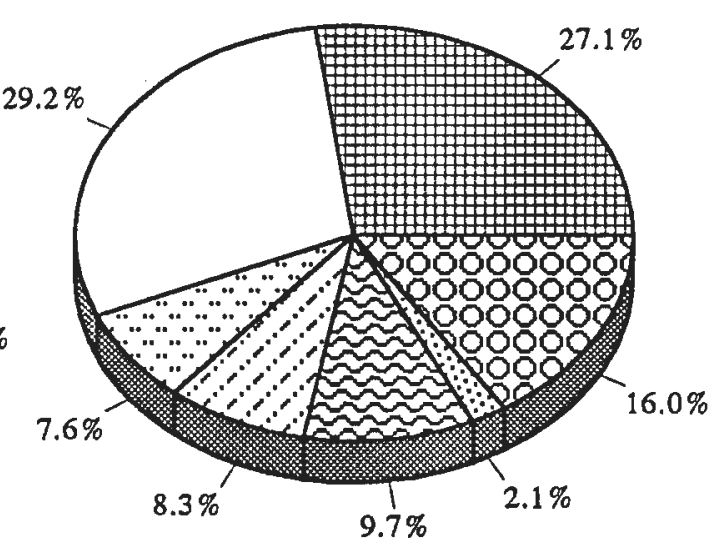

$\geq 15$ anos
Pai ou mãe

... Avô / tio/primo

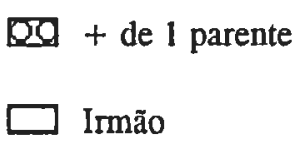

Q + de 1 parente

E Conjuge

Ed Filho

Eutros 
Tabela 5.1-3

Distribuição dos 600 casos de hanseníase segundo tipo, sexo, idade, contactantes domiciliares e duração dos sintomas.

\begin{tabular}{|c|c|c|c|c|c|c|}
\hline \multirow{3}{*}{ Característica } & \multicolumn{6}{|c|}{ Tipo de Hanseníase } \\
\hline & \multicolumn{2}{|c|}{$\begin{array}{c}\text { Multibacilares } \\
\text { (188) }\end{array}$} & \multicolumn{2}{|c|}{$\begin{array}{c}\text { Paucibacilares } \\
\text { (311) }\end{array}$} & \multicolumn{2}{|c|}{$\begin{array}{l}\text { Prováveis } \\
\quad(101)\end{array}$} \\
\hline & № & $\%$ & № & $\%$ & $\mathrm{~N}$ & $\%$ \\
\hline \multicolumn{7}{|l|}{ Faixa etária } \\
\hline$<15$ anos & 9 & 4,8 & 41 & 13,2 & 9 & 8,9 \\
\hline$\geq 15$ anos & 179 & 95,2 & 270 & 86,8 & 92 & 91,1 \\
\hline média de idade (anos) & \multicolumn{2}{|c|}{36,4} & \multicolumn{2}{|c|}{33,1} & \multicolumn{2}{|c|}{34,0} \\
\hline desvio-padrão & \multicolumn{2}{|c|}{16,4} & \multicolumn{2}{|c|}{16,7} & \multicolumn{2}{|c|}{16,1} \\
\hline \multicolumn{7}{|l|}{ Sexo } \\
\hline Feminino & 49 & 26,1 & 200 & 64,3 & 53 & 52,5 \\
\hline Masculino & 139 & 73,9 & 111 & 35,7 & 48 & 47,5 \\
\hline \multicolumn{7}{|l|}{$\begin{array}{l}\text { Contactante Intra/extra } \\
\text { domiciliar }\end{array}$} \\
\hline Não & 133 & $71,1^{b}$ & 220 & $70,7^{b}$ & 57 & $56,4^{\mathrm{c}}$ \\
\hline Sim & 54 & 28,9 & 91 & 29,3 & 44 & 43,6 \\
\hline \multicolumn{7}{|l|}{ Duração dos Sintomas $^{\mathrm{d}}$} \\
\hline$\leq 1$ ano & 132 & 70,2 & 223 & 73,1 & 59 & 58,1 \\
\hline $2-3$ anos & 36 & 19,1 & 45 & 14,8 & 15 & 14,9 \\
\hline$\geq 4$ anos & 18 & 9,7 & 37 & 12,1 & 23 & 23,7 \\
\hline mediana & \multicolumn{2}{|c|}{12} & \multicolumn{2}{|c|}{12} & \multicolumn{2}{|c|}{12} \\
\hline intervalo semi-interquartilico & \multicolumn{2}{|c|}{20} & \multicolumn{2}{|c|}{20} & \multicolumn{2}{|c|}{30} \\
\hline
\end{tabular}

${ }^{2}$ Análise de Variância $\mathrm{F}_{(2,597)}=1,9 \mathrm{p}>0,05$

b NS ao nível de 0,$05 ; 1$ caso multibacilar sem informação

$b$ versus $c(p<0,01)$

d 2 casos multibacilares, 6 casos paucibacilares e 4 casos prováveis sem informação 
Figura 5.1-2

Pirâmide populacional dos casos de hanseniase por sexo, faixa etária e categorias de definição de casos.

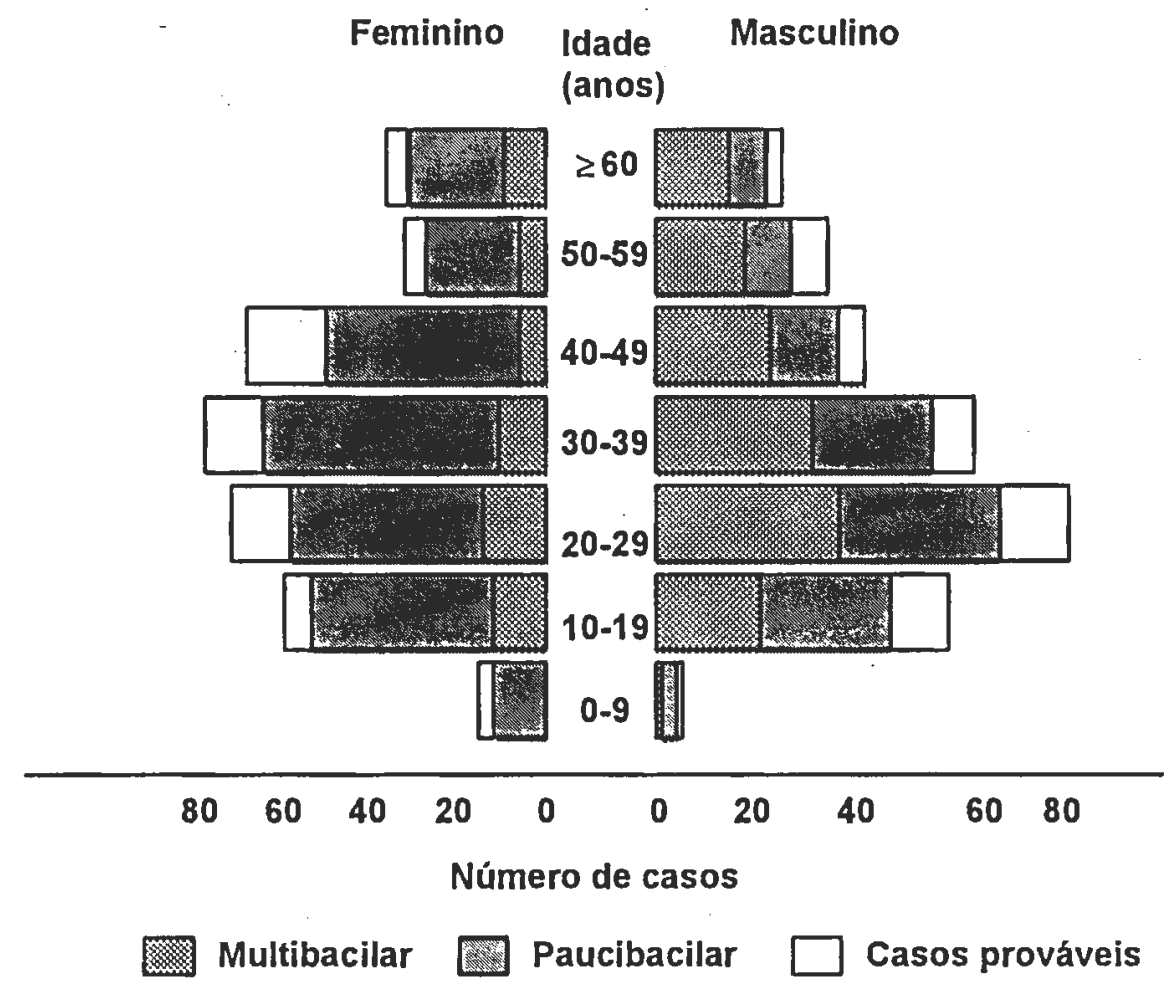


Figura 5.1-3

Percentagem de casos de hanseníase e respectivos limites de $95 \%$ de confiança com baciloscopia positiva segundo idade e sexo.

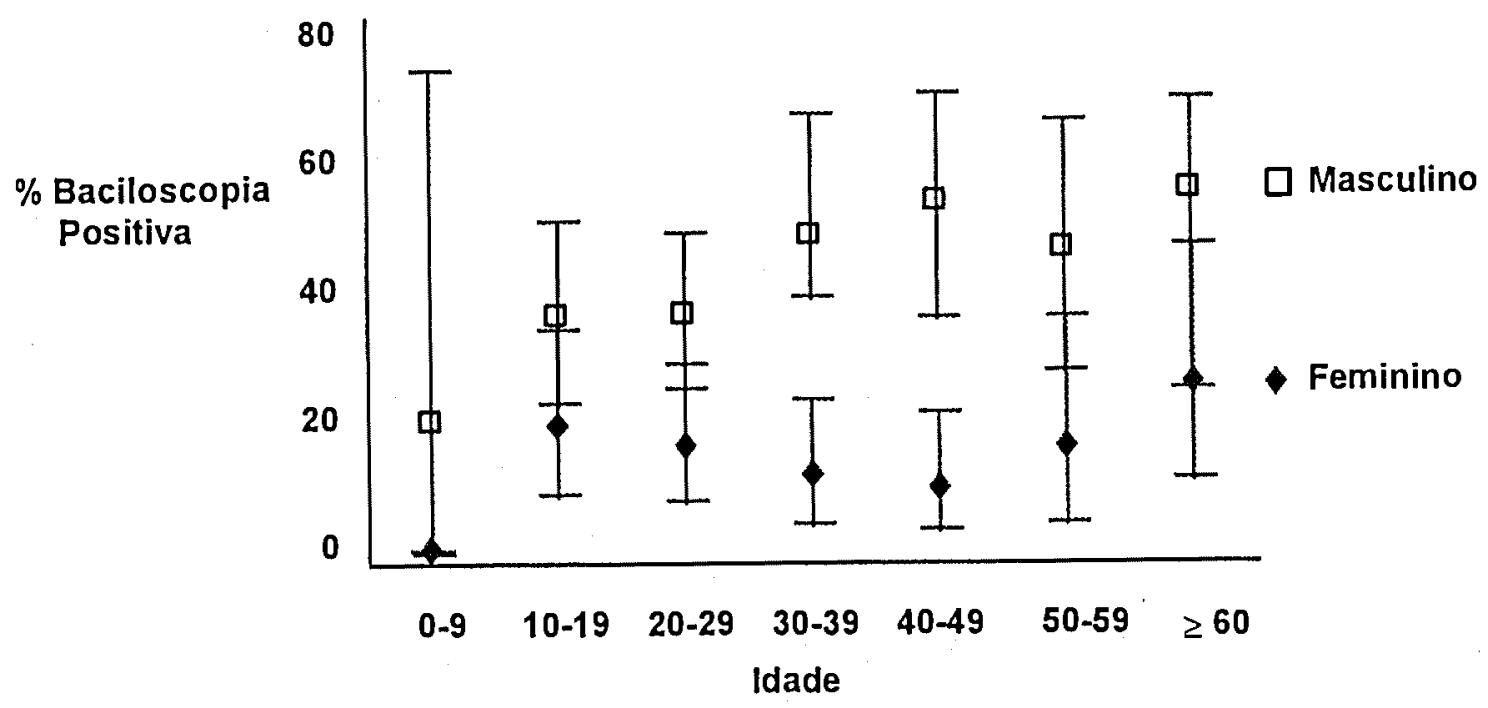


Figura 5.1-4

Percentuais de índices baciloscópicos e pontos de corte para definição de caso multibacilar (MB)

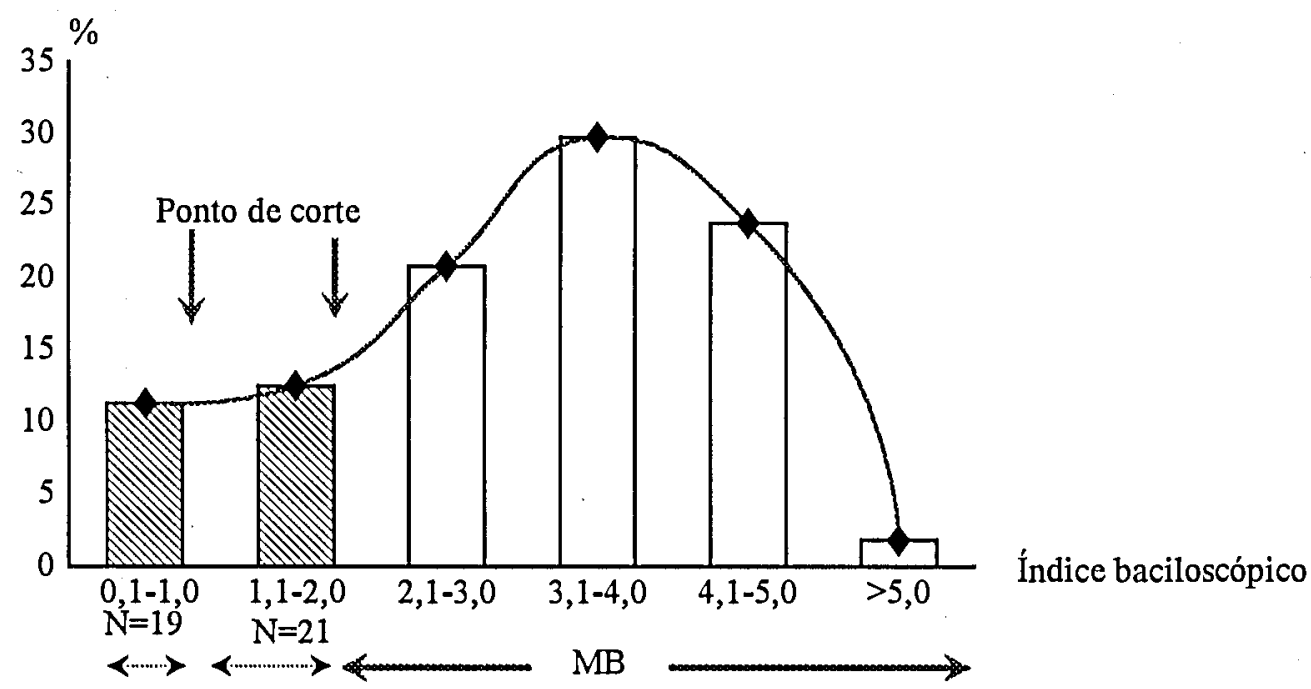

casos multibacilares com índice baciloscópico $<2,0$

Excluidos casos com baciloscopia negativa (Paucibacilares) 
Figura 5.1-5

Distribuição de Ramos e Folhas e Gráficos de Caixas para a variável meses de duração dos sintomas.

A - Formas multibacilares

Meses

Ramos e Folhas

$250+^{\star}$

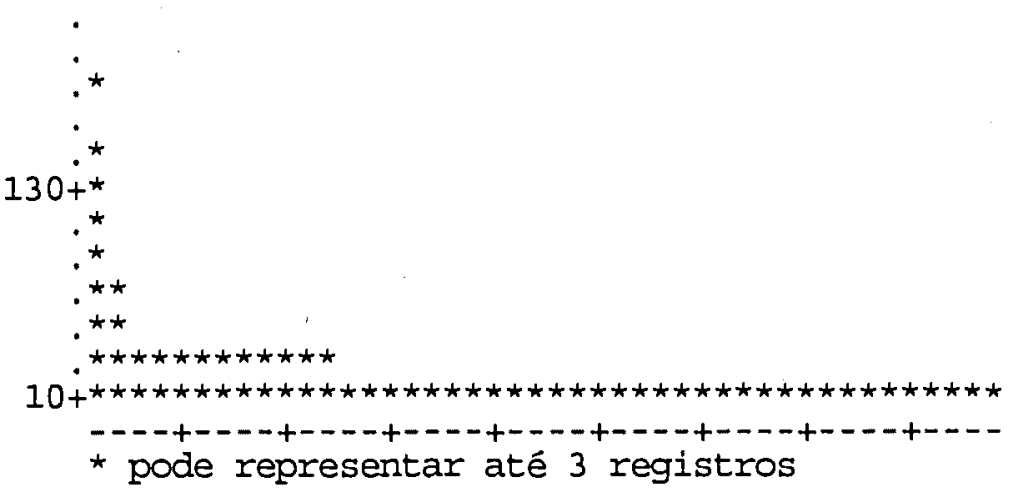

2 casos multibacilares sem informação
\# Gráfico - Caixa

1

1

$\frac{1}{3}$

1

5

36

132

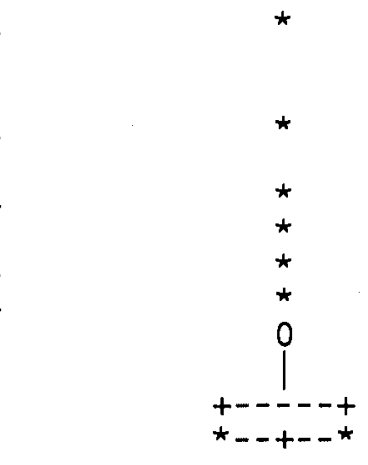

B - Formas paucibacilares

Meses

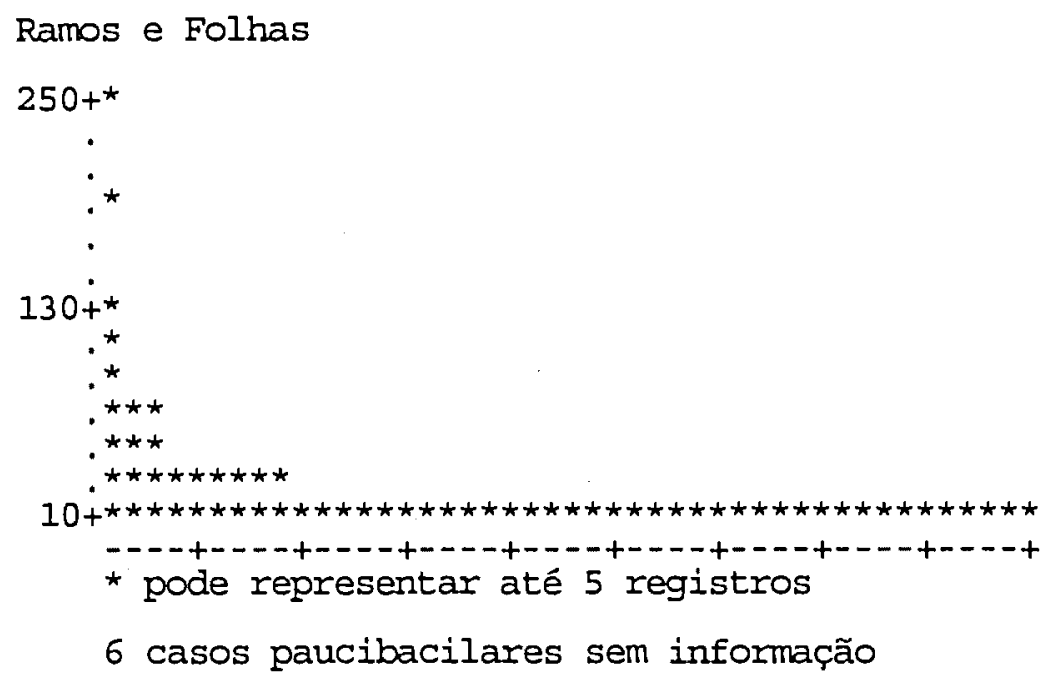

\# Grafico - Caixa

1

1

3

13

14
45

223

$\star$

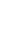

.

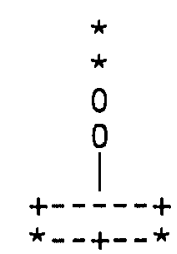

6 casos paucibacilares sem informação 
Figura 5.1-5 (Continuação)

Distribuição de Ramos e Folhas e Gráficos de Caixas para a variável meses de duração dos sintomas.

C - Formas prováveis

Meses

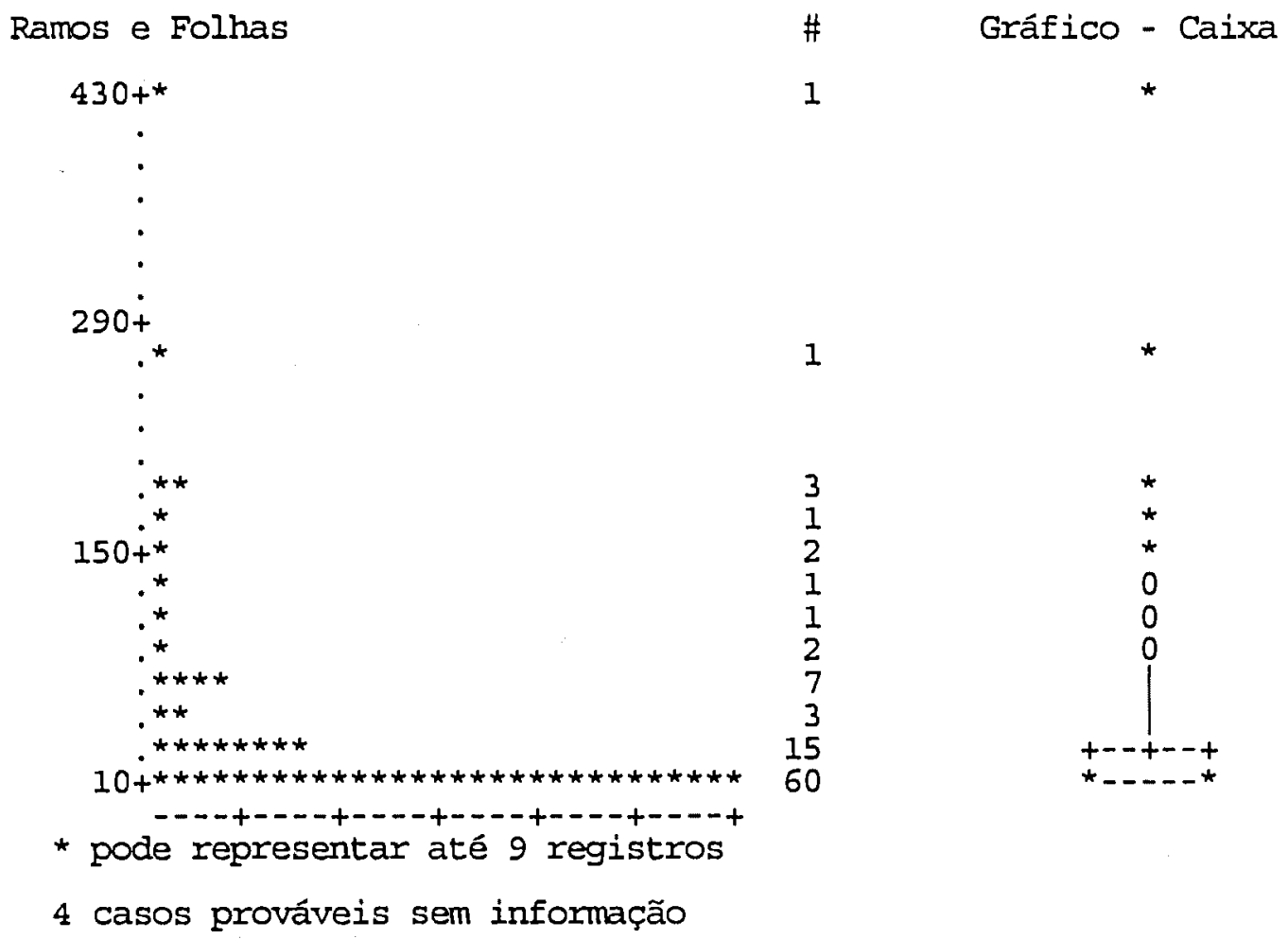




\subsection{Distribuição espacial e características migratórias dos casos}

O coeficiente global de detecção de hanseníase para a área de estudo foi de 48,2 por 100000 hab., indicando que a região é de alta endemicidade e semelhante à estatística oficial para o Estado de Goiás (Ministério da Saúde, 1994c). A área de estudo apresenta coeficiente de detecção aproximadamente 10 vezes maior ao de 5 por 100000 hab., estimado para o período de eliminação da hanseníase em situações operacionais de completa cobertura pela PQT (Feenstra, 1994). No entanto, indicadores calculados para grandes áreas representam a média de ocorrência de casos de recém-diagnosticados hanseníase na região, e taxas estimadas para menor nível de agregação espacial podem fornecer uma idéia mais detalhada de distribuição intra-urbana da hanseníase.

No presente estudo, 9 dos 64 distritos apresentaram população inferior a 2000 hab., com 2 casos de hanseníase. Estes distritos foram excluídos da análise no intuito de diminuir a instabilidade das taxas de deteç̧ão calculadas por distrito urbano, conforme apresentado na Figura 5.2-1. Assim, os 55 distritos urbanos da cidade de Goiânia e os 3 municípios contíguos do aglomerado (Aparecida de Goiânia, Trindade e Senador Canedo) foram analisados de acordo com as taxas de detecção de casos de hanseníase recém-diagnosticados por 100000 hab., através de análise exploratória de dados em gráfico-caixa e os correspondentes diagramas de ramos e folhas (Figura 5.2-2). O limite mínimo de população de 10000 hab. tem sido recomendado para o cálculo de coeficientes e utilizado em estudos de diferenciais regionais de mortalidade por Estado e municípios (Hoover et al., 1975; Hoover \& Fraumeni Jr, 1975; Matos et al., 1990; Boschi, et al., 1991). No entanto, esta recomendação parece indadequada para áreas intra-urbanas. Para a cidade de Goiânia os 64 distritos foram considerados uma opção adequada para desagregação espacial urbana em recente estudo ecológico sobre a distribuição da hanseníase na cidade (Martelli et al., 1995a). O distrito, como unidade espacial, possibilita o uso de dados demográficos dos setores censitários $(n=845)$ e delimita sub-regiões homogêneas do ponto de vista sócio-econômico estabelecido pelo órgão 
de planejamento municipal. Em contraste, há 340 bairros na cidade, cujos limites geográficos não se sobrepõem aos setores censitários, inviabilizando o cálculo de taxas por falta do denominador populacional. Estatísticas agregadas por grandes áreas têm reduzida possibilidade de discriminar de maneira mais acurada localidades de risco e aglomerados de eventos mórbidos.

De forma geral, as questões relativas à geografia médica e suas inúmeras outras denominações referentes ao estudo da distribuição espacial dos eventos de saúde são dificultadas pela inexistência de dados localizatórios, e limites arbitrários das unidades de estudo, freqüentemente escolhidos por conveniência de existência de áreas administrativas previamente delimitadas (King, 1979; Meade, 1986; Gesler, 1986).

A mediana da série das taxas globais de detecção de casos de hanseníase por distrito foi de 40,5 por 100000 hab., sendo que $50 \%$ desta distribuição encontra-se entre os valores de 29 a 69 por 1000000 hab., representado na Figura 5.2-2 pelo desenho de uma caixa. Os valores extremos são considerados taxas de difícil ocorrência por localizarem-se em zonas de rejeição ou de baixa probabilidade. Assim taxas globais superiores a 120 casos por 100000 hab. até 186 casos por 100000 hab. são considerados valores extremos, com 3 distritos urbanos nesta categoria, representados na Figura 5.2-2 pela letra "o" de "outliers". Valores considerados extremos máximos para as taxas de 239 e 262 por 100000 hab., foram representados na mesma figura por um asterisco $\left(^{*}\right)$.

Os mapas 5.2-1 e 5.2-2 apresentam total de casos por distritos e mapas temáticos com estratos de alta, média e baixa endemicidade estabelecidos pela representação gráfica do diagrama de ramos e folhas. Vale ressaltar que estes mapas não possibilitam estabelecer a provável fonte geográfica de aquisição da infecção, devido ao longo período de latência da hanseníase que pode alcançar vários anos. Esta defasagem temporal do local de detecção do caso e da respectiva infecção será melhor abordada na parte referente à migração. 
A representação em ramos e folhas das taxas de detecção de casos em menores de 15 anos indica que a freqüência de não ocorrência de casos menores de 15 anos é maior do que a freqüência de sua ocorrência. $O$ valor mais freqüente da distribuição, moda, é zero (0), sendo a mediana também de 0 casos, com o intervalo inter-quartílico (Q1-Q3) de 0 a 24 casos menores de 15 anos por 100000 hab. dentre os 58 distritos urbanos da cidade de Goiânia. As taxas extremas máximas apresentam valores de 111 e 199 casos por 100000 hab. para o distrito de número 48 e o município de Senador Canedo, áreas contíguas. Para os maiores de 14 anos a mediana das taxas gerais de detecção de casos foi de 61 casos por 100 000 hab., variando de 0 a 363 casos por 100000 hab. Os mapas 5.2-3 e 5.2-4 mostram a distribuição do número absoluto de casos em menores de 15 anos e de áreas de risco conforme as taxas discriminadas pelos quartis do diagrama de ramos e folhas. De forma geral, as dificuldades sobre a potencial fonte de aquisição podem ser minimizadas pela distribuição espacial nestas faixas de menor idade, já que possibilitam identificar exposições mais recentes e estes casos tendem a apresentar menor mobilidade, quando comparados com os casos adultos.

Com a metodologia de análise exploratória para as taxas globais, 10 distritos podem ser agrupados como representando $25 \%$ das menores taxas de deteç̧ão (Q1), 12 estariam acima do limite superior, permitindo avaliar os diferencias intra-urbanos de hanseníase e possibilitando a implementação de medidas de controle direcionadas para áreas de maior risco. Houve superposição das localidades com taxas de detecção extremas em menores de 15 anos com as de maiores taxas gerais da periferia leste da cidade. Esta observação corrobora a utilidade desta metodologia para se estabelecerem áreas de risco, uma vez que casos em menores de 15 anos são sinalizadores de áreas com alta transmissão da infecção (Bechelli \& Dominguez, 1966; Bechelli et al., 1973; Fine, 1982).

Esta abordagem mais pormenorizada dos eventos de saúde, por meio de diagrama de ramos e folhas, permite visualizar, através do ordenamento dos coeficientes de deteç̧ão de casos, as áreas intra-urbanas de maior incidência de 
casos. Possibilita, desta forma, identificar as localidades geradoras do maior número de casos recém-diagnosticados, isto é, os bolsões intra e periurbano, permitindo direcionar a investigação nestes "estratos-alvos" através de um maior detalhamento das características epidemiológicas e operacionais locais. As estatísticas agregadas tendem a mascarar o fenômeno das desigualdades intraurbanas (King, 1979; Phillips, 1993). A heterogeneidade da distribuição espacial dos casos de hanseníase deste estudo exemplifica a coexistência de diferentes cenários epidemiológicos dentro de uma mesma área de conurbação urbana, cujos indicadores agregados, de carácter global, delimitavam apenas uma única região de alta endemicidade. Esta distribuição desigual da hanseníase dificulta os cálculos dos coeficientes de prevalência e de detecção, uma vez que apenas o subgrupo da população exposta ao risco de se infectar deve ser incluída no denominador dos coeficientes acima citados (Feenstra, 1994).

Quando se aplica os parâmetros de alta, média e baixa endemicidade (Ministério da Saúde, 1994c) para as localidades estudadas, 89\% (52/58) destas seriam consideradas de alta e média endemicidade, e apenas 5 estariam na faixa de baixa endemicidade. Embora estes indicadores possam ser adequados para comparação entre macrorregiões ou interpaíses, apresentam restrições em seu uso em áreas intra-urbanas, particularmente pela dificuldade na discriminação dos riscos diferenciais de adoecer entre as localidades. Esta exploração das propriedades latentes das séries estatísticas parece-nos bastante oportuna, particularmente por não existir hipótese pré-estabelecida para distribuição dos casos de hanseníase em área urbana que possibilite utilizar metodologias estatísticas clássicas.

A ocorrência e a distribuição de muitas doenças infecciosas e parasitárias têm-se alterado em conseqüência da urbanização, migração interna e mudanças econômicas (Zicker et al., 1989; Mott et al., 1990; Barreto, 1991, PAHO, 1994). A urbanização da hanseníase tem sido reconhecida, enquanto problema de saúde pública, em diversos documentos oficiais e publicações de anos recentes (WHO, 1988; Andrade, 1993; Andrade et al., 1994; Martelli et al., 1995a). A periferização 
das populações e aumento dos diferenciais intra-urbanos dos eventos de morbimortalidade, particularmente no contexto subdesenvolvido, são fenômenos significativos, porém, de mais difícil quantificação (Phillips, 1993).

Em controvertido artigo sobre o descréscimo da hanseníase com a urbanização em países da Europa, Hunter \& Thomas (1984) levantam a hipótese de existência de interferência cruzada com a tuberculose, e exemplifica essa tese com dados de populações da África. Na América Latina, embora, a urbanização seja um fenômeno populacional expressivo nas últimas décadas, o declínio da endemicidade tem sido enfocado em decorrência da implantação da PQT. De fato, a introdução da PQT tem sido considerada o maior avanço recente do controle da hanseníase, com reduções drásticas nas taxas de prevalência pelo encurtamento do período de prevalência, pela diminuição do tempo de tratamento. No entanto, os coeficientes de prevalência de hanseníase utilizados para monitorar o descenso refletem o componente tempo de duração do tratamento e não necessariamente a transmissão da infecção (Smith, 1992a; Fine, 1992a; Noordeen et al., 1992; Feenstra, 1994).

Diversos estudos sobre análise de série temporal em hanseníase para países e regiões foram publicados, utilizando-se dos registros dos programas de controle (Lombardi, 1989; Motta \& Zuniga, 1990; Noordeen et al., 1992). Encontra-se bem estabelecido que a distribuição geográfica da hanseníase não é uniforme, com alguns grupos mais expostos, isto é, com maior risco de aquisição da infecção que outros. A correlação entre hanseníase e áreas de baixo nível sócio-econômico tem sido amplamente reconhecida (Zuniga, 1982; Ulrich et al., 1993). No entanto, a comparabilidade dos resultados obtidos pelo presente estudo fica prejudicada, uma vez que o único trabalho recente sobre hanseníase em área urbana refere-se a um estudo caso-controle para avaliar fatores de risco, mostrando a distribuição dos casos de hanseníase entre diferentes setores censitários de um município de alta endemicidade do Rio de Janeiro (Andrade, 1990; Andrade et al., 1994). 
A necessidade de diretrizes específicas em áreas urbanas foi recentemente abordado por Andrade (1993) como questão crucial para os gerentes do programa de controle, citando, entre as dificuldades operacionais encontradas para o controle da hanseníase, a mobilidade populacional na cidade do Rio de Janeiro. A migração inter-regiões e a caracterização das subpopulações metropolitanas são fenômenos bastante explorados (Taschner \& Bógos, 1986; Rocha \& Villela, 1990), o mesmo não ocorrendo com a mobilidade espacial intra-urbana (Smolka, 1992). Esse último autor, ao tempo que reconhece a importância e a carência de pesquisas sobre a mobilidade espacial intra-urbana em nosso meio, estabelece, através de matrizes de fluxo migratório, as características da estratificação social em relação à segregação residencial do espaço para a área urbana do Rio de Janeiro.

Em nosso estudo, a matriz do fluxo de migração intra-urbana para os últimos 10 anos foi construída como modelo para se avaliar a mobilidade espacial neste período (Tabela 5.2-1). As células em diagonal representam os membros estáveis de cada grande área de planejamento urbano neste período. $O$ índice de mobilidade espacial foi de $33 \%$, indicando que em uma década aproximadamente um terço dos casos deslocou-se geograficamente entre as grandes áreas de planejamento urbano da cidade. Convém ressaltar que o número de mudanças de domicílio desta população pode estar subestimado, uma vez que estão computadas apenas as mudanças de domicílios que ultrapassam os limites geográficos das grandes áreas de planejamento. Pela distribuição dos elementos na matriz fica evidente que o fluxo migratório foi em direção às áreas periféricas da cidade. Assim, as células da parte superior da matriz congregam aproximadamente $80 \%$ dos migrantes intra-urbanos. Esta característica de migração centro-periferia pode também ser confirmada através do saldo migratório maior de $10 \%$ para os municípios do entorno da capital (área VIII). O deslocamento intra-urbano dos casos observados parece não refletir migração diferencial ou ainda segregação social causado pela doença, uma vez que os casos eram recém- diagnosticados, e os índices de mobilidade espacial bem como a direção do fluxo migratório obtidos são semelhantes aos descritos para a população em geral de algumas capitais brasileiras (Rocha \& Villela, 1990). 
Este fluxo migratório intra-urbano traz à tona a questão do local de residência atual e o local de exposição. Esta dificuldade ocorre também para doenças relacionadas a riscos ambientais, havendo defasagem de superposição dos mapas de risco construídos com endereço da residência atual e o local fonte de exposição. Para doenças transmissiveis esta dificuldade de se estabelecer a sequência de infecção em uma série de casos, casos índices, e seus respectivos casos secundários impossibilita determinar a cadeia de transmissão e a rota de dispersão através da análise espacial.

Nesta abordagem limitou-se a avaliar as características da distribuição e mobilidade intra-urbana dos casos como fatores potencialmente complicadores na identificação de risco ambientais e familiares em doença de longo período de incubação para subsidiar as discussões metodológicas relativas à captação de casos e dinâmica de transmissão da hanseníase. A distribuição espacial dos casos, bem como a mobilidade intra-urbana detectada, apresentam, obviamente implicações na identificação dos aglomerados intra-urbanos, na aderência dos pacientes ao tratamento, no delineamento das intervenções com longos períodos de seguimento, nos sistemas de vigilância de hanseníase, no planejamento dos serviços de saúde, e ainda os aspectos de segregação social em decorrência do estigma, entre outras conseqüências. Estes últimos tópicos, embora de grande interesse em saúde pública, não são objeto do presente estudo. 
Figura 5.2-1

Distribuição da população de Goiânia por regiões ${ }^{a}$ e casos de hanseníase

$$
\begin{aligned}
& \text { População } \\
& <2000 \\
& 2000 \mid-10000 \\
& 10000 \mid-20000 \\
& 20000 \mid-30000 \\
& 30000 \mid-40000 \\
& 40000 \mid-50000 \\
& \geq 50000
\end{aligned}
$$

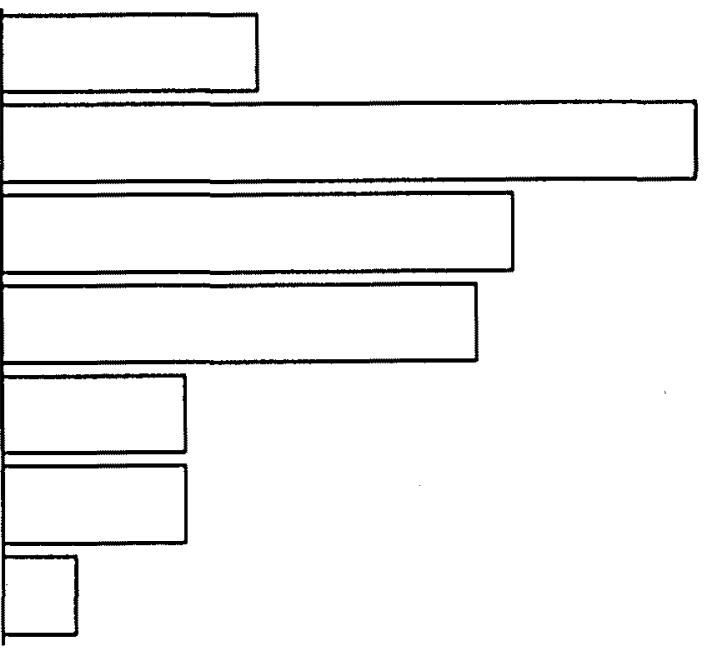

Total
Regiões Casos

92

19

65

14

126

13

110

5

88

5

86

2

122

67

599

a regiões representam os 64 distritos urbanos da capital e os 3 municipios do entorno (Aparecida de Goiânia, Trindade e Senador Canedo) 
Figura 5.2-2

Distribuição de Ramos e Folhas e Gráficos de Caixas para taxas de hanseníase por 100000 habitantes em Distritos urbanos de Goiânia.

\section{A -Taxa Global}
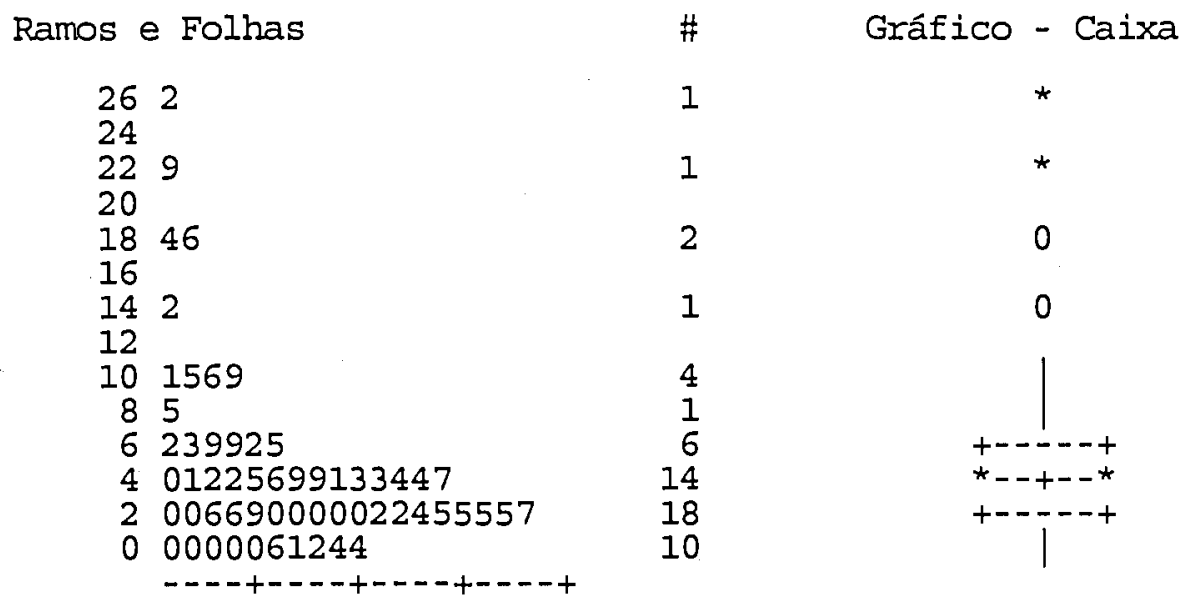
Figura 5.2-2 (Continuação)

Distribuição de Ramos e Folhas e Gráficos de Caixas para taxas de hanseníase por 100000 habitantes em Distritos urbanos de Goiânia.

B - Taxa em menores de 15 anos
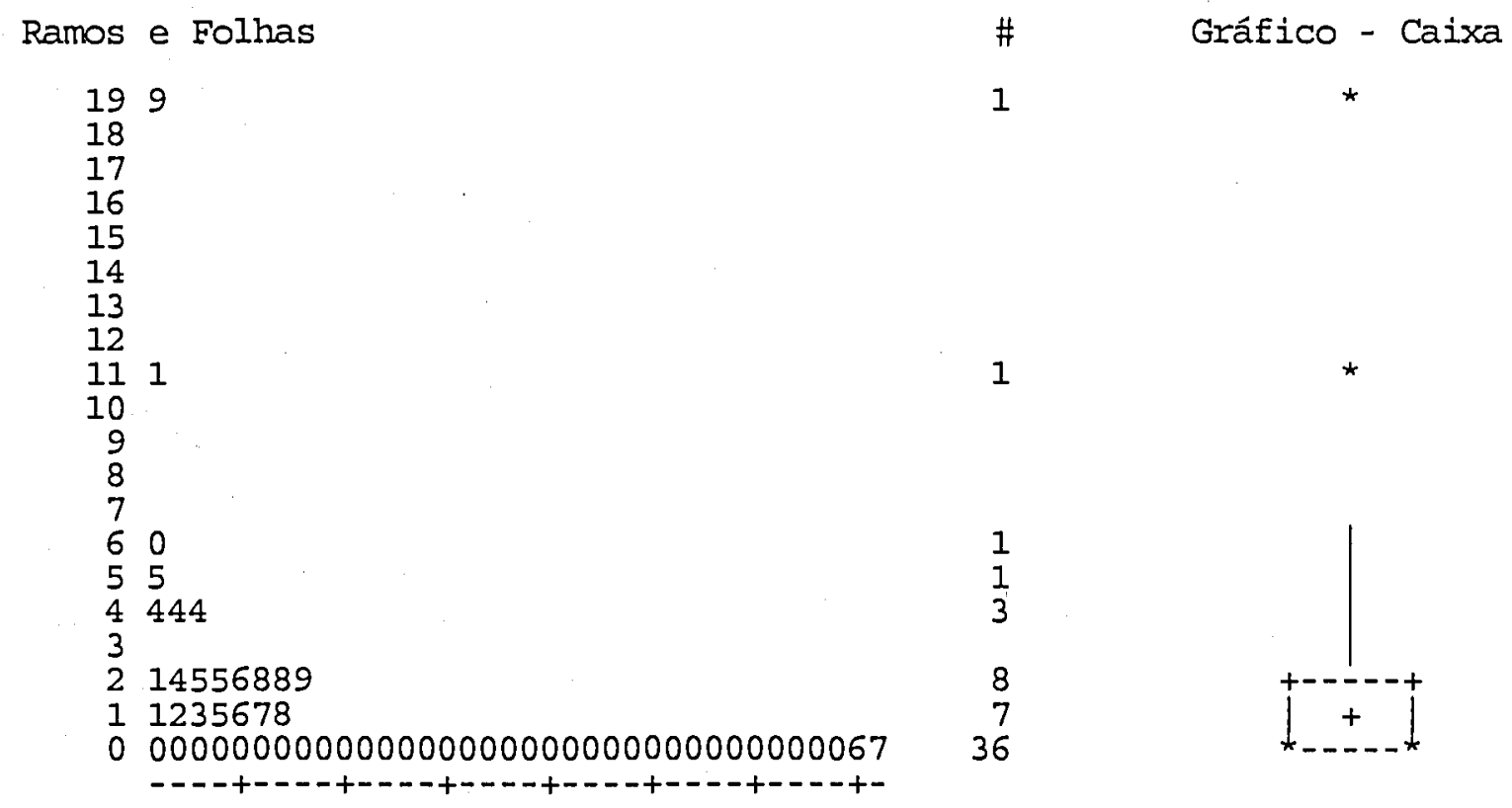

1

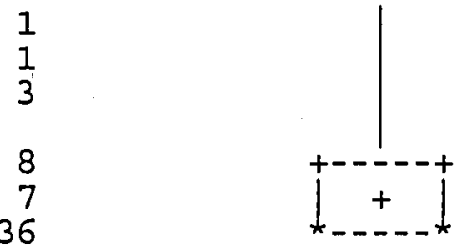

C - Taxa em maiores de 14 anos

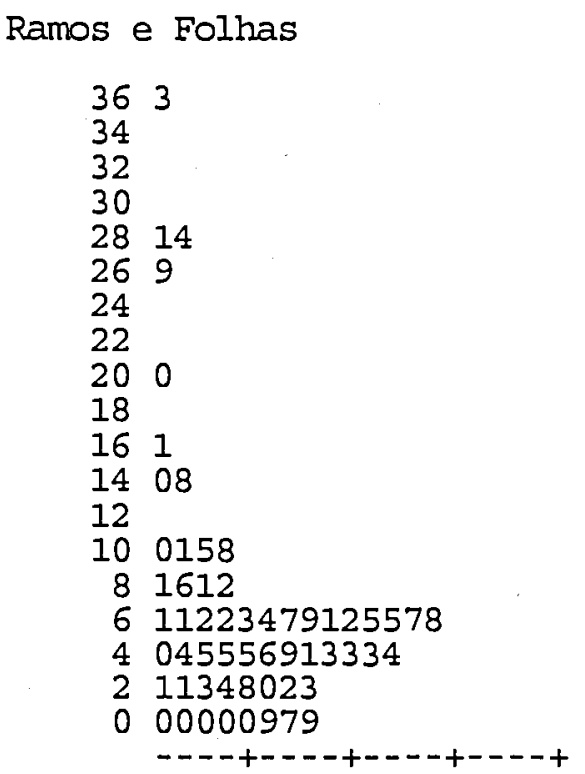

\#

1

2
1

1

$\frac{1}{2}$

4

4
14

12

8
Gráfico - Caixa

$\star$

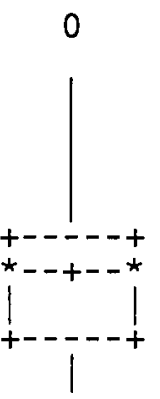


Tabela 5.2-1

Distribuição dos fluxos de migração intra-urbana dos casos de hanseníase em áreas administrativas do município de Goiânia e municípios do aglomerado, nos últimos 10 anos.

\begin{tabular}{|c|c|c|c|c|c|c|c|c|}
\hline \multirow[b]{2}{*}{ ORIGEM ${ }^{a}$} & \multicolumn{8}{|c|}{ DESTINO $^{\mathrm{b}}$} \\
\hline & I & II & III & IV & V & VI/VII & VIII & Total \\
\hline I & $\underline{49}$ & 10 & 6 & 3 & 10 & 3 & 15 & 96 \\
\hline II & 10 & $\underline{107}$ & 12 & 2 & 12 & 10 & 21 & 174 \\
\hline III & 2 & $\overline{1}$ & $\underline{30}$ & - & 3 & 4 & 7 & 47 \\
\hline IV & 1 & 5 & 2 & $\underline{18}$ & 2 & 3 & 7 & 38 \\
\hline V & - & 4 & 2 & $\overline{1}$ & $\underline{83}$ & 1 & 19 & 110 \\
\hline VI/VII & 1 & 1 & 1 & 1 & 3 & $\underline{28}$ & 5 & 40 \\
\hline VIII & - & 2 & - & - & 1 & 2 & $\underline{88}$ & 93 \\
\hline Total & 63 & 130 & 53 & 25 & 114 & 51 & 162 & 598 \\
\hline
\end{tabular}

${ }^{a}$ Origem - local da primeira residência no município de Goiânia e aglomerado.

${ }^{b}$ Destino - local de moradia atual no município de Goiânia e aglomerado.

Área I $\quad-$ (Centro Expandido). Distritos 1-7, 9-11, 51.

Área II $\quad-$ (Coroa Central). Distritos 8, 12-17, 20, 43-45, 49, 50, 52-54, 59, 60.

Área III - (Expansão Urbana Preferencial). Distritos 18, 19, 21-28, 30.

Área IV - (Controle I). Distritos 31-34, 41.

Área V - (Controle II). Distritos 46-48, 55-58, 61.

Área VI/VII - (Risco/Expansão Urbana Residual). Distritos 29, 35-40, 42, 62-64.

Área VIII - (Área Periurbana). Municípios do Aglomerado (Aparecida de Goiânia, Senador Canedo e Trindade).

Números em itálico e sublinhados representam não-migrantes

Índice de Mobilidade $=33 \%$

Saldo Migratório $=11,5 \%$ (relativo a área periurbana - VIII) 
Mapa $5,2-1$

Casos de Hansenlase pelos djslrjlos urbanos de Gojânja e munjcipjos do aglomerado

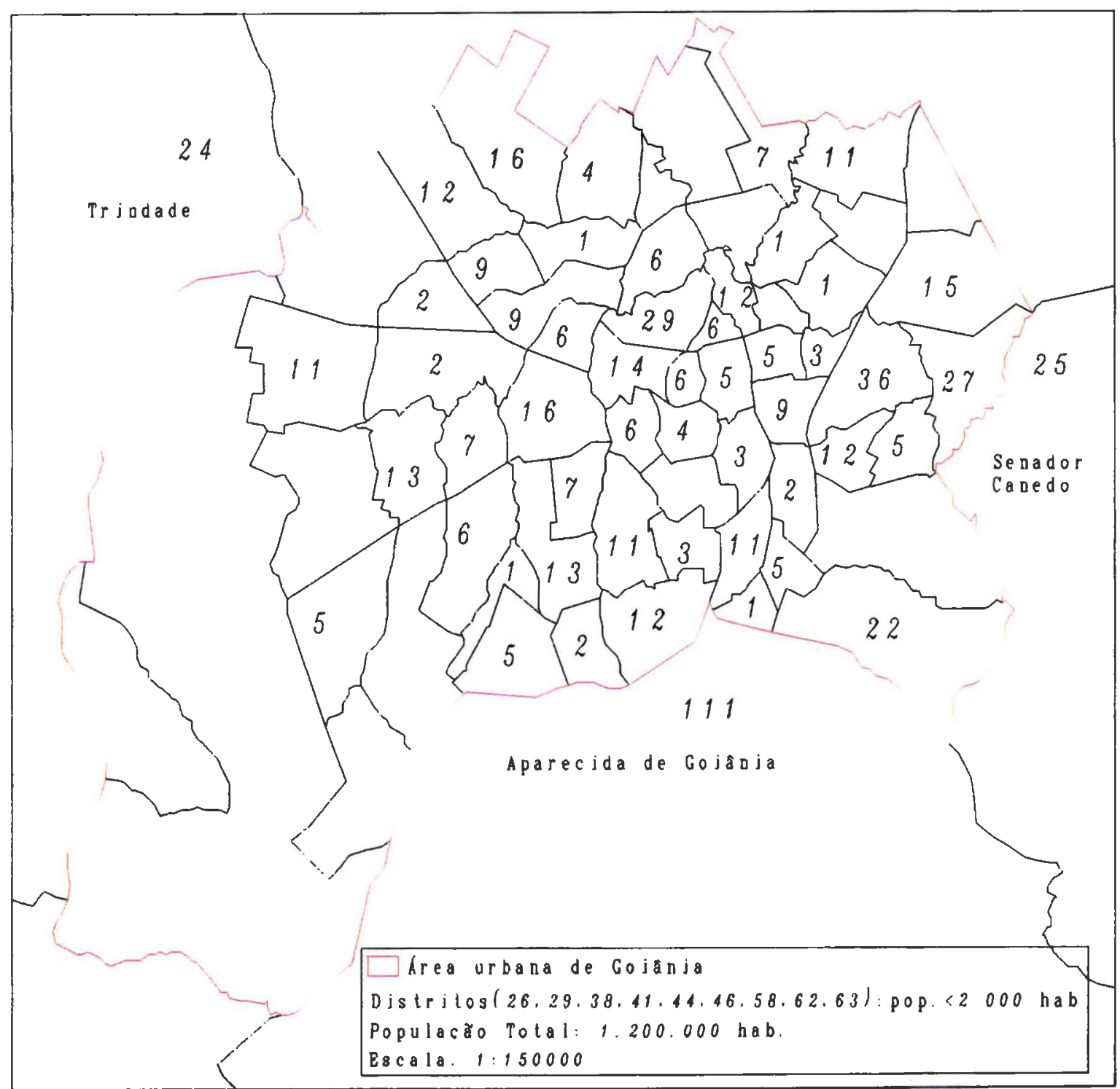


Mapa 5.2-2

Taxas de Hanseníase por 100000 hab. pelos distritos

* urbanos de Goiânia e municípios do aglomerado

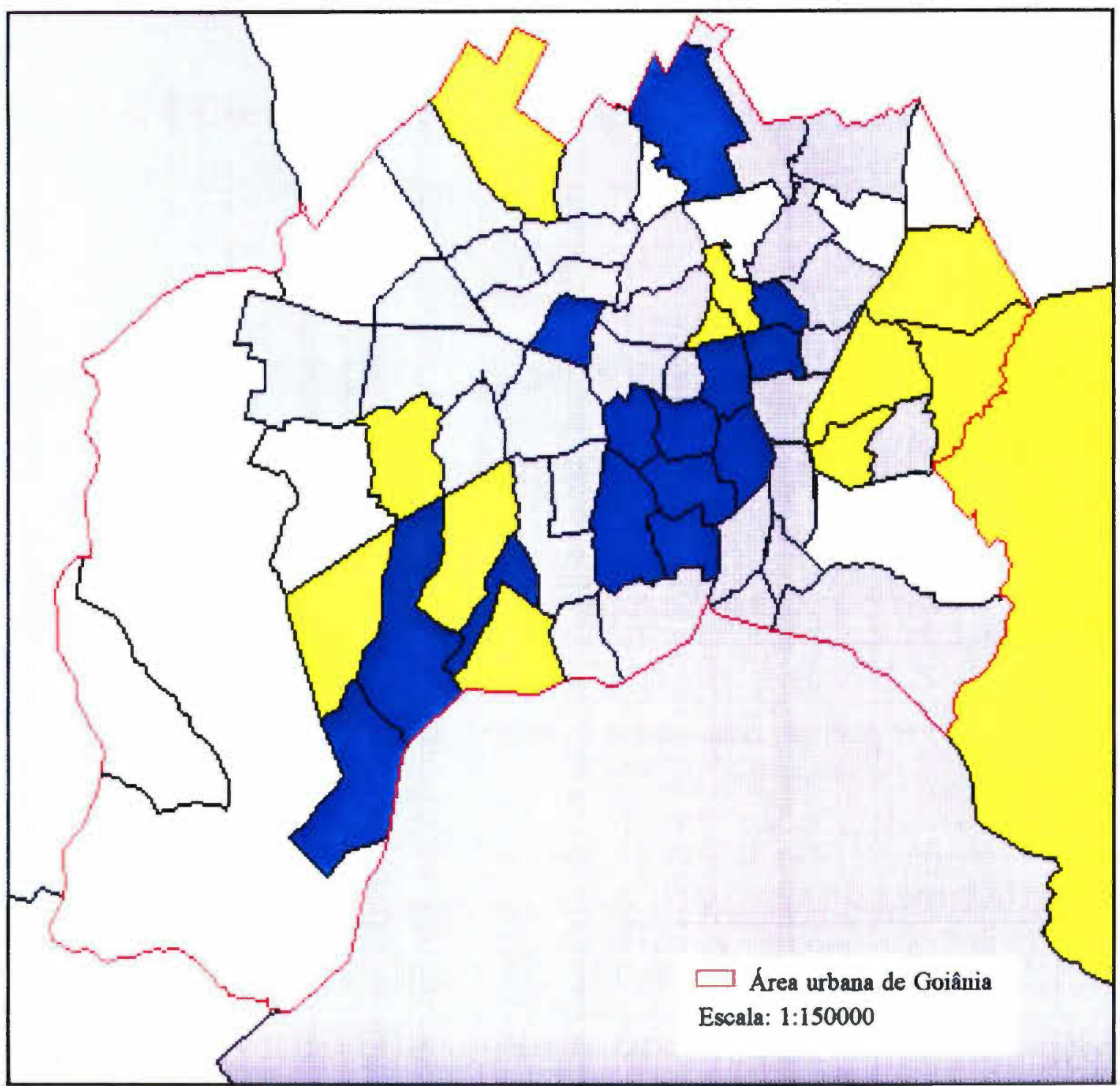

Baixa $<29$ casos por 100000 hab.

Média $\geq 29<70$ casos por 100000 hal $\square$ Alta $\geq 70$ casos por 100000 hab. 
Mapa $5 \cdot 2-3$

Casos de Hansen rase em menores de 15 anos pelos distrjtos urbanos de Gojânja e entorno da capjtal

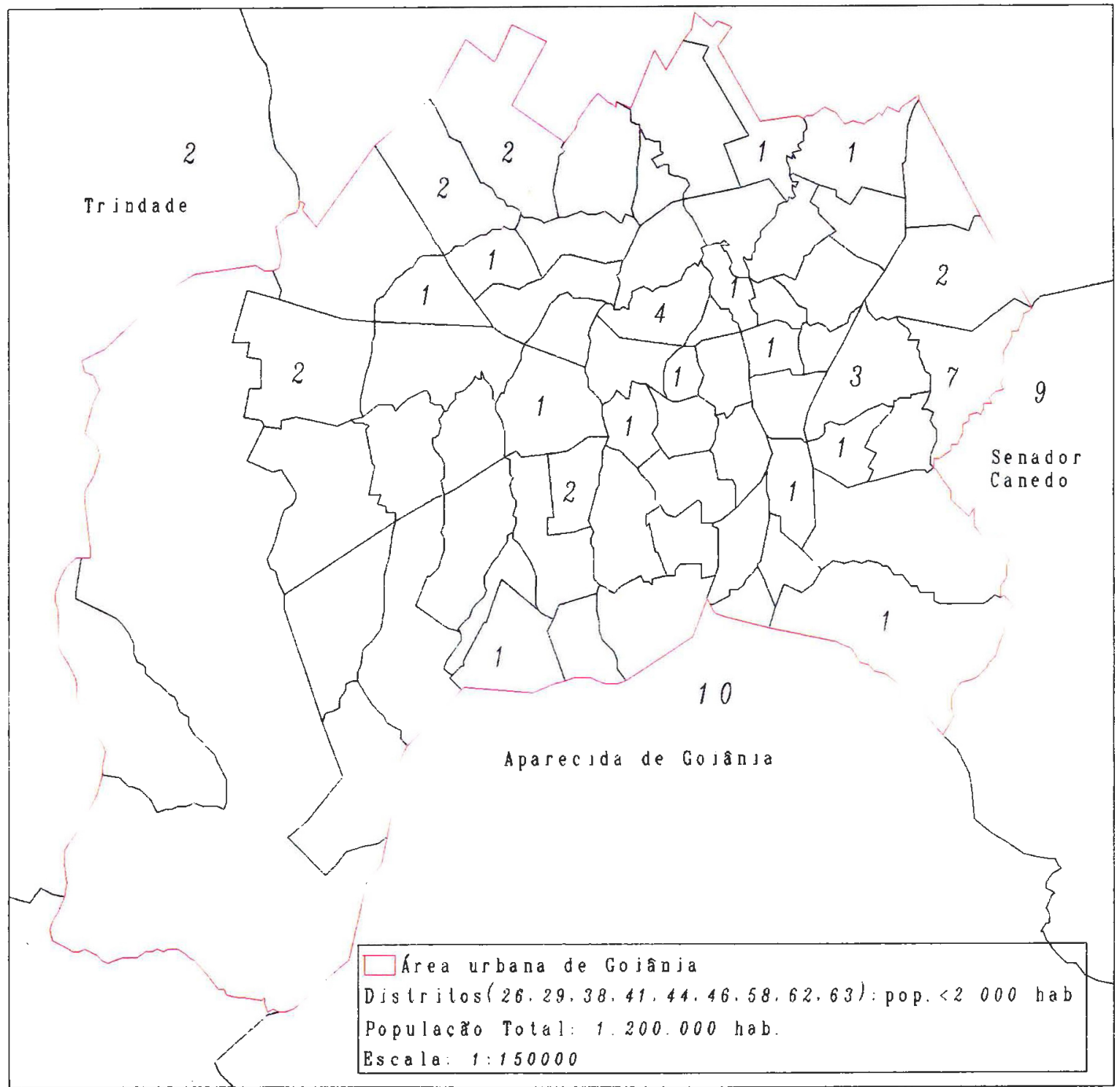


Mapa 5.2-4

ㄴ) Taxas de Hanseníase em menores de 15 anos por 100000 hab. pelos distritos urbanos de Goiânia e municípios do aglomerado

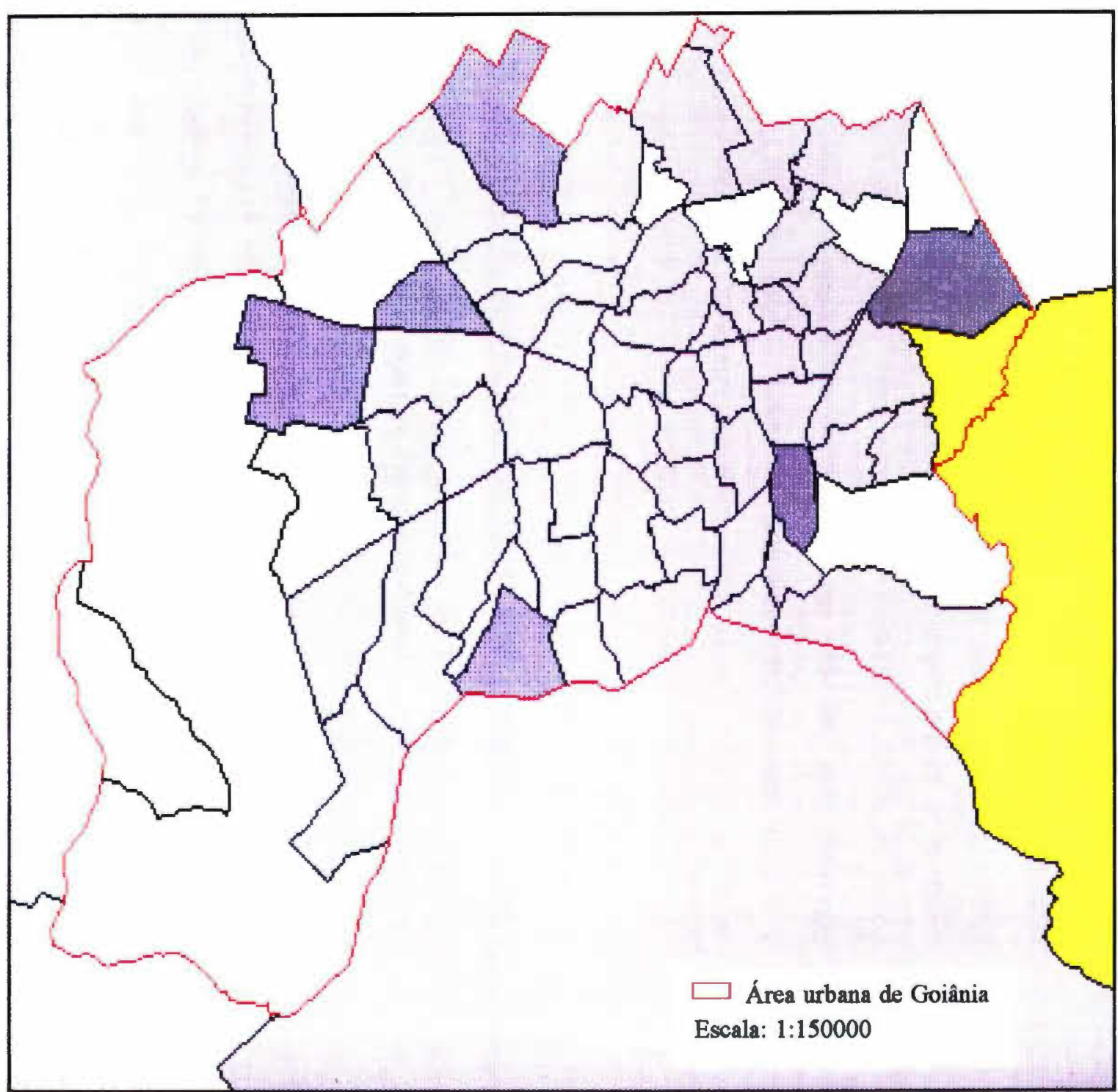

Baixa $<29$ casos por 100000 hab.

Alta $\geq 29 \leq 100$ casos por 100000 hab.

Extrema $>100$ casos por $100000 \mathrm{hab}$.

População $<2000$ hab. 


\subsection{Caracterização de casos e controles}

Neste tópico foram apresentadas comparações das principais características entre casos e controles seguidas dos resultados de prevalência dos marcadores sorológicos do vírus $B$ no item 5.4. Conforme revisão realizada no item Introdução, a falta de informações sobre as características sócio-demográficas representa um dos aspectos críticos mais importantes na interpretação dos estudos de associação entre hanseníase e infecção pelo VHB. Assim, parece-nos importante verificar a similaridade de casos e controles obtida pelo delineamento e, ao mesmo tempo, estabelecer quais as variáveis a serem incorporadas na avaliação da associação entre hanseníase e VHB.

Local de residência - O local de residência dos 552 casos e 552 controles, de acordo com a área de abrangência das unidades de saúde, encontra-se na Tabela 5.3-1. A distribuição percentual de casos e controles por unidade de saúde é idêntica, uma vez que corresponde ao emparelhamento de área de residência, conforme previsto no delineamento do estudo. Vale ressaltar que, apesar de os casos terem sido identificados e notificados por uma única unidade de saúde, (CSJB), menos de $10 \%$ deles habitavam na área de abrangência desta unidade. Esta centralização do atendimento ambulatorial revela, ainda, a persistência de uma estrutura vertical do Programa de Controle de Hanseníase, na área urbana de Goiânia.

Sexo $e$ idade - De forma geral, sexo e idade são importantes fatores constitucionais considerados variáveis de confusão nos estudos de caso-controle (Breslow \& Day, 1980; Datta, 1993). A idade tem sido reconhecida como um fator de risco para hanseníase (Bechelli et al. 1973; Fine, 1982) e, também, para aquisição da infecção pelo VHB (Edmunds et al., 1993). Indivíduos do sexo masculino apresentam-se associados com a forma multibacilar de hanseníase (Rao et al., 1969; Ulrich et al., 1993). Parece existir também maior incidência de 
hepatite $B$ entre homens, em conseqüência da maior exposição viral (Shapiro \& Margolis, 1990; Robinson, 1990).

As freqüências de distribuições das variáveis sexo e faixa etária estão apresentadas na Tabela 5.3-2. A média de idade foi de $33,7(\mathrm{dp}=14,6)$ e 33,4 $(\mathrm{dp}=15,5)$ para os casos e controles, diferença estatisticamente não significante. Ambos os grupos apresentaram iguais distribuições nas faixas etárias de $<15$ anos $(\mathrm{N}=52)$ e $\geq 15$ anos $(\mathrm{N}=500)$. Não se observou diferença na proporção do sexo masculino e feminino entre os participantes.

As variáveis sexo e idade foram também avaliadas para as categorias de multibacilares (MB), paucibacilares (PB) e prováveis ( $\mathrm{PR}$ ), comparando-as aos controles (Tabelas 5.3-3 e 5.3-4). Convém ressaltar que, neste tipo de análise, essas categorias de casos utilizadas foram apresentadas em escala nominal e não em escala ordinal, como se estivessem agrupadas em formas leves, moderadas e graves. Assim, as notações de multibacilar (1), paucibacilar (2), provável (3) e controle (0) serviram apenas para mostrar os cálculos das estimativas de risco e não correspondem a um gradiente de gravidade da doença. Não houve associação entre as formas de hanseníase (multibacilares, paucibacilares e prováveis) e controles em relação à idade (Tabela 5.3-3). Fica evidente na Tabela 5.3-4 que casos paucibacilares estiveram positivamente associados a pacientes do sexo feminino $(\mathrm{OR}=1,7$ IC95\% 1,3-2,3), enquanto formas multibacilares apresentaram-se negativamente associadas ao sexo feminino ( $O R=0,3$ IC95\% 0,2-0,5). Desta forma, indivíduos masculinos apresentaram maior risco de serem multibacilares em oposição a uma relativa proteção do sexo feminino, confirmando as evidências epidemiológicas da análise descritiva do item 5.1 .

Cicatriz vacinal de BCG - A proporção de indivíduos "não vacinados" entre casos, isto é, sem cicatriz vacinal de BCG, foi de $81,5 \%$ versus $61,2 \%$ entre controles, diferença estatisticamente significante (Tabela 5.3-2). Em análise univariada, indivíduos sem cicatriz vacinal de BCG apresentaram uma estimativa 
de risco 5,9 vezes maior (IC 95\% 3,3-10,0) de serem casos multibacilares, quando comparados aos controles, enquanto a estimativa de risco para o grupo paucibacilar foi de 2,0 (IC $95 \%$ 1,5-2,8). Para os casos multibacilares o odds ratio ajustado por idade e sexo implicou em aumento de mais de $10 \%$, no odds ratio bruto, com ampliação do intervalo de confiança. Sexo foi a variável que mais alterou esta estimativa $(O R=6,2$ IC95\% 3,6-10,6). A vacina $B C G$ apresentou graus diferentes de proteção em relação às formas multibacilares e paucibacilares, estatisticamente significantes pela não interseção dos intervalos de confiança dos dois grupos.

Estes resultados foram semelhantes aos encontrados em estudo de casocontrole também realizado em Goiânia por Rodrigues et al. (1992), embora a avaliação do efeito protetor da vacina BCG na hanseníase não seja objeto do presente estudo. Estudos sobre a eficácia / efetividade da vacina BCG contra hanseníase têm mostrado proteção à hanseníase, embora com resultados controversos em diferentes partes do mundo (Muliyil et al., 1991; Fine, 1992b; Convit et al., 1992; Bertolli, 1994). De acordo com McGlynn et al. (1985) a infecção pelo $M$. Tuberculosis teria alguma ação sobre a replicação do vírus $\mathrm{B}$, sugerindo uma possível interação biológica entre os dois organismos. Em conseqüência, a vacina BCG poderia prevenir a infecção viral. Levando-se em conta estas evidências epidemiológicas, a presença de cicatriz vacinal de BCG foi explorada, enquanto variável de confusão.

Estado nutricional - No presente estudo, as similaridades entre casos e controles em relação ao estado nutricional foram avaliadas, uma vez que, no contexto mundial, a desnutrição é considerada uma das principais causas de alteração da imunidade celular (Tramont, 1990; Shetty et al., 1994). A proporção de desnutridos entre os casos foi de $5,7 \%$ e de $4,7 \%$ nos controles, incluindo-se desnutridos de Grau I, Grau II e Grau III. Esta diferença percentual entre casos e controles em relação ao estado nutricional não é estatisticamente significante $\left(x^{2}=0,3 p=0,6\right)$ (Tabela 5.3-2). 
Optou-se por comparar os índices nutricionais em adultos uma vez que indivíduos acima de 18 anos correspondem a 80,7\% (891/1104) dos participantes do estudo. Em atualizações recentes sobre nutrição, o índice de massa corporal (IMC) foi considerado, de forma isolada, o método ideal para avaliação nutricional, na medida que reflete as conseqüências sociais, físicas e econômicas do déficit nutricional dos adultos em uma comunidade (Ferro-Luzzi, et al., 1992; Shetty et al., 1994).

A maioria dos estudos sobre nutrição em hanseníase refere-se a avaliações antropométricas na infância. Variações na prevalência de hanseníase entre 35 localidades do Sul da Índia foram comparadas com indicadores sócio-econômicos e condições nutricionais, encontrando-se significante correlação entre a prevalência da doença e o estado nutricional de crianças de 1-4 anos (Sommerfelt et al., 1985). Em outro estudo, medidas antropométricas em crianças e cálculos do Índice de Quetelet foram avaliados nos pacientes "lepromatosos" em nível populacional. Os autores concluíram que deficiências nutricionais moderadas estavam associados à pobreza e à baixa ingestão de alimentos e não à doença (Rao et al., 1986). Foster (1988) em extensa revisão sobre o tema, observou uma lacuna de dados confiáveis sobre o efeito da nutrição em hanseníase.

Em relação à infecção pelo VHB, a imunossupressão, em conseqüência da desnutrição, pode estar associada mais freqüentemente à persistência de antigenemia, quando comparado com indivíduos imunologicamente normais (Robinson, 1993).

Indicadores sócio-econômicos - De acordo com a literatura, baixas condições sócio-econômicas são consideradas como fator de risco para a hanseníase (Fine, 1982; Ponnighaus et al., 1994b). Tem sido relatado que indivíduos vivendo em condições sócio-econômicas desfavoráveis são mais expostos ao vírus da hepatite $B$ (London \& Blumberg, 1985; Shapiro \& Margolis, 1990). 
A Tabela 5.3-6 compara alguns indicadores de condição sócio-econômica entre casos e controles. Quanto à escolaridade, 12,0\% dos casos e 11,8\% dos controles não concluíram um ano completo de escola e os maiores percentuais de escolaridade foram encontrados na faixa de 1 a 4 anos de educação formal. A renda avaliada em salários mínimos à época da entrevista, também apresentou distribuição semelhante entre casos e controles, com menores percentuais para controles na categoria de um salário mínimo. No entanto, esta diferença não é estatísticamente significante conforme correção de Bonferroni $(\alpha=0,0025)$ estipulada para este conjunto de dados. Destaca-se a alta proporção dos participantes que referiram ser proprietários da moradia atual. No entanto, a maior proporção de casa própria no grupo controle também não alcançou o nível de significância. Casos e controles não diferiram em relação ao número de moradores por casa e número de pessoas por cômodo.

Em relação às atividades de trabalho, cerca de $50 \%$ dos participantes adultos referiram estar engajados em algum tipo de trabalho remunerado (Tabela 5.3-7). Destes, $60 \%$ puderam ser incluídos em três Grupos de Ocupação de acordo com a classificação do Ministério do Trabalho (1993):

a) Grupo 3 - Trabalhadores de Serviços Administrativos e Trabalhadores Assemelhados (agentes administrativos de serviços públicos e privados, secretários, datilógrafos, caixas e trabalhadores assemelhados);

b) Grupo 5 - Trabalhadores de Serviços de Turismo, Hospedagem, Serventia, Higiene e Embelezamento, Segurança e trabalhadores assemelhados;

c) Grupo 9 - Trabalhadores de Fabricação de Produtos de Borracha e Plástico (pintores, carpinteiros, trabalhadores da construção civil e trabalhadores assemelhados, condutores de veículos, trabalhadores braçais não qualificados em outras epígrafes).

Estas características de inserção no mercado de trabalho, além de refletir as principais atividades desenvolvidas por indivíduos de baixa renda na cidade de Goiânia (IPLAN, 1992a), indicam que os pacientes hansenianos não diferem do grupo controle em relação à ocupação no momento do diagnóstico. 
Os aspectos relativos à mobilidade espacial estão apresentados na Tabela 5.3-8. Menos de $20 \%$ dos participantes, casos e controles, eram naturais do município de Goiânia, enquanto cerca de $50 \%$ referiram ser naturais de outros municípios do Estado. O total de participantes que não relataram procedência rural foi de $301(54,5 \%)$ para casos e $342(62,0 \%)$ para controles, incluindo-se os não migrantes e migrantes urbanos-urbanos. Entre os casos, a proporção de migrantes rurais-urbanos foi de $45,5 \%$ enquanto nos controles $38,0 \%$, diferença estatisticamente não significante ao nível estipulado $\left(x^{2}=5,9 \quad p=0,01\right)$. A permanência em anos no aglomerado urbano de Goiânia foi semelhante nos dois grupos, bem como o tempo de residência na moradia atual. O deslocamento de indivíduos dos municípios vizinhos para a capital por motivo de trabalho, migração pendular, foi de $16,4 \%$ para os casos e de $20,4 \%$ para os controles, diferença não significante $\left(x^{2}=1,3 p=0,3\right)$.

No presente estudo verificou-se a composição de migrantes e a procedência rural/urbana entre casos e controles, considerando-se que: (i) migrantes poderiam constituir uma parcela mais pobre da população e, portanto, poderiam apresentar maiores prevalências de hanseníase e de marcadores virais e/ou (ii) distribuição desigual entre casos e controles na proporção de migrantes poderia explicar, de forma alternativa, a associação entre hanseníase e infecção pelo VHB. Este último pressuposto é particularmente importante, devido à diversidade da distribuição regional da hanseníase, conforme apresentada no ítem 5.2. Da mesma forma, em relação ao VHB, existe variação na prevalência de infecção no cenário epidemiológico brasileiro (Bensabath et al., 1987). Recentemente, a influência da migração e da procedência rural na prevalência de marcadores sorológicos do vírus da hepatite B foi enfatizada (Passos et al., 1993a; Passos et al., 1993b).

A interpretação dos resultados referentes às características sócio-econômicas dos participantes deve levar em conta as medidas utilizadas e o contexto social particular vivenciado pelos diferentes subgrupos populacionais estudados. Algumas reflexões sobre o uso destes indicadores em epidemiologia foram revistos por 
Liberatos et al., (1988). Segundo estes autores, o grau de escolaridade em número de anos constitui, para indivíduos adultos, informação mais precisa e fidedigna do que ocupação ou renda, pois, apresenta nítida relação com as condições sociais aliadas à facilidade de coleta de dados. Em relação à ocupação, há uma certa instabilidade no dado, uma vez que representa a situação de momento.

No presente estudo, os casos de hanseníase foram recém-diagnosticados, o que impossibita que as variáveis medidas correspondam a um possível descenso social ocasionado pela doença, "social downgrade". Correspondem, sim, a condições de vida anteriores ao aparecimento da doença, representando exposição e não decorrência do evento. Parece improvável que a direção da associação entre pobreza e doença esteja invertida pela característica de definição de caso adotada no estudo. Poder-se-ia conjecturar sobre alterações nas condições sócio-econômicas para os contactantes de casos, em decorrência da doença prévia de seus familiares. Este fenômeno não foi observado nos resultados, uma vez que as principais características sócio-econômicas são semelhantes entre os grupos. As características de poucos anos de escolaridade e rendimento indicaram baixo nível sócio-econômico de toda a população de estudo, contrapondo-se à elevada proporção de indivíduos com casa própria (Tabela 5.3-6). Estes dados podem parecer, à primeira vista, inconsistentes, no entanto, o parcelamento desordenado do solo urbano, a legalização de invasões e, em menor escala, a implementação de mutirões para construção de moradia na periferia urbana, adotados como medida social na última década, através de política governamental, parecem explicar esta particularidade regional (IPLAN, 1992a).

Em alguns estudos, as condições sócio-econômicas e fatores de risco associados à doença são avaliados através do tipo de construção da casa, bem como da existência de equipamentos e serviços disponíveis (Ponnighaus et al., 1994b, Bertolli, 1994). No presente estudo, optou-se pela não investigação de variáveis referentes à qualidade da moradia, uma vez que a entrevista foi realizada na unidade 
de saúde, impossibilitando a inspeção das condições da habitação in loco pelos entrevistadores.

Utilização dos serviços de saúde - Quanto à utilização dos serviços de saúde, foram observadas diferenças entre os grupos de casos e controles (Tabela 5.3-9). A totalidade dos controles foi procedente da demanda espontânea dos ambulatórios, contrastando com a menor proporção dos casos de hanseníase. Assim 65,8\% dos casos foram encaminhados por outros serviços de saúde e várias hipóteses não excludentes podem ser levantadas: (i) existência de altos índices de suspeição clínica de hanseníase pela rede básica; (ii) baixa capacidade de diagnóstico e de tratamento das unidades de saúde; (iii) centralização de recursos diagnósticos e terapêuticos. Estes achados parecem condizentes com os resultados encontrados de maior proporção de consultas nos últimos 6 meses para os casos, quando comparados aos controles $\left(\mathrm{x}^{2}=43,8 \mathrm{p}<0,001 \mathrm{gl}=1\right)$. A demora no diagnóstico da hanseníase parece refletir componentes operacionais dos serviços de saúde, o nível de conhecimento da doença pelos profissionais de saúde e o tempo dispendido pelos indivíduos após a percepção dos sintomas para comparecer aos serviços de saúde.

O relato de hospitalização nos últimos 5 anos foi de $24,3 \%$ e $13,1 \%$ para casos e controles respectivamente, diferença estatisticamente significante $\left(x^{2}=22,8\right.$ $\mathrm{p}<0,001)$. A hospitalização e o isolamento asilar têm sido reconhecidos como um fator de risco para infecção pelo VHB (Shapiro \& Margolis, 1990). Em pacientes hansenianos da forma virchowiana, institucionalizados, verificaram-se prevalências maiores de marcadores sorológicos ao VHB, quando comparadas com pacientes de mesma forma clínica tratados em ambulatório (Rosa et al., 1992). No presente estudo, embora os casos fossem pacientes recém-diagnosticados, a comparação da hospitalização entre casos e controles mostrou uma associação positiva entre esta variável e pacientes com hanseníase. Desta forma, a escolha de casos e de controles em ambulatórios não possibitou excluir a hospitalização prévia como uma potencial variável de confusão na associação estudada. Outros fatores de risco associados à 
hepatite $B$, como uso de injeções, drogas e prática sexual estiveram distribuídos de forma semelhante entre casos e controles.

Em resumo, os resultados deste estudo mostraram que casos e controles se equipararam do ponto de vista sócio-econômico, indicando que o emparelhamento realizado por área de abrangência das unidades de saúde parece ter assegurado semelhança quanto aos aspectos sócio-econômicos entre os grupos estudados. Sexo e cicatriz vacinal de BCG estiveram associados com os diferentes tipos de hanseníase, quando comparados ao grupo controle. Interessante ressaltar que, embora seja esperado que indivíduos com baixas condições sócio-econômicas apresentem também baixa probabilidade de serem vacinados (Fine, 1992b), o emparelhamento por residência não tornou casos e controles comparáveis do ponto de vista vacinal, reforçando as evidências de um efeito protetor da vacina $B C G$ na hanseníase. A maior proporção de hospitalização dos casos comparado aos controles indicou, que o emparelhamento por local de residência no delineamento do estudo, não eliminou completamente as diferenças entre os grupos. Assim, na análise de dados dos resultados referentes à associação entre hanseníase e infecção pelo VHB, foram levadas em consideração as seguintes variáveis: sexo, idade, cicatriz vacinal de BCG e hospitalização prévia. 
Tabela 5.3-1

Distribuição dos casos e controles segundo área de abrangência da unidade de saúde e local de residência.

\begin{tabular}{lrrrr}
\hline Característica & \multicolumn{2}{c}{ Casos } & \multicolumn{2}{c}{$\begin{array}{c}\text { Controles } \\
(552)\end{array}$} \\
& \multicolumn{2}{c}{$(552)$} & \multicolumn{2}{c}{ № $\%$} \\
& № $\%$ & & \\
\hline Residência na Abrangência & & & & \\
Unidades de Saúde & & & 54 & 9,8 \\
CSJB & 54 & 9,8 & 108 & 19,6 \\
CAIS Jardim Novo Mundo & 108 & 19,6 & 38 & 6,9 \\
CIAMS Novo Horizonte & 38 & 6,9 & 50 & 9,1 \\
CIAMS Urias Magalhães & 50 & 9,1 & 115 & 20,8 \\
CAIS do Dergo & 115 & 20,8 & 31 & 5,6 \\
CAIS Cândido de Moraes & 31 & 5,6 & 156 & 28,2
\end{tabular}


Tabela 5.3-2

Características de casos e controles em relação à idade, sexo, cicatriz vacinal de $\mathrm{BCG}$ e índice de massa corporal.

\begin{tabular}{|c|c|c|c|c|}
\hline \multirow[t]{2}{*}{ Característica } & \multicolumn{2}{|c|}{$\begin{array}{l}\text { Casos } \\
(552)\end{array}$} & \multicolumn{2}{|c|}{$\begin{array}{c}\text { Controles } \\
(552)\end{array}$} \\
\hline & № & $\%$ & № & $\%$ \\
\hline \multicolumn{5}{|l|}{ Idade (anos) ${ }^{\mathrm{a}}$} \\
\hline média & 33,7 & & 33,4 & \\
\hline desvio-padrão & 14,6 & & 15,5 & \\
\hline \multicolumn{5}{|l|}{ Sexo } \\
\hline Feminino & 276 & 50,0 & 283 & 51,3 \\
\hline Masculino & 276 & 50,0 & 269 & 48,7 \\
\hline \multicolumn{5}{|c|}{ Cicatriz Vacinal de BCG $^{b}$} \\
\hline $\operatorname{Sim}$ & 102 & 18,5 & 195 & 38,8 \\
\hline Não & 445 & 81,5 & 308 & 61,2 \\
\hline \multicolumn{5}{|c|}{ Índice de Massa Corporal ${ }^{\mathrm{c}}$} \\
\hline Normal & 398 & 94,3 & 447 & 95,3 \\
\hline \multicolumn{5}{|l|}{ Desnutrição } \\
\hline Grau I & 18 & 4,3 & 14 & 3,0 \\
\hline Grau II & 4 & 0,9 & 6 & 1,3 \\
\hline Grau III & 2 & 0,5 & 2 & 0,4 \\
\hline média & 23,5 & & 23,6 & \\
\hline desvio-padrão & 4,2 & & 3,9 & \\
\hline
\end{tabular}

a Teste $\mathrm{t}=0,31 \mathrm{p}=0,7$

b 5 casos e 49 controle sem informação

- Índice de massa corporal $=\mathrm{kg} / \mathrm{m}^{2}$, calculado para participantes com idade superior a 17 anos. Teste $\mathrm{t}=0,36 \mathrm{p}=0,7$ 
Tabela 5.3-3

Odds ratio (OR) e intervalo de $95 \%$ de confiança (IC 95\%) para formas multibacilares, paucibacilares e casos prováveis de hanseníase por faixa etária.

\begin{tabular}{lcrrrrl}
\hline & & \multicolumn{2}{c}{ Idade (anos) } & & OR $^{\mathrm{a}}$ & (IC 95\%) \\
\cline { 3 - 5 } Categoria & & $<15$ & $\geq 15$ & & \\
\hline Controle & $(0)$ & 37 & 515 & & 1 \\
Multibacilar & $(1)$ & 8 & 166 & 1,4 & $(0,7-3,3)$ \\
Paucibacilar & $(2)$ & 27 & 256 & 0,7 & $(0,4-1,1)$ \\
Provável & $(3)$ & 5 & 90 & 1,3 & $(0,5-3,4)$ \\
\hline
\end{tabular}

a Odds ratio não ajustado

$$
\begin{aligned}
& \Psi_{(1,0)}=\frac{166 \times 37}{8 \times 515}=1,4 \\
& \Psi_{(2,0)}=\frac{256 \times 37}{27 \times 515}=0,7 \\
& \Psi_{(3,0)}=\frac{90 \times 37}{5 \times 515}=1,3
\end{aligned}
$$


Tabela 5.3-4

Odds ratio (OR) e intervalo de $95 \%$ de confiança (IC 95\%) para formas multibacilares, paucibacilares e casos prováveis de hanseníase por sexo.

\begin{tabular}{|c|c|c|c|c|c|}
\hline \multirow[b]{2}{*}{ Categoria } & & \multicolumn{2}{|c|}{ Sexo } & \multirow[t]{2}{*}{$\mathrm{OR}^{\mathrm{a}}$} & \multirow[t]{2}{*}{ (IC 95\%) } \\
\hline & & Masc. & Fem. & & \\
\hline Controle & $(0)$ & 269 & 283 & & 1 \\
\hline Multibacilar & (1) & 129 & 45 & 0,3 & $(0,2-0,5)$ \\
\hline Paucibacilar & (2) & 101 & 182 & 1,7 & $(1,3-2,3)$ \\
\hline Provável & (3) & 46 & 49 & 1,0 & $(0,6-1,5)$ \\
\hline
\end{tabular}

adds ratio não ajustado

$$
\begin{aligned}
& \Psi_{(1,0)}=\frac{45 \times 269}{129 \times 283}=0,3 \\
& \Psi_{(2,0)}=\frac{182 \times 269}{101 \times 283}=1,7 \\
& \Psi_{(3,0)}=\frac{49 \times 269}{46 \times 283}=1,0
\end{aligned}
$$


Tabela 5.3-5

Odds ratio (OR) e intervalo de $95 \%$ de confiança (IC 95\%) para formas multibacilares, paucibacilares e casos prováveis de hanseníase em relação à presença de cicatriz vacinal de BCG.

\begin{tabular}{|c|c|c|c|c|c|c|c|}
\hline \multirow[b]{2}{*}{ Categoria } & & \multicolumn{2}{|c|}{ Cicatriz BCG } & \multirow[t]{2}{*}{$\mathrm{OR}^{\mathrm{a}}$} & \multirow[t]{2}{*}{ (IC 95\%) } & \multirow[t]{2}{*}{$\mathrm{OR}^{\mathrm{b}}$} & \multirow[t]{2}{*}{ (IC 95\%) } \\
\hline & & Não & Sim & & & & \\
\hline Controle $^{c}$ & $(0)$ & 308 & 195 & & 1 & & 1 \\
\hline Multibacilar $^{c}$ & (1) & 156 & 17 & 5,9 & $(3,3-10,0)$ & 6,6 & $(3,7-11,1)$ \\
\hline Paucibacilar $^{\mathfrak{c}}$ & (2) & 213 & 66 & 2,0 & $(1,5-2,8)$ & 2,1 & $(1,5-3,0)$ \\
\hline Provável & (3) & 76 & 19 & 2,5 & $(1,5-4,3)$ & 2,5 & $(1,5-4,3)$ \\
\hline
\end{tabular}

- Odds ratio não ajustado

b Odds ratio ajustado por sexo, e faixa etária ( $<15$ e $\geq 15$ anos)

c 49 controles, 1 caso multibacilar e 4 casos paucibacilares sem informação

$$
\begin{aligned}
& \Psi_{(1,0)}=\frac{156 \times 195}{17 \times 308}=5,8 \\
& \Psi_{(2,0)}=\frac{213 \times 195}{66 \times 308}=2,0 \\
& \Psi_{(3,0)}=\frac{76 \times 195}{19 \times 308}=2,5
\end{aligned}
$$


Tabela 5.3-6

Características sócio-econômicas dos casos e controles.

\begin{tabular}{|c|c|c|c|c|}
\hline \multirow[t]{2}{*}{ Característica } & \multicolumn{2}{|c|}{$\begin{array}{l}\text { Casos } \\
(552)\end{array}$} & \multicolumn{2}{|c|}{$\begin{array}{c}\text { Controles } \\
(552)\end{array}$} \\
\hline & & $\%$ & & \\
\hline \multicolumn{5}{|c|}{ Escolaridade (anos) } \\
\hline Nenhuma & 66 & 12,0 & 65 & 11,8 \\
\hline $1-4$ & 346 & 62,7 & 330 & 59,8 \\
\hline$\geq 5$ & 140 & 25,3 & 157 & 28,4 \\
\hline \multicolumn{5}{|c|}{ Rendimento Familiar (salários mínimos) } \\
\hline$\leq 1$ & 71 & 13,1 & 45 & 8,1 \\
\hline $2-5$ & 352 & 63,8 & 373 & 67,6 \\
\hline$\geq$ & 117 & 22,1 & 132 & 23,9 \\
\hline média & \multirow{2}{*}{\multicolumn{2}{|c|}{$\begin{array}{l}4,2 \\
5,4\end{array}$}} & \multirow{2}{*}{\multicolumn{2}{|c|}{$\begin{array}{l}4,0 \\
3,6\end{array}$}} \\
\hline desvio-padrão & & & & \\
\hline \multicolumn{5}{|l|}{ Casa Própria } \\
\hline Sim & 367 & 66,6 & 400 & 72,5 \\
\hline Não & 184 & 33,4 & 152 & 27,5 \\
\hline \multicolumn{5}{|c|}{ Número de Moradores por Casa } \\
\hline média & \multirow{2}{*}{\multicolumn{2}{|c|}{$\begin{array}{l}4,6 \\
1,9\end{array}$}} & \multirow{2}{*}{\multicolumn{2}{|c|}{$\begin{array}{l}4,4 \\
1,9\end{array}$}} \\
\hline desvio-padrão & & & & \\
\hline \multicolumn{5}{|c|}{ Número de Pessoas por Cômodo ${ }^{c}$} \\
\hline$<1$ & \multicolumn{2}{|c|}{$267 \quad 48,5$} & 278 & 49,9 \\
\hline $1-<2$ & \multicolumn{2}{|c|}{$240 \quad 43,5$} & \multicolumn{2}{|l|}{251} \\
\hline$\geq 2$ & \multicolumn{2}{|c|}{$44 \quad 18,0$} & \multicolumn{2}{|l|}{53} \\
\hline média & \multirow{2}{*}{\multicolumn{2}{|c|}{$\begin{array}{l}1,6 \\
0,7\end{array}$}} & \multirow{2}{*}{\multicolumn{2}{|c|}{1,7}} \\
\hline desvio-padrão & & & & 7 \\
\hline
\end{tabular}

a 12 casos e 2 controles sem informação

b 1 caso sem informação

c 1 caso sem informação 
Tabela 5.3-7

Distribuição de casos e controles segundo características sócio-econômicas.

\begin{tabular}{|c|c|c|c|c|}
\hline \multirow[t]{2}{*}{ Característica } & \multicolumn{2}{|c|}{$\begin{array}{l}\text { Casos } \\
(540)\end{array}$} & \multicolumn{2}{|c|}{$\begin{array}{c}\text { Controles } \\
(547)\end{array}$} \\
\hline & & 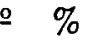 & № & $\%$ \\
\hline \multicolumn{5}{|l|}{ Trabalho Atual ${ }^{a}$} \\
\hline Remunerado & 299 & 54,3 & 276 & 50,5 \\
\hline Dona de casa & 117 & 21,7 & 117 & 21,4 \\
\hline Estudante & 70 & 13,0 & 75 & 13,7 \\
\hline Desempregado & 38 & 7,0 & 28 & 5,1 \\
\hline Aposentado/sem atividade & 16 & 3,0 & 51 & 9,3 \\
\hline \multicolumn{5}{|l|}{ Grupos de Ocupação ${ }^{b}$} \\
\hline Grupo 1 - Profissões Científicas & 30 & 10,0 & 24 & 8,7 \\
\hline Grupo 3 - Serviços Administrativos & 61 & 20,4 & 47 & 17,0 \\
\hline Grupo 4 - Trabalhadores do Comércio & 36 & 12,0 & 32 & 11,6 \\
\hline Grupo 5 - Trabalhadores de Serviço & 63 & 21,1 & 63 & 22,8 \\
\hline Grupo 6 - Agropecuária & 13 & 4,3 & 5 & 1,8 \\
\hline Grupo 7 - Produção Industrial & 16 & 5,4 & 23 & 8,3 \\
\hline Grupo 8 - Trabalhadores do Couro & 14 & 4,7 & 18 & 6,5 \\
\hline Grupo 9 - Trabalhadores da Borracha & 63 & 21,1 & 64 & 23,2 \\
\hline
\end{tabular}

a Incluídos casos e controles maiores de 18 anos. 11 casos e 3 controles informaram afastamento temporário do trabalho por doenças e 1 caso sem informação

- Grupos de Ocupação conforme Código Brasileiro de Ocupação, Ministério do Trabalho, 1991. 3 casos sem informação. Incluídos participantes com trabalho remunerado. 
Tabela 5.3-8

Indicadores de mobilidade espacial dos casos e controles.

\begin{tabular}{|c|c|c|c|c|}
\hline \multirow[t]{2}{*}{ Indicador } & \multicolumn{2}{|c|}{$\begin{array}{l}\text { Casos } \\
(552)\end{array}$} & \multicolumn{2}{|c|}{$\begin{array}{c}\text { Controles } \\
(552)\end{array}$} \\
\hline & & $\%$ & № & $\%$ \\
\hline \multicolumn{5}{|l|}{ Naturalidade } \\
\hline Municipio de Goiânia & 100 & 18,1 & 96 & 17,4 \\
\hline Outros municípios Estado de Goiás & 284 & 51,5 & 238 & 43,1 \\
\hline Outros Estados & 168 & 30,4 & 218 & 39,5 \\
\hline \multicolumn{5}{|l|}{ Migrantes $^{\mathrm{a}}$} \\
\hline Não Migrante & 301 & 54,5 & 342 & 62,0 \\
\hline Rural-urbano & 251 & 45,5 & 210 & 38,0 \\
\hline \multicolumn{5}{|l|}{ Duração da residência no $\mathrm{AGLUG}^{\mathrm{b}}$} \\
\hline$<1$ ano & 131 & 23,7 & 143 & 25,9 \\
\hline $1-5$ & 91 & 16,5 & 90 & 16,3 \\
\hline $6-10$ & 107 & 19,4 & 88 & 15,9 \\
\hline $\begin{array}{l}11-15 \\
\geq 16\end{array}$ & 191 & 34,6 & 213 & 38,6 \\
\hline média & \multicolumn{2}{|c|}{14,7} & \multicolumn{2}{|c|}{14,9} \\
\hline desvio-padrão & \multicolumn{2}{|c|}{10,3} & \multicolumn{2}{|c|}{10,9} \\
\hline \multicolumn{5}{|l|}{ Tempo de Residência na Moradia $^{c}$} \\
\hline$<1$ & 140 & 25,4 & 145 & 26,8 \\
\hline $1-3$ & 107 & 19,4 & 93 & 16,9 \\
\hline $\begin{array}{l}4-6 \\
>6\end{array}$ & 255 & 46,2 & 282 & 51,2 \\
\hline média & \multicolumn{2}{|c|}{8,7} & \multicolumn{2}{|c|}{10,0} \\
\hline desvio-padrão & \multicolumn{2}{|c|}{8,3} & \multicolumn{2}{|c|}{9,4} \\
\hline \multicolumn{5}{|l|}{ Migração Pendular ${ }^{d}$} \\
\hline Não & 250 & 83,6 & 219 & 79,6 \\
\hline $\operatorname{Sim}$ & 49 & 16,4 & 56 & 20,4 \\
\hline
\end{tabular}

${ }^{a} x^{2}=6,0 p=0,015$

b AGLUG - Aglomerado Urbano de Goiânia

c 1 controle sem informação. Teste $t \mathrm{p}=0,02$

d Correspondente aos casos $(\mathrm{N}=299)$ e controles $(\mathrm{N}=276)$ com trabalho atual remunerado

1 controle sem informação do local de trabalho 
Tabela 5.3-9

Indicadores de utilização dos serviços de saúde, uso de injeção, drogas e prática sexual dos casos e controles.

\begin{tabular}{|c|c|c|c|c|}
\hline \multirow[t]{2}{*}{ Indicador } & \multicolumn{2}{|c|}{$\begin{array}{l}\text { Casos } \\
(552)\end{array}$} & \multicolumn{2}{|c|}{$\begin{array}{l}\text { Controles } \\
(552)\end{array}$} \\
\hline & & & & \\
\hline \multicolumn{5}{|l|}{ Tipo de Demanda } \\
\hline Encaminhamento & 363 & 65,8 & - & - \\
\hline Espontânea & 79 & 14,3 & 552 & 100,0 \\
\hline Contactante de paciente & 110 & 19,9 & - & - \\
\hline \multicolumn{5}{|c|}{ Número de Consultas nos Últimos 6 Meses $^{a}$} \\
\hline Nenhuma & 128 & 23,3 & 224 & 40,8 \\
\hline 1 & 187 & 34,0 & 138 & 25,1 \\
\hline 2 & 104 & 18,9 & 103 & 18,8 \\
\hline$\geq 3$ & 131 & 23,8 & 84 & 15,3 \\
\hline média & \multicolumn{2}{|c|}{$\begin{array}{l}1,9 \\
2.5\end{array}$} & \multicolumn{2}{|c|}{$\begin{array}{l}1,3 \\
1,6\end{array}$} \\
\hline aesvio-paarao & & & & \\
\hline \multicolumn{5}{|c|}{ Hospitalização nos Últimos 5 Anos $^{\mathrm{b}}$} \\
\hline Não & 418 & 75,7 & 479 & 86,9 \\
\hline Sim & 134 & 24,3 & 72 & 13,1 \\
\hline \multicolumn{5}{|l|}{ Uso de Injeções ${ }^{\complement}$} \\
\hline Raramente & 462 & 83,7 & 436 & 79,0 \\
\hline Freqüentemente & 90 & 16,3 & 116 & 21,0 \\
\hline \multicolumn{5}{|c|}{ Usuário de Droga Recreativa } \\
\hline Não & 543 & 98,4 & 549 & 99,5 \\
\hline Sim & 9 & 1,8 & 3 & 0,5 \\
\hline \multicolumn{5}{|l|}{ Prática Sexual $^{d}$} \\
\hline Heterosexual & 478 & 99,0 & 488 & 100,0 \\
\hline Homosexual/Bisexual & 5 & 1,0 & & - \\
\hline
\end{tabular}

a 2 casos e 3 controles sem informação. Teste $t \mathrm{p}<0,01$

b 1 controle sem informação. $X^{2}=28,8 p<0,0001$

c $\mathrm{X}^{2}=3,7 \mathrm{p}=0,05$

d 52 casos e 52 controles menores de 15 anos, 17 casos e 12 controles sem informação 


\subsection{Associação da infecção pelo vírus da hepatite B entre casos e controles}

Entre as particularidades dos estudos de caso-controle em doenças infecciosas destacam-se: (i) novos casos surgem em decorrência dos casos antigos, isto é, a incidência depende da prevalência da doença, condição conhecida como dependência de eventos (Giesecke, 1994); (ii) os grupos estudados precisam ser comparáveis quanto à exposição ao agente infeccioso específico (Halloran \& Struchiner, 1991). Estes requisitos de dependência dos eventos e de similaridade da exposição ao agente infeccioso entre casos e controles representam alguns dos desafios a serem transpostos no delineamento de estudos de caso-controle.

Neste estudo, os casos e os controles foram comparados quanto à prevalência de soropositividade ao anti-HBc, marcador de exposição ao VHB, enquanto condição necessária para a ocorrência da persistência do antígeno viral. É esperado que indivíduos expostos ao vírus tenham capacidade de produzir anticorpos (anti-HBc), constituindo marcador sorológico de infecção viral de longa duração. De forma simplificada, a evolução desta infecção viral na população está na dependência de fatores biológicos individuais, podendo resultar em produção de anticorpos protetores ou em persistência do antígeno viral (Hoofnagle, 1981; Anderson \& May, 1991).

Neste tópico foram apresentados, numa primeira etapa, os resultados referentes ao anti-HBc obtidos em análise univariada e multivariada, para verificar a associação entre os subgrupos da doença e dos controles, quanto à exposição ao vírus da hepatite $B$. Em seguida, a resposta humoral protetora e a persistência do antígeno de superfície da hepatite B foram apresentadas.

Marcador anti-HBc - A Tabela 5.4-1 apresenta a proporção dos marcadores sorológicos do vírus da hepatite B (VHB) para casos e controles. Entre. os participantes do estudo, $18,1 \%$ dos casos e $19,6 \%$ dos controles foram soropositivos ao anti-HBc, diferença estatísticamente não significante. Estes resultados indicam 
que casos e controles apresentaram prevalências similares de infecção viral e, portanto, igual oportunidade de terem sido expostos ao VHB.

$\mathrm{O}$ anti-HBc foi detectado enquanto marcador sorológico único em 7,6\% dos pacientes hansenianos e 8,0\% dos controles. Em estudos populacionais, a proporção de indivíduos infectados com marcador único varia de $3 \%$ a $5 \%$, podendo este intervalo ser interpretado como período de janela imunológica (Hoofnagle, 1981). Em alguns subgrupos populacionais, como usuários de droga, este marcador, de forma isolada, tem sido detectado de $10,7 \%$ a $35,1 \%$ (Levine et al., 1994). A interpretação do anti-HBc, na ausência de outro marcador do VHB, é complexa. É possível, também, que este perfil indique um portador "silencioso", com produção de AgHBs não passível de detecção pelos testes sorológicos usuais (Robinson, 1990; Levine et al., 1994). De forma geral, resultados falso-positivos de testes utilizados com finalidade de triagem populacional, podem ocorrer na dependência da prevalência da infecção na população (Galen \& Gambino, 1975).

Os resultados de prevalência de anti-HBc do presente estudo foram semelhantes aos obtidos em triagem sorológica de pacientes da forma virchowiana, procedentes de ambulatório da rede pública de Goiânia (Rosa et al., 1992). Como esperado, a prevalência de anti-HBc nos pacientes institucionalizados, colônia de hansenianos, foi pelo menos 3 vezes maior que a do grupo de ambulatório, respectivamente $56,1 \%$ e $18,1 \%$ pela técnica de radioimunoensaio (RIA), sinalizando maior exposição viral nos primeiros. A comparabilidade do estudo anterior com o atual, fica prejudicada, uma vez que aquela investigação se restringiu à forma virchowiana.

No presente estudo, foi realizada uma análise univariada para as formas $\mathrm{MB}, \mathrm{PB}$ e PR, comparado-se a prevalência da variável de exposição - positividade ao anti-HBc - entre estes subgrupos de casos e os controles (Tabela 5.4-2). Foram seguidas as mesmas notações do item 5.3, no intuito de facilitar a apresentação dos cálculos das estimativas de risco. Casos multibacilares apresentaram odds ratio de 
1,3 (IC95\% 0,9-2,0). Do mesmo modo, para casos paucibacilares e prováveis, os intervalos de $95 \%$ de confiança também incluiram a unidade, indicando ausência de associação entre o marcador anti-HBc e os subgrupos de casos e os controles.

Alguns estudos da associação entre hanseníase e VHB compararam os marcadores entre os dois subgrupos da doença, isto é, pacientes "lepromatosos" versus tuberculóides, na ausência de um grupo controle (Papaevangelou et al., 1972; Goireina et al., 1972; Shwe \& Zuckerman, 1972; Zyngier et al., 1979; Ottati \& Candeias, 1979). Nesta abordagem, resultados de odds ratio diferentes da unidade não permitem concluir se o fator sob estudo está associado a um aumento de risco em um grupo, ou ao decréscimo de risco no grupo considerado como controle. Este aspecto metodológico, em relação à estratégia de análise em diferentes subgrupos de casos, foi abordado por Liang \& Steward (1987), reforçando a inadequação da comparação entre os subgrupos de casos.

Considerando-se que a análise das características entre casos e controles do item 5.3 apontou como potenciais variáveis de confusão sexo, idade, hospitalização prévia e cicatriz vacinal de BCG, as prevalências de exposição viral, de acordo com as formas de hanseníase, não devem ser interpretadas somente à luz de análise univariada. Desta forma, casos e controles foram estratificados por estas variáveis, conforme apresentado nas Tabelas 5.4-3 a 5.4-5.

Para os multibacilares, os cálculos das estimativas de risco ajustadas pela técnica de Mantel \& Haenszel (1959) mostraram pequena alteração do odds ratio, quando comparada à estimativa de risco não ajustada (Tabelas 5.4-3). Os valores dos odds ratios ajustados para cada uma das formas paucibacilar e provável não se alteraram (Tabela 5.4-4 e 5.4-5). Este tipo de análise estratificada constituiu uma etapa preliminar na exploração dos dados uma vez que esta estratégia não possibilita avaliar o efeito das variáveis de confusão, de forma simultânea, o que foi realizado através da análise multivariada. 
Os resultados do modelo de regressão logística, incorporando a variável de resposta politômica, encontram-se na Tabela 5.4-6. Os odds ratios para as formas multibacilares foram de 0,9 (IC95\% 0,7-1,3); 1,0 (IC95\% 0,7-1,3) para as paucibacilares e 1,1 (IC95\% 0,8-1,5) para as formas prováveis. Estes resultados indicam que, mesmo após controlar para as potenciais variáveis de confusão, o marcador de infecção (anti-HBc) não esteve associado aos diferentes tipos de hanseníase, reforçando que pacientes $\mathrm{MB}, \mathrm{PB}$ e $\mathrm{PR}$ e os controles apresentaram prevalências semelhantes de infecção ao VHB. Nenhuma interação foi observada entre a variável de exposição e idade e/ou sexo, não havendo evidência estatística de uma modificação de efeito.

As variáveis incluídas no modelo de regressão logística, os respectivos coeficientes de regressão e odds ratio encontram-se apresentados na Tabela 5.4-7. Para esta análise, os casos MB $(\mathrm{N}=173)$ foram comparados aos controles $(\mathrm{N}=552)$, obtendo-se odds ratio de 1,0 (IC95\% 0,2-4,3). Casos PB $(\mathrm{N}=278)$ e PR $(\mathrm{N}=93)$ apresentaram $\mathrm{OR}=0,5$ (IC95\% $0,1-2,2)$ e de 0,4 (IC95\% 0,03-2,7), respectivamente. Estes resultados indicam ausência de associação entre hanseníase e infecção pelo VHB em concordância com a análise de regressão logística politômica.

Embora as conclusões sejam semelhantes com a aplicação de ambos os modelos multivariados, a regressão logística com variável binária apresentou menor precisão, mostrada pela maior amplitude dos intervalos de confiança. De fato, a vantagem do modelo de regressão logística politômica, ao invés dos métodos convencionais, consiste em usar toda a informação disponível de forma simultânea, aumentando o poder estatístico da amostra (Armstrong \& Sloan, 1989). Adicionalmente, a técnica de regressão logística politômica apresenta como vantagem não só a avaliação das diferenças entre fator de risco e subgrupos da doença, mas a relação entre um subgrupo e outro (Dubin \& Paternack, 1986). 
O único estudo de caso-controle que utilizou análise multivariada para lidar com as variáveis de confusão foi o realizado em Papua, Nova Guiné por Serjeantson \& Woodfield (1978). O marcador anti-HBc não foi avaliado e mais de um terço dos participantes apresentaram evidências sorológicas de anti-HBs e ou AgHBs, sinalizando a área como de alta transmissibilidade ao VHB, diferente do cenário epidemiológico da presente investigação.

Os resultados deste estudo contrastam com a investigação de caso-controle realizado na Grécia por Papaioannou et al. (1986). Esses autores concluíram que os pacientes hansenianos, independente da forma, apresentaram maior risco para aquisição da infecção pelo VHB. No entanto, convém ressaltar que os casos e respectivos controles foram selecionados em hospitais e em ambulatórios, sem menção do tempo de permanência de hospitalização.

Marcador anti-HBs - As proporções de indivíduos imunes foram semelhantes para ambos os grupos, 9,2\% dos casos e $10,2 \%$ dos controles com o marcador anti-HBs (Tabela 5.4-1). Assim, neste estudo, o grupo controle apresentou prevalência de anti-HBs semelhante a primodoadores de sangue da mesma cidade (10,9\%), utilizando-se a mesma técnica sorológica (Martelli et al., 1990).

Conforme especificado no item Metodologia, os testes para deteç̧ão do antiHBs, após triagem em série com o anti-HBc, devem ser interpretados como decorrentes da infecção viral, uma vez que a vacina contra hepatite $B$ não é administrada de forma universal em nosso meio. A Tabela 5.4-8 mostra que as formas multibacilar, paucibacilar e provável de hanseníase não estiveram associadas à soropositividade ao marcador anti-HBs, indicando que a capacidade de produzir resposta protetora à infecção foi semelhante entre os subgrupos de casos e controles.

Os índices de Elisa, para o marcador anti-HBs, estão apresentados no diagrama de dispersão para as formas multibacilar (MB), paucibacilar (PB) e controle (CT), possibilitando visualizar, os níveis de anticorpos protetores ao VHB. 
Não houve diferença estatísticamente significante entre os grupos estudados aferida pelo teste de Kruskal-Wallis (Figura 5.4-1). Estes resultados reforçam as evidências obtidas pela análise dos marcadores enquanto variável dicotômica, mostrando também que a capacidade de produção de anticorpos em pacientes hansenianos de forma multibacilar não se encontra comprometida.

A maioria dos estudos do final da década de 70 e década de 80, incluiram, além do AgHBs, o marcador anti-HBs (Saha \& Dutta, 1977; Sher et al., 1977; Chiron et al., 1978a; Chiron et al., 1978b; Fakunle \& Whittle, 1981; Ree \& Talonu, 1981). A comparação entre os percentuais de indivíduos portadores com os marcadores sorológicos de exposição e imunidade estão apresentados a seguir.

Estado de portador viral - Foram positivos ao marcador AgHBs 1,3\% dos casos e $1,4 \%$ dos controles. Todos os portadores apresentaram idade superior a 17 anos e a relação entre masculinos e femininos foi de 1,8. Entre os 7 pacientes hansenianos portadores, 3 eram multibacilares, 2 paucibacilares e 2 prováveis. As prevalências de portadores ao VHB foram semelhantes às encontradas para a cidade de Goiânia em primodoadores de sangue (Martelli et al., 1991) e compativeis com áreas de baixa a média endemicidade da infecção pelo VHB.

Estudos conduzidos em diferentes regiões apresentaram mais de $8 \%$ de portadores nos controles (Chiron et al., 1978a; Nuti et al., 1979; Serjeantson \& Woodfield, 1978), indicando áreas de alta endemicidade para o vírus B. Nestas circunstâncias, a transmissão viral ocorreria precocemente durante a infância (Shapiro \& Margolis, 1990). Há dificuldades na interpretação dos resultados neste contexto porque a idade de aquisição da infecção ao VHB se constituiria no principal determinante do estado de portador (Beasley, 1988; Robinson, 1990). Edmunds et al. (1993) confirmaram que a idade precoce no momento da infecção viral determina o estado de portador, através de meta-análise das investigações populacionais conduzidas em países subdesenvolvidos e desenvolvidos. Por este motivo, a nosso ver, a idade de aquisição da infecção se constitui numa variável 
modificadora de efeito, e não uma variável de confusão passível de ajuste na análise de dados.

$\mathrm{Na}$ maioria dos estudos, a associação entre hanseníase e hepatite $\mathrm{B}$ foi avaliada em situações de sobreposição de alta endemicidade para ambas as infecções/doença, conforme mencionado por Chiron et al. (1985). A área de estudo da presente investigação, a cidade de Goiânia, caracterizada como de baixa endemicidade para o VHB, indica que a aquisição da infecção ocorre principalmente em adultos, através de transmissão sexual (Porto et al. 1994). Entre adultos, a proporção de infectados pelo VHB que evolui para estado de portador tem sido considerada muitas vezes inferior à observada na infância. O risco de se tornar um portador parece ser semelhante tanto em pacientes com quadro agudo quanto nos indivíduos com infecção subclínica (Edmunds et al., 1993).

Embora a idade de aquisição da hanseníase também se constitua em importante variável a ser considerada na avaliação da hanseníase e VHB, a ausência de um marcador de infecção ao $M$. leprae e o seu longo período de incubação permitem apenas especular sobre o papel da idade da aquisição desta infecção. Embora a hepatite B também seja considerada de longo período de incubação entre as hepatites virais, de 30 a 180 dias, a escala de tempo do período de incubação na hanseníase parece variar de 2 a 15 anos para as diferentes formas clínicas (Fine, 1982; Robinson, 1990).

Esquematicamente, estabelecer a associação entre duas doenças/infecções significa compreender os compartimentos em nível populacional, de suscetíveis, infectados/ portadores e imunes e como estas interações biológicas poderiam alterar o curso de cada uma das afecções em termos de gravidade e prognóstico (Anderson \& May, 1990). Em outras palavras, trata-se de investigar em que momento, dentro da dinâmica de propagação das infecções, esta interação biológica pode ocorrer e quais os possíveis desdobramentos em termos de prognóstico e de eficiência da transmissão (Smith et al., 1988). 
Estas considerações são particularmente importantes, porque a direcionalidade entre as variáveis de exposição e a de resposta não pode ser determinada neste tipo de delineamento. As prevalências dos marcadores sorológicos da hepatite B - de infecção, de imunidade e de estado de portador - foram avaliadas como similares para as formas $\mathrm{MB}, \mathrm{PB}$ e PR. Porém, não é possível estabelecer se formas de hanseníase constituem grupos de risco para estado de portador ou viceversa. Limitações sobre a classificação de hanseníase, marcadores de infecção e simultaneidade das medidas de exposição e resposta em estudos de caso-controle encontram-se discutidas no item Considerações Metodológicas.

Os cálculos dos índices de probabilidade de persistência de infecção (PPI), que levam em conta o número de portadores dividido pelo total dos marcadores positivos foram de 0,044 e 0,046 para o grupo de casos e controles, respectivamente. O PPI para as diferentes formas foi de 0,044 - MB; 0,032 - PB; 0,071 -PR. Estes indices foram baixos, podendo ser interpretados como resposta imune-humoral adequada, com formação de anticorpos protetores ao VHB, indicando clearance do antígeno entre os diferentes subgrupos de casos e os controles.

Esta característica de baixos PPI em subgrupos de casos e controles foi também encontrada no estudo de caso-controle de Papaioannou et al. (1986) para pacientes "lepromatosos", tuberculóides e controles, em concordância com os resultados deste estudo. Serjeantson \& Woodfield (1975) obtiveram resultados divergentes, concluindo que o subgrupo dos "lepromatosos" apresentaram uma resposta imunológica deficiente, que não só os predispunha às formas mais graves de hanseníase, mas também diminuiria a capacidade de produção de anticorpos protetores. Outros estudos, para os quais foi possível calcular o índice de resposta humoral, mostraram resultados variáveis, e a comparação com o presente estudo fica dificultada, devido às diferenças na sensibilidade e especificidade das técnicas empregadas (Saha \& Dutta, 1977; Sher et al., 1977; Ree \& Talonu, 1981; Fakunle \& Whittle, 1981; Chiron et al., 1985). Parece-nos sem objetivo comparar 
exaustivamente os estudos da literatura com os dados obtidos. Isto porque, variações na prevalência de exposição ao VHB em diferentes grupos populacionais parecem refletir mais os diferentes critérios de seleção de participantes e a endemicidade ao VHB da região de estudo que propriamente a possibilidade de interação biológica entre hanseníase e VHB.

Os resultados obtidos nesta investigação mostraram que: (i) os subgrupos de casos e controles apresentaram prevalências semelhantes dos marcadores de exposição, de imunidade e de estado de portador; (ii) houve capacidade similar entre casos e controles para produção de anticorpos protetores, avaliada através dos percentuais do marcador anti-HBs e quantitativamente através do Índice de Elisa e (iii) houve ainda baixa probabilidade de persistência da antigenemia mensurada pelo PPI. Em síntese, não houve evidências epidemiológicas de uma associação entre hanseníase e infeç̧ão pelo vírus da hepatite $B$, quando esta associação foi avaliada através de estudo de caso-controle, conduzido em área de baixa endemicidade ao VHB e alta endemicidade de hanseníase. 
Tabela 5.4-1

Distribuição de marcadores sorológicos para a infecção pelo vírus da hepatite B entre casos e controles.

\begin{tabular}{|c|c|c|c|c|}
\hline \multirow[t]{2}{*}{$\begin{array}{l}\text { Marcadores } \\
\text { Sorológicos }\end{array}$} & \multicolumn{2}{|c|}{$\begin{array}{l}\text { Casos } \\
(552)\end{array}$} & \multicolumn{2}{|c|}{$\begin{array}{c}\text { Controles } \\
(552)\end{array}$} \\
\hline & № & $\%$ & № & $\%$ \\
\hline \multicolumn{5}{|l|}{ Exposiçãoa } \\
\hline Anti-HBc (+) & 100 & 18,1 & 108 & 19,6 \\
\hline \multicolumn{5}{|l|}{ Imunidade ${ }^{b}$} \\
\hline anti-HBs $(+)$ & 51 & 9,2 & 56 & 10,2 \\
\hline \multicolumn{5}{|l|}{ Portadores } \\
\hline AgHBs $(+)$ & 7 & 1,3 & 8 & 1,4 \\
\hline
\end{tabular}

a 7 casos limítrofes considerados positivos, 8 casos e 2 controles sem resultados sorológicos

b 3 controles sem resultados sorológicos 
Tabela 5.4-2

Odds ratio (OR) e intervalo de $95 \%$ de confiança (IC 95\%) para formas multibacilares, paucibacilares e casos prováveis de hanseníase em relação ao marcador anti-HBc do vírus da hepatite $\mathrm{B}$.

\begin{tabular}{llccccc}
\hline & & \multicolumn{2}{c}{ anti-HBc } & & \\
\cline { 3 - 5 } Categoria & & $(-)$ & $(+)$ & OR & $($ IC 95\%) \\
\hline Controles & $(0)$ & 442 & 108 & 1 & \\
Multibacilar & $(1)$ & 131 & 42 & 1,3 & $(0,9-2,0)$ \\
Paucibacilar & $(2)$ & 238 & 40 & 0,7 & $(0,4-1,0)^{\mathrm{a}}$ \\
Provável & $(3)$ & 75 & 18 & 1,0 & $(0,5-1,8)$ \\
\hline
\end{tabular}

Registros sem resultados de anti-HBc: 2 controles, 1 multibacilar, 5 paucibacilar e 2 prováveis

${ }^{a} \mathrm{p}=0,07$

$$
\begin{aligned}
& \Psi_{(1,0)}=\frac{42 \times 442}{131 \times 108}=1,3 \\
& \Psi_{(2,0)}=\frac{40 \times 442}{238 \times 108}=0,7 \\
& \Psi_{(3,0)}=\frac{18 \times 442}{75 \times 108}=1,0
\end{aligned}
$$


Tabela 5.4-3

Número de casos multibacilares associados ao marcador anti-HBc estratificados por idade; sexo, hospitalização e cicatriz de BCG, com os respectivos odds ratio (OR) e intervalo de $95 \%$ de confiança (IC 95\%).

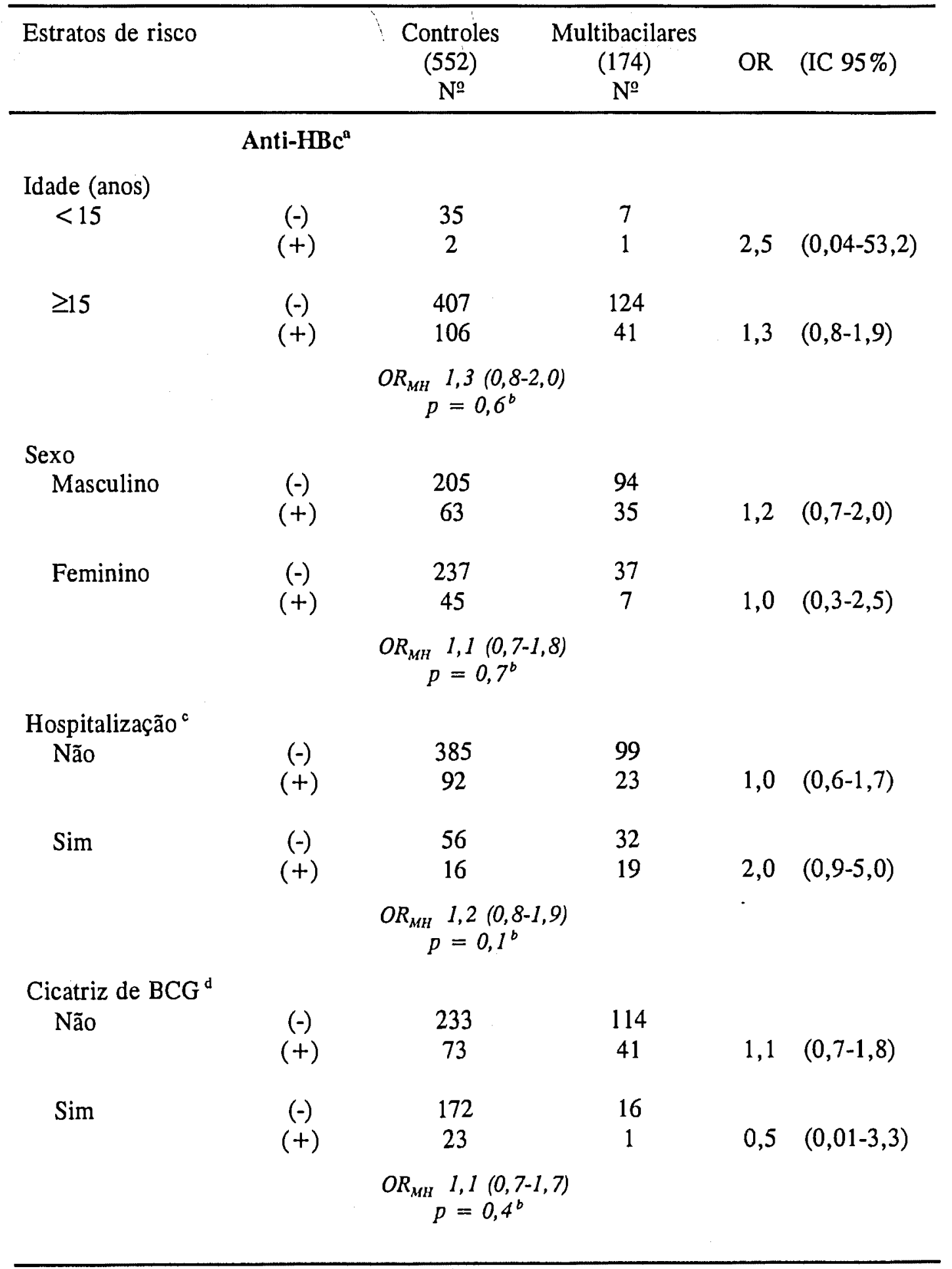

a Registros sem resultados de anti-HBc: 2 controles, 1 multibacilar

b Teste Woolf de heterogeneidade entre estratos;

${ }^{c}$ Hospitalização nos últimos 5 anos. 3 controles sem informação

d 51 controles e 2 multibacilares sem informação. 
Tabela 5.4-4

Número de casos paucibacilares associados ao marcador anti- $\mathrm{HBc}$ estratificados por idade, sexo, hospitalização e cicatriz de BCG, com os respectivos odds ratio (OR) e intervalo de $95 \%$ de confiança (IC $95 \%$ ).

\begin{tabular}{|c|c|c|c|c|c|}
\hline Estratos de risco & & $\begin{array}{c}\text { Controles } \\
(552) \\
\mathrm{N}^{2}\end{array}$ & $\begin{array}{l}\text { Paucibacilares } \\
\text { (283) } \\
\text { № }\end{array}$ & OR & (IC 95\%) \\
\hline & Anti-HBc ${ }^{a}$ & & & & \\
\hline $\begin{array}{l}\text { Idade (anos) } \\
\quad<15\end{array}$ & $\begin{array}{l}(-) \\
(+)\end{array}$ & $\begin{array}{c}35 \\
2\end{array}$ & $\begin{array}{c}24 \\
1\end{array}$ & 0,7 & $(0,01-14,8)$ \\
\hline$\geq 15$ & $\begin{array}{l}(-) \\
(+)\end{array}$ & $\begin{array}{l}407 \\
106\end{array}$ & $\begin{array}{c}214 \\
39\end{array}$ & 0,7 & $(0,5-1,1)$ \\
\hline \multicolumn{6}{|c|}{$\begin{array}{c}O R_{M H} 0,7(0,5-1,1) \\
p=0,9^{b}\end{array}$} \\
\hline $\begin{array}{l}\text { Sexo } \\
\quad \text { Masculino }\end{array}$ & $\begin{array}{l}(-) \\
(+)\end{array}$ & $\begin{array}{c}205 \\
63\end{array}$ & $\begin{array}{l}84 \\
16\end{array}$ & 0,6 & $(0,3-1,2)$ \\
\hline Feminino & $\begin{array}{l}(-) \\
(+)\end{array}$ & $\begin{array}{c}237 \\
45\end{array}$ & $\begin{array}{l}154 \\
24\end{array}$ & 0,8 & $(0,5-1,4)$ \\
\hline \multicolumn{6}{|c|}{$\begin{array}{c}O R_{M H} 0,7(0,5-1,1) \\
p=0,5^{b}\end{array}$} \\
\hline $\begin{array}{l}\text { Hospitalização }{ }^{c} \\
\text { Não }\end{array}$ & $\begin{array}{l}(-) \\
(+)\end{array}$ & $\begin{array}{c}385 \\
92\end{array}$ & $\begin{array}{l}198 \\
27\end{array}$ & 0,6 & $(0,4-0,9)$ \\
\hline Sim & $\begin{array}{l}(-) \\
(+)\end{array}$ & $\begin{array}{l}56 \\
16\end{array}$ & $\begin{array}{l}40 \\
13\end{array}$ & 1,1 & $(0,4-2,8)$ \\
\hline \multicolumn{6}{|c|}{$\begin{array}{c}O R_{M H} 0,7(0,4-1,0) \\
p=0,2^{b}\end{array}$} \\
\hline $\begin{array}{l}\text { Cicatriz de BCG }{ }^{d} \\
\text { Não }\end{array}$ & $\begin{array}{l}(-) \\
(+)\end{array}$ & $\begin{array}{c}233 \\
73\end{array}$ & $\begin{array}{l}175 \\
35\end{array}$ & 0,6 & $(0,4-1,0)$ \\
\hline Sim & $\begin{array}{l}(-) \\
(+)\end{array}$ & $\begin{array}{l}172 \\
23\end{array}$ & $\begin{array}{c}59 \\
5\end{array}$ & 0,6 & $(0,2-1,8)$ \\
\hline \multicolumn{6}{|c|}{$\begin{array}{c}O R_{M H} 0,6(0,4-1,0) \\
p=0,9^{b}\end{array}$} \\
\hline
\end{tabular}

${ }^{a} 7$ participantes sem sorologia: 2 controles e 5 paucibacilares;

${ }^{b}$ Teste Woolf de heterogeneidade entre estratos;

c 3 controles e 5 paucibacilares sem informação;

d 51 controles e 9 paucibacilares sem informação. 
Tabela 5.4-5

Número de casos prováveis associados ao marcador anti-HBc estratificados por idade, sexo, hospitalização e cicatriz de $\mathrm{BCG}$, com os respectivos odds ratio (OR) e intervalo de $95 \%$ de confiança (IC 95\%).

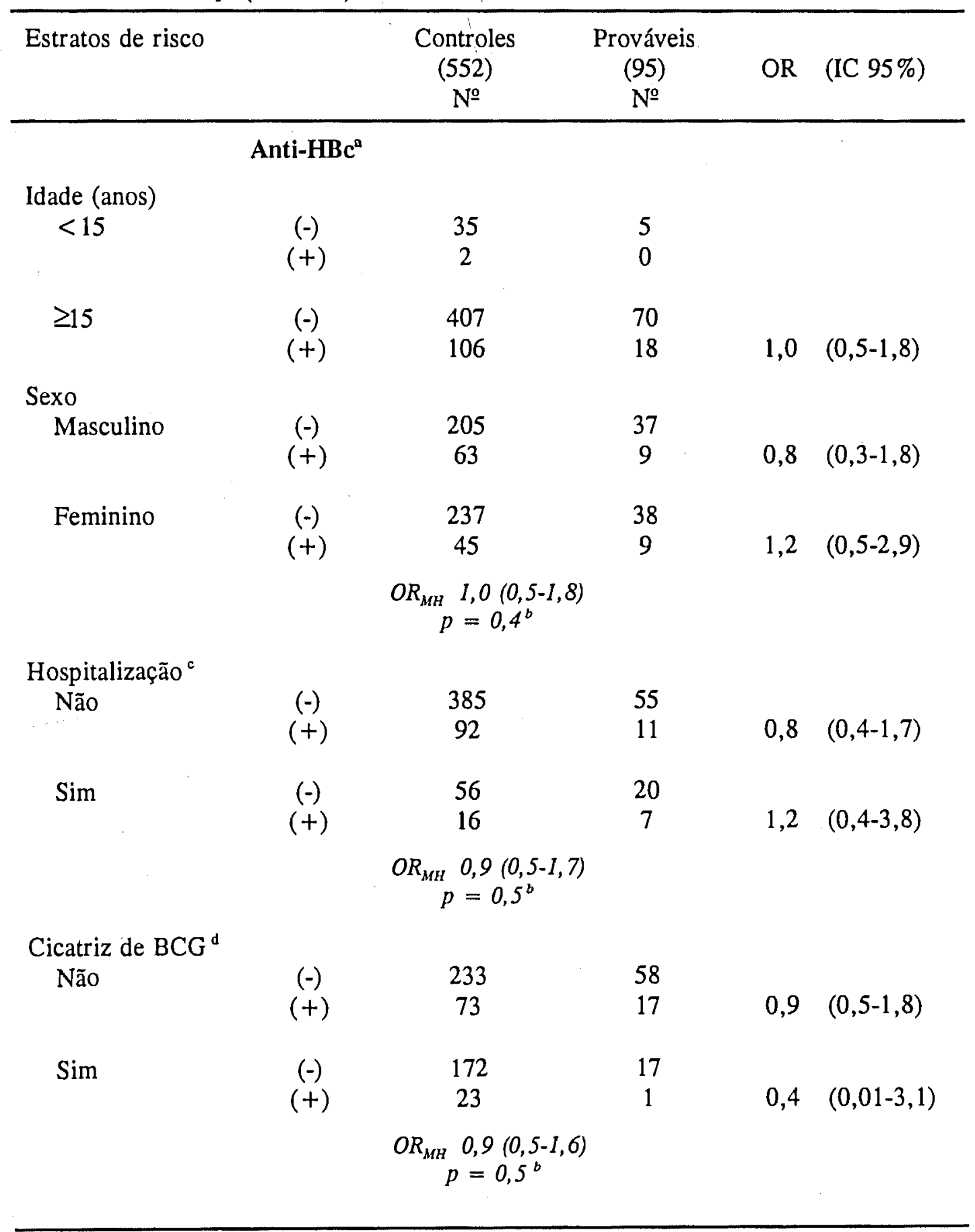

a Registros sem informação: 2 casos e 2 controles;

- Teste Woolf de heterogeneidade entre estratos;

- 4 controles e 2 casos sem informação;

d 51 controles e 2 casos sem informação. 
Tabela 5.4-6

Coeficiente de regressão e odds ratio resultante de modelo de regressão logística com variável de resposta politômica.

\begin{tabular}{|c|c|c|c|c|c|}
\hline & Variáveis $^{\mathfrak{a}}$ & Coeficiente & $\begin{array}{l}\text { Erro } \\
\text { Padrão }\end{array}$ & OR & $\mathrm{p}$ \\
\hline Multibacilar (1) & $\begin{array}{l}\text { anti-HBc } \\
\text { Idade } \\
\text { Sexo } \\
\text { Hospitalização } \\
\text { Cicatriz de BCG }\end{array}$ & $\begin{array}{r}-0,0452 \\
-0,3408 \\
0,0095 \\
0,5101 \\
-0,4186\end{array}$ & $\begin{array}{l}0,1401 \\
0,2143 \\
0,1405 \\
0,1356 \\
0,1354\end{array}$ & $\begin{array}{l}0,95 \\
0,71 \\
1,01 \\
1,66 \\
0,66\end{array}$ & $\begin{array}{c}0,74 \\
0,11 \\
0,95 \\
<0,001 \\
0,002\end{array}$ \\
\hline Interação & $\begin{array}{l}\text { Anti-HBc x idade } \\
\text { AntiHBc x sexo }\end{array}$ & $\begin{array}{r}0,3901 \\
-0,1061\end{array}$ & $\begin{array}{l}0,3041 \\
0,1393\end{array}$ & $\begin{array}{l}1,48 \\
0,98\end{array}$ & $\begin{array}{l}0,20 \\
0,44\end{array}$ \\
\hline Constante & & 1,1910 & - & - & - \\
\hline Paucibacilar (2) & $\begin{array}{l}\text { anti-HBc } \\
\text { Idade } \\
\text { Sexo } \\
\text { Hospitalização } \\
\text { Cicatriz de BCG }\end{array}$ & $\begin{array}{r}-0,0250 \\
0,0313 \\
0,5792 \\
-0,0482 \\
0,3731\end{array}$ & $\begin{array}{l}0,1673 \\
0,2447 \\
0,1672 \\
0,1477 \\
0,1736\end{array}$ & $\begin{array}{l}0,97 \\
1,03 \\
1,78 \\
0,95 \\
1,45\end{array}$ & $\begin{array}{l}0,88 \\
0,90 \\
<0,001 \\
0,74 \\
0,03\end{array}$ \\
\hline Interação & $\begin{array}{l}\text { Anti-HBc } x \text { idade } \\
\text { AntiHBc x sexo }\end{array}$ & $\begin{array}{r}0,0657 \\
-0,0745\end{array}$ & $\begin{array}{l}0,3136 \\
0,1661\end{array}$ & $\begin{array}{l}1,07 \\
0,93\end{array}$ & $\begin{array}{l}0,83 \\
0,65\end{array}$ \\
\hline Constante & & 0,2609 & - & - & - \\
\hline Prováveis (3) & $\begin{array}{l}\text { anti-HBc } \\
\text { Idade } \\
\text { Sexo } \\
\text { Hospitalização } \\
\text { Cicatriz de BCG }\end{array}$ & $\begin{array}{r}0,1300 \\
-0,0539 \\
-0,2809 \\
0,2909 \\
-0,0466\end{array}$ & $\begin{array}{l}0,1520 \\
0,2207 \\
0,1535 \\
0,1389 \\
0,1473\end{array}$ & $\begin{array}{l}1,14 \\
0,95 \\
0,75 \\
1,34 \\
0,95\end{array}$ & $\begin{array}{l}0,39 \\
0,81 \\
0,07 \\
0,04 \\
0,75\end{array}$ \\
\hline Interação & $\begin{array}{l}\text { Anti-HBc } \times \text { idade } \\
\text { Anti-HBc } \times \text { sexo }\end{array}$ & $\begin{array}{r}0,1349 \\
-0,0211\end{array}$ & $\begin{array}{l}0,3066 \\
0,1514\end{array}$ & $\begin{array}{l}1,14 \\
0,98\end{array}$ & $\begin{array}{l}0,66 \\
0,89\end{array}$ \\
\hline Constante & & 0,7070 & - & - & - \\
\hline
\end{tabular}

${ }^{\text {a } I d a d e ~}<15$ anos e $\geq 15$ anos 
Tabela 5.4-7

Coeficiente de regressão e odds ratio resultante de modelo de regressão logística para casos multibacilares, paucibacilares e prováveis.

\begin{tabular}{|c|c|c|c|c|c|}
\hline & Variáveis & Coeficiente & $\begin{array}{l}\text { Erro } \\
\text { Padrão }\end{array}$ & OR & $\mathrm{p}$ \\
\hline Multibacilar (1) & $\begin{array}{l}\text { anti-HBc } \\
\text { Idade } \\
\text { Sexo } \\
\text { Hospitalização } \\
\text { Cicatriz de BCG }\end{array}$ & $\begin{array}{r}0,0347 \\
-0,0941 \\
-1,3380 \\
1,0500 \\
-1,9470\end{array}$ & $\begin{array}{l}0,73 \\
0,45 \\
0,68 \\
0,24 \\
0,29\end{array}$ & $\begin{array}{l}1,03 \\
0,91 \\
0,26 \\
2,86 \\
0,14\end{array}$ & $\begin{array}{c}0,96 \\
0,84 \\
0,05 \\
<0,001 \\
<0,001\end{array}$ \\
\hline Interação & $\begin{array}{l}\text { anti-HBc } \times \text { idade } \\
\text { anti-HBc } \times \text { sexo }\end{array}$ & $\begin{array}{l}0,0079 \\
0,1026\end{array}$ & $\begin{array}{r}0,005 \\
0,54\end{array}$ & $\begin{array}{l}0,99 \\
1,11\end{array}$ & $\begin{array}{l}0,15 \\
0,85\end{array}$ \\
\hline Constante & & 2,1980 & - & - & - \\
\hline Paucibacilar (2) & $\begin{array}{l}\text { anti-HBc } \\
\text { Idade } \\
\text { Sexo } \\
\text { Hospitalização } \\
\text { Cicatriz de BCG }\end{array}$ & $\begin{array}{c}-0,6085 \\
-0,3923 \\
0,0292 \\
0,4449 \\
-0,8971\end{array}$ & $\begin{array}{l}0,71 \\
0,31 \\
0,52 \\
0,21 \\
0,19\end{array}$ & $\begin{array}{l}0,54 \\
0,67 \\
1,03 \\
1,56 \\
0,41\end{array}$ & $\begin{array}{c}0,39 \\
0,21 \\
0,95 \\
0,04 \\
<0,001\end{array}$ \\
\hline Interação & $\begin{array}{l}\text { anti-HBc } \times \text { idade } \\
\text { anti-HBc } \times \text { sexo }\end{array}$ & $\begin{array}{r}-0,0089 \\
0,3960\end{array}$ & $\begin{array}{r}0,005 \\
0,43\end{array}$ & $\begin{array}{l}0,99 \\
1,49\end{array}$ & $\begin{array}{l}0,07 \\
0,36\end{array}$ \\
\hline Constante & & 1,1110 & - & - & - \\
\hline Prováveis (3) & $\begin{array}{l}\text { anti-HBc } \\
\text { Idade } \\
\text { Sexo } \\
\text { Hospitalização } \\
\text { Cicatriz de BCG }\end{array}$ & $\begin{array}{r}-0,8595 \\
0,1391 \\
-0,8838 \\
1,0590 \\
-1,0770\end{array}$ & $\begin{array}{l}0,95 \\
0,54 \\
0,74 \\
0,27 \\
0,30\end{array}$ & $\begin{array}{l}0,42 \\
1,15 \\
0,41 \\
2,88 \\
0,34\end{array}$ & $\begin{array}{c}0,37 \\
0,80 \\
0,23 \\
<0,001 \\
<0,001\end{array}$ \\
\hline Interação & $\begin{array}{l}\text { anti-HBc } \times \text { idade } \\
\text { anti-HBc } \times \text { sexo }\end{array}$ & $\begin{array}{r}-0,0067 \\
0,6564\end{array}$ & $\begin{array}{l}0,01 \\
0,59\end{array}$ & $\begin{array}{l}0,99 \\
1,93\end{array}$ & $\begin{array}{l}0,33 \\
0,27\end{array}$ \\
\hline Constante & & $-0,3787$ & - & - & - \\
\hline
\end{tabular}

Análise de regressão logística não condicional.

Multibacilares $(\mathrm{N}=173)$ e Controles $(\mathrm{N}=552)$;

Paucibacilares $(\mathrm{N}=278)$ e Controles $(\mathrm{N}=552)$;

Prováveis $(\mathrm{N}=93)$ e Controles $(\mathrm{N}=552)$. 
Tabela 5.4-8

Odds ratio (OR) e intervalo de $95 \%$ de confiança (IC 95\%) para formas multibacilares, paucibacilares e casos prováveis de hanseníase em relação ao marcador anti-HBs do vírus da hepatite $B$.

\begin{tabular}{|c|c|c|c|c|c|}
\hline \multirow{2}{*}{ Categorias } & & \multicolumn{2}{|c|}{ anti-HBs } & \multirow[b]{2}{*}{ OR } & \multirow[b]{2}{*}{ (IC 95\%) } \\
\hline & & $(-)$ & $(+)$ & & \\
\hline Controles & $(0)^{a}$ & 492 & 56 & 1 & \\
\hline Multibacilar & (1) & 151 & 23 & 1,3 & $(0,8-2,3)$ \\
\hline Paucibacilar & (2) & 263 & 20 & 0,7 & $(0,4-1,2)$ \\
\hline Provável & (3) & 87 & 8 & 0,8 & $(0,3-1,8)$ \\
\hline
\end{tabular}

a 3 controles sem resultados de anti-HBs

$$
\begin{gathered}
\Psi_{(1,0)}=\frac{23 \times 492}{151 \times 56}=1,3 \\
\Psi_{(2,0)}=\frac{20 \times 492}{263 \times 56}=0,7 \\
\Psi_{(3,0)}=\frac{8 \times 492}{87 \times 56}=0,8
\end{gathered}
$$


Figura 5.4-1

Índice de Elisa para o marcador sorológico anti-HBs de acordo com as formas clínicas de hanseníase

Indice de ELISA

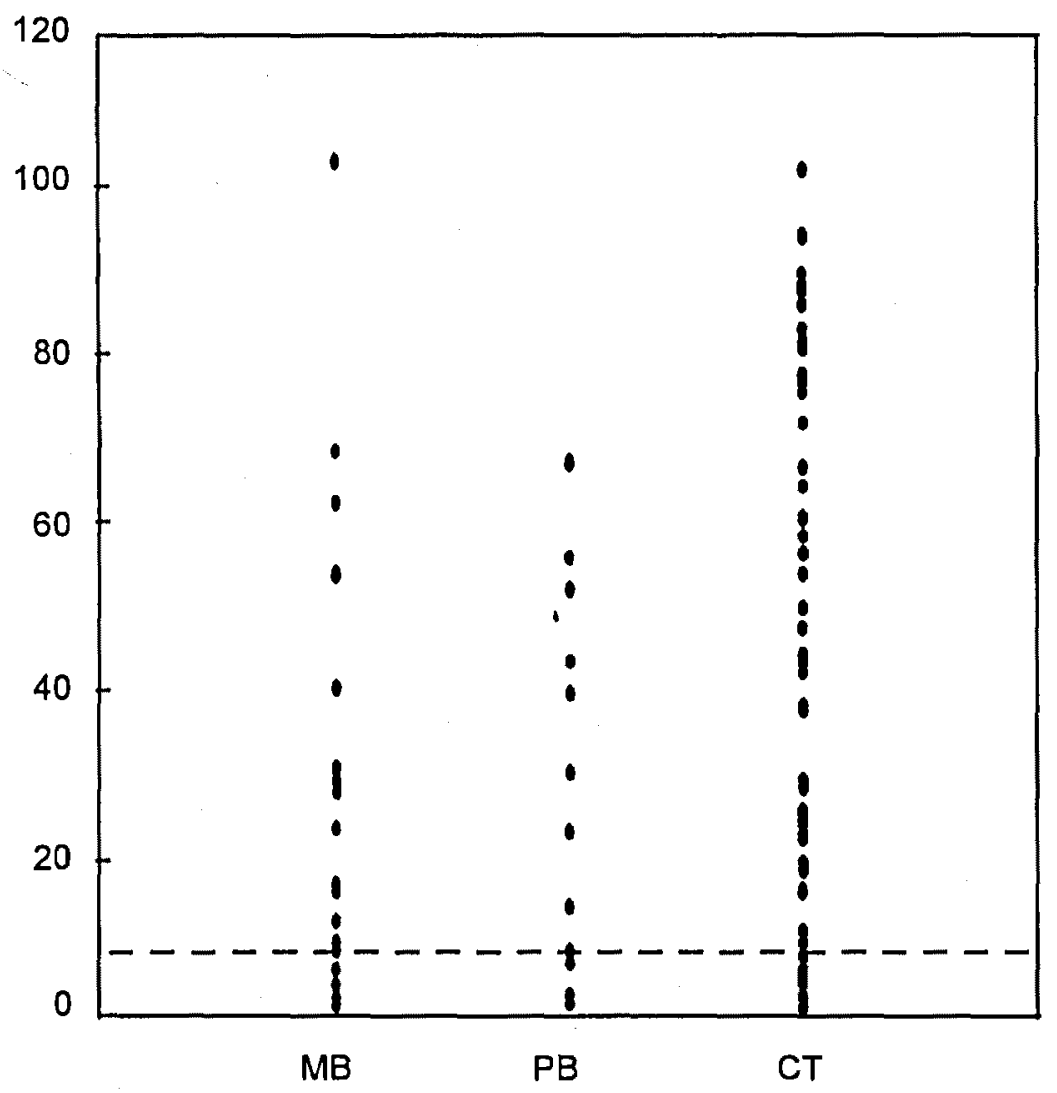

$\mathrm{MB}=$ Multibacilar

$\mathrm{PB}=$ Paucibacilar

$\mathrm{CT}=$ Controles 


\subsection{Considerações Metodológicas}

Ao interpretar os resultados desse estudo de caso-controle procurou-se levar em consideração as limitações inerentes ao tipo de delineamento, aos potenciais viéses de seleção de casos e controles, aos erros de medidas das variáveis de exposição e de efeito e as opções de análise de dados. Assim, os recursos metodológicos utilizados no presente estudo para minimizar estas limitações, bem como as vantagens do emprego da metodologia tipo caso-controle na presente investigação, são discutidos neste item.

\section{Delineamento e seleção de casos de hanseníase}

Entre as vantagens dos estudos de caso-controle destaca-se a eficiência deste tipo de delineamento para doenças raras e de longos períodos de incubação (Schlesselman, 1982; Henneckens \& Buring, 1987; Selby, 1994). A hanseníase apresenta ambas as características, pois pode ser considerada doença rara do ponto de vista populacional e apresenta longo e variável período de incubação de acordo com as formas clínicas (Fine, 1982; Noordeen, 1995). Desta forma, a seleção de casos através de inquéritos populacionais e/ou a opção pelo delineamento de coorte foram consideradas inviáveis do ponto de vista operacional, mesmo nesta região de alta endemicidade.

Pode parecer um contra-senso na perspectiva clínica diagnosticar 600 casos novos de hanseníase em um ano, e caracterizar este evento como doença rara. Em estudos epidemiológicos avalia-se, além do numerador (casos), o denominador, isto é, a população sob risco de adoecer da qual os casos se originaram (Rose \& Barker, 1986; Victora, 1993; Grisso, 1993). Assim, em um contexto de um (1) por 1000 hab. de prevalência deveriam ser examinados 96000 (amostra aleatória simples) ou 384000 (amostra por conglomerado). Opromolla et al., (1990) estimou prevalências de hanseníase em 10000 indivíduos da demanda de ambulatório geral na cidade de 
Taubaté, São Paulo, sendo detectados 40 casos de hanseníase. Talhari et al., (1987) em mais de 100000 escolares examinados em área de prevalência da hanseníase de 12 por 1000 hab. diagnosticaram 107 casos novos. Portanto, a opção de utilizar a demanda espontânea de ambulatório especializado de dermatologia, população de maior risco de adoecimento, apresenta vantagens operacionais óbvias.

Hospitais e ambulatórios especializados têm-se constituído em fontes típicas para selecionar casos de doenças pouco freqüentes na população em estudos de caso-controle. Conceitualmente, o estudo de caso-controle pode ser visto como sendo uma coorte da qual casos e controles são originários. Um aspecto a ser valorizado é a definição metodológica rigorosa da base populacional neste tipo de delineamento (Rodrigues \& Kirkwood, 1990; Gail, 1991; Clayton \& Hills, 1993). Neste estudo, o local de residência dos pacientes foi o critério de elegibilidade utilizado para delimitar espacialmente a área de estudo, e para selecionar controles. Assim, foram excluídos $27 \%$ (231/855) dos pacientes não residentes na área de estudo (Goiânia e municípios do aglomerado). Nesta estratégia adotada, em analogia aos registros de cânceres de base populacional e aos registros de mortalidade, procurou-se minimizar o efeito da invasão de pacientes de outras localidades, em decorrência da oferta de serviços de saúde especializados, em grandes centros urbanos.

Idealmente, o estudo deveria abranger todos os casos novos de hanseníase da área urbana de Goiânia. Em estudo anterior, Martelli et al. (1995a) mostraram que no CSJB foram atendidos $80 \%$ dos casos recém-diagnosticados na região, sendo esta população considerada amostra representativa dos casos notificados do município. A preocupação metodológica com a seleção de casos em centros especializados seria a obtenção de amostra incompleta da população alvo, tanto do ponto de vista de morbidade (tipos de hanseníase e gravidade da doença) quanto de acesso aos serviços de saúde, o que interfereriria na validade externa, isto é, na generalização dos resultados do estudo (Henneckens \& Buring, 1987; Sitthi-amorn \& Poshyachinda, 1993). Os resultados obtidos neste estudo mostraram diversidade 
dos casos quanto à forma clínica, sendo cerca de metade dos pacientes do sexo feminino. Ao contrário do padrão de uso dos serviços de saúde descrito para países asiáticos e africanos (Bertolli, 1994), em nosso meio ocorre predomínio de mulheres entre usuários dos serviços de saúde pública (Silva et al., 1995, Carvalho et al., 1988), o que fala contra uma sub-representatividade de pacientes do sexo feminino por razões culturais e/ou de acesso diferencial aos serviços de saúde. Por outro lado, devido à baixa condição sócio-econômica dos pacientes, pressupõe-se uma pequena perda de casos. Parece improvável a existência de vício de seleção devido a captação parcial e/ou diferencial da população de alvo.

A identificação dos casos em instituições de saúde não implicou em utilização de dados secundários. Tanto o exame clínico como os exames laboratoriais foram realizados, independentemente da rotina, para minimizar viéses de classificação dos participantes, casos e controles, em decorrência das variações inter-observadores inerentes à prática clínica e laboratorial da rotina de atendimento.

\section{Critérios para definição e classificação de Caso}

A problemática de seleção do caso pode ser esquematizado em duas etapas: definir conceitualmente o caso e identificá-lo operacionalmente. Assim, definição de casos e fonte de casos são geralmente estabelecidas pelos critérios de elegibilidade do estudo (Henneckens \& Buring, 1987; Lasky \& Stolley, 1994). Se estas são questões teóricas de ordem geral em estudos de caso-controle, representam um problema para os epidemiologistas nas investigações em hanseníase. Entre os entraves na conceituação dos casos pode-se citar a ausência de marcadores de infecção, de um padrão de referência ouro para definição de casos e das diferentes classificações de hanseníase existentes.

O Guia Epidemiológico do Ministério da Saúde divide os casos de hanseníase em: "suspeitos" na presença de um ou mais sinais clínicos, e "confirmados" quando além de achados clínicos há positividade aos exames 
baciloscópicos e/ou histopatológicos e/ou história epidemiológica de contato (Pereira \& Penna, 1994). No entanto, a definição de hanseníase adotada pelo Programa de Controle da Hanseníase ( $\mathrm{PCH}$ ), privilegia os critérios clínicos - "um caso de hanseníase é uma pessoa apresentando sinais clínicos da doença, com ou sem confirmação bacteriológica do diagnóstico, e requerendo quimioterapia", conforme o Comitê de Peritos da OMS (WHO, 1988). Enfatiza ainda que a "clínica prevalece soberana" na definição de caso para fins de tratamento (Ministério da Saúde, 1994a). Está bem estabelecido que critérios clínicos exclusivos apresentam, em geral, alta sensibilidade em detrimento da especificidade diagnóstica (Galen \& Gambino, 1975; Sheps \& Schechter, 1984; Mertens, 1993). Segundo Brenner \& Savitz (1990), a adoção acrítica de critérios clínicos, sem padronização, no recrutamento de casos em estudos de caso-controle de base hospitalar e/ou ambulatorial pode comprometer a validade da investigação. Esses autores recomendam que "se diversos procedimentos diagnósticos estão disponíveis, a especificidade do diagnóstico de caso deve ter prioridade sobre a sensibilidade" embora possa haver algum prejuízo de precisão pela diminuição do número de casos. Portanto, neste estudo a triagem em série - triagem clínica inicial e posterior realização de exames bacteriológico e histopatológico - visou aumentar a especificidade do diagnóstico de hanseníase, além de garantir padronização, com a categorização de casos em multibacilares, paucibacilares e prováveis.

Uma restrição na avaliação de caso em hanseníase advém do fato de que procedimentos invasivos podem ser obtidos, por razões éticas e práticas, apenas para os indivíduos considerados clinicamente suspeitos. Analogamente à hanseníase, também nos registros de câncer, apenas os casos suspeitos são submetidos a exames confirmatórios, enquanto para os demais participantes da coorte a ausência de doença não é confirmada (Brenner \& Gefeller, 1993). Nestas circuntâncias, apenas o Valor Preditivo Positivo (VPP) da suspeição diagnóstica pode ser estimado, e não a sensibilidade e a especificidade. $\mathrm{O} \mathrm{VPP}_{1}$ do diagnóstico clínico de hanseníase, pela definição de caso adotada pelo estudo, foi calculado em 72,0\% [(188 MB + 311 $\mathrm{PB} / 624$ casos em potencial], quando se estabelece qualquer dos exames 
confirmatórios como padrão ouro de referência. Alternativamente, $\mathrm{VPP}_{2}$ de $87,0 \%$ $[(188 \mathrm{MB}+311 \mathrm{~PB}+44 \mathrm{PR}$ com contatos) / 624 casos em potencial], poderia ser calculado utilizando os parâmetros de definição de casos confirmados preconizados pelo citado Guia Epidemiológico. A inclusão dos 44 casos prováveis com história de contato como confirmados, significa um acréscimo de $15,0 \%$ no $\mathrm{VPP}_{1}$ e redução de $28,0 \%$ dos falso-positivos para $15,0 \%$. Considerando-se que tanto o exame baciloscópico quanto o exame histopatológico são técnicas diagnósticas mais específicas do que sensíveis, acredita-se que qualquer dos resultados dos VPPs seja conservador, o que indicaria que os percentuais de falsos-positivos possam, de fato, ser menor que os estimados. Vale ressaltar, que casos recrutados em "locais especializados", como o CSJB, apresentam em geral, altos valores preditivos positivos (VPP) devido à maior prevalência da doença na demanda referida (Galen \& Gambino, 1975; Sheps \& Schechter, 1984).

Aspectos referentes à imprecisão diagnóstica, como aferição de sintomas subjetivos ou semi-objetivos, e mesmo a controvérsia quanto à classificação, não é exclusividade da hanseníase. Também em outras doenças a valorização de sintomas de difícil mensuração podem predominar no critério diagnóstico em conjunto com exames complementares, constituindo-se gradientes de certeza e/ou de gravidade (Jones et al., 1993; Scollard, 1993). A construção de algorítmos para caracterizar casos de hanseníase conforme grau de certeza diagnóstica foi proposto por Ponnighaus et al. (1987) em estudo populacional no Malaui, e vem sendo citado como exemplo para caracterizar sub-grupos homogêneos de casos para finalidade de análise (Smith et al., 1988).

A inclusão somente de casos virgens de tratamento específico, recém-diagnosticados, visou à aproximação dos "casos incidentes" da doença. Admite-se que, para os casos "novos", as informações obtidas quanto ao local/moradia, às condições sócio-econômicas, às características de uso dos serviços de saúde e aos fatores de risco ambientais refletem as condições pré-diagnóstico. Pacientes com maior tempo de doença poderiam desenvolver incapacidades físicas. 
Adicionalmente a natureza estigmatizante da doença poderia alterar as condições de vida dos pacientes, invertendo a direção da associação estudada entre as condições sócio-econômicas (variáveis de exposição) e a hanseníase (variável de efeito).

Outra vantagem de se utilizar "casos incidentes" é que estes não sofrem variações dos critérios diagnósticos com o tempo, em conseqüência a modismos diagnósticos. Convém lembrar que mesmo utilizando-se de casos "recémdiagnosticados", à semelhança da AIDS, o longo e insidioso período de incubação da doença pode não evitar a tendenciosidade de lembrança no que tange às características de exposição na aquisição da infecção (Rothman, 1986; Alcabes et al., 1993).

Critério de elegibilidade e fonte de seleção de controles

A seleção de controles, talvez, seja um dos tópicos mais discutidos e enfatizados como uma fonte potencial de viés em estudos de caso-controle. Uma das regras básicas é selecionar controles semelhantes em tudo ao caso, exceto na variável de exposição que se quer estudar (Sacket, 1979; Breslow \& Day, 1980; Rodrigues \& Kirkwood, 1990; Wacholder et al., 1992a; Wacholder et al., 1992b; Wacholder et al., 1992c; Sitthi-amorn \& Poshyachinda, 1993; Clayton \& Hills, 1993).

Considerando-se que os casos de hanseníase foram restritos aos residentes na cidade de Goiânia e área conurbada, os limites geográficos desses municípios identificaram a base espacial de estudo, ou da coorte subjacente em que este estudo de caso-controle está inserido. Assim, residir em Goiânia constituiu um dos critérios de elegibilidade para seleção dos controles.

Em decorrência do padrão de distribuição intra-urbana dos casos, caracterizado por grande dispersão, a opção de selecionar controles aleatoriamente da população e/ou de vizinhança acarretaria em trabalho de campo complexo e de 
alto custo. Em países subdesenvolvidos, estudos de caso-controle em doenças infecciosas indicaram que controles de vizinhança podem não garantir o emparelhamento sócio-econômico dos grupos, reforçando a propriedade de seleção de controles ambulatoriais. Em outras palavras, indivíduos que utilizam o mesmo tipo de serviço de saúde tendem a compartilhar condições de vida semelhantes. Ao contrário, o crescimento desordenado das cidades, com desenvolvimento rápido das periferias urbanas pode ocasionar uma certa heterogeneidade sócio- econômica na mesma vizinhança (Cousens, et al., 1988; Wacholder et al., 1992b). Este estudo mostrou que os controles ambulatoriais, selecionados de serviços de saúde localizados na área de procedência dos casos, apresentavam características sóciodemográficas similares aos casos. A preocupação com o balanceamento sócioeconômico dos grupos deve-se à necessidade de controlar as potenciais variáveis de confusão relacionadas à fatores ambientais, que por estar associados ao risco de exposição e ao mesmo tempo à doença, poderiam alterar as estimativas de odds ratio obtidas.

Entre as vantagens óbvias de selecionar controles ambulatoriais/ hospitalares, ao invés de controles de vizinhança, está a conveniência de proceder ao exame físico completo dos controles para excluir hanseníase, bem como para coletar material biológico para os exames sorológicos. Ambos os grupos tenderiam, também, a recordar de forma semelhante dos eventos passados, evitando o viés de lembrança, além de uma baixa recusa para participação dos controles na investigação (Wacholder et al., 1992b).

A opção por controles ambulatoriais deve ser cuidadosamente planejada, quando existe acesso diferencial aos serviços de saúde para casos e controles (coorte de base do estudo). Exemplificando, o centro de saúde onde os casos foram recrutados não dispunha de outro ambulatório com padrão de captação de clientela similar. Esta característica de "centro de referência de dermatologia" inviabilizou a utilização da mesma unidade de saúde para recrutamento de controles. Para contornar esta dificuldade, selecionaram-se controles de 7 ambulatórios da rede 
básica de saúde, localizados na área de residência dos casos, e distribuídos nas diferentes macroregiões da cidade.

Esta estratégia parte do pressuposto que casos e controles adotariam critérios semelhantes de utilização dos serviços de saúde, e percorreriam a mesma trajetória desde o ponto inicial de atendimento da demanda espontânea da população da área até o seu referenciamento. Outro pressuposto implícito na escolha de controles ambulatoriais é o acesso universal e o uso freqüente dos serviços de saúde (Wacholder et al., 1992b). Por exemplo, indivíduos com problemas dermatológicos deveriam procurar espontaneamente os serviços públicos de sáude e frente à suspeita de hanseníase seriam encaminhados ao CSJB. Assim, "indivíduos não doentes - controles" teriam tido chance de ser incluídos como caso, se apresentassem sinais cardinais de hanseníase. De fato, algumas características de disponibilidade e distribuição dos serviços de saúde regionalmente, apresentadas por este estudo, parecem indicar que esses pressupostos de uso semelhante dos serviços de saúde, para ambos os grupos, sejam aceitos sem grandes restrições.

Pela característica do local de recrutamento dos participantes, a equipe de campo reconhecia a condição de casos ou controles dos entrevistados, embora não soubessem da hipótese de trabalho. Porém, um potencial viés de entrevistador é minimizado quando a principal variável de exposição é medida através de um marcador biológico. Por exemplo, a detecção de antígeno e anticorpos do VHB, realizada neste estudo, foi uma avaliação que independeu do observador. (Hulka \& Margolin, 1992; Henneckens \& Buring, 1987; Correa et al., 1994; Austin et al., 1994).

Erros de medidas das variáveis de exposição

A qualidade dos estudos de caso-controle depende de sobremaneira da acurácia, concordância e validade dos dados de exposição, tanto os testes laboratoriais quanto dos aferidos pela entrevista (Correa et al., 1994; Mertens, 
1993). Diferentemente dos estudos experiementais onde a aleatorização torna os grupos comparáveis, em estudos de caso-controle a mensuração das variáveis de confusão permite que as estimativas de risco sejam ajustadas (Datta, 1993). A sensibilidade e especificidade dos testes diagnósticos foram discutidos anteriormente no contexto da definição de caso, e a mesma lógica pode ser aplicada para a validação dos testes sorológicos para infecção pelo VHB, que é a principal variável de exposição do presente estudo. A utilização de um único marcador de infecção ao VHB, pela técnica de ELISA, vem sendo universalmente adotada para triagem sorológica, seja pelos bancos de sangue, seja em investigações epidemiológicas. Questiona-se, no entanto, a possibilidade de obtenção de resultados com baixa especificidade. Este óbice talvez seja mais pertinente para regiões de alta endemicidade ao VHB e não para regiōes de baixa endemicidade como a do presente estudo (Lok et al., 1988; Parkinson et al., 1990). Estes aspectos de validação dos testes sorológicos foram discutidos, neste mesmo cenário epidemiológico, em relação a diferentes grupos de risco populacionais (Martelli et al., 1990; Rosa et al., 1992; Porto et al., 1994).

No intuito de minimizar as dificuldades de uso de um ponto de corte padrão para variáveis contínuas, procedeu-se à avaliação semi-quantitativa dos anticorpos protetores virais (anti-HBs) entre os diferentes sub-grupos de casos e controles. Os resultados obtidos, em ambas as avaliações, exposição qualitativa e quantitativa de anticorpos, não indicaram diferença de imunidade protetora entre pacientes multibacilares, paucibacilares e controles.

\section{Estratégia de análise de dados}

Embora reconhecendo o caráter não probabilístico da seleção de casos da demanda espontânea, isto é, ausência de aleatoriedade, considerou-se viável analisar descritivamente os casos, sob a hipótese de representatividade da casuística (Sanches, 1993; Armenian \& Lilienfeld, 1994). 
Para a análise multivariada procurou-se categorizar as variáveis de exposição por blocos, estabelecidos a priori, de acordo com um nexo temático, possibilitando constituir-se uma certa hierarquização dos dados: (i) macro-ambiental, urbano/ rural, tempo de moradia; (ii) intra-domiciliar, número de pessoas por residência; (iii) fatores de risco e/ou de medidas preventivas específicas, como anos de escolaridade, renda, vacinação BCG prévia. É óbvio que conjuntos de dados que avaliam a mesma dimensão tendem a apresentar colinearidade, sendo este aspecto levado em conta na análise.

Foram construídos vários modelos de regressão logística seguindo-se o princípio de incluir preferencialmente variáveis com significado biológico para testar a hipótese de que pacientes multibacilares apresentam freqüência maior de estado de portador ao VHB do que os paucibacilares $e$ os não hansenianos. Adicionalmente, covariáveis que alteraram em pelo menos $10 \%$ as estimativas de riscos não ajustadas foram também incluídas no modelo multivariado. Este tipo de estratégia visou a tornar os modelos mais simples, e apenas as covariantes conhecidas através de estudos prévios foram incorporadas na equação linear (Greenland, 1989; Gail, 1991; Concato et al., 1993; Kleinbaum, 1994).

O modelo de regressão linear habitualmente construído com variável de resposta dicotômica - controles codificados (0) e casos (1) - não possibilita analisar os casos categorizados em diferentes níveis. A estratégia de expandir o modelo para múltiplos subgrupos de casos através da regressão logística politômica possibilitou verificar heterogeneidade de fatores de risco entre os casos multibacilares, paucibacilares e prováveis de forma simultânea. Uma analogia com múltiplos subgrupos de casos, é a escolha de mais de um tipo de controle (Begg \& Gray, 1984; Hosmer \& Lemeshow, 1989; Gail, 1991, Thompson, 1994). Os resultados obtidos através dos modelos testados foram semelhantes, não se detectando diferenças nas estimativas de risco de estado de portador do VHB e hanseníase, não havendo rejeição da hipótese de nulidade. 
Em resumo, o princípio de selecionar controles da mesma população que a de casos foi satisfeito, casos e controles pertenciam a grupos sócio-econômicos semelhantes e compartilhavam de ambiente comum. As estimativas de risco obtidas parecem resultados válidos, não mascarando, se existentes, as verdadeiras diferenças entre os grupos. As questões relativas à seleção de casos e controles em hanseníase continuarão representando um desafio para a validade dos estudos, na ausência de novos marcadores biológicos de infecção e sistemas de classificação que permitam maior uniformidade na identificação e na classificação dos casos. 


\section{CONCLUSÕES}

1. Os resultados obtidos, neste estudo de caso-controle, mostram que os subgrupos de casos (multibacilares e paucibacilares) e controles apresentaram prevalências semelhantes dos marcadores de exposição, de imunidade e de estado de portador. A capacidade de produzir anticorpos protetores, avaliada através dos percentuais do marcador anti-HBs e quantitativamente através do Índice de Elisa, foi similar entre casos e controles. Não houve evidências epidemiológicas de uma associação entre hanseníase e infecção pelo vírus da hepatite B, conduzido em área de baixa endemicidade ao VHB e alta endemicidade à hanseníase.

2. Houve nítida predominância do sexo masculino entre pacientes multibacilares quando comparados aos paucibacilares. Casos prováveis de hanseníase apresentaram história de contactante estatisticamente maior que as demais formas de hanseníase. Estes resultados apontam a necessidade de uma padronização de definição de casos, não só nos estudos de casocontrole, mas também no Programa de Controle da Hanseníase, para se alcançar a meta de eliminação da hanseníase.

3. Utilizando a metodologia de análise exploratória, foi possível estabelecer estratos de alta, média e baixa endemicidade para casos de hanseníase nos diferentes distritos urbanos da cidade de Goiânia. A construção de diagrama de ramos e folhas possibilitou identificar, através do ordenamento das taxas de detecção de hanseníase, bolsões intra-urbanos potencialmente geradores do maior número de casos novos. Esta estratégia para análise da distribuição espacial de casos possibilita direcionar as atividades do Programa de Controle da Hanseníase em área urbana, implementando, de forma hierarquizada, ações de vigilância epidemiológica. 


\section{REFERÊNCIAS BIBLIOGRÁFICAS}

ALBUQUERQUE, M.F.P.L.; MORAIS, H.M.M. \& XIMENES, R. A expansão da hanseníase no nordeste brasileiro. Rev. Saúde Pública, 23(2):107-16, 1989.

ALCABES, P., MUNOZ, A., VLAHOV, D. \& FRIEDLAND, G.H. Incubation period of Human Immunodeficiency Virus. Epidemiol. Rev., 15(2):303-18, 1993.

ALEXANDER, G.J.M. Immunology of Hepatitis B virus infection. Br. Med. Bull., 46(2):354-67, 1990.

ALMARRI, A. \& BATCHELOR, J.R. HLA and hepatitis B infection. Lancet, 344:1194-5, 1994.

ANANTHAKRISHNAN, R.; ARNDT-HANSER, A. \& WALTER, H. Studies on the Australian Antigen. I. Associations between Australia Antigen and leprosy. Humangenetik, 16:235-9, 1972.

ANDERSON, R.M. \& MAY, R.M. Infectious disease of humans, Dynamics and Control, Oxford: Oxford University Press, 1991.

ANDRADE, A.L.S.S.; ZICKER, F.; LUQUETTI, A.O.; OLIVEIRA, R.M.; SILVA, S.A.; SOUZA, J.M.P. \& MARTELLI, C.M.T. Surveillance of Trypanosoma cruzi transmission by serological screening of schoolchildren. Bull. World Health Organ., 70(5):625-9, 1992.

ANDRADE, A.L.S.S.; ZICKER, F. \& MARTELLI, C.M.T. An epidemiological approach to study congenital Chagas' disease. Cad. Saúde Públ., 10(supl. 2):345-51, 1994.

ANDRADE, V.L.G. Características epidemiológicas da hanseníase em área urbana, município de São Gonçalo - Rio de Janeiro. Rio de Janeiro, 1990. [Dissertação de Mestrado - Escola Nacional de Saúde Pública].

ANDRADE, V.L.G. Urban leprosy control: The need for specific guidelines for programme managers, 1993. [Mimeografado]

ANDRADE, V.L.G., SABROZA, P.C. \& ARAUJO, A.J.G. Fatores associados ao domicílio e à família na determinação da hanseníase, Rio de Janeiro, Brasil. Cad. Saúde Publ., 10(supl. 2):281-92, 1994.

ARMENIAN, H.K. \& LILIENFELD, D.E. Overview and historical perspective. Epidemiol. Rev., 16(1):1-5, 1994. 
ARMSTRONG, B.G. \& SLOAN, M. Ordinal regression models for epidemiologic data. Am. J. Epidemiol., 129(1): 191-204, 1989.

AUSTIN, H., HILL, H.A., FLANDERS, W.D. \& GREENBERG, R.S. Limitations in the application of case-control methodology. Epidemiol. Rev., 16(1):65-76, 1994.

BALAKRISHNAN, S.; BHATIA, V.N. \& HARIKRISHNAN, S. Hepatitis-B-surface antigen (HBsAg) in leprosy patients. Leprosy in India, 55(1):45-8, 1983.

BANERJEE, K.; SAURABHI, G.; MOUDGIL, K.D. \& KHANDEKAR, P. Status of HBV DNA and HBsAg in Leprosy Patients. Int. J. Lepr. Other Mycobact. Dis., 62(3):444-6, 1994.

BARRETO, M.L. Geographical and Socioeconomic factors relating to the distribution of Schistosoma mansoni infection in an urban area of northeast Brazil. Bull. World Health Organ., 69(1):93-102, 1991.

BARRETO, M.L. \& ANDRADE, M.E.B. Impacto da infecção chagásica sobre algumas características demográficas: Resultados de um estudo ecológico. Cad. Saúde Públ., 10(supl. 2):273-80, 1994.

BEASLEY, R.P. Hepatitis B virus - The major etiology of hepatocellular carcinoma. Cancer, 61(10):1942-56, 1988.

BECHELLI, L.M. \& DOMINGUEZ, V.M. The leprosy problem in the world. Bull. World Health Organ., 34:811-26, 1966.

BECHELLI, L.M.; GARBAJOSA, P.G.; GYI, M.M.; UEMURA, K.; SUNDARESAN, T.; TAMONDONG, C.; DOMINGUEZ, V.M.; SANSARRICQ, H. \& WALTER, J. Proposed method for estimating leprosy prevalence based on rates in children. Bull. World Health Organ., 48:502-3, 1973.

BEGG, C.B. \& GRAY, R. Calculation of polychotomous logistic regression parameters using individualized regressions. Biometrika, 71:11-8, 1984.

BENSABATH, G.; HADLER, S.C.; SOARES, M.C.P.; FIELDS, H. \& MAYNARD. J. Caracteristicas serologicas y epidemiologicas de la hepatitis virica aguda. Bol. Of. Sanit. Panam., 103(4):351-62, 1987. 
BERTOLLI, J.M. A case-control study of the efectiveness of BCG Vaccine for Preventing Clinical Leprosy in Yangon, Myanmar, 1994. [Tese de Doutoramento - Universidade da Califórnia].

BLASER, M.J. \& COHN, D.L. Opportunistic infections in patients with AIDS: Clues to the epidemiology of AIDS and the relative virulence of pathogens. Rev. Infect. Dis., 8(1):21-30, 1986.

BLOOM, B.R.; MODLIN, R.L. \& SALGAME, P. Stigma variations: Observations on supressor T cells and leprosy. Ann. Rev. Immunol., 10:453-88, 1992.

BLUMBERG, B.S.; MELARTIN, L.; LECHAT, M. \& GUINTO, R.S. Association between lepromatous leprosy and Australia Antigen. Lancet, 173-6, 1967.

BLUMBERG, B.S. \& MELARTIN, L. Australia antigen and lepromatous leprosy studies in South India and Elsewhere. Int. J. Lepr. Other Mycobact. Dis., 38(1):60-7, 1970.

BLUMBERG, B.S.; MELARTIN, L.; GUINTO, R. \& LECHAT, M. Lepromatous leprosy and Australia Antigen with comments on the genetics of leprosy. J. Chronic. Dis., 23:507-16, 1970.

BOSCHI, C.; COLEMAN, M.P. \& CASTILHO DE, E.A. Diferenciais regionais de mortalidade por câncer no estado do Rio de Janeiro, Brasil, 1979-1981. Rev. Saúde Pública, 25(4):267-75, 1991.

BRAGA, C.A.V. Hanseníase no Estado do Amazonas - Estudo das características epidemiológicas da hanseníase no Município de Lábrea, 1993. [Dissertação de Mestrado - Escola Nacional de Saúde Pública da FIOCRUZ]

BRENNER, H. \& SAVITZ, D.A. The effects of sensivity and specificity of case selection on validity, sample size, precision, and power in hospital-based case-control studies. Am. J. Epidemiol., 132(1):181-92, 1990.

BRENNER, H. \& GEFELLER, O. Use of the positive predictive value to correct for disease misclassification in epidemiologic studies. Am. J. Epidemiol., 138(11):1007-15, 1993.

BRESLOW, N.E. \& DAY, N.E. Statistical methods in cancer research. Switzerland, International Agency for Research on Cancer, Lyon, V.1. Scientific publication $\mathrm{N}^{\circ} .32,1980$.

BRITTON, W.J. Leprosy 1962-1992. 3. Immunology of leprosy. Trans. R. Soc. Trop. Med. Hyg., 87:508-14, 1993. 
CARTEL, J.L.; SPIEGEL, A.; NGUYEN NGOC, L.; MOULIA-PELAT, J.P.; MARTIN, P.M.V. \& GROSSET, J.H. Leprosy in French Polynesia. The possible impact of multidrug therapy on epidemiological trends. Lepr. Rev., 63:223-30, 1992.

CARVALHO, F.M., SILVANY-NETO, A.M., PAIM, J.S., MELO, A.M.C. \& AZARO, M.G.A. Morbidade referida e utilização de consulta médica em cinco populações do Estado da Bahia. Ciência e Cultura, 40:853-8, 1988.

CESTARI, T.F.; FERREIRA, J. \& LOUREIRO, R. Epidemiologia da hanseníase no Rio Grande do Sul. An. Bras. Dermatol., 64(5):271-4, 1989.

CHAKARBARTY, M.S.; MUKERJEE, K.K.; CHAKARBARTY, S.K.; GHOSH S. \& CHOUDHURY, S. Hepatitis B surface antigen (HBsAg) in leprosy patients in Calcuta: its prevalence and subtypes. Lepr. India.,51(2): 182-188, 1979.

CHIRON, J.P.; DENIS, F.; MAUPAS, P. \& LANGUILLON, J. Infection par le virus de l'hépatite $B$ chez les hanséniens. I. - Détection de l'antigène et de l'anticorps de surface do virus de l'hépatite B par radio-immunologie. Bull. Soc. Med. Afr. Noire Lgue. Frse., 23(2):174-82, 1978a.

CHIRON, J.P.; DENIS, F.; MAUPAS, P.; ROUX, G. \& LANGUILLON, J. Infection par le virus de l'hépatite B chez les hanséniens. II. - Titre sérique des antigènes de surface du virus de l'hépatite $B$ et des anticorps homologues. Bull. Soc. Med. Afr. Noire Lgue. Frse., 23(4):402-5, 1978 b.

CHIRON, J.P.; DENIS, F.; YVONNET, B.; COURSAGET, P.; DIOP MAR, I. \& LANGUILLON, J. Lepre et hépatite B. Acta Leprol., III(2):169-99, 1985.

CLAYTON, D. \& HILLS, M. Statistical Models in Epidemiology, New York:Oxford University Press, 1993.

COLSTON, M.J. Leprosy 1962-1992. 2. The microbiology of Mycobacterium leprae; progress in the last 30 years. Trans. R. Soc. Trop. Med. Hyg., 87:504-7, 1993.

CONCATO, J., FEINSTEIN, A.R. \& HOLFORD, T.R. The risk of determining risk with multivariable models. Ann. Intern. Med., 118(3):201-10, 1993.

CONGRESSO INTERNACIONAL DE LEPROLOGIA - VI. Report of Classification Commitee Members, 75-80, 1953. 
CONVIT, J., SAMPSON, C., ZUNIGA, M., SMITH, P.G., PLATA, J., SILVA, J., MOLINA, J., PINARDI, M.E., BLOOM, B.R. \& SALGADO, A. Immunoprophylactic trial with combined Mycobacterium leprae/BCG vaccine against leprosy: preliminary results. Lancet, 339:446-50, 1992.

CORREA, A., STEWART, W.F., YEH, H.C. \& SANTOS-BURGOA, C. Exposure measurement in case-control studies: reported methods and recommendations. Epidemiol. Rev., 16(1):18-32, 1994.

COUROUCÉ, A.M. Quantification of post-vaccination humoral immunity. In: Coursaget, P. \& Tong, M.J. Progress on Hepatitis B Immunization. França, John Libbey Eurotext, 1990. p. 67-72.

COUSENS, S.N., FEACHEM, R.G., KIRKWOOD, B.R., MERTENS, T.E. \& SMITH, P.G. Case-control studies of childhood diarrhoea. III. Matching. WHO - Documento, 1988.

DAMASCO, M.H.S.; SARNO, E.N.; LOBAO, A.S.; ALVARENGA, F.B.F.; PORTO, J.A.; ROSANKAIMER, F. \& KAPLAN, G. Effect of cutaneous cell-mediated immune response to rIFNy on Mycobacterium leprae viability in the lesions of lepromatous leprosy. Braz. J. Med. Biol. Res., 25:457-65, 1992.

DATTA, M. You cannot exclude the explanation you have not considered. Lancet, 342:345-7, 1993.

DUBIN, N. \& PASTERNACK, B.S. Risk assessment for case-control subgroups by polychotomous logistic regression. Am. J. Epidemiol., 123(6):1101-117, 1986.

EDMUNDS, W.J.; MEDLEY, G.F.; NOKES, D.J.; HALL, A.J. \& WHITTLE, H.C. The influence of age on the development of hepatitis B carrier state. Proc. R. Soc. Lond, B, 253:197-201, 1993.

EDWARDS, M. Hepatitis B serology help in interpretation. Pediatr. Clin. North Am., 35(3):503-15, 1988.

FAKUNLE, Y.M. \& WHITTLE, H.C. Hepatitis-B virus infection in patients with leprosy: a serological study in a leprosarium in Northern Nigeria. Trans. R. Soc. Trop. Med. Hyg., 75:623-5, 1981.

FEENSTRA, P. Sustainability of leprosy control services in low endemic situations. Trop. Geogr. Med., 46(2):65-71, 1994.

FERRO-LUZZI, A., SETTE, S., FRANKLIN, M. \& JAMES, W.P.T. A simplified approach of assessing adult chronic energy deficiency. Eur. J. Clin. Nutr., 46:173-86, 1992. 
FIELDS, H.A. \& MAYNARD, J.E. Hepatitis B Virus. In: Bergmeyer, H.U., ed. Methods of Enzymatic Analysis, Third edition. New York, 1985. p. 457-68.

FINE, P.E.M.; WOLF, E.; PRITCHARD, J.; WATSON, B.; BRADLEY, D.J.; FESTENSTEIN, H. \& CHACKO, C.J.G. HLA-Linked genes and leprosy: a family stydy in Karigiri, south India. J. Infect. Dis., 140(2):152-61, 1979.

FINE, P.E.M. Immunogenetics of susceptibility to leprosy, tuberculosis, and leishmaniasis. An epidemiological perspective. Int. J. Lepr. Other Mycobact. Dis., 49(4):437-54, 1981.

FINE, P.E.M. Leprosy: The epidemiology of a slow bacterium. Epidemiol. Rev., $4: 161-88,1982$.

FINE, P.E.M. Immunological tools in leprosy control. Int. J. Lepr. Other Mycobact. Dis., 57(3):671-86, 1989.

FINE, P.E.M. Reflections on the elimination of leprosy. Int. J. Lepr. Other Mycobact. Dis., 60(1):71-80, 1992a.

FINE, P.E.M. Vaccination against leprosy: neglecting the obvious?. Quaderni di cooperazione sanitaria - Health cooperation papers, 12:211-16, $1992 \mathrm{~b}$.

FLEISS, J.L. Statistical Methods for rates and proportions. $2^{\text {nd }}$ ed., New York, Ed. John Wiley \& Sons, 1981.

FOSTER, R.L. Nutrition in leprosy: a review. Int. J. Epidemiol., 56(1):66-81, 1988.

FRANCIS, T.I. \& SMITH, J.A. Australia (Au) antigen in nigerian patients with leprosy. Int. J. Lepr. Other Mycobact. Dis., 40(1):68-72, 1972.

FUNDAÇÃO INSTITUTO BRASILEIRO DE GEOGRAFIA E ESTATÍSTICA FIBGE. Censo Demográfico. Rio de Janeiro, 1991. Nº 27.

GAIL, M.H. A bibliography and comments on the use of statistical models in epidemiology in the 1980s. Stat. Med., 10:1819-85, 1991.

GALEN, R.S. \& GAMBINO, S.R. Beyond normality: the predictive value and efficiency of medical diagnosis, New York:John Wiley \& Sons ed., 1975.

GEORGE, K.; JOHN, K.R.; MULIYIL, J.P. \& JOSEPH, A. The role of intrahousehold contact in the transmission of leprosy. Lepr. Rev., 61:60-3, 1990. 
GESLER, W. The uses of spatial analysis in medical geography: a review. Soc. Sci. Med., 10:963-73, 1986.

GIESECKE, J. Modern Infectious Disease Epidemiology, Boston:Little, Brown and Company, 1994.

GOIRIENA, G.F.J.; MONGE, J.V. \& PEREZ, P.B. Presencia del Hbs Ag en una población de enfermos leprosos. Rev. Sanid. Hig. Publica (Madrid), 52:1467-78, 1978.

GONTIJO JUNIOR, O.M. \& FURTADO, T.A. Aspectos epidemiológicos da hanseníase em Minas Gerais. An. Bras. Dermatol., 63(Supl 1):246-52, 1988.

GREENLAND, S. Modeling and variable selection in epidemiologic analysis. Am. J. Public Health, 79(3):340-9, 1989.

GRISSO, J.A. Making comparisons. Lancet, 342:157-60, 1993.

HALLORAN, M.E. \& STRUCHINER, C.J. Study designs for dependent happenings. Epidemiology, 2:331-8, 1991.

HENNECKENS, H.C. \& BURING, J.E. Epidemiology in Medicine, $5^{\text {th }}$ ed. Boston: Toronto, Ed. Little, Brown and Company, 1987.

HOOFNAGLE, J.H. Serologic markers of Hepatitis B virus infection. Annu. Rev. Med., 32:1-11, 1981.

HOOVER, R. \& FRAUMENI JR, J.F. Cancer Mortality in United States counties with chemical industries. Environ. Res., 9:196-207, 1975.

HOOVER, R.; MASON, T.J.; MCKAY, F.W. \& FRAUMENI JR, J.F. Cancer by country: new resource for etiologic clues. Science, 189:1005-7, 1975.

HOSMER, D.W. \& LEMESHOW, S. Applied logistic regression, New York, NY: John Wiley and Sons, Inc., pp. 216-45, 1989.

HULKA, B.S. \& MARGOLIN, B.H. Methodological issues in epidemiologic studies using biologic markers. Am. J. Epidemiol., 135(2):200-9, 1992.

HUNTER, J.M. \& THOMAS, M.O. Hypothesis of leprosy, tuberculosis and urbanization in Africa. Soc. Sci. Med., 19(1):27-57, 1984.

INSTITUTO DE PLANEJAMENTO MUNICIPAL - IPLAN. Plano de Desenvolvimento Integrado de Goiânia. Volume I:1-112, 1992a. 
INSTITUTO DE PLANEJAMENTO MUNICIPAL - IPLAN. Plano de Desenvolvimento Integrado de Goiânia. Volume II:113-217, $1992 \mathrm{~b}$.

IRGENS, L.M. Epidemiological aspects and implications of the disappearence of leprosy from Norway; some factors contributing to the decline. Lepr. Rev., 52(1):147-65, 1981.

IRGENS, L.M. \& SKJAEVEN, R. Secular trends in age at onset, sex ratio, and type index in leprosy observed during declining incidence rates. Am. J. Epidemiol., 122(4):695-705, 1985.

JANEWAY Jr., C.A.S. \& TRAVERS, P. T-cell mediated immunity. In: Immunology. $1^{\text {st }}$ ed. Oxford, Ed. Blackwell Scientific Publications: p.1-26, 1994.

JONES, P.W., ZIADE, M.F.M., DAVIS, M.J. \& DAWES, P.T. An index of disease activity in rheumatoid arthritis. Stat. Med., 12:1171-81, 1993.

KAPLAN, G. The role of rIL-2 in the modulation of cellular immunity in resistance to infection. Immunol. Lett., 30:199-200, 1991.

KAUFMANN, S.H.E. Immunity to intracellular bacteria. In: Paul, W.E. Fundamental Immunology, New York, Ed. Raven Press Ltda. p. 1251-1286, 1993.

KAUFMANN, S.H.E., FLESCH, I.E.A., NEUKAMM, B., RUSS, F., TEIXEIRA, H.C. \& YAMAMOTO, S. T cell subsets and cytokines in intracellular bacterial infections. In: Romagnani, S., Mosmann, T.R. \& Abbas, A.K., ed. New advances on cytokines. Raven Press. p.239-48, 1992.

KELKAR, S.S.; NIPHADKAR, K.B.; KHARE, P.M. \& JUNNARKAR, R.V. Hepatitis B antigen in a leprosy hospital. Bull. World Health Organ., 48:555-8, 1973.

KING, P.E. Problems of spatial analysis in geographical epidemiology. Soc. Sci. Med., 13D:249-52, 1979.

KLEINBAUM, D.G. Logistic Regression - A self-learning text. New York, Ed. Springer-Verlagen, 1994.

KRONVALL, G. The potential of immunological tests as tools in the epidemiology of leprosy. Lepr. Rev., 52(1):207-19, 1981.

KULKARNI, K.V.; BAXI, A.J.; PATANAKAR, V.M. \& DAS, P.C. Studies on Australia Antigen in India. Vox Sang., 22:510-8, 1972. 
LASKY, T. \& STOLLEY, P.D. Selection of cases and controls. Epidemiol. Rev., 16(1):6-17, 1994.

LECHAT, M.F.; PREHN, L.M.; BLUMBERG, B.S. \& MORIS, R. Australia antigen in Zaire. Studies on leprosy. Ann. Soc. Belg. Med. Trop., 53(3): 173-8, 1973.

LEVINE, O.S., VLAHOV, D. \& NELSON, K.E. Epidemiology of Hepatitis B Virus Infection among injecting drug users: Seroprevalence, risk factors, and viral interactions. Epidemiol. Rev., 16(2):418-36, 1994.

LIANG, K. \& STEWART, W.F. Polychotomous logistic regression methods for matched case-control studies with multiple case or control groups. Am. J. Epidemiol., 125(4):720-30, 1987.

LIBERATOS, P., LINK, B.G. \& KELSEY, J.L. The measurement of social class in epidemiology. Epidemiol. Rev., 10:87-121, 1988.

LOK, A.S.F., LAI, C.L. \& WU, P.C. Prevalence of isolated antibody to hepatitis B in an area endemic for hepatitis B infection: Implications in hepatitis B vaccination programs. Hepatology, 8:766-70, 1988.

LOMBARDI, C. Evaluation of leprosy epidemiology in 12 countries of the Americas, 1980-1983. Bull. Pan. Am. Health Organ., 23(3):284-94, 1989.

LOMBARDI, C. Tendência secular da detecção da hanseníase no Estado de São Paulo. Rev. Pat. Trop., 22(2):407-87, 1993.

LOMBARDI, C.; COHEN, S.; LEIKER, D.L.; SOUZA, J.M.P.; CUNHA, P.R.; MARTELLI, C.M.T.; ANDRADE, A.L.S.S. \& ZICKER, F. Agreement between histopathological results in clinically diagnosed cases of indeterminate leprosy in São Paulo, Brazil. Acta Leprol., 9(2):83-8, 1994.

LONDON, W.T. \& BLUMBERG, B.S. Comments on the role of epidemiology in the investigation of hepatitis B virus. Epidemiol. Rev., 7:59-79, 1985.

MANTEL, N. \& HAENSZEL, W. Statistical aspects of the analysis of data from retrospective studies of disease. J. Natl. Cancer Inst., 22:719-48, 1959.

MARTELLI, C.M.T.; ANDRADE, A.L.S.S.; CARDOSO, D.D.P.; SOUSA, L.C.S.; SILVA, S.A.; SOUSA, M.A. \& ZICKER, F. Soroprevalência e fatores de risco para a infecção pelo vírus da Hepatite $B$ pelos marcadores AgHBs e Anti-HBs em prisioneiros e primodoadores de sangue. Rev. Saúde Pública, 24(4):270-6, 1990. 
MARTELLI, C.M.T., ANDRADE, A.L.S.S., CARDOSO, D.D.P., SILVA, S.A. \& ZICKER, F. Considerações metodológicas na interpretação do rastreamento sorológico da hepatite $B$ em doadores de sangue. Rev. Saúde Pública, 25(1):11-6, 1991 .

MARTELLI, C.M.T.; MORAIS NETO, O.L.; ANDRADE, A.L.S.S.; SILVA, S.A.; SILVA, I.M. \& ZICKER, F. Considerações sobre classificação e definição de casos em hanseníase nos programas de controle. Rev. Soc. Bras. Med. Trop., Supl. 1:21, 1994.

MARTELLI, C.M.T., MORAIS NETO, O.L., ANDRADE, A.L.S.S., SILVA, S.A., SILVA, I.M. \& ZICKER, F. Spatial patterns of Leprosy in an urban area in Central Brazil. Bull. World Health Organ., 73:315-9, $1995 a$.

MARTELLI, C.M.T.; ANDRADE, A.L.S.S.; GROSSI, M.A.F.; LEBOEUF, M.A.A.; LOMBARDI, C. \& ZICKER, F. Changes in leprosy clinical pattern after multidrug therapy implementation. Int. J. Lepr. Other Mycobact. Dis., 63(1):95-7, $1995 \mathrm{~b}$.

MASTRO, T.D.; REDD, S.C. \& BREIMAN, R.F. Imported leprosy in the United States, 1978 through 1988: an epidemic without secondary transmission. Am. J. Public Health, 82(8):1127-30, 1992.

MATOS, E.L.; PARKIN, D.M.; LORIA, D.I. \& VILENSKY, M. Geographical patterns of cancer mortality in Argentina. Int. J. Epidemiol., 19(4):860-70, 1990.

MCGLYNN, K.A.; LUSTBADER, E.D. \& LONDON, W.T. Immune responses to hepatitis B virus and tuberculosis infections in southeast asian refugees. Am. J. Epidemiol., 122(6):1032-6, 1985.

MEADE, M.S. Geographic analysis of disease and care. Annu. Rev. Public Health, 7:313-35, 1986.

MERTENS, T.E. Estimating the effects of misclassification. Lancet, 342:418-21, 1993.

MINISTÉRIO DA SAÚDE. Controle da Hanseníase: uma proposta de integração ensino-serviço. Secretaria Nacional de Programas Especiais de Saúde. Divisão Nacional de Dermatologia Sanitária, 1-120, 1989.

MINISTÉRIO DA SAÚDE. Guia de Controle da Hanseníase. Secretaria Nacional de Programas Especiais de Saúde. Divisão Nacional de Dermatologia Sanitária. Brasília, 1-156, 1994a. 
MINISTÉRIO DA SAÚDE. Informe Epidemiológico do SUS. Ano III No. $1: 5-132,1994 b$.

MINISTÉRIO DA SAÚDE. Programa Nacional de Eliminação e Controle da Hanseníase. Dados epidemiológicos e operacionais. Coordenação Nacional de Dermatologia Sanitária, 1994c.

MINISTÉRIO DO TRABALHO. Sistema Nacional de Emprego. Classificação Brasileira de Ocupaçōes. Brasília: SINE, Ministério do Trabalho , 1993.

MODLIN, R.L. \& REA, T.H. Leprosy: New insight into an ancient disease. J. Acad. Dem., 17:1-16, 1987.

MOTT, K.E.; DESJEAUX, P.; MONCAYO, A.; RANQUE, P. \& RAADT, P. Parasitic diseases and urban development. Bull. World Health Organ., 68(6):691-8, 1990.

MOTTA, C.P. \& ZUNIGA, M.G. Time trends of hansen's disease in Brazil. Int. J. Lepr. Other Mycobact. Dis., 58(3):453-61, 1990.

MULIYIL, J.; NELSON, K.E. \& DIAMOND, E.L. Effect of BCG on the risk of leprosy in an endemic area: a case control study. Int. J. Lepr. Other Mycobact. Dis., 59(2):229-36, 1991.

NOORDEEN, S.K. \& BRAVO, L.L. The world leprosy situation. Rapp. Trimest. Statist. Sanit. Mond., 39:122-37, 1986.

NOORDEEN, S.K.; BRAVO, L.L. \& SUNDARESAN, T.K. Estimated number of leprosy cases in the world. Bull. World Health Organ., 70(1):7-10, 1992.

NOORDEEN, S.K. Recent developments in leprosy control. Trop. Geogr. Med., S5-S12, 1994.

NOORDEEN, S.K. Elimination of leprosy as a public health problem: progress and prospects. Bull. World Health Organ., 73:1-6, 1995.

NUTI, M.; TARABINI, G.; PALERMO, P.; TARABINI, G.L. \& THAMER, G. Leprosy and hepatitis B virus markers: incidence of $\mathrm{HBsAg}$ and $\mathrm{HBeAg}$ in Somalian patients. Int. J. Lepr. Other Mycobact. Dis., 47(4):580-4, 1979.

OPROMOLLA, D.V.; NOBREGA, R.C.; DA SILVA, C.; GONÇALVES, N.N.; PADOVANI, S.H.; PADOVANI, C.R. \& GONÇALVES, A. An estimation of hanseniasis by research in non-specific demand for health services. Rev. Saúde Pública, 24(3):178-85, 1990. 
OTTATI, S. \& CANDEIAS, J.A.N. Subtipos do Antígeno Austrália (HBsAg) em doentes de hanseníase de São Paulo, Brasil. Rev. Saúde Pública, 13:366-9, 1979.

OTTENHOFF, T.H.M. Immunology of leprosy: Lessons from and for leprosy. Int. J. Lepr. Other Mycobact. Dis., 62(1):108-21, 1994.

PAHO. Demographic transition in the Americas. Epidemiological Bulletin/PAHO, 15(1):9-12, 1994.

PANNIKAR, V.K. Defining a case of leprosy. Lepr. Rev., 63(Suppl.):61s-5s, 1992.

PAPAEVANGELOU, G.J.; PAPASTAVROPOULOS, J. \& KOUREA, T. Hepatitis associated antigen (HAA) in leprosy. Lepr. Rev., 42:273-6, 1972.

PAPAIOANNOU, D.J.; KAKLAMANI, P.; PARISSIS, G.; KOUMANTAKI, I.G.; KARALIS, D.T. \& TRIACHOPOULOS, D.B. Hepatitis B virus (HBV) serum markers in Greek leprosy patients. Int. J. Lepr. Other Mycobact. Dis., 54(2):245-51, 1986.

PARKINSON, A.J., MCMAHON, B.J., HALL, D., RITTER, D. \& FITZGERALD, M.A. Comparison of enzyme immunoassay with radioimmunoassay for the detection of antibody to hepatitis $B$ core antigen as the only marker of hepatitis B infection in a population with a high prevalence of hepatitis B. J. Med. Virol., 30:253-7, 1990.

PASSOS, A.D.C.; GOMES, U.A.; FIGUEIREDO, J.F.C.; NASCIMENTO, M.M.P.; OLIVEIRA, J.M.; GASPAR, A.M.C. \& YOSHIDA, C.F.T. Influência da migração na prevalência de marcadores sorológicos de hepatite $B$ em comunidade rural. 1 - Análise da prevalência segundo local de nascimento. Rev. Saúde Pública, 27(1):30-5, 1993 .

PASSOS, A.D.C.; GOMES, U.A.; FIGUEIREDO, J.F.C.; NASCIMENTO, M.M.P.; OLIVEIRA, J.M.; GASPAR, A.M.C. \& YOSHIDA, C.F.T. Influência da migração na prevalência de marcadores sorológicos de hepatite $B$ em comunidade rural. 2 - Análise comparativa de algumas caracteristicas das populações estudadas. Rev. Saúde Pública, 27(1):36-42, $1993 \mathrm{~b}$.

PATTERSON, F.; BAUMGART, K.; BRITTON, W.; GALLAGHER, N. \& BAGSHAWE, A. Hepatitis B and leprosy: Differential transmission in a village in Papua New Guinea. Viral Hepatitis and Liver Disease, 168-89, 1988.

PATTYN, S.R. Future trends in the treatment of leprosy. Trop. Geogr. Med., 46(2):85-8, 1994. 
PENNA, G.O. Hanseníase: Epidemiologia e controle. Rev. Soc. Bras. Med. Trop., 27(Suplemento III):37-44, 1994.

PEREIRA, G.F. \& PENNA, G. Hanseníase. In: Guia de Vigilância Epidemiológica. Ministério da Saúde - Fundação Nacional de Saúde/CENEPI. Brasília, 1994, p. 163-78.

PHILliPS, D.R. Urbanization and human health. Parasitology, 106(Suppl.):S93-S107, 1993.

PIMENTEL, M.I.F.; SAMPAIO, E.P.; NERY, J.A.C.; MALTA, A.M.C.; SAAD, M.H.F.; DUPPRE, N.C.; MIRANDA, A.; ALMEIDA, S.M.; PEREIRA JR., A.C. \& SARNO, E.N. Imunidade celular e humoral na hanseníase borderline tuberculoid (BT). A Folha Médica, 107(3):105-11, 1993.

PONNIGHAUS, J.M., FINE, P.E.M., BLISS, L., SLINEY, I.J., BRADLEY, D.J. \& RESS, R.J.W. The lepra evaluation project (LEP) an epidemiological study of leprosy in nothern Malawi. 1: Methods. Lepr. Rev., 58:359-75, 1987.

PONNIGHAUS, J.M.; BOERRIGTER, G.; FINE, P.E.M.; PONNIGHAUS, I.M. \& RUSSEL, J. Disabilities in leprosy patients ascertained in a total population survey in karonga district, northern Malawi. Lepr. Rev., 61:366-74, 1990.

PONNIGHAUS, J.M.; MWANJASI, L.J.; FINE, P.E.M.; SHAW, M.; TURNER, A.C.; OXBORROW, S.M.; LUCAS, S.B.; JENKINS, P.A.; STERNE, J.A.C. \& BLISS, L. Is HIV infection a risk factor for leprosy?. Int. J. Lepr. Other Mycobact. Dis., 59(2):221-8, 1991.

PONNIGHAUS, J.M., FINE, P.E.M., STERNE, J.A.C., BLISS, L., WILSON, R.J., MALEMA, S.S. \& KILETA, S. Incidence rates of leprosy in Karonga District, Northern Malawi: Patterns by age, sex, BCG status and classification. Int. J. Lepr. Other Mycobact. Dis., 62(1):10-23, 1994a.

PONNIGHAUS, J.M., FINE, P.E.M., STERNE, J.A.C., MALEMA, S.S., BLISS, L. \& WILSON, R.J. Extend schooling and good housing conditions are associated with reduced risk of leprosy in rural Malawi. Int. J. Lepr. Other Mycobact. Dis., 62(3):345-52, 1994 b.

PORTO, S.O.B., CARDOSO, D.D.P., QUEIROZ, D.A.O., ROSA, H., ANDRADE, A.L.S.S., ZICKER, F. \& MARTELLI, C.M.T. Prevalence and risk factors for HBV infection among street youth in Central Brazil. J. Adolesc. Health, 15:577-81, 1994. 
QUARESMA, M.E.P.; RODARTE, A.; FERREIRA, M.G. \& SILVA, M.T.P. Estudo epidemiológico da hanseníase, com base na casuística da rede pública em Goiânia-Goiás. Rev. Pat. Trop., 18(1):81-97, 1989.

RAO, K.N., LAKSHMI, V. \& SAHA, K. Undernutrition in lepromatous leprosy, part I. Is it associated with poverty or with disease?. Lepr. Rev., 57:299-309, 1986.

RAO, P.S.S.; KARAT, A.B.A. \& KARAT, S. Epidemiological studies in leprosy in Gudiyatham Taluk II . Patterns of familial aggregation of leprosy in an endemic area. Lepr. Rev., 40:93-8, 1969.

REA, T.H. \& MODLIN, R.L.: Leprosy. In Norris, D.A. Immune mechanisms in cutaneous disease. New York, Ed. Marcel Dekker Inc., 1989.

REE, G.H. \& TALONU, M.T. Hepatitis B antigen and antibody in Papua New Guinean patients with leprosy. J. Infect., 3:41-4, 1981.

REITAN, L.J. The specificity of the immunodeficiency in lepromatous leprosy. Lepr. Rev., 57(Suppl 2):203-5, 1986.

RENNER, C.H. \& PATARRA, N.L. Migrações: In Santos, J.L.F., Levy, M.S. \& Szmrecsányi, T. Dinâmica da população - teoria, métodos e técnicas de análise. São Paulo. Ed. T. A. Queiroz Ltda, 1980.

RIDLEY, D.S. \& JOPLING, J. A classification of leprosy for research purposes. Lepr. Rev., 33(1):119-28, 1962.

RIDLEY, D.S. \& JOPLING, W.H. Classification of leprosy according to immunity. Int. J. Lepr. Other Mycobact. Dis., 34(3):255-73, 1966.

ROBINSON, W.S. Hepatitis B virus and hepatitis Delta virus. In: Mandell, G.L., Gordon, D.R. \& Bennet, J.E. ed. Principles and Practice of Infectious Diseases. $3^{\text {rd }}$ ed. New York, Churchill Livingstone, 1990. p. 1204-31.

ROCHA, S. \& VILLELA, R. Caracterização da subpopulação pobre metropolitana nos anos 80 - Resultados de uma análise multivariada. R. Bras. Econ., 44(1):35-52, 1990.

RODRIGUES, L. \& KIRKWOOD, B.R. Case-control designs in the study of common diseases: updates on the demise of the rare disease assumption and the choice of sampling scheme for controls. Int. J. Epidemiol., 19:205-13, 1990. 
RODRIGUES, M.L.O., SILVA, S.A., NETO, J.C.A., ANDRADE, A.L.S.S., MARTELLI, C.M.T. \& ZICKER, F. Protective effect of intradermal BCG against leprosy; a case-control study in Central Brazil. Int. J. Lepr. Other Mycobact. Dis., 60(3):335-9, 1992.

ROSA, H., COSTA, A.P.V.F., FERRAZ, M.L., PEDROZA, S.C., ANDRADE, A.L.S.S., MARTELLI, C.M.T. \& ZICKER, F. Association between Leprosy and Hepatitis B infection. A survey in Goiânia, central Brazil. Rev. Inst. Med. Trop. São Paulo, 34(5):421-6, 1992.

ROSA, H.; PEDROSA, S. \& CARDOSO, D.D.P. Hepatitis B vaccination in leprosy patients. Mem. Inst. Oswaldo Cruz, 89(3):377-8, 1994.

ROSE, G. \& BARKER, D.J.P. Epidemiology for the uninitiated. $2^{\text {nd }}$ ed., Great Britain, Ed. Britsh Medical Journal, 1986.

ROTHMAN, K.J. Modern Epidemiology. $4^{\text {th }}$ ed., Boston/Toronto, Ed. Little, Brown and Company, 1986.

SACKET, D.L. Bias in analytic research. J. Chron. Dis., 32:51-63, 1979.

SAHA, K. \& DUTTA, R.N. Subtypes of Australia Antigen in persistent Australia antigenemia and sporadic hepatitis among patients with lepromatous leprosy and their segregated children with no apparent clinical illness. Int. J. Lepr. Other Mycobact. Dis., 45(1):38-48, 1977.

SALZANO, F.M. \& BLUMBERG, B.S. The Australia antigen in Brazilian healthy persons and in leprosy and leukaemia patients. J. Clin. Pathol., 23:39-42, 1970.

SANCHES, O. Análise rotineira de dados de vigilância em saúde pública: que procedimentos estatísticos utilizar?. Rev. Saúde Pública, 27(4):300-4, 1993.

SARNO, E.N.; AZULAY, D.R.; VIEIRA, L.M.; QUADRA, A.A.; BARBOSA, I.V. \& AZULAY, R.D. Prevalencia do antigeno Australia (HBsAg) em pacientes hansenianos. Rev. Ass. Med. Brasil, 26:391-2, 1980.

SAS INSTITUTE INC - SAS Introductory Guide for Personal Computers. Cary, NC. - USA, Version 6, 1985.

SCHATZMAYR, H.G. Aspectos atuais da utilização de reativos no diagnóstico das hepatites virais. Mod. Hepatol., 14(1):41-2, 1989.

SCHLESSELMAN, J.J. Case-control studies - Design, conduct and analysis, New York, Ed. Oxford University Press, 1982. 
SCOLLARD, D.M. Time and change: new dimensions in the immunopathologic spectrum of leprosy. Ann. Soc. Belg. Med. Trop., 73(Suppl. 1):5-11, 1993.

SEHGAL, V.N. \& SRIVASTAVA, G. Indeterminate leprosy. A passing phase in the evolution of leprosy. Lepr. Rev., 58:291-9, 1987.

SEHGAL, V.N. \& SEHGAL, S. Leprosy in young urban children. Int. J. Dermatol., 27(2):112-4, 1988.

SEHGAL, V.N.; JOGINDER \& SHARMA, V.K. Immunology of leprosy. A comprehensive survey. Int. J. Dermatol., 28(9):574-84, 1989.

SELBY, J.V. Case-control evaluations of treatment and program efficacy. Epidemiol. Rev., 16(1):90-101, 1994.

SERC - Statistical and Epidemiological Research Corporation EGRET Epidemiological, Graphics, Estimation and Testing package. Seattle, WA USA, Version 0.19.6, 1991.

SERJEANTSON, S. \& WOODFIELD, D.G. Immune response of leprosy patients to hepatitis B virus. Am. J. Epidemiol., 107(4):321-7, 1978.

SERJEANTSON, S. \& DRY, P. Lymphocytotoxins in leprosy and in asymptomatic hepatitis B virus infection. Clin. Exp. Immunol., 39:289-96, 1980.

SHAPIRO, N.C. \& MARGOLIS, H.S. Hepatitis B epidemiology and prevention. Epidemiol. Rev., 12:221-7, 1990.

SHEPS, S.B. \& SCHECHTER, M.T. The assessment of diagnostic tests. JAMA, 252(17):2418-22, 1984.

SHER, R.; MACKAY, M.E.; MACNAB, G.M.; KOK, S.H. \& KOORNHOF, H.J. Hepatitis B antigen, Hepatitis B antibody, and subtypes in leprosy. Infect. Immun., 17(1):1-3, 1977.

SHERIF, M.M., ABOU-AITA, B.A., BARRY, M.W., ISMAIL, M.M.; ELASHRY, S.H; SOLIMAN, H. \& ATTIA, A.M. Hepatitis B surface antigen in different secretions of Egyptians Leprosy patients. In: Viral hepatitis and liver disease, edited by Zuckerman, A.J. New York: Alan R. Liss, 1988, p. 184-5.

SHETTY, P.S., JAMES, W.P.T. \& FERRO-LUZZI, A. Malnutrition and the immune response. 1. Malnutrition in the community: recent concepts. Trans. R. Soc. Trop. Med. Hyg., 88:612-4, 1994. 
SHWE, T. \& ZUCKERMAN, A.J. Australia antigen and antibody in British patients with Leprosy. J. Clin. Pathol., 25:401-2, 1972.

SILVA, L.M.V., FORMIGLI, V.L.A., CERQUEIRA, M.P., KRUCHEVSKY, L., TEIXEIRA, M.M.A., BARBOSA, A.S.M., CONCEIÇÃO, P.S.A., KHOURI; M.A. \& NASCIMENTO, C.L. O processo de distritalização e a utilização de serviços de saúde - Avaliação do caso de Pau da Lima, Salvador, Bahia, Brasil. Cad. Saúde Públ., 11(1):72-84, 1995.

SITTHI-AMORN, C. \& POSHYACHINDA, V. Bias. Lancet, 342:286-8, 1993.

SMITH, P.G. Revised estimates of global leprosy numbers. Lepr. Rev., 62:317-8, 1992a.

SMITH, P.G. Editorial - The serodiagnosis of leprosy. Lepr. Rev., 63:97-100, $1992 b$.

SMITH, P.G.; MORROW, R.H. \& CHIN, J. Investigating interactions between HIV infection and tropical diseases. Int. J. Epidemiol., 17(4):705-7, 1988.

SMOLKA, M.O. Mobilidade intra-urbana no Rio de Janeiro: da estratificação social a segregação residencial no espaço. Rev. Bras. Est. Pop., 9(2):97-114, 1992.

SOMMERFELT, H.; IRGENS, L.M. \& CHRISTIAN, M. Geographical variations in the occurrence of leprosy: Possible roles played by nutrition and some other environmental factors. Int. J. Lepr. Other Mycobact. Dis., 53(4):524-32, 1985.

SPSS/PC - Statistical Package for Social Science/PC. SPSS Inc. Marija J Norusis, Versao 4.0., Chicago, 1990.

SWANEPOEL, R. \& CRUICKSHANK, J.G. Carta - Australia Antigen in Rhodesia. Lancet, 446, 1972.

TALHARI, S.; TORRECILA, M.A.A. \& TALHARI, A.C. A study of leprosy and other skin diseases in school children in the state of Amazonas, Brazil. Lepr. Rev., 58:233-7, 1987.

TALHARI, S. \& NEVES, R.G. Hanseniase, Manaus: ISEA-Instituto Superior de Estudos da Amazônia, Ed. 2 pp. 1-144, 1989.

TASCHNER, S.P. \& BÓGUS, L.M.M. Mobilidade espacial da populaçäo brasileira: aspectos e tendências. Rev. Bras. Est. Pop., 3(2):87-132, 1986. 
THOMAS, H.C. The hepatitis B virus and the host response. J. Hepatol., 11:S83-9, 1990.

THOMPSON, W.D. Statistical analysis of case-control studies. Epidemiol. Rev., 16(1):33-50, 1994.

TRAMONT, E.C. Host defense mechanisms - General or nonspecific host defense mechanisms. In: Mandell, G.L., Gordon, D.R. \& Bennet, J.E. ed. Principles and Practice of Infectious Diseases. $3^{\text {rd }}$ ed. New York, Churchill Livingstone, 1990. p. 33-41.

TRINDADE, M.A.B. \& NEMES, M.I.B. Incapacidades físicas em hanseníase no momento do diagnóstico: Características epidemiológicas dos casos registrados de 1983 a 1988 no Estado de São Paulo. Hansenol. Int., 17(1/2):8-14, 1992.

TUKEY, J.W. Exploratory data analysis. Readings, Mass. Addison-Wesley, 1977.

ULRICH, M.; ZULUETA, A.M.; CACERES-DITTMAR, G.; SAMPSON, C.; PINARDI, M.E.; RADA, E.M. \& ARANZAZU, N. Leprosy in women: characteristics and repercussions. Soc. Sci. Med., 37(4):445-56, 1993.

VAISHNAVI, C.; SOKHEY, C.; KAUR, S.; KUMAR, B.; DILAWARI, J.B. \& GANGULY, N.K. Leprosy and Hepatitis B surface antigen. Indian J. Lepr., 61(2):211-5, 1989.

VICTORA, C.G. What's the denominator?. Lancet, 342:97-9, 1993.

VOLLER, A.; BARTLETT, A. \& BIDWELL, D.E. Enzyme immunoassays with special reference to ELISA techniques. J. Clin. Pathol., 31:507-20, 1978.

VRIES, R.R.P. Genetic control of immunopathology induced by Mycobacterium leprae. Am. J. Trop. Med. Hyg., 44(4 Suppl.):12-6, 1991.

WACHOLDER, S., MCLAUGHLIN, J.K., SILVERMAN, D.T. \& MANDEL, J.S. Selection of controls in case-control studies. I - Principles. Am. J. Epidemiol., 135(9):1019-28, 1992a.

WACHOLDER, S., SILVERMAN, D.T., MCLAUGHLIN, J.K. \& MANDEL, J.S. Selection of controls in case-control studies. II - Type of Controls. Am. J. Epidemiol., 135(9):1029-41, 1992 b.

WACHOLDER, S., SILVERMAN, D.T., MCLAUGHLIN, J.K. \& MANDEL, J.S. Selection of control in case-control studies. III - Design Options. Am. J. Epidemiol., 135(9):1042-50, $1992 \mathrm{c}$. 
WORLD HEALTH ORGANIZATION - WHO. Expert Commitee on Leprosy Sixth Report. Geneva, 1988. (WHO Technical Report Series, 768).

YAMAMURA, M.; UYEMURA, K.; DEANS, R.J.; WEINBERG, K.; REA, T.H.; BLOOM, B.R. \& MODLIN, R.L. Defining protective responses to pathogens: cytokine profiles in leprosy lesions. Science, 254(5029):277-9, 1991.

YOSHIDA, C.F.T.; MERCADANTE, L.A.C.; GASPAR, A.M.C.; MAIA, M.M.S.; BERRO, O.J.; ALMEIDA, E.C.C. \& SCHATZMAYR, H.G. Anticorpos Anti-HBs obtidos em coelhos e sua utilização como reagentes para testes sorológicos no diagnóstico da Hepatite B. Mem. Inst. Oswaldo Cruz, 79(3):329-36, 1984.

ZÁRATE, N.O.V. La lepra en el Ecuador. Hansenol. Int., 17(1/2):33-41, 1992.

ZICKER, F.; OLIVEIRA, R.M.; LUQUETTI, A.O. \& SMITH, P.G. Seroprevalence for Trypanosoma cruzi infection among unskilled urban workers in Central Brazil. Trans. R. Soc. Trop. Med. Hyg., 83:511-3, 1989.

ZUNIGA, M. Avances en la epidemiologia de la lepra. Bol. Dermatol. Sanit., $18: 1,1982$.

ZYNGIER, F.R.; COSTA, F.G.; ZILBERMAN, S.D.; GREY, P.S.S.; LEMME, A.C.; GAZE, R. \& PEREIRA, A. Carta - Prevalence of HBsAg in a Brazilian leprosarium. Trans. R. Soc. Trop. Med. Hyg., 73(5):599, 1979. 


\section{ANEXO 1}

Sumário das publicações sobre associação entre hanseníase e o marcador AgHBs.

\begin{tabular}{|c|c|c|c|}
\hline \multirow{2}{*}{$\begin{array}{l}\text { País / Ano } \\
\text { Autor }\end{array}$} & \multicolumn{3}{|c|}{ Número de Pacientes } \\
\hline & $\begin{array}{l}\text { Lepromatosa } \\
\mathrm{N}(\%)\end{array}$ & $\begin{array}{l}\text { Tuberculoide } \\
\text { N (\%) }\end{array}$ & $\begin{array}{l}\text { Controles } \\
\mathrm{N}(\%)\end{array}$ \\
\hline $\begin{array}{l}\text { Filipinas - 1967/70 } \\
\text { Blumberg et al. }\end{array}$ & $803 \quad(9,9)$ & $605 \quad(4,3)$ & $1287 \quad(5,0)$ \\
\hline India 1970 : 19 : & $556: 1,(6.3)$ & $385: 16:(1,3)$ & $253.9(2.8)$ \\
\hline $\begin{array}{l}\text { Índia - } 1972 \\
\text { Ananthakrishnan et al }\end{array}$ & $290 \quad(6,2)$ & $283(2,8)$ & $353 \quad(1,7)$ \\
\hline 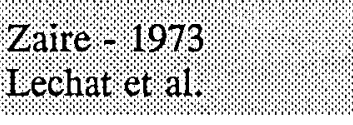 & 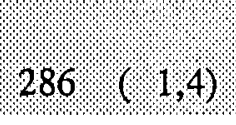 & $361,1,(1,1,4)$ & 191 : 1 ( $1.8 .8 \%$ \\
\hline $\begin{array}{l}\text { Rodesia - } 1972 \\
\text { Swanepoel et al. }\end{array}$ & $281 \quad(1,0)$ & n.d. & $4011 \quad(3,6)$ \\
\hline India 1979 Grakrabarty 1 et al & $234:(1,8,8)$ & 431 (1: $(1,2.5)$ & ? \\
\hline $\begin{array}{l}\text { Índia - } 1973 \\
\text { Kelkar et al. }\end{array}$ & $221 \quad(5,0)$ & $127 \quad(6,3)$ & $200 \quad(2,0)$ \\
\hline $\begin{array}{l}\text { Grecria. } 1972 \\
\text { Papaevangelou }\end{array}$ & 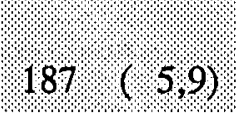 & (153: $15,10.7$ ? & 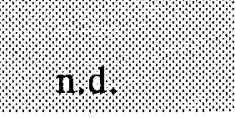 \\
\hline $\begin{array}{l}\text { Índia - } 1983 \\
\text { Balakrishnan et al. }\end{array}$ & $180 \quad(28,9)$ & $7 \quad(14,3)$ & $31(6,5)$ \\
\hline Japão 1970 Blumberg & $180:(1,1,8)$ & 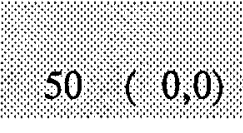 & 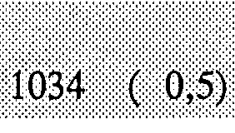 \\
\hline $\begin{array}{l}\text { Austrália - } 1970 \\
\text { Blumberg et al. }\end{array}$ & $170 \quad(0,0)$ & n.d. & $217 \quad(0,0)$ \\
\hline Brasil' 1970 ' 19 : & $158=(10,0)$ & $42.10(0.0) \%$ & $275 \%(0,0)$ \\
\hline $\begin{array}{l}?-1978 \\
\text { Goiriena et al. }\end{array}$ & $(8,3)$ & $38 \quad(2,6)$ & n.d. \\
\hline Hong Kong - 1970 & $143,(2,8)$ & $30.1 .(10.0)$ & 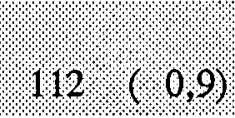 \\
\hline $\begin{array}{l}\text { Brasil - } 1980 \\
\text { Sarno et al. }\end{array}$ & $129(1,6)$ & $24 \quad(0,0)$ & $300 \quad(2,0)$ \\
\hline
\end{tabular}


(Continuação) Sumário das publicações sobre associação entre hanseníase e marcador AgHBs.

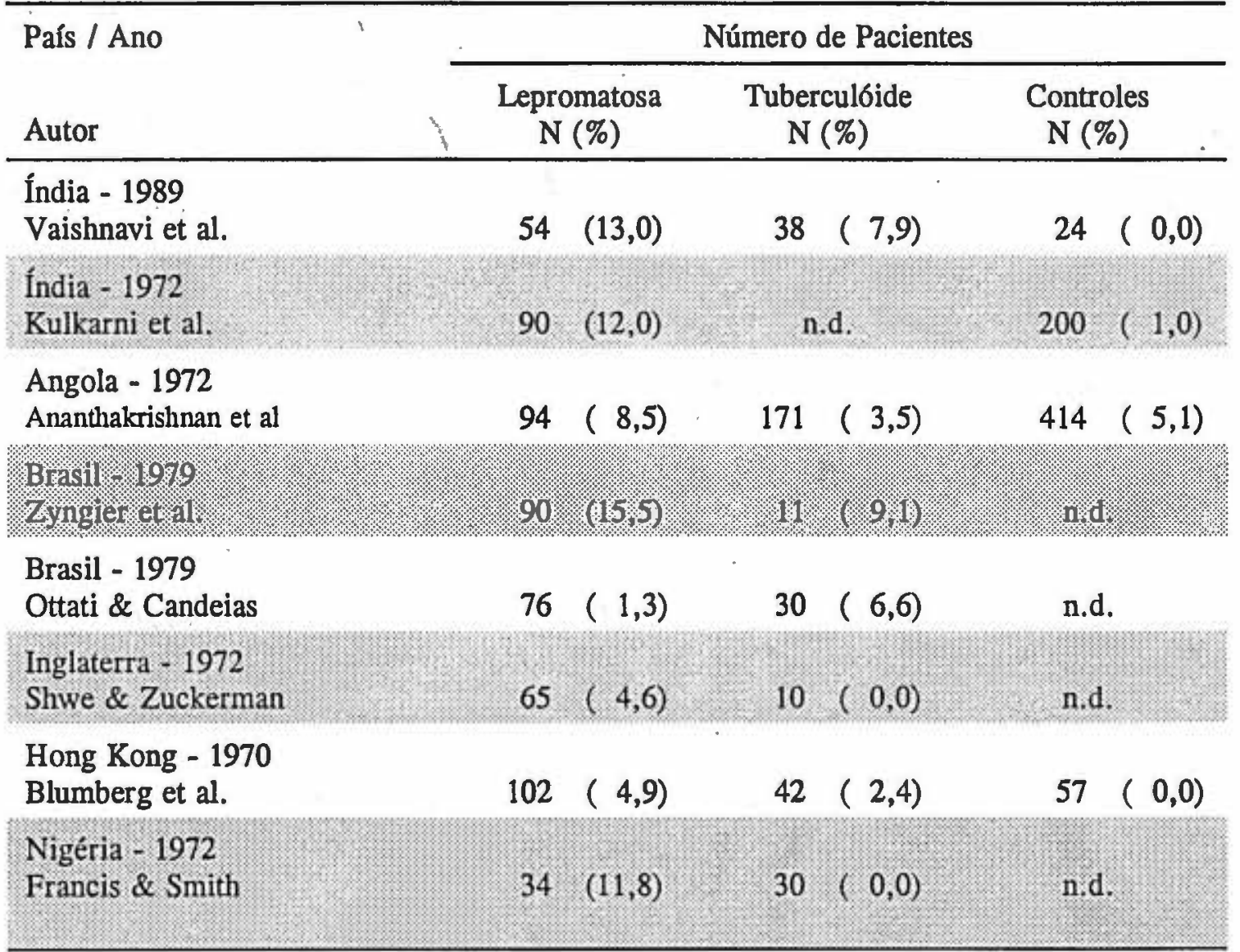

$\mathrm{N}=$ Total de pacientes

(\%) = percentual de marcadores AgHBs positivos

n.d. = não disponfivel 
Sumário das publicações sobre associação entre hanseníase e infecção pelo vírus da hepatite B.

\begin{tabular}{|c|c|c|c|c|c|c|c|c|c|}
\hline \multirow{3}{*}{$\begin{array}{l}\text { País / Ano } \\
\text { Autor }\end{array}$} & \multicolumn{9}{|c|}{ Número de Pacientes } \\
\hline & \multicolumn{3}{|c|}{ Lepromatosa } & \multicolumn{3}{|c|}{ Tuberculbide } & \multicolumn{3}{|c|}{ Grupo de Comparação } \\
\hline & $\mathrm{N}$ & $\mathrm{Ag}(\%)$ & Ac (\%) & $\mathrm{N}$ & $\mathrm{Ag}(\%)$ & Ac $(\%)$ & $\mathrm{N}$ & $\mathrm{Ag}(\%)$ & Ac (\%) \\
\hline $\begin{array}{l}\text { Índia - } 1977 \\
\text { Saha \& Dutta }\end{array}$ & 135 & $(10,3)$ & $(0,74)$ & & n.d. & & 2982 & $(2,28)$ & $(0,1)$ \\
\hline Africa 1979 & 174 & $(6.3)$ & $(379)$ & 55 & $(9,0)$ & $(34,5)$ & & r. & \\
\hline $\begin{array}{l}\text { Senegal - } 1978 \\
\text { Chiron et al. }\end{array}$ & 247 & $(25,0)$ & $(46,6)$ & 224 & $(24,6)$ & $(40,5)$ & 100 & $(12,0)$ & $(38,0)$ \\
\hline $\begin{array}{l}\text { Somalia } 199.99 \\
\text { Nutive } 1 \text {. }\end{array}$ & 135 & $(24,4)$ & $(46,6)$ & 87. & $(1,5)$ & $(58.6)$ & 146 & $(178)$ & $(4,5,5)$ \\
\hline $\begin{array}{l}\text { Nigéria - } 1981 \\
\text { Fakunle \& Whittle }\end{array}$ & 20 & $(40,0)$ & $(45,0)$ & 42 & $(23,8)$ & $(35,7)$ & 40 & $(10,0)$ & $(62,5)$ \\
\hline $\begin{array}{l}\text { Papua - } 1981 \\
\text { Ree et al. }\end{array}$ & 70 & $(14,3)$ & $(7,0)$ & 24 & $(12,5)$ & $(12,5)$ & 40 & $(5,0)$ & $(12,5)$ \\
\hline
\end{tabular}

$\mathrm{Ag}=$ percentual de marcadores positivos ao AgHBs

$A c=$ percentual de marcadores positivos ao anti-HBs 
Sumário das publicações sobre associação entre hanseníase e infecção pelo vírus da hepatite B. Estudos de caso-controle.

\begin{tabular}{|c|c|c|c|c|c|c|c|c|c|}
\hline \multirow{3}{*}{$\begin{array}{l}\text { País / Ano } \\
\text { Autor }\end{array}$} & \multicolumn{9}{|c|}{ Número de Pacientes } \\
\hline & \multicolumn{3}{|c|}{ Lepromatosa } & \multicolumn{3}{|c|}{ Tuberculoide } & \multicolumn{3}{|c|}{$\begin{array}{l}\text { Grupo de } \\
\text { Comparação }\end{array}$} \\
\hline & $\mathrm{N}$ & $\mathrm{Ag}(\%)$ & Ac (\%) & $\mathrm{N}$ & $\mathrm{Ag}(\%)$ & $\mathrm{Ac}(\%)$ & $\mathrm{N}$ & $\mathrm{Ag}(\%)$ & Ac (\%) \\
\hline $\begin{array}{l}\text { Nova Guinés }-1978 \\
\text { Serjeantson \& Woodfield }\end{array}$ & 86 & $(17,4)$ & $(23,5)$ & 196 & $(8,7)$ & $(28,5)$ & 290 & $(10,0)$ & $(24,1)$ \\
\hline $\begin{array}{l}\text { Grecra' } 1986 \text {. } \\
\text { Paparionnou et al. }\end{array}$ & $135 \%$ & $(6,7)$ & $(79,2)$ & 82 & $(8,5)$ & $(78,0)$ & 382. & $(5,8)$ & $(53.7)$ \\
\hline
\end{tabular}

$\mathrm{N}=$ Total de pacientes

$\mathrm{Ag}=$ percentual de marcadores positivos ao AgHBs

$\mathrm{Ac}=$ percentual de marcadores positivos ao anti-HBs

a marcador anti-HBs

${ }^{b}$ marcadores anti-HBc e anti-HBs 


\section{ANEXO 2}

\section{UFG/SUS}

PROJETO: HBV/HAN

$\begin{array}{ll}\text { UNIDADE } & ( \\ \text { PRONT } & (\quad) \\ \text { NO } & (\quad) \\ \text { CACO } & (\quad .)\end{array}$

IDENTIFICAÇÃO

(Preencher para todos os indivíduos elegíveis, casos e controles)

1. Nome:

NOME $\quad(\quad)$

2. Data de Nascimento:

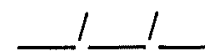

AGE

3. Data do exame:

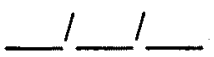

DAT

4. SEXO: MASC ( 1 ) FEM ( 2 )

SEX

5. Paciente do ambulatório de:

Dermatologia ( 1 )

Clínica médica ( 2 )

Carteira de Saúde ( 3 )

Outros (4)

6. Peso:

PES

7. Altura:

ALT

AMB
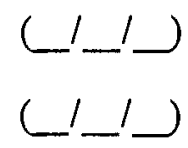

INTERROGATÓRIO SINTOMATOLÓGICO

8. Paciente apresenta lesões de pele e/ou alteração de sensibilidade?

LES Não (1) Sim (2)

9. É contato de paciente em tratamento? Não (1) Sim (2)

CONT

Caso sim,

Nome do Contato

NOMECONT

PRONTC

MLES

YLES

DLES

Meses

Dias

Não sabe ( 99 )

Não se aplica ( 88 )

11. Estas foram as primeiras lesões deste tipo:

PLES

Não (1) Sim (2)

Não se aplica ( 88 ) 
Caso não, responda os ítens 12 e 13

12. Há quanto tempo você teve outras lesões?

meses
anos
dias

Não se aplica ( 88 )

13. As lesões curaram sozinhas?

Não (1) $\quad \operatorname{Sim}(2)$

Não se aplica ( 88 )

14. Você faz ou já fez tratamento com estes remédios?

(Mostrar medicação específica para hanseníase)
Não ( 1 )
$\operatorname{Sim}(2)$
NS/NR ( 9 )

15. Qual o tempo de duração deste tratamento?

$\begin{array}{ll}\text { Dia } & \text { Não se aplica ( 88) } \\ \text { Mês } & \\ \text { Ano } & \end{array}$

16. Alguma pessoa que mora na sua casa toma ou já tomou esta medicação?

Não (1) Sim (2) NS/NR ( 9 )

Grau Parentesco

Não se aplica ( 8 )

\section{EXAME FÍSICO}

\section{EXAME NEURO-DERMATOLÓGICO:}

17. Tipo de lesão:

( 1 ) Mancha hipocromica

( 2 ) Mancha hipercromica

( 3 ) Mancha eritematosa

( 4 ) Placa eritemato-infiltrada

( 5 ) Placa eritemato-infiltrada, limites bem definidos

( 6 ) Placa eritemato-infiltrada, limites difusos

( 7 ) Infiltração difusa sem lesão de pele

( 8 ) Não se aplica

( 9 ) Sem informação

(10) Miscelanea

Descrever

18. Número de lesões: lesões +10 lesões $(11)$

Não se aplica ( 88 ) $\begin{array}{lll}\text { MALES } & ( & ) \\ \text { YALES } & (\quad) \\ \text { DALES } & (\quad)\end{array}$

CURA

COMT

$\begin{array}{ll}\text { DTRAT } & (\quad) \\ \text { MTRAT } & (\quad) \\ \text { ATRAT } & (\quad)\end{array}$

COMFA ( )

CONTAC ( )

\section{CARACF ( )}

NLES 
Distribuição das lesões:

\section{MAPEAR NO DIAGRAMA EM ANEXO}

19. Espessamento e sensibilidade de nervos:

$$
\begin{array}{cc}
\text { Codifique: Não (1) } \quad \operatorname{Sim}(2) & \text { Duvidoso (3) } \\
\text { Espessamento } & \begin{array}{c}
\text { Sensivel à } \\
\text { palpação }
\end{array}
\end{array}
$$

Retroauricular

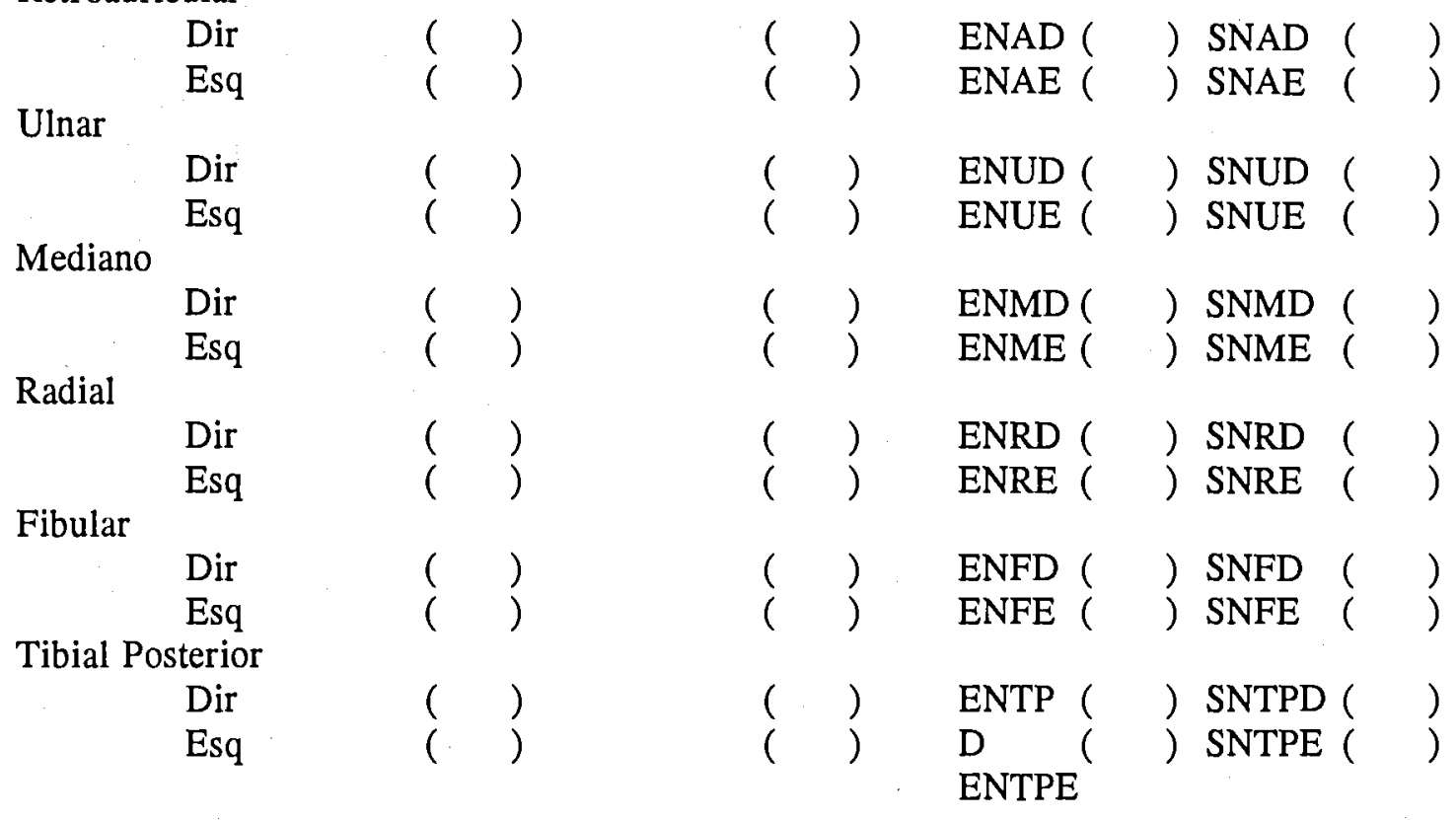

Outro: Especificar o nervo

20. Outras alterações

Especificar para

Não ( 1 ) Sim ( 2 ) Duvidoso ( 3 )

Não avaliado ( 9 ) 
Perda de sombrancelha

Lagoftalmo

Infiltração de pavilhão auricular

Fraqueza Muscular Localizada

Queda de punho

Queda de pé

Perda de sensibilidade no(s) local(is) da(s) lesão(ões):

Tátil

Térmica

Dolorosa

Edema de extremidade

Artrite

Orquite

Aumento de fígado

Aumento de baço

21. Presença de:

Cicatriz vacinal de BCG

Não (1) Sim (2) Duvidoso (3)

TATI

TERM

DOLO

EDEM

ARTRI

ORQU

FIGA

BAÇO

BCGC

TATO

22. Presença de tatuagem:

Não (1) $\quad \operatorname{Sim}(2)$

23. O paciente apresenta reações:

TREA $\quad(\quad)$

Não (0) Reação Tipo I ( 1 )

Reação Tipo II ( 2 )

24. Na avaliação clínica:

Caso certo (1) Provável (2)

Outra doença ( 3 ) Qual

(Caso 1 ou 3 continuar)

AVAL $\quad(\quad)$

DOENCA ( )

25. Forma clínica de hanseníase:

I (1) BT (2) BB ( 3) BL (4) TT ( 5)

LL (6) Não se aplica ( 8 )

CLAS

26. Qual o grau de incapacidade que o paciente apresenta?

Olhos:

Grau 0 ( 0) Grau 1(1) Grau 2(2) Grau 3(3)

Mãos:

Grau 0(0) Grau 1(1) Grau 2(2) Grau 3(3)

Pés:

Grau 0 (0) Grau 1(1) Grau 2(2) Grau 3(3)

Grau de incapacidade final:

Grau 0 (0) Grau 1(1) Grau 2(2) Grau 3(3)

GINCO ( )

Não se aplica ( 8 )

GINCM ( )

GINCP $\quad(\quad)$

GINCF ( )

27. Coleta de exames:

Baciloscopia

Não (1) Sim (2)

BAC 
Biopsia de pele

Não (1) $\quad \operatorname{Sim}(2)$

Reação de Mitsuda

Não (1) $\quad \operatorname{Sim}(2)$

Sangue

Não (1) Sim (2)

BIO

MIT

SANG

Observações:

Assinatura do Médico

MED 
RESULTADO DE EXAMES:

1. Resultado do teste de MITSUDA.

Negativo ( 1 ) Duvidoso ( 2 ) Positivo $+(3)$

RMIT

Positivo $++(4)$ Positivo $+++(5)$

2. RESULTADO DA BACILOSCOPIA:

2.1. - CSJB - Lâmina GUIA

Resultado IB =

Não realizado ( 9 )

2.2. - UFG

Lóbulo Orelha dir.

Lobulo Orelha esq.

Cotovelo dir.

Cotovelo esq.

Lesão 1

Lesão 2

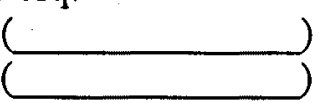

$\mathrm{IB}=$

$\mathrm{IB}=$

$\mathrm{IB}=$

$\mathrm{IB}=$

$\mathrm{IB}=$

$\mathrm{IB}=$

RBACG

RBACP ( )

3. RESULTADO DO EXAME HISTOPATOLÓGICO:

LOD

LOE

COTD

COTE

LES1

LES2

RHIST

$\begin{array}{llllll}\text { I ( } 1) & \mathrm{BT}(2) & \mathrm{BB}(3) & \mathrm{BL}(4) & \mathrm{TT}(5) & \mathrm{LL}(6)\end{array}$ Inespecífico ( 8 ) Outra doença ( 8 )

NÍVEL DE CERTEZA:

NCERT

1. Hanseníase confirmada

2. Consistente com hanseníase mas não diagnóstico

3. Inespecífico

4. Indicativo de outra doença:

5. Dentro dos limites de normalidade

ODOENÇA ( )

OUTROS EXAMES:

Preencher após resultado dos exames

DIAGNÓSTICO FINAL:

DFIN

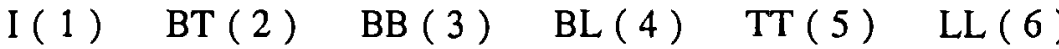

DFINH

Caso descartado ( 7 )

COMP

Outra doença ( 8 ) 


\section{ANEXO 3 \\ UFG/SUS/FNS/MACROREGIÃO CENTRO-OESTE \\ PROJETO: HBV/HAN}

$\begin{array}{ll}\mathrm{NO} & (\quad) \\ \mathrm{CACO} & (\quad)\end{array}$

\section{ENTREVISTA}

(Todos os indivíduos elegíveis, casos e controles)

\section{IDENTIFICAÇÃO}

Nome:

INC

Data de nascimento:

AGE

Sexo MASC (1)

FEM ( 2 )

SEX

Nome da mãe:

INCM

(Responsável)

Endereço:

$\begin{array}{llll}\text { Rua } & \mathrm{n}^{\mathbf{0}} \quad \text { Qd } & \text { Lote }\end{array}$

ENDERECO $(\quad)$
COD1 $\quad$

Telefone:

Bairro Cidade Estado

ZONA $(\quad)$

Endereço:

(Contato)

\begin{tabular}{llll}
\hline Rua & $\mathrm{n}^{\mathbf{0}}$ & Qd & Lote
\end{tabular}

Telefone:

Bairro $\quad$ Cidade $\quad$ Estado

Local de Trabalho:

COD2

Endereço:

Rua $\quad \mathrm{n}^{\mathrm{o}}$ Qd Lote

Telefone:

Bairro Cidade $\quad$ Estado

Data entrevista:

- 1

DAT1

Entrevistador:

ENTR

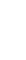




\section{POSIÇÃO NA FAMÍLIA}

Chefe (1) Cônjuge (2)

Filho (4) Parente (5)

Outro (6) Especificar

\section{ESTADO CIVIL}

Solteiro ( 1 ) Casado ( legalmente ou não) (2)

ECIV

Desquitado, divorciado ou separado ( 3 ) Viúvo (4)

\section{ESCOLARIDADE}

4.1. Até que ano da escola o $\mathrm{Sr}(\mathrm{a})$ cursou?

1. nunca frequentou sabe ler e escrever

ESC

2. nunca frequentou não sabe ler e escrever

3. primário ou $1^{\circ}$ grau incompleto ano/série

4. ginásio ou $2^{\circ}$ grau incompleto ano/série

5. colegial ou $2^{\circ}$ grau completo

6. cursos técnicos de nível médio completo

7. cursos técnicos de nível médio incompleto

8. universidade completa

9. universidade incompleta

(Registre nos ítens 3 e 4 o último ano de escolaridade)

\section{CONDIÇÃO SÓCIO-ECONÔMICA}

5.1. Atualmente o $\mathrm{Sr}(\mathrm{a})$. exerce alguma atividade (seja ela remunerada ATI ou não remunerada) de trabalho?

1. sim, em atividade

2. sim, afastado por motivo de doença

3. sim, é também aposentado

4. não, desempregado

5. não, aposentado

6. não, dona de casa

7. não, só estudante

8. não, outros

Caso a resposta seja: 6,7 ou 8 , passe para a questão $\mathrm{n}^{0} 5.9$.

5.2. Qual é/era o seu cargo/ocupação ou função em seu trabalho OCUP (principal)? Descreva as tarefas mais frequentes que desenvolve em seu trabalho. 
1. empregado assalariado sem carteira assinada

2. empregado assalariado com carteira profissional assinada

3. empregado familiar não remunerado

4. conta própria ou autônomo sem estabelecimento

6. empregador com até 4 funcionários fixos

7. empregador com 5 ou mais funcionários fixos

8. para trabalhador rural que não se enquadre nas alternativas acima, descrever a situação.

9. NS/NR

88. Não se aplica

5.4. Descreva qual é/era a atividade do estabelecimento, empresa, negócio ou instituição em que trabalha/trabalhou.$$
\text { negrio ou instituiça em que trabalha/trabalhou. }
$$

5.5. Em que município fica o lugar onde o $\mathrm{Sr}(\mathrm{a})$ trabalha/trabalhou?

1. no próprio Município de residência

2. outro Município

8. não se aplica

(Para os desempregados passe para a questão 5.9.)

5.6. Quanto o $\mathrm{Sr}(\mathrm{a})$ ganhou com esse trabalho no mês passado?

SAL

1. salário líquido. $\mathrm{Cr} \$$ S.M.

9. NS/NR

88. Não se aplica

5.7. Além deste trabalho o $\mathrm{Sr}(\mathrm{a})$ tem algum outro tipo de trabalho remunerado? (fixo ou eventual)

SALO

1. não (Passe para a questão 5.9.)

2. $\operatorname{sim}$

9. NS/NR

8. Não se aplica 
5.8. O Sr(a) tem algum outro rendimento além do(s) declarado(s)

SALA anteriormente?

1. กão

2. sim, Quanto? Cr\$

S.M.

VALOR ( )

3. NS/NR

8. Não se aplica

5.9. Quais pessoas que moram na mesma casa?

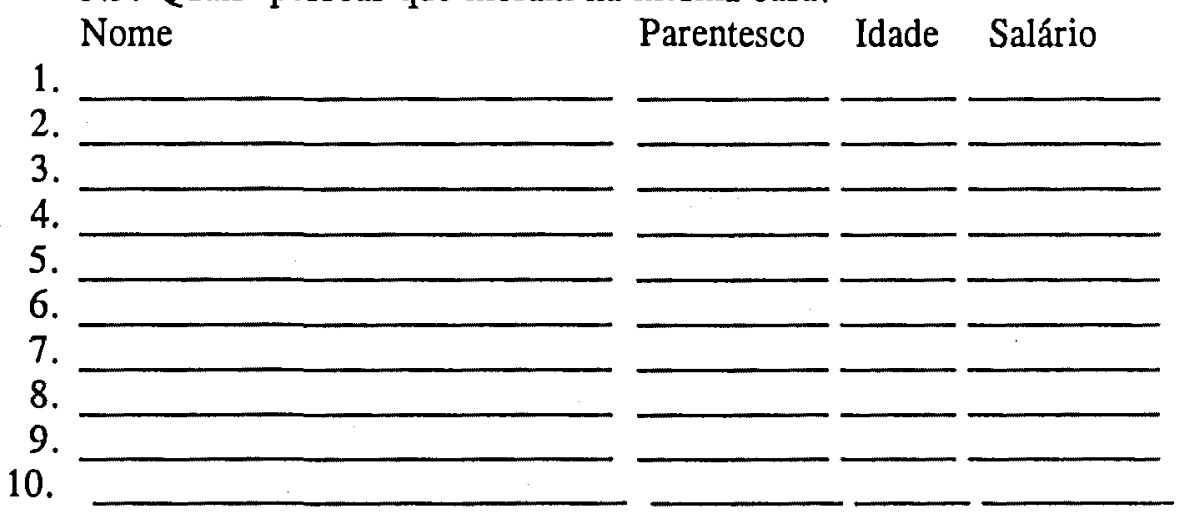

Obs.:

Total dos rendimentos:

Número de moradores da casa:

Número de moradores $\mathrm{c} /$ renda:

5.10. Caso seja dependente, qual a ocupação do chefe da casa:

PROF
1. Trabalhador de roça
8. Militar/Polícia
2. Comerciante
9. Pedreiro
3. Desempregado
10. Servente
4. Comerciário
11. Mestre de Obras
5. Vigilante
12. Aposentado
6. Fazendeiro
13. Dona de Casa
7. Funcionário Público
14. Outras

5.11. Gasto no último mês com:

1. energia elétrica. $\mathrm{Cr} \$$

9. NS/NR

S.M.

ENG

88. Não se aplica

5.12. O Sr(a) tem algum tipo de plantação ou de criação que contribui PLANT no orçamento familiar?

1. กão

2. sim

9. NS/NR 
5.13. O Sr(a) possui?

(Leia as questões para o entrevistado)

CODIFIQUE NÃO (1) SIM ( 2 )

1. Refrigerador

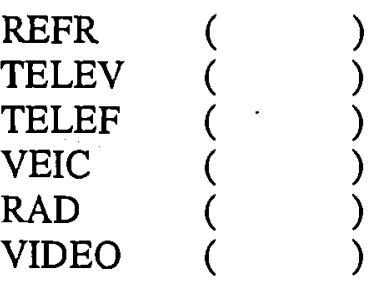

\section{MIGRAÇÃO}

6.1. Onde o $\operatorname{Sr}(a)$ nasceu?

1. no próprio município de residência atual

2. outro município de Goiás. Qual?

3. outro Estado do país. Qual? que município?

4. outro país. Qual?

9. NS/NR

$\begin{array}{lll}\text { NAS } & ( & ) \\ \text { MUNIC } & ( & ) \\ \text { ESTADO } & (\end{array}$

6.2. Zona

ZON

1. Cidade

2. Periferia

3. Chácara Urbana

4. Rural

6.3. Há quanto tempo o $\mathrm{Sr}(\mathrm{a})$ mora no município de residência atual?

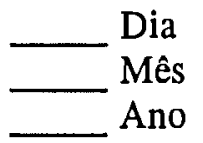

6.4. Relacione os municípios em que o $\operatorname{Sr}(a)$ já morou nos últimos 10 anos em ordem cronológica.

Município/Estado

1.

2 .

3.

4.

5 .

6.

7.

8.

9.

10.
Tempo de Moradia

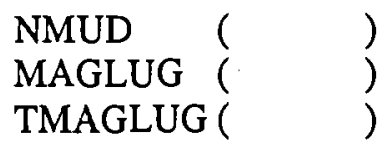

Preencher para os moradores do AGLUG. 
6:5. Pergunte sobre as mudanças de residência nos bairros de Goiânia e aglomerado urbano.

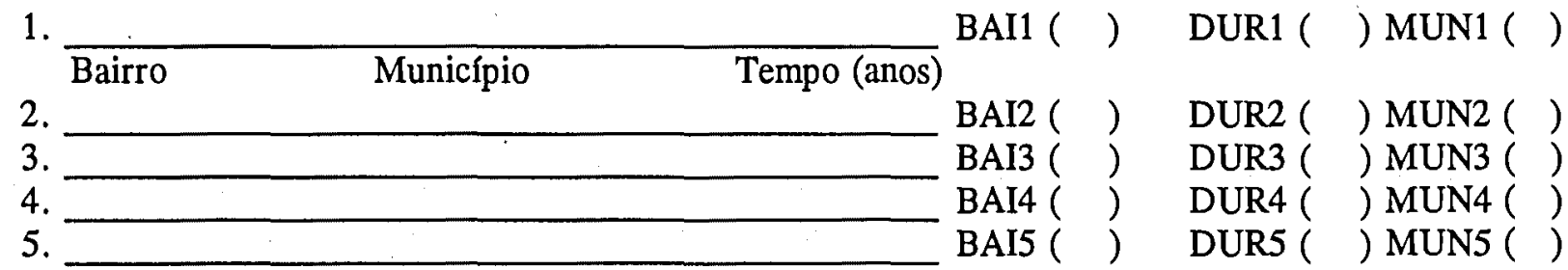

88. Não se aplica.

\section{AVALIAÇÃO DA RESIDÊNCIA ATUAL}

7.1. Número de cômodos:

$\begin{array}{lll}\text { NCOM } & ( & \\ \text { NPES } & ( & ) \\ \text { PCAS } & ( & \text { ( ) } \\ \text { ENER } & ( & \\ \text { AGU } & ( & \end{array}$

7.5. A casa é servida por que tipo de água?

$\begin{array}{ll}\text { Encanada (1) } & \text { Cisterna (2) } \\ \text { Outros (3) } & \text { NS/NR (9) }\end{array}$

7.6. A casa apresenta:
Rede de esgoto ( 1 )
Fossa ( 2)

Outro ( 3 )

NS/NR ( 9 )

\section{HISTÓRIA FAMILIAR DE DOENÇA DE PELE}

Pergunte ao paciente sobre a presença de doenças de pele em familiares:

Alguma pessoa da sua familia está ou esteve em tratamento prolongado para doença de pele ou para hanseníase? (mais de 6 meses).

\section{ASSINALE EM CASO AFIRMATIVO:}

$\begin{array}{ll}\text { Codifique: } & \text { Não (1) Sim (2) NS/NR (9) } \\ & \text { Não se aplica ( 8) }\end{array}$

1. Pai

2. Mãe

3. Irmão

4. Cônjuge

$\mathrm{N}^{\mathrm{o}}$

5. Filho

6. Outro

$\mathrm{N}^{\mathrm{o}}$

$\mathrm{N}^{\circ}$

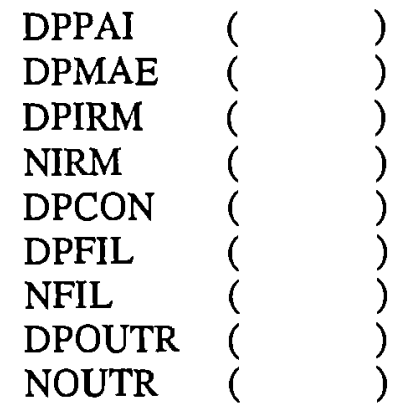


9. DOAÇÕES E TRANSFUSÕES DE SANGUE

9.1. Você já doou sangue alguma vez?

Não (1) $\quad$ Sim (2) NS (9)

SAND

Se afirmativo,

9.2. Quantas vezes você doou sangue nos últimos dois anos?

SANDR $\quad(\cdot)$

9.3. Você já recebeu transfusão de sangue?

SANT

Não ( 1 )

$\operatorname{Sim}(2)$

NS ( 9 )

Se afirmativo,

9.4. Quantas vezes?

Não se aplica ( $\overline{88}$ )

SANTQ $\quad(\quad)$

9.5. Você se lembra de ter tido alguma doença poucos meses depois deDATS uma transfusão de sangue?

Não ( 1 ), Hepatite ( 2 ), Doença do coração ( 3 ),

Anemia ( 4 ), Sintoma mal definido ( 5 ),

Outra ( 6 )

Não se aplica ( 8 )

\section{USO DE MEDICAÇÃO INJETÁVEL E VACINAÇÃO}

Para os ítens 1 e 2 codifique de acordo com os critérios abaixo:

Raramente : menos de 2 injeções nos últimos 2 anos.

Algumas vezes $\quad: 1$ vez nos últimos 6 meses.

Frequente : mais de 1 vez nos últimos 6 meses.

10.1. Você costuma tomar injeções intramuscular e/ou endovenosa? INJEC $\quad(\quad)$

Nunca ( 1 ) Raramente (2) Algumas vezes (3)

Frequentemente (4) NS/NR (9)

10.2. Você faz uso de droga injetável?

DROGA $(\quad)$

Nunca ( 1 ) Raramente ( 2 ) Algumas vezes ( 3 )

Frequentemente (4) NS/NR (9)

10.3. Qual a sua prática sexual?

PSEX

Heterossexual ( 1) Homossexual (2) Bissexual ( 3 )

NS/NR ( 9 ) Não se aplica ( 8 )

10.4. Quantos parceiros sexuais diferentes você teve no último ano? PARSEX

Nenhum ( 0 ) Um ( 1 ) Dois a cinco (2)

Mais que cinco (3) NS/NR (9) Não se aplica ( 8 ) 
10.5. Você já foi vacinado contra Hepatite B?

VACHEPB

Não ( 1 ) Sim ( $\quad$ NS/NR ( 9 )

Caso sim,

Quantas doses da vacina contra Hepatite B (Engerix B) você tomou?

Não se aplica ( 8 )

\section{USO DE SERVIÇOS DE SAÚDE}

11.1. Quando o $\mathrm{Sr}$ (a) necessita de uma consulta médica qual o serviço SERPRO é procurado?

1. Centro de saúde mais próximo de casa

2. Centro de saúde próximo do trabalho

3. Centro de saúde público independente da localização

4. Médico de convênio

5. Médico particular

6. Hospital Público

7. Hospital Filantrópico

8. Outros

11.2. Nos últimos 6 meses o $\operatorname{Sr}(a)$ fez quantas consultas médicas? CON $\mathrm{N}^{0}$ de consultas

NS/NR ( 99 )

11.3. Você foi hospitalizado alguma vez nos últimos 5 anos?

(não considere parto)

HOSP

Não ( 1 ) $\quad \operatorname{Sim}(2) \quad$ NS/NR ( 9 )

11.4. Quantas vezes você foi hospitalizado?

HOSPV

Não se aplica ( 88 )

11.5. Considerando-se todas as hospitalizações, quantos dias você

HOSPD permaneceu internado nos últimos 5 anos?

Não se aplica ( 88 )

11.6. Qual o motivo da sua hospitalização?

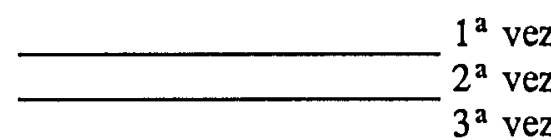

Doença de pele ( 1 ), Infecção ( 2 ), Doença do coração ( 3 ), Doença digestiva ( 4 ), Cirurgia ( 5 ), outra (9)

Não se aplica ( 8 ) 
11.7. Você fez algum tratamento médico no ano passado ou está no TRAT momento em tratamento?

Não ( 1 ) Sim (2) caso afirmativo,

11.8. Você está tratando de que?

(Use o código ànterior do ítem 11.6)

Não se aplica ( 8 )

11.9. Quantas consultas médicas o $\mathrm{Sr}$ (a) realizou devido a este

NCONS problema?

11.10 Qual a forma de entrada do paciente no CSJB?

1. Procurou o serviço espontaneamente

2. Encaminhado por médico da rede pública.

(Qual unidade?

3. Encaminhado por outros médicos

4. Encaminhado por outra pessoa

5. Foi Transferido para esta Unidade

6. Exames de contatos domiciliares

7. Exames de contatos extra-domiciliares

9. Outros

Observaçōes: 


\section{ANEXO 4 \\ UFG/SUS/FNS/MACROREGIÃO CENTRO-OESTE \\ PROJETO:HBV/HAN}

\section{ROTEIRO PARA PREENCHIMENTO E CODIFICAÇÃO DO QUESTIONÁRIO}

Questionário a ser preenchido pelo médico para avaliar se o caso é compatível ou não com hanseníase.

\begin{tabular}{|c|c|c|}
\hline UNIDADE & : & Unidade de saúde onde o paciente foi atendido. \\
\hline PRONT & $:$ & Número do prontuário no registro da unidade. \\
\hline NO & : & Número de ordem do questionário. \\
\hline $\mathrm{CACO}$ & : & $\begin{array}{l}\text { Codifique os participantes em Caso }=1 \text {, Controle }=2 . \\
\text { IDENTIFICAÇÃO }\end{array}$ \\
\hline NOME & : & Nome do paciente. \\
\hline AGE & $:$ & Data de nascimento do paciente. \\
\hline DAT & : & Data do exame. \\
\hline SEX & : & Codifique quanto ao sexo: Masculino $=1$, Feminino $=2$. \\
\hline AMB & : & $\begin{array}{l}\text { Codifique o ambulatório de procedência do paciente. } \\
\text { Dermatologia }=1 \text {, Clínica médica }=2 \text {, Carteira de saúde }=3 \text {, } \\
\text { Outros }=4 \text {. Caso a resposta seja Outros, especificar o ambulatório. }\end{array}$ \\
\hline PES & : & Codifique o peso do paciente em kilogramas (kg). \\
\hline ALT & : & $\begin{array}{l}\text { Codifique a altura do paciente em centímetros }(\mathrm{cm}) \text {. } \\
\text { INTERROGATÓRIO SINTOMATOLÓGICO }\end{array}$ \\
\hline LES & : & $\begin{array}{l}\text { Codifique quanto a presença de lesões de pele. } \\
\text { Não }=1, \operatorname{Sim}=2 \text {. }\end{array}$ \\
\hline CONT & : & $\begin{array}{l}\text { Codifique se o paciente é ou não contato de casos de hanseníase. } \\
\text { Não }=1, \operatorname{Sim}=2 .\end{array}$ \\
\hline NOMECONT & : & Nome do contato do paciente. \\
\hline PRONTC & & Número do prontuário do contato do paciente se paciente do CSJB. \\
\hline
\end{tabular}


MLES : Codifique a duração da(s) lesão(ões) de pele em meses (o paciente apresenta lesões de pele com duração compreendida entre $\geq 1$ mês $\mathrm{e}<12$ meses).

YLES : Codifique a duração das lesões em anos (o paciente apresenta lesões de pele com duração $\geq 1$ ano).

DLES : Codifique a duração das lesões em dias (o paciente apresenta lesões de pele com duração $<30$ dias).

PLES : Codifique se estas foram as primeiras lesões deste tipo a surgirem.

Não $=1$, Sim $=2$, Não se aplica $=8$.

MALES : $\quad$ Caso estas não foram as primeiras lesões codifique há quanto tempo teve outras lesões em meses. Sem informação $=99$, Não se aplica $=88$.

YALES : Codifique há quanto tempo teve outras lesões em anos. Sem informação $=99$, Não se aplica $=88$.

DALES : Codifique há quanto tempo teve outras lesões em dias. Sem informação $=99$, Não se aplica $=88$.

CURA : $\quad$ Codifique se as lesões curaram sozinhas, sem tratamento médico.

Não $=1, \operatorname{Sim}=2$, Não se aplica $=8$, Sem informação $=9$.

COMT : Codifique quanto ao uso anterior de medicamento específico para hanseníase.

Não $=1, \operatorname{Sim}=2$, Não responde $=9$.

DTRAT : Caso tenha feito tratamento anterior, codifique a duração em dias.

Sem informação $=99$.

MTRAT : $\quad$ Codifique a duração do tratamento em meses.

Sem informação $=99$.

ATRAT : Codifique a duração do tratamento em anos.

Sem informação $=99$.

COMFA : Codifique quanto ao uso de medicamento específico para hanseníase em pessoas que moram na mesma casa.

Não $=1, \operatorname{Sim}=2$, Não sabe informar $=9$.

CONTAC : Caso Sim na pergunta anterior, registre o grau de parentesco da pessoa que utilizou o medicamento específico para hanseníase.

EXAME FÍSICO NEURO-DERMATOLÓGICO

Deve ser feito para os casos suspeitos de MH. 
CARACF $\quad: \quad$ Colocar o número correspondente as descrições.

NLES $\quad$ : Registre o número de lesões até 10 . Mais de $10=11$, Não se aplica $=88$.

Distribuição das lesões:

Mapear no diagrama em anexo.

\section{ESPESSAMENTO E ALTERAÇÃO DE SENSIBILIDADE EM NERVOS}

Registre Não $=1, \operatorname{Sim}=2$, Duvidoso $=3$, para espessamento dos nervos especificados. Em caso de outro nervo acometido registre o nome.

Registre Não $=1, \operatorname{Sim}=2$, Duvidoso $=3$ para alteração de sensibilidade nos nervos especificados.

Para os ítens abaixo codifique Não $=1, \operatorname{Sim}=2$, Duvidoso $=3$.

SOMB

Perda de sombrancelha.

LAGO

Presença de lagoftalmo.

PAVA

Infiltração de pavilhão auricular.

FRAZ

Fraqueza muscular.

PUNH

Queda do punho.

QUPE

Queda do pé.

TATI

Perda da sensibilidade tátil nas lesões.

TERM

Perda da sensibilidade térmica nas lesões.

DOLO : Perda da sensibilidade dolorosa nas lesões.

EDEM : $\quad$ Presença de edema de extremidades.

ARTRI : $\quad$ Presença de artrite.

ORQU : $\quad$ Presença de orquite.

FIGA

BACO

Aumento do fígado (Hepatomegalia).

BCGC

Aumento do baço.

TATO : Codifique quanto a presença de tatuagem.

Não $=1, \operatorname{Sim}=2$.

TREA : Codifique quanto ao tipo de reação.

Ausência de reação $=0$, Tipo $\mathrm{I}=1$, Tipo $\mathrm{II}=2$.

AVAL : Codifique quanto a avaliação clínica sobre o caso.

Caso certo de $\mathrm{MH}=1$, Caso provável de $M H=2$, Caso de outra doença $=3$.

DOENCA : Caso ítem anterior $=3$, registre nome da doença. 
CLAS : Caso AVAL = Certo ou Provável, codifique quanto a forma clínica de hanseníase.

Indeterminado $(\mathrm{I})=1, \mathrm{BT}=2, \mathrm{BB}=3, \mathrm{BV}=4$, Tuberculóide $(\mathrm{TT})=5$, Virchowiana $(\mathrm{V})=6$, Não se aplica $=8$.

GINCO : Codifique quanto ao grau e incapacidade nos olhos.

Grau $0=0$, Grau I $=1$, Grau II $=2$, Grau III $=3$.

GINCM : $\quad$ Codifique quanto ao grau e incapacidade nas mãos.

Grau $0=0$, Grau I = 1, Grau II $=2$, Grau III $=3$.

GINCP : Codifique quanto ao grau e incapacidade nos pés.

Grau $0=0$, Grau $\mathrm{I}=1$, Grau II $=2$, Grau III $=3$.

GINCF : Codifique quanto ao grau e incapacidade final.

Grau $0=0$, Grau I $=1$, Grau II $=2$, Grau III $=3$. Não se aplica $=8$.

BAC : Codifique quanto a coleta de exames para baciloscopia.

Não $=1, \operatorname{Sim}=2$.

BIO : $\quad$ Codifique quanto a coleta de material para biópsia de pele.

Não $=1, \operatorname{Sim}==2$, Coleta em outro local $=3$.

MIT : Codifique quanto a realização do teste de mitsuda.

Não $=1, \operatorname{Sim}=2$.

SANG : Codifique quanto a coleta de sangue.

Não $=1, \operatorname{Sim}=2$.

MED : $\quad$ Codifique quanto ao nome o médico.

\section{RESULTADO E EXAMES}

RMIT : Codifique quanto ao resultado do teste de mitsuda.

Negativo (Ausência de qualquer reação no local) $=1$

Duvidosa (Infiltração menor que $3 \mathrm{~mm}$ ) $=2$

Positiva + (Infiltração de 3 a $5 \mathrm{~mm}$ ) $=3$

Positiva ++ (Infiltração maior que $5 \mathrm{~mm})=4$

Positiva +++ (Infiltração maior que $10 \mathrm{~mm}$ ou ulcerada) $=5$

Não realizado $=9$.

RBACG : Codifique quanto ao resultado da baciloscopia realizada na unidade de saúde ( $(\mathrm{IB}=0$ até $\mathrm{IB}=6)$. Não realizada $=9$.

RBACP : Codifique quanto ao resultado da baciloscopia realizada pela pesquisa. Não realizada $=9$.

LOD : Codifique o resultado da baciloscopia no lóbulo da orelha direita.

LOE $\quad$ : Codifique o resultado da baciloscopia no lóbulo da orelha esquerda. 
COTD $\quad: \quad$ Codifique o resultado da baciloscopia no cotovelo direito.

COTE : Codifique o resultado da baciloscopia no cotovelo esquerdo.

LES1 : $\quad$ Codifique o resultado da baciloscopia da lesão especificada 1.

LES2 : Codifique o resultado da baciloscopia da lesão especificada 2.

RHIST : Codifique quanto ao resultado do exame histopatológico.

$\mathrm{I}=1, \mathrm{BT}=2, \mathrm{BB}=3, \mathrm{BL}=4, \mathrm{TT}=5, \mathrm{LL}=6$, Inespecífico

$=7$, Dentro dos limites de normalidade $=8$, Não realizado $=9$.

NCERT : Codifique quanto ao nível de certeza do exame anatomo-patológico.

1. Hanseníase confirmada

2. Consistente com hanseníase mas não diagnóstico.

3. Inespecífico.

4. Indicativo de outra doença.

5. Dentro dos limites de normalidade.

9. Não coletao/Sem informação.

ODOENCA : $\quad$ Caso NCERT $=4$, registrar o nome da doença.

OUTROS

EXAMES

Registre o resultado de outros exames realizados.

DFIN

Codifique quanto ao diagnóstico final da forma clínica.

Baciloscopia positiva ao exame histopatológico ou baciloscopia e formas clínicas $\mathrm{BT}=2, \mathrm{BB}=3, \mathrm{BL}=4, \mathrm{LL}=6$, Outra forma clínica $=7$, Não se aplica $=8$.

DFINH : Codifique quanto ao diagnóstico final da forma clínica. Baciloscopia negativa.

Indeterminado $(\mathrm{I})=1, \mathrm{BT}=2$, Tuberculóide $(\mathrm{TT})=5$, Outra forma clínica $=7$, Não se aplica $=8$.

COMP $\quad: \quad$ Baciloscopia negativa sem resultado de histopatológico.

Clínica compatível com hanseníase: Não $=1$, Sim $=2$, Não se aplica $=8$. 


\section{UFG/SUS/MACROREGIÃO CENTRO-OESTE \\ PROJETO: HBV/HAN}

Deve ser preenchido por todos os indivíduos elegíveis: Casos e Controles.

NO : Número de ordem do questionário.

CACO $\quad$ Codifique os participantes em Caso $=1$, Controle $=2$.

AGE : $\quad$ Data de nascimento do paciente.

SEX $\quad$ : $\quad$ Codifique quanto ao sexo: Masculino $=1$, Feminino $=2$.

NOME $\quad: \quad$ Nome do paciente.

INC $\quad: \quad$ Codifique as iniciais do nome do paciente.

NOME DA MAE : $\quad$ Registre o nome da mãe do paciente.

INCM $\quad: \quad$ Codifique as iniciais do nome da mãe.

ENDERECO : Registre o endereço completo do paciente.

COD1 : Codificação do endereço de residência do paciente.

ZONA $\quad: \quad$ Urbana $=1$, Rural $=2$, Sem informação $=9$.

ENDERECO

CONTATO : Caso o paciente não more em Goiânia ou Aglomerado, registre endereço de contato.

LOCAL DE

TRABALHO : Registre o local de trabalho do paciente.

ENDERECO DE

TRABALHO : Registre o endereço completo do local de trabalho.

COD2 : Codifícação do endereço de trabalho do paciente.

DAT1 : $\quad$ Registre a data da entrevista.

ENTR : Codifique quanto ao entrevistador. 
POS : Codifique quanto a posição que o paciente ocupa na família.

Chefe $=1$, Cônjuge $=2$, Mãe $=3$, Filho $=4$, Parente $=5$, Outro $=6$ (especificar).

ECIV : Codifique quanto ao estado civil do paciente.

Solteiro $=1$, Casado (legalmente ou não) $=2$, Desquitado, Divorciado ou Separado $=3$, Viúvo $=4$.

ESC : Codifique quanto a escolaridade do paciente.

1. nunca frequentou sabe ler e escrever

2. nunca frequentou não sabe ler e escrever

3. primário ou $1^{\circ}$ grau incompleto ano/série

4. ginásio ou $2^{\circ}$ grau incompleto ano/série

5 . colegial ou $2^{\circ}$ grau completo

6. cursos técnicos de nivel médio completo

7. cursos técnicos de nível médio incompleto

8. universidade completa

9. universidade incompleta

\section{CONDIÇÃo SÓCIO-ECONÔMICA}

ATI : Codifique se o paciente exerce alguma atividade de trabalho.

1. Sim, em atividade

2. Sim, afastado por motivo de doença

3. Sim, é também aposentado

4. Não, desempregado

5. Não, aposentado

6. Não, dona de casa

7. Não, só estudante

8. Não, outras

Caso a resposta seja 6,7 ou 8 , passe para a questão 4.9 .

OCUP

Registre qual é/era o cargo/ocupação ou função que o paciente desenvolve ou desenvolvia no seu trabalho principal e descreva as tarefas mais frequentes que desenvolve em seu trabalho.

TRA

Codifique quanto a posição ocupada no trabalho.

1. Empregado assalariado sem carteira profissional assinada.

2. Empregado assalariado com carteira profissional assinada.

3. Empregado familiar não remunerado.

4. Conta própria ou autônomo com estabelecimento.

5. Conta própria ou autônomo sem estabelecimento.

6. Empregador com até 4 funcionários fixos.

7. Empregador com 5 ou mais funcionários fixos.

8. Para trabalhador rural que não se enquadre nas alternativas acima, descreva a situação.

RATIV : Registre qual é/era a atividade do estabelecimento, empresa, negócio ou instituição em que o paciente trabalha/trabalhou. 
MUN : Codifique o município onde o paciente trabalha/trabalhou.

No próprio município de residência $=1$, Outro município $=2$, Não se aplica $=8$.

SAL : Codifique com relação ao salário que recebeu no trabalho no último mês.

Registre o salário líquido em $\mathrm{Cr} \$$, e em salários mínimos. Caso o paciente não saiba informar codifique 9 . Não se aplica $=88$.

SALO : Codifique quanto a presença de outro trabalho remunerado (fixo ou eventual).

Não $=1, \operatorname{Sim}=2$, Não sabe/Não responde $=9$, Não se aplica $=$ 8.

SALA : Codifique quanto a presença de outro rendimento além do(s) declarado(s) anteriormente.

Não $=1, \operatorname{Sim}=2$, NS/NR $=9$, Não se aplica $=8$.

VALOR $\quad: \quad$ Caso SALA $=$ Sim, registre o salário em $\mathrm{Cr} \$$ e salários mínimos.

Relacione as pessoas que moram na mesma casa registrando o grau de parentesco, idade (em dias, meses ou anos) e o salário líquido.

SALT : Codifique quanto à renda total dos moradores em $\mathrm{Cr} \$$ e salários mínimos.

NUMPES $\quad: \quad$ Codifique quanto ao número de moradores da casa.

NUMPSAL : $\quad$ Codifique quanto ao número de moradores com rendimento.

PROF : Codifique quanto a profissão do chefe da casa em caso do paciente ser dependente.

Trabalhador de roça $=1$, Comerciante $=2$, Desempregado $=3$, Comerciário $=4$, Vigilante $=5$, Fazendeiro $=6$, Funcionário público $=7$, Militar $/$ Polícia $=8$, Pedreiro $=9$, Servente $=10$, Mestre de obras $=11$, Aposentado $=12$, Dona de casa $=13$, Outras $=14$ (Especificar).

ENG : $\quad$ Codifique quanto ao gasto com energia elétrica no último mês.

Caso NS/NR codifique 99, Não se aplica $=88$.

PLANT : $\quad$ Codifique quanto a présença de algum tipo de plantação ou criação.

Não $=1, \operatorname{Sim}=2, N S / N R=9$

Codifique quanto a presença de bens de consumo.

Não tem $=1, \operatorname{Sim}=2, \mathrm{NS} / \mathrm{NR}=9$

REFR : Refrigerador.

TELEV : Televisão.

TELEF : Telefone.

VEIC : Veículo auto-motor. 
RAD

VIDEO

NAS

MUNIC

ESTADO

PAIS

ZON

DTEMP

MTEMP

YTEMP

NMUD

MAGLUG

TMAGLUG

BAI1

DUR1

MUN1

NCOM

NPES
Rádio.

Vídeo-cassete.

\section{MIGRAÇÃO}

Codifique quanto ao município de nascimento.

No próprio município de residência $=1$

Outro município de Goiás $=2$ (registre qual)

Outro Estado do país $=3$ (registro o Estado e município)

Outro país $=4$ (Registre o país)

Não sabe/Não responde $=9$.

Codifique quanto a zona de residência da família no município onde nasceu.

Cidade $=1$, Periferia $=2$, Chácara urbana $=3$, Rural $=4$, $\mathrm{NS} / \mathrm{NR}=9$.

: Codifique quanto ao tempo de moradia no município de residência atual em dias.

: Ídem para mês.

: Ídem para ano.

: Codifique quanto ao número de munícípios de residência nos últimos 10 anos.

: Codifique quanto ao número de mudanças entre municípios do AGLUG.

Tempo de moradia em anos no AGLUG.

Registre o nome do bairro, município e tempo de moradia em cada bairro em anos.

Codifique $01^{\circ}$ bairro de residência no AGLUG.

Codifique o tempo de moradia no BAI1 em anos.

Codifique o município do BAI1.

$\begin{array}{ll}\text { BAI2/BAI3/BAI4/BAI5 } & \text { ídem BAI1 } \\ \text { DUR2/DUR3/DUR4/DUR5 } & \text { ídem DUR1 } \\ \text { MUN2/MUN3/MUN4/MUN5 } & \text { ídem MUN1 }\end{array}$

\section{AVALIAÇÃO DA RESIDÊNCIA ATUAL}

Codifique o número de cômodos da casa (Quarto, sala).

Codifique o número de pessoas que moram na casa (número de pessoas que dormem diariamente na casa). 
ENER : Codifique quanto à presença de energia elétrica.

Não $=1, \operatorname{Sim}=2$

PCAS : : Codifique quanto à propriedade da casa.

Não $=1, \operatorname{Sim}=2$

AGU : Codifique quanto ao tipo de abastecimento de água.

Encanada (sistema público) $=1$, Cisterna $/$ Poço $=2$, Outros $=3$, $\mathrm{NS} / \mathrm{NR}=9$.

ESG : $\quad$ Codifique quanto ao destino do esgoto.

Rede pública de esgoto $=1$, Fossa $=2$, Outro $=3, \mathrm{NS} / \mathrm{NR}=9$.

\section{HISTÓRIA FAMILIAR}

DOENCA DE

PELE

Codifique para cada familiar quanto a presença de doença de pele.

Não $=1, \operatorname{Sim}=2$, Não sabe $=99$.

\section{DOAÇÕES E TRANSFUSÕES DE SANGUE}

SAND : Codifique quanto a doação de sangue.

Não $=1, \operatorname{Sim}=2$, NS/NR $=9$.

SANDR : $\quad$ Codifique quanto ao número de vezes que o paciente doou sangue.

SANT : Codifique quanto ao recebimento de transfusões de sangue.

Não $=1, \operatorname{Sim}=2, \mathrm{NS} / \mathrm{NR}=9$.

SANTQ $\quad$ : Codifique quanto ao número de transfusões de sangue.

DATS : $\quad$ Codifique quanto a presença de doenças após transfusão de sangue.

Não $=1$, Hepatite $=2$, Doença do coração $=3$, Anemia $=4$, Sintoma mal definido $=5$, Outra $=6$ (Especificar).

\section{USO DE MEDICAÇÃO INJETÁVEL E VACINAÇÃO}

Para os ítens 1 e 2 utilizar códigos:

Raramente $=$ Menos de 2 injeções nos últimos 2 anos.

Algumas vezes $=1$ vez nos últimos 6 meses.

Freqüente $=$ Mais de $1 \mathrm{vez}$ nos últimos 6 meses.

INJEC : Codifique quanto ao uso de injeções intramuscular e/ou endovenosa.

Nunca $=1$, Raramente $=2$, Algumas vezes $=3$, Freqüentemente $=4, \mathrm{NS} / \mathrm{NR}=9$.

DROGA : Codifique quanto ao uso de droga injetável. 
Nunca $=1$, Raramente $=2$, Algumas vezes $=3$, Freqüentemente $=4, \mathrm{NS} / \mathrm{NR}=9$.

PSEX : $\quad$ Codifique quanto a prática sexual.

Heterossexual $=1$, Homossexual $=2$, Bissexual $=3, \mathrm{NS} / \mathrm{NR}=9$, Não se aplica $=8$.

PARSEX : Codifique quanto ao número de parceiros sexuais no último ano.

Nenhum $=0, \mathrm{Um}=1$, Dois a cinco $=2$, Mais que cinco $=3$, NS/NR $=9$, Não se aplica $=8$.

VACHEPB : $\quad$ Codifique quanto a ser vacinado contra Hepatite B.

Não $=1, \operatorname{Sim}=2$, NS/NR $=9$.

NDOSES : $\quad$ Codifique o número de doses contra hepatite B o paciente tomou.

Não se aplica $=8$.

\section{USO DE SERVIÇOS DE SAÚDE}

SERPRO : $\quad$ Codifique quanto ao serviço de saúde procurado pelo paciente.

Posto de Saúde mais próximo de casa $=1$, Posto de Saúde mais próximo ao trabalho $=2$, Médico de convênio $=3$, Médico particular $=4$, Hospital Público $=5$, Hospital Filantrópico $=6$, Outros $=7$ (Registre qual).

CON : Codifique quanto a realização de consultas médicas nos últimos 6 meses.

Nenhuma $=1,1-2$ consultas $=2,3-5$ consultas $=3$, Mais de 5 consultas $=4, \mathrm{NS} / \mathrm{NR}=9$.

HOSP : $\quad$ Codifique quanto hospitalização nos últimos 5 anos.

Não $=1, \operatorname{Sim}=2$, Não sabe/Não responde $=9$.

HOSPV : $\quad$ Codifique quanto ao número de vezes que foi hospitalizado.

HOSPD : Codifique quanto ao número de dias de internação hospitalar considerando todas as hospitalizações nos últimos 5 anos. NS/NR = 9.

Codifique quanto ao motivo da hospitalização. Use os seguintes códigos:

Doença de pele $=1$, Infecção $=2$, Doença do coração $=3$, Doença digestiva $=4$, Cirurgia $=5$, Outra $=9$ (Especificar), Não se aplica $=8$.

HOS1 : $\quad$ Motivo da hospitalização na primeira vez.

HOS2, HOS3 ídem.

TRAT : Codifique quanto a realização de algum tipo de tratamento pelo paciente no ano passado ou no momento. 
Não $=1, \operatorname{Sim}=2$.

MTRAT : Codifique quanto ao motivo do tratamento. Utilize códigos do ítem 10.6 .

NCONS : Codifique quanto ao número de consultas médicas realizadas para o problema de pele atual.

ENT : $\quad$ Codifique quanto a forma de entrada neste serviço.

Procurou o serviço espontaneamente $=1$, Encaminhado por médico da rede pública $=2$ (Especificar a unidade), Encaminhado por outros médicos $=3$, Encaminhado por outra pessoa $=4$, Foi transferido para esta unidade $=5$, Exames de contatos domiciliares $==6$, Exames de contatos extradomiciliares $=7$, Outros $=9$ (Especificar).

OBS : $\quad$ Registre observações sobre o paciente.

ABRANG : Região de abrangência.

1. Região Central - CSJB

2. Cais J. Novo Mundo

3. Novo Horizonte

4. Urias Magalhães

5. Dergo

6. Cândido de Moraes

7. Pedro Ludovico

DIST : $\quad$ Distritos.

Goiânia ( 1 - 64)

Aparecida de Goiânia ( 65 )

Senador Canedo ( 66 )

Trindade ( 67 )

ZONA : $\quad$ Zona atual.

1. Centro Expandido

2. Coroa Central

3. Expansão Urbana Preferencial

4. Controle I

5. Controle II

6. Risco

7. Expansão Urbana Residencial

8. Rural

9. Aparecida de Goiânia, Senador Canedo e Trindade

AREAI : Área de origem.

DISTI : $\quad$ Distrito de origem.

CODMUN $\quad:$ 1. Goiânia

2. Aparecida de Goiânia

3. Bonfinópolis 
4. Guapó

5. Bela Vista de Goiás

6. Aragoiânia

7. Goianira

COD3

: Código do Bairro de residência há 10 anos

DIST10

Distrito há 10 anos

MUD10

Número de mudanças nos últimos 10 anos.

AREA10 : Área do IPLAN nos últimos 10 anos. 